CENTRO UNIVERSITÁRIO FEI

SERGIO SKORETZKY FOSSA

AVALIAÇÃO DO PERFIL DE PILOTAGEM DO MOTOCICLISTA BRASILEIRO NA CIDADE DE SÃO PAULO E SUA RELAÇÃO COM A DURABILIDADE DO VEÍCULO

São Bernardo do Campo 


\section{AVALIAÇÃO DO PERFIL DE PILOTAGEM DO MOTOCICLISTA BRASILEIRO NA CIDADE DE SÃO PAULO E SUA RELAÇÃO COM A DURABILIDADE DO VEÍCULO}

Dissertação apresentada ao Centro Universitário FEI, como parte dos requisitos necessários para obtenção do título de Mestre em Engenharia Mecânica. Orientado pelo Prof. Dr. Roberto Bortolussi e coorientado pelo Dr. Kemal Öztürk.

São Bernardo do Campo 
Skoretzky Fossa, Sergio.

Avaliação do perfil de pilotagem do motociclista brasileiro na cidade de são paulo e sua relação com a durabilidade do veículo / Sergio

Skoretzky Fossa. São Bernardo do Campo, 2019.

166 p. : il.

Dissertação - Centro Universitário FEI.

Orientador: Prof. Dr. Roberto Bortolussi.

Coorientador: Prof. Dr. Kemal Öztürk.

1. Motocicleta. 2. Perfil de Condução. 3. Aquisição de Dados. 4. Análise de Dados. 5. Durabilidade. I. Bortolussi, Roberto, orient. II. Título.

Elaborada pelo sistema de geração automática de ficha catalográfica da FEI com os dados fornecidos pelo(a) autor(a). 
Aluno: Sergio Skoretzky Fossa

Título do Trabalho: Avaliação do perfil de pilotagem do motociclista brasileiro na cidade de São Paulo e sua relação com a durabilidade do veículo.

Área de Concentração: Materiais e Processos

Orientador: Prof. Dr. Roberto Bortolussi

Data da realização da defesa: $18 / 12 / 2019$

\section{Avaliação da Banca Examinadora:}

São Bernardo do Campo,

\section{MEMBROS DA BANCA EXAMINADORA}

Prof. Dr. Roberto Bortolussi

Prof. Dr. Sergio Delijaicov

Prof. Dr. Tarcisio Antonio Hess Coelho
Ass.:

Ass. :

Ass. :

A Banca Julgadora acima-assinada atribuiu ao aluno o seguinte resultado:

APROVADO $\square \quad$ REPROVADO

\section{VERSÃO FINAL DA DISSERTAC̄ÃO}

APROVO A VERSÃO FINAL DA DISSERTAÇÃO EM QUE FORAM INCLUÍDAS AS RECOMENDAÇÕES DA BANCA EXAMINADORA
Aprovação do Coordenador do Programa de Pós-graduação

Prof. Dr. Rodrigo Magnabosco 
A minha esposa Samira e aos meus pais, Anastásia e João. 


\section{AGRADECIMENTOS}

A minha esposa pelo apoio e compreensão durante os dias, noites e finais de semana que tiveram que ser dedicados a este trabalho;

Aos meus pais pelo exemplo que sempre me deram, criação, educação e apoio. Sem eles certamente eu não teria chegado até aqui;

A todos os colegas que concordaram em participar da pesquisa e colaboraram de forma ativa para que os dados pudessem ser adquiridos;

Ao meu orientador, Prof. Dr. Roberto Bortolussi pela orientação e ajuda durante toda a condução da pesquisa;

Ao meu coorientador, Dr. Kemal Öztürk pela grande ajuda e orientação durante todas as etapas do trabalho, em especial durante o tratamento dos sinais e análise dos dados adquiridos durante a pesquisa;

Aos Senhores Rudolf Schrupp e Bernhard Weber pelo apoio durante a instrumentação e configuração do sistema de análise de dados;

Aos responsáveis pelo departamento de Engenharia Experimental da BMW Motorrad, Sr. Jens Stäbe e Sr. Holger Englisch por apoiarem o desenvolvimento desta pesquisa;

Aos colaboradores da Itaim Express, em especial ao Sr. Fernando Souza, que prestou todo o apoio e suporte para que os dados junto aos motofretistas pudessem ser colhidos;

Ao Sr. Sergio Oliveira da ABRACICLO pelo suporte durante a coleta de dados relevantes ao setor das duas rodas;

Ao amigo e Eng. Rafael Moura, que me ajudou durante toda a condução do trabalho com sua vasta experiência no ramo das duas rodas. 
"Seja você quem for, seja qual for a posição social que você tenha na vida, a mais alta ou a mais baixa, tenha sempre como meta muita força, muita determinação e sempre faça tudo com muito amor e com muita fé em Deus, que um dia você chega lá. De alguma maneira você chega lá”.

Ayrton Senna da Silva 


\section{RESUMO}

A principal ideia deste trabalho é apresentar uma proposta para a avaliação do perfil de pilotagem adotado por condutores brasileiros na cidade de São Paulo e sua influência com a durabilidade de uma motocicleta. Durante a execução da pesquisa, foi utilizada uma moto equipada com sensores e um sistema de aquisição de dados capaz de coletar informações da rede de bordo e dos sensores adicionais que foram anexados ao veículo. Para que o estudo pudesse ser executado, um banco de dados foi desenvolvido com as informações adquiridas durante sessões de pilotagem executadas por 30 diferentes condutores. Eles foram convidados a participar da pesquisa, de forma que o padrão de condução dos participantes pudesse ser avaliado. Após a coleta dos dados, um estudo estatístico baseado em testes de hipóteses foi aplicado para as três variáveis de interesse (tempo de condução, velocidade média e porcentagem de abertura do acelerador), todas monitoradas em tempo real durante a pilotagem por um trajeto real em vias públicas. Os testes estatísticos confirmaram que para estas variáveis, pelo menos uma das classes de condutores estudadas se destacou em comparação com as demais, sendo que com a intensão de se desenvolver uma análise de durabilidade a partir dos dados colhidos, a força vertical no eixo dianteiro da motocicleta foi calculada para cada piloto ao longo do tempo de execução do percurso. Posteriormente, a partir da aplicação de um algoritmo baseado na teoria de contagem de ciclos Rainflow, uma nova análise estatística para que uma comparação entre os intervalos de confiança associados aos quocientes de severidade média entre as três amostras da população de pilotos fosse executada. Ao término do trabalho, concluiu-se que dois dos três grupos analisados apresentaram características semelhantes associadas aos carregamentos impostos pelos diferentes pilotos.

Palavras-chave: Motocicleta. Perfil de Condução. Aquisição de Dados. Análise de Dados. Durabilidade. 


\begin{abstract}
The aim of this paper is to present a method to evaluate the riding profile adopted by Brazilian riders in São Paulo city and its influence in the vehicle durability. For that, it was used an instrumented motorcycle which was equipped with sensors and a data acquisition device. The system was able to collect the vehicle on board signals and the information provided by the additional sensors. In order to enable the analysis, a data set was developed with the measurements collected during the riding sessions performed by 30 different riders, which were invited to participate in this research to provide the necessary data for the riding profile evaluation. A statistical analysis based on hypothesis tests was then applied to the three most relevant variables (riding time, average speed and throttle body opening), all real time monitored during the riding through a route performed in public roads. The hypothesis tests confirmed that for these variables, at least one group of riders was different between the others that were investigated. In order to enable a relation to the durability analysis by the collected data, the vertical force applied in the front wheel axle was calculated against the riding time for each rider. Lately, through a Rainflow cycles counting algorithm implementation, a new statistical analysis was performed to compare the confidence intervals for the quotients in the median severity associated to the three studied riders' samples. At the end, it was concluded that two from the three analyzed groups presented similar load characteristics.
\end{abstract}

Keywords: Motorcycle. Riding profile. Data Acquisition. Data Analysis. Durability 


\section{LISTA DE ILUSTRAÇÕES}

Figura 1 - Aumento da frota nacional de veículos de duas rodas em comparação com a frota geral de veículos

Figura 2 - Distribuição da frota de veículos automotores de duas rodas por região. 30

Figura 3 - Distribuição da frota de veículos automotores de duas rodas na região sudeste .... 31

Figura 4 - Forma de aplicação e uso dos veículos de duas rodas 32

Figura 5 - Placa de uma motocicleta registrada na Alemanha. 34

Figura 6 - Tipos e quantidades de pendências verificadas durante as inspeções obrigatórias em motocicletas - Alemanha - período de 2009 a 2018

Figura 7 - Pendencias observadas nas inspeções periódicas distribuídas por grupo construtivo - Alemanha - período de 2009 a 2018. 35

Figura 8 - Evento MotoCheck Up (16 Edição) - realizado em Brasília - DF

Figura 9 - Itens que apresentaram necessidade de manutenção nas 24 edições do projeto Motocheck-up, organizado pela ABRACICLO.

Figura 10 - Distribuição de probabilidade dos carregamentos impostos por condutores normais, pistas de teste e resistência estrutural do componente.

Figura 11 - Evolução da qualidade do veículo durante a fase de desenvolvimento 41

Figura 12 - Modelo V aplicado ao processo de desenvolvimento de um veículo 42

Figura 13 - Dispositivo de ensaio de quatro colunas 43

Figura 14 - Dispositivo de ensaio de duas colunas para motocicletas 44

Figura 15 - Dispositivo de ensaio desenvolvido para motocicletas em operação.

Figura 16 - Quadro e dispositivo de duas colunas desenvolvidos em ambiente computacional

Figura 17 - Modelo computacional para análises de tensões principais máximas em determinadas frequências de interesse no paralama dianteiro de uma motocicleta 48

Figura 18 - Diferencial exposto a 50 dias de teste dinâmico de corrosão e diferencial após 7 anos de uso $(200.000 \mathrm{~km})$

Figura 19 - Comparação entre trinca obtida durante teste acelerado em bancada (esquerda) e trinca obtida durante rodagem (direita) ....

Figura 20 - Teste de durabilidade de motocicletas em ambiente real de utilização (vias públicas)

Figura 21 - Campo de provas de Miramas (BMW) 
Figura 22 - Pistas especiais - a) Pot Holes, b) Cobblestones e c) Body Twist) ......................53

Figura 23 - Como veículos atuais geram e armazenam diferentes tipos de dados ..................56

Figura 24 - Tipos de dados coletados pelas montadoras em veículos equipados com sistemas de conectividade

Figura 25 - Distribuição da velocidade média adotada por condutores de diferentes mercados para um determinado modelo de motocicleta.

Figura 26 - Progressão dos custos totais de qualidade ao longo do processo de desenvolvimento da qualidade

Figura 27 - Comparação entre os custos de garantia por unidade vendida entre dois segmentos de produto em diferentes mercados

Figura 28 - Diagrama S-N para o Aço SCM 435 temperado a $300{ }^{\circ} \mathrm{C}$ por 60 minutos........... 64

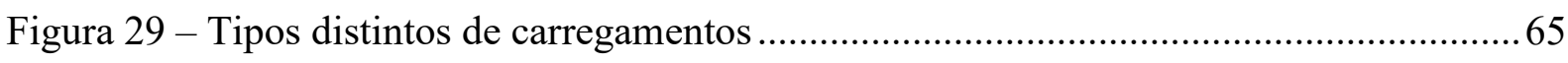

Figura 30 - Exemplo de carregamento real obtido a partir da coleta de sinais .......................66

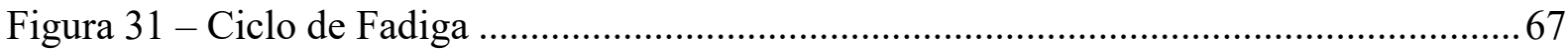

Figura 32 - Definição do método Rainflow proposta por Rychlik (1987).............................. 68

Figura 33 - Representação esquemática do comportamento uniaxial tensão-deformação de muitos materiais durante a deformação no sentido inicial e reverso, mostrando o efeito Bauschinger

Figura 34 - Exemplo de aplicação da teoria de Masing......................................................... 71

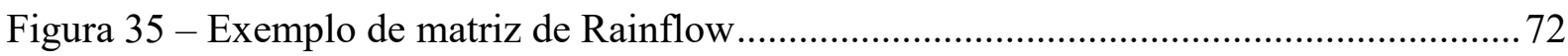

Figura 36 - Variação do tamanho do intervalo de confiança em relação ao tamanho da amostra. 78

Figura 37 - Distribuição normal para $\log A e q / k N$ (a) e histograma estimado para densidade de probabilidade log-normal (b)

Figura 38 - Exemplo de sistema de aquisição de dados veiculares 81

Figura 39 - Exemplo de sistema de aquisição de dados veiculares instalados em uma motoneta 83

Figura 40 - Valores da força resultante em ambas as rodas de uma motocicleta 84

Figura 41 - Exemplo de arquitetura CAN aplicada em uma motocicleta 86

Figura 42 - Comparação do efeito de três tipos de filtros aplicados em um sinal 88

Figura 43 - Sinais da aceleração angular do centro de massa de um veículo de duas rodas em relação a Z. Imagem superior - sinal descrito no dominio do tempo. Imagem inferior - sinal descrito no dominio da frequência 90 
Figura 44 - Filtragem do sinal da aceleração angular do centro de massa de um veículo de duas

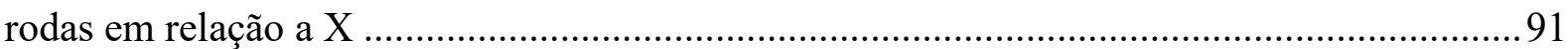

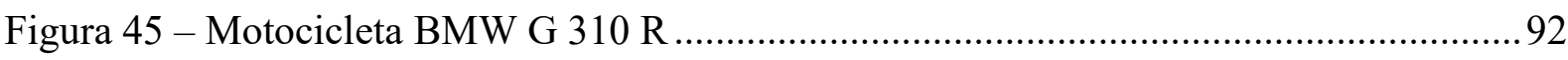

Figura 46 - Detalhes da instrumentação instalada na motocicleta em estudo..........................95

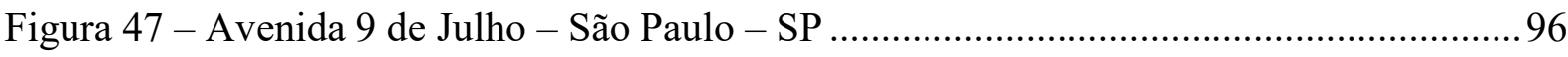

Figura 48 - Trajeto escolhido durante o levantamento dos dados ....................................... 97

Figura 49 - Distribuição dos limites de velocidade para o trajeto escolhido ...........................97

Figura 50 - Diagrama de corpo livre para cálculo da força na roda dianteira ...................... 100

Figura 51 - Ângulo de inclinação da motocicleta em relação ao plano horizontal................ 103

Figura 52 - Composição do movimento de esterçamento de um veículo de duas rodas ....... 104

Figura 53 - Tempo gasto pelos pilotos de cada classe durante a execução do percurso........ 107

Figura 54 - Valores das médias e desvios padrão para o tempo gasto pelos pilotos de

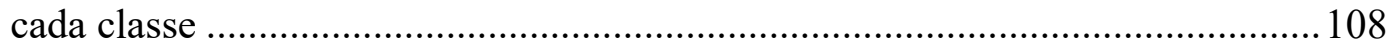

Figura 55 - Diagrama de caixa para os dados de velocidade instantânea adotada pelo conjunto dos 30 pilotos

Figura 56 - Velocidade instantânea adotada pelos pilotos de cada classe

Figura 57 - Valores das médias e desvios padrão para a velocidade média dos pilotos de cada classe.

Figura 58 - Porcentagem de abertura do acelerador adotada pelo conjunto dos 30 pilotos... 116

Figura 59 - Distribuição da porcentagem de abertura do acelerador adotada por cada um dos 30 pilotos durante a execução do percurso

Figura 60 - Quantidade de dados associados ao intervalo de abertura de borboleta de $50 \%$ a $100 \%$ de acordo com cada classe de condutores

Figura 61 - Quantidade de dados referentes a abertura da borboleta do acelerador de acordo com cada classe em estudo

Figura 62 - Valores dos intervalos de confiança (95\%) para o tempo gasto pelos pilotos de cada classe durante a execução do percurso

Figura 63 - Valores dos intervalos de confiança (95\%) para a velocidade média do veículo de acordo com cada classe em estudo.

Figura 64 - Valores dos intervalos de confiança (95\%) para a média dos dados associados a abertura da borboleta do acelerador de acordo com cada classe em estudo ..... 124

Figura 65 - Força vertical no eixo da roda dianteira .......................................................... 126

Figura 66 - Valores verificados para FzfMÉD para cada piloto e sua respectiva classe ...... 127

Figura 67 - Spectro Rainflow com filtragem de ciclos com amplitude inferior a 100 N ...... 128 
Figura 68 - Representação do número de ciclos Rainflow, sem filtragem $(\mathrm{h}=0)$ e com filtragem $(\mathrm{h}=100)$.

Figura 69 - Histograma de distribuição dos ciclos Rainflow, sem filtragem $(\mathrm{h}=0)$ e com filtragem $(\mathrm{h}=100)$.

Figura 70 - Valores calculados para o pseudo dano para cada piloto e sua respectiva classe.

Figura 71 - Valores calculados para a amplitude equivalente para cada piloto e sua respectiva classe

Figura 72 - Gráfico de probabilidade desenvolvido junto ao software estatístico Minitab $^{\circledR}$ para correlação dos dados de amplitude equivalente junto a distribuição de Weibull 134 


\section{LISTA DE TABELAS}

Tabela 1 - Principais dados técnicos do modelo BMW G 310 R …........................................ 93

Tabela 2 - Dados dos condutores participantes da pesquisa ................................................99

Tabela 3 - Grandezas necessárias para o cálculo da força na roda dianteira ........................ 102

Tabela 4 - Valores para o tempo gasto pelos pilotos 22 e 26 e sua relação com o tempo

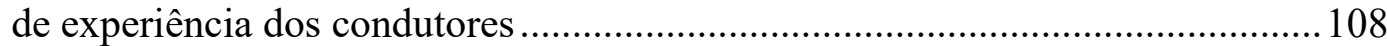

Tabela 5 - Comparação entre os perfis de velocidade de cada classe de condutores ............ 114

Tabela 6 - Método adotado para os testes de hipótese para as variáveis de interesse ........... 120

Tabela 7 - Avaliação das médias para o tempo gasto durante a execução do percurso

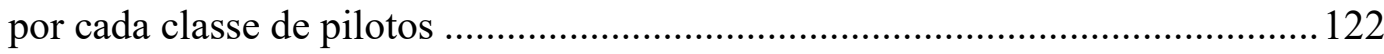

Tabela 8 - Análise de variância para o tempo gasto por cada classe de pilotos .................... 122

Tabela 9 - Avaliação das médias para a velocidade média do veículo para cada classe de pilotos

Tabela 10 - Análise de variância para a velocidade média do veículo para cada classe de pilotos.

Tabela 11 - Avaliação das médias para os valores de abertura média do acelerador para cada classe de pilotos.

Tabela 12 - Análise de variância para os valores de abertura média do acelerador para cada classe de pilotos

Tabela 13 - Teste de correlação para os dados de amplitude equivalente observados de acordo com a classe dos pilotos

Tabela 14 - Erro associado a adoção da distribuição log-normal de acordo com cada população

Tabela 15 - Valores de amplitude equivalente associados aos pilotos da classe

"Locomoção Urbana"

Tabela 16 - Valores de amplitude equivalente associados aos pilotos da classe "Motofretistas"

Tabela 17 - Valores de amplitude equivalente associados aos pilotos da classe "Hobby"

Tabela 18 - Comparação entre os valores calculados para as medianas dos valores de amplitude equivalente 


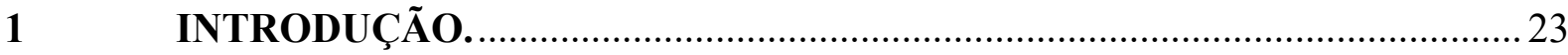

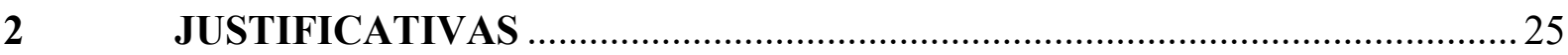

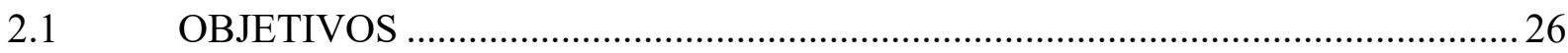

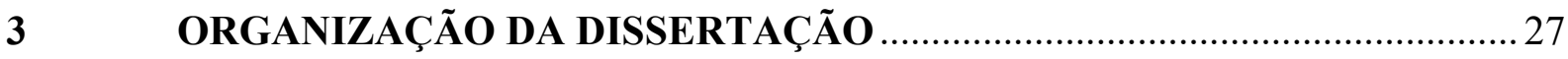

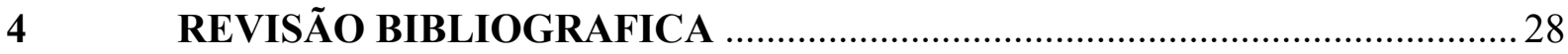

4.1 A EVOLUÇÃO DO MERCADO BRASILEIRO DE MOTOCICLETAS ............. 29

4.2 A QUESTÃO DA MANUTENÇÃO DO VEÍCULO ……..................................... 33

4.3 A IMPORTÂNCIA DO ESTUDO DA DURABILIDADE NA ENGENHARIA

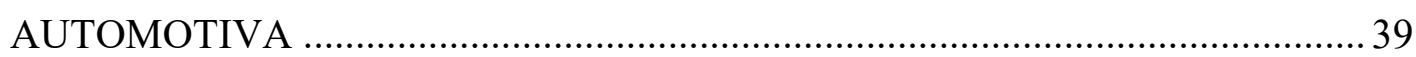

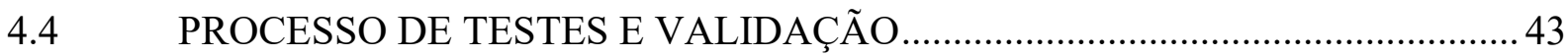

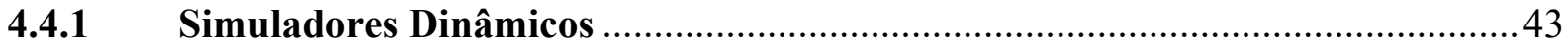

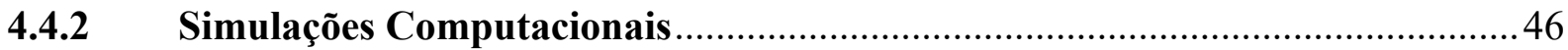

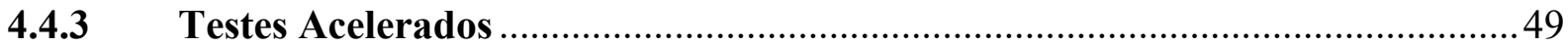

4.4.4 A Importância dos Ensaios Reais em Campo...................................................... 51

4.5 A IMPORTÂNCIA DE SE CONHECER O PERFIL DE UTILIZAÇÃO.............. 54

4.6 OS CUSTOS ASSOCIADOS COM A QUESTÃO DA DURABILIDADE .......... 59

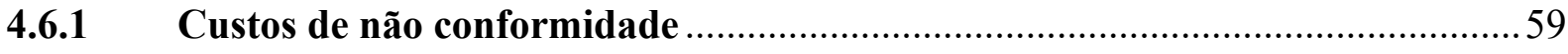

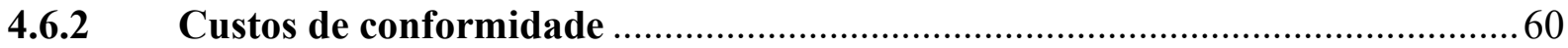

4.7 ANÁLISE DE DADOS PARA AVALIAÇÃO DA DURABILIDADE ..................62

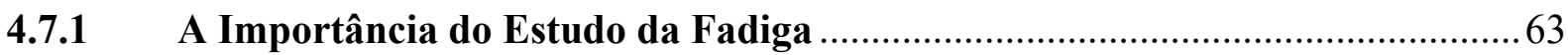

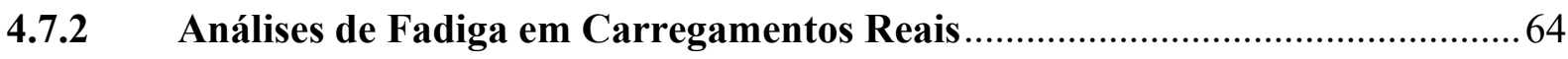

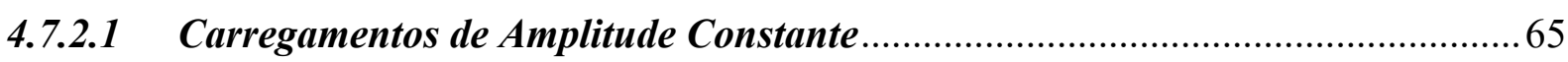

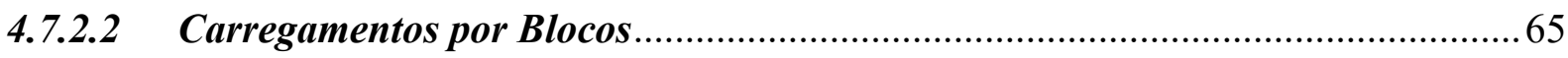

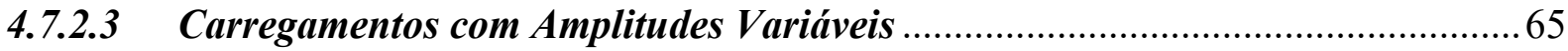

4.7.3 Carregamentos com Amplitude Variável, Ciclo de Fadiga e o Método

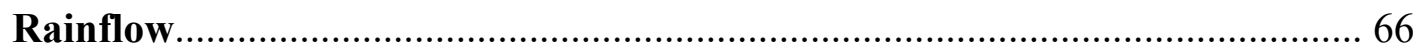

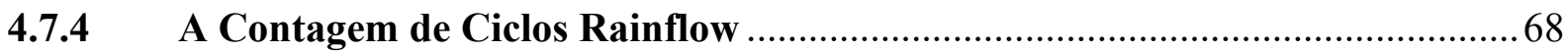

4.7.5 O Acúmulo de Danos e o Conceito de Pseudo-Dano ........................................... 73

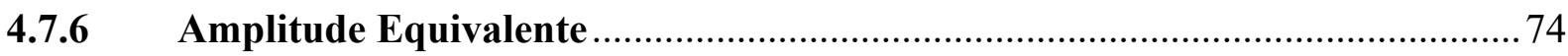

4.7.7 Avaliação de Carregamentos Impostos pelo Usuário ….................................. 74

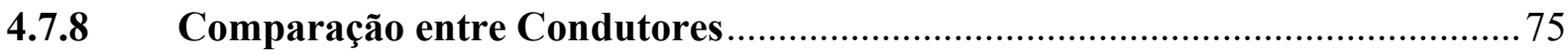

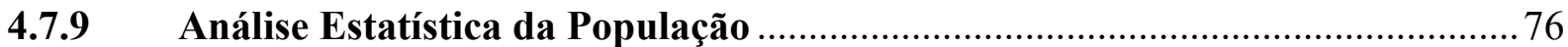




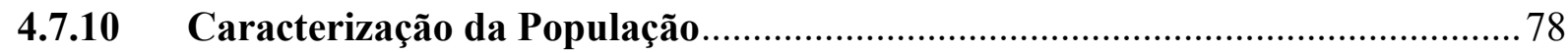

4.7.11 Comparação Entre Diferentes Populações ..................................................... 80

4.8 AQUISIÇÃO E TRATAMENTO DE DADOS PARA AVALIAÇÕES DE DURABILIDADE EM VEÍCULOS AUTOMOTORES .................................... 81

4.8.1 A Aplicação de Sistemas de Coleta de Dados em Motocicletas ........................ 82

4.8.2 Aquisição de Dados Via Rede CAN (Controller Area Network) ........................ 85

4.8.3 Tratamento e Pré-Processamento de Sinais ...................................................... 87

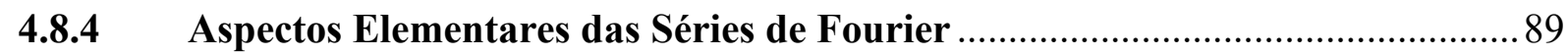

4.8.5 Filtros Para o Cálculo da Força Vertical na Roda Dianteira ........................... 91

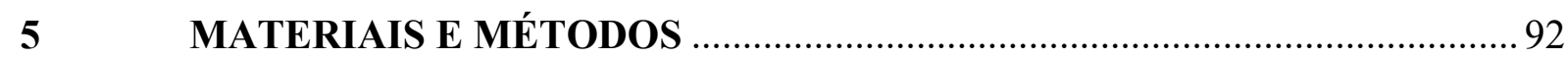

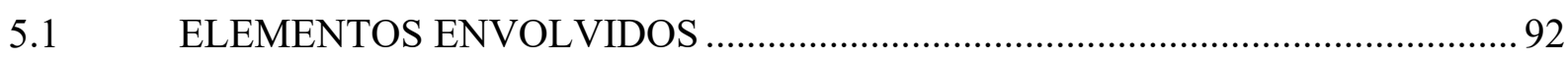

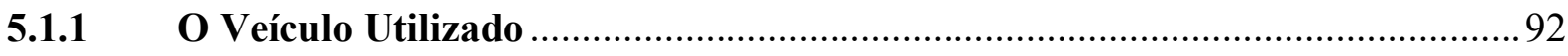

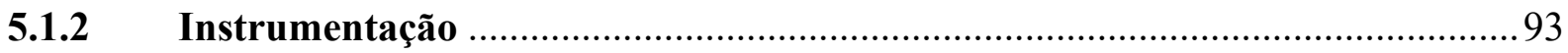

5.1.2.1 GPS

5.1.2.2 Sensores de Posição da Suspensão Dianteira e Traseira ...................................... 94

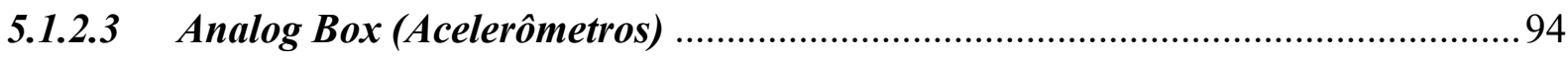

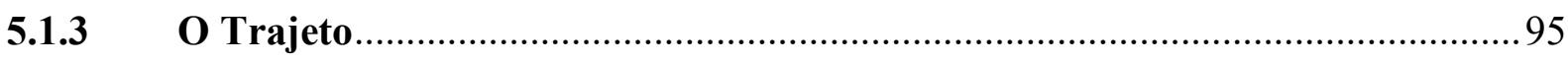

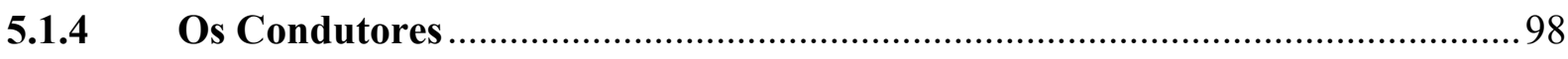

5.1.5 Metodologia Aplicada para Cálculo da Força Vertical na Roda Dianteira ..... 99

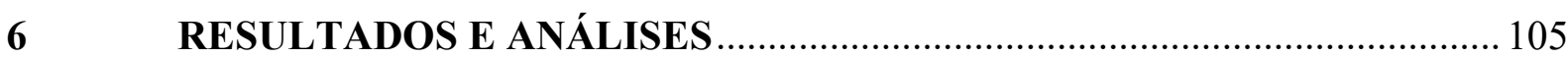

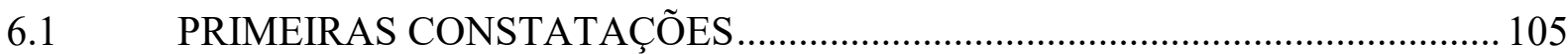

6.1.1 Tempo Gasto Para Conclusão do Percurso …....................................................... 106

6.1.2 Velocidade do Veículo e Porcentagem de Abertura do Acelerador ................ 109

6.1.2.1 Velocidade Instantânea Durante a Execução do Percurso.................................. 110

6.1.2.2 Velocidade Média Durante a Execução do Percurso ....................................... 114

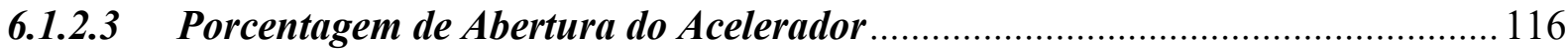

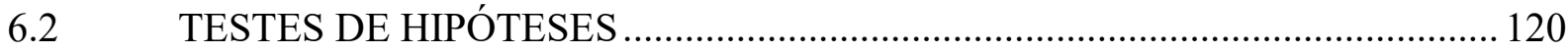

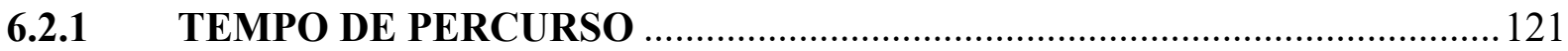

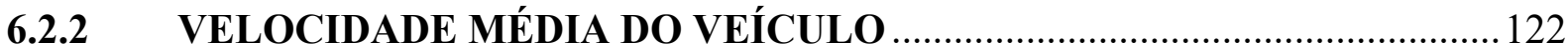

6.2.3 PORCENTAGEM DE ABERTURA DO ACELERADOR ............................ 124

6.3 ANÁLISE DOS PARÂMETROS ASSOCIADOS A DURABILIDADE ............ 126

6.3.1 Força Vertical no Eixo da Roda Dianteira ................................................... 126

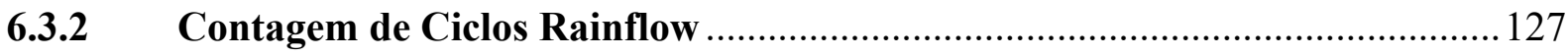

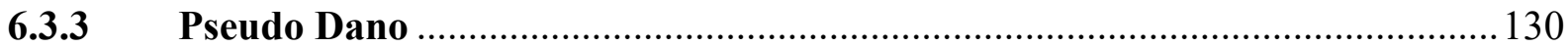




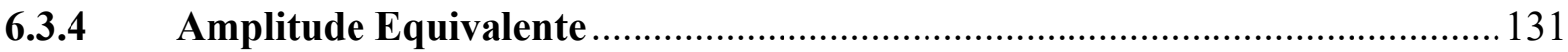

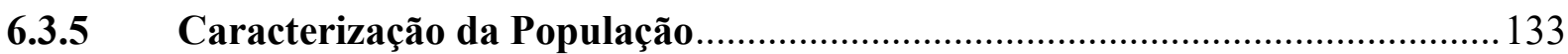

6.3.6 Comparação Entre as Populações ..................................................................... 134

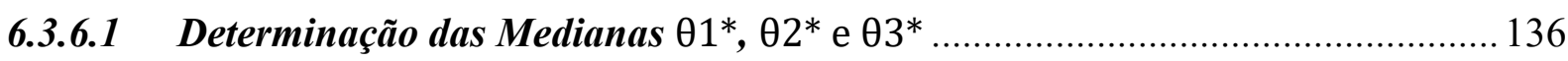

6.3.6.2 Determinação dos Intervalos de Confiança Associados aos Quocientes de

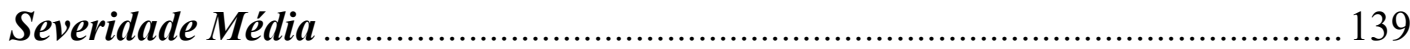

6.3.6.2.1 Comparação entre o Perfil "Motofretista" e "Locomoção Urbana"................... 139

6.3.6.2.2 Comparação entre o Perfil "Hobby" e "Motofretista" ......................................... 139

6.3.6.2.3 Comparação entre o Perfil "Hobby" e "Locomoção Urbana"............................. 140

6.3.6.2.4 Consolidação dos Resultados .............................................................................. 140

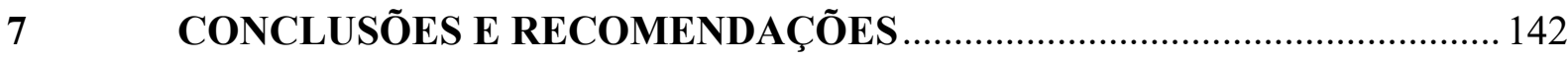

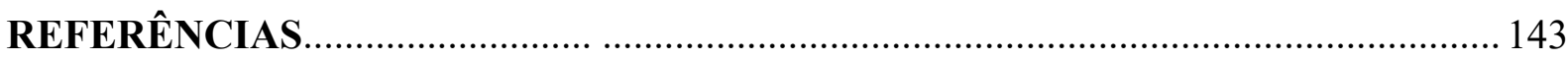

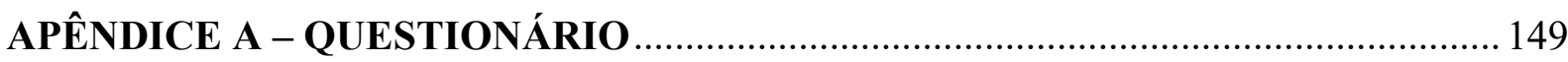

APÊNDICE B - ALGORÍTIMO DESENVOLVIDO EM MATLAB ${ }^{\circledR}$ PARA ANÁLISE DO PERFIL DE VELOCIDADE ADOTADO

PELOS 30 PILOTOS ……...................................................... 151

APÊNDICE C - ALGORÍTIMO DESENVOLVIDO EM MATLAB ${ }^{\circledR}$ PARA ANÁLISE DO PERFIL DE UTILIZAÇÃO DO ACELERADOR

PELOS 30 PILOTOS 156

APÊNDICE D - ALGORÍTIMO DESENVOLVIDO EM MATLAB ${ }^{\circledR}$ PARA

CÁLCULO DA FORÇA VERTICAL NO EIXO DIANTEIRO, CONTAGEM DE CICLOS RAINFLOW, CÁLCULO DO PSEUDO DANO E AMPLITUDE EQUIVALENTE PARA CADA PILOTO 


\section{INTRODUÇÃO}

O veículo de duas rodas é hoje um dos principais meios de locomoção em grandes centros urbanos e vem ganhando cada vez mais espaço em nossa sociedade. No mundo, a frota de veículos motorizados de duas rodas passa dos 313 milhões de veículos. No Brasil, a frota supera os 27 milhões de unidades, representando cerca de $8 \%$ da frota mundial de veículos automotores de duas rodas. No estado de São Paulo, unidade da federação com maior frota circulante, o volume deste tipo de veículo supera os 5 milhões, e na capital paulista, tal número ultrapassa 1,2 milhões.

Apesar da representatividade considerável do Brasil dentro da distribuição do mercado mundial, pouco se sabe sobre o perfil de pilotagem do motociclista brasileiro. De acordo com Forcetto (2016), a classe de trabalhadores que utiliza a motocicleta como meio de locomoção em centros urbanos, popularmente denominado como "motoboys", apresenta um tipo de pilotagem agressiva, sendo que este tipo de comportamento, segundo Rocha Neto e Menezes Jr. (2016), pode estar associado com acelerações e freadas bruscas, condições de interesse para avaliações sobre a durabilidade do veículo.

Ferreira, Santos e Nassi (2014) identificam a idade do condutor como sendo uma das características determinísticas relacionadas com a forma que ele pilota sua motocicleta, mas deixa claro que os diferentes perfis no Brasil ainda precisam ser estudados com maiores detalhes.

Para que uma determinação técnica do perfil de utilização de veículos automotores seja executada, Gorges, Öztürk e Liebich (2017), sugerem que os dados da rede de bordo de veículos equipados com tecnologia de transferência de dados via protocolo de comunicação CAN sejam utilizados em conjunto com equipamentos de medição com alta taxa de aquisição de dados. Essa avaliação, se mostra tecnicamente viável para que um dos desafios da engenharia moderna seja avaliado, uma vez que, conforme apontado por Weber (2009), a determinação e monitoramento da forma de utilização de veículos automotores é de grande interesse dos fabricantes.

A pesquisa em questão, faz uso deste tipo de tecnologia em conjunto com um grupo de 30 motociclistas de três diferentes classes. Condutores que fazem o uso do veículo de 2 rodas para locomoção urbana, motofretistas profissionais e motociclistas que fazem o uso deste tipo de veículo somente como objeto de lazer, percorreram o mesmo trajeto na mesma faixa de horário e nos mesmos dias da semana. Durante a pilotagem, dados da rede de bordo e de sensores adicionais instalados, permitiram que diversos sinais fossem armazenados em tempo 
real, como por exemplo, velocidade das rodas, porcentagem de abertura da borboleta do acelerador, variação da posição longitudinal da roda dianteira e traseira (curso da suspensão dianteira e traseira), aceleração angular do centro de gravidade do veículo, etc.

Após uma análise preliminar dos sinais obtidos, baseado em estudos desenvolvidos por Reiser (2008) e ISO (2009), foram escolhidas três variáveis de interesse (tempo, velocidade e abertura do acelerador) para que a análise dos diferentes perfis de condução fosse executada a partir da aplicação de testes estatísticos.

Em seguida, através dos dados que foram obtidos, um modelo desenvolvido e validado por Gorges, Öztürk e Liebich (2017) foi aplicado para que a força vertical na roda dianteira fosse possível de ser calculada. Na sequência, foi implementado um algoritmo para contagem de ciclos Rainflow com o intuito de se determinar o pseudo dano, amplitude equivalente e intervalo de confiança associado ao quociente de severidade média para o sinal da força vertical na roda dianteira, observado para cada grupo de condutores avaliados. Essa metodologia, proposta por Johannesson e Speckert (2014), permitiu então que a comparação entre a severidade dos carregamentos impostos pelas três classes de condutores estudadas fosse possível de ser executada. 


\section{JUSTIFICATIVAS}

Determinar e conhecer o perfil de utilização do cliente é hoje um dos principais desafios da indústria. No ramo automotivo, muito se tem investido em plataformas de aquisição de dados embarcadas para que as montadoras possam ter acesso aos dados de utilização de seus veículos. Segundo Rocha Neto e Menezes Jr. (2016), o acesso aos dados de utilização do consumidor permite que as montadoras tomem ações mais efetivas voltadas para a manutenção adequada do veículo, consumo de combustível e redução de riscos de acidentes.

No segmento de duas rodas isso não é diferente. Gorges, Öztürk e Liebich (2017) já apontaram a importância de se ter acesso aos dados do perfil de utilização de motocicletas durante o desenvolvimento de novos modelos. Sabe-se que os veículos de duas rodas são caracterizados por sua diversidade de aplicação, que hoje se desdobra em diversas frentes além da simples locomoção. Cada segmento, seja ele voltado para o deslocamento urbano, lazer ou aplicação comercial, possui seus próprios pré-requisitos quando se avaliam as expectativas dos clientes e respectivas formas de utilização.

Apesar do avanço da tecnologia sobre o uso de sistemas embarcados capazes de monitorar o perfil de utilização dos clientes em tempo real, pouco foi publicado sobre as características técnicas de utilização de motocicletas pelo motociclista brasileiro. A literatura cientifica em sua maioria versa sobre a associação da motocicleta com os índices de acidentes no trânsito. Ferreira (2009), por exemplo, aponta para a importância de se conhecer o comportamento do motociclista para que soluções mais efetivas para a redução dos índices de fatalidade no trânsito sejam encontradas. Já Zamel (2009), destaca as principais características sociodemográficas e de personalidade de um grupo de profissionais do segmento de motofrete da cidade de Porto Alegre, chamando a atenção para os números de acidentes, mortes e mutilações envolvendo esse tipo de profissional.

Dessa forma, verifica-se uma oportunidade para que um mapeamento técnico baseado em dados quantitativos sobre a forma de condução de motociclistas brasileiros e sua relação com os parâmetros de durabilidade do veículo seja apresentado. 


\subsection{OBJETIVOS}

Avaliar a forma de condução de uma motocicleta por diferentes tipos de condutores brasileiros de forma quantitativa, de forma que a partir da análise dos dados colhidos, determinar se de fato existem diferenças em relação a forma de pilotagem adotada pelos diferentes tipos de condutores que normalmente utilizam motocicletas na cidade de São Paulo. A análise desenvolvida deverá ser capaz de determinar se todas as classes de condutores envolvidas no estudo possuem padrão de pilotagem semelhante de acordo com as análises das variáveis de interesse (tempo, velocidade e abertura do acelerador) e se a magnitude dos carregamentos verticais impostos no eixo dianteiro da motocicleta se mostram associados com as diferenças observadas junto aos padrões de pilotagem das três classes de condutores. 


\section{ORGANIZAÇÃO DA DISSERTAÇÃO}

A presente dissertação está organizada de forma a apresentar no Capítulo 4, a importância de se conhecer o perfil técnico de utilização da motocicleta durante a fase de projeto do veículo. Além disso, neste capítulo, dedica-se atenção especial a revisão da bibliografia referente a análise de dados para o estudo dos impactos das diferentes formas de condução junto a durabilidade em veículos automotores. No Capítulo 5, apresenta-se a metodologia utilizada durante a presente pesquisa, dedicada a obter dados para análise da influência do perfil de pilotagem de 30 condutores junto a parâmetros de durabilidade de uma motocicleta, como pseudo dano, amplitude equivalente e intervalo de confiança associado ao quociente de severidade média. No Capítulo 6, apresentam-se os cálculos empregados durante a avaliação dos dados e discutem-se os resultados obtidos. No Capítulo 7 são explicitadas as conclusões e recomendações finais do trabalho. 


\section{REVISÃO BIBLIOGRAFICA}

A revisão da bibliografia buscou por trabalhos acadêmicos em portais de pesquisas digitais como o portal Pergamum, Google Scholar, Elsevier, Biblioteca Digital USP, Science Direct, Portal de Periódicos CAPES, com o objetivo de se localizar documentos associados com as palavras chave "perfil de pilotagem", "motocicleta", "sistemas de aquisição de dados em motocicletas", "identificação do perfil do motociclista", "durabilidade de motocicletas". Para uma maior eficácia na busca, também foram utilizados os termos correspondentes em inglês de forma a se obter uma maior chance de retorno nas pesquisas. Entretanto, as buscas efetuadas se limitam de forma significativa quando associamos o termo "motocicleta" aos filtros de buscas. Como exemplo, ao pesquisar por "driver behavior" na plataforma Google Scholar, são encontrados 59.400 resultados, no entanto, quando a pesquisa é executada para o conjunto "motorcycle rider behavior", "motorcycle durability" a quantidade de resultados cai para 88 .

De forma a buscar mais documentos com associação relevante a atividade de classificação do perfil de condução de motocicletas, trabalhos acadêmicos desenvolvidos em parceria com a indústria foram utilizados. Aqui, destaca-se a participação de Gorges, Öztürk e Liebich, (2017) que trabalharam de forma a propor formas de classificação do perfil de condução de pilotos através da interpretação dos sinais da rede de bordo do veículo.

Documentos científicos elaborados para apresentação da problemática envolvendo o uso de veículos automotores de duas rodas e seus impactos nos números de acidentes viários, também foram consultados com intuito de se conhecer o estado da arte do conhecimento aplicado até então para se distinguir os diferentes tipos de condutores de veículos automotores de duas rodas.

Para que a avaliação de sinais obtidos com o intuito de se estudar os impactos na durabilidade do veículo, trabalhos acadêmicos dedicados ao estudo da fadiga para a verificação da durabilidade de projetos de componentes automotivos foram consultados. O objetivo foi o de buscar dentro das diferentes estratégias e metodologias conhecidas para as avaliações de durabilidade, qual delas seria a mais eficaz para classificar os dados coletados em três perfis de utilização de motocicletas (condutor urbano, profissional do segmento do moto frete e condutor esporádico que utiliza a motocicleta somente para uso em lazer). 


\subsection{A EVOLUÇÃO DO MERCADO BRASILEIRO DE MOTOCICLETAS}

A frota brasileira de veículos de duas rodas supera hoje os 27 milhões de unidades, sendo que nos últimos 10 anos ela cresceu 107,1\% segundo ABRACICLO (2019). Quando comparamos esse aumento com a evolução da frota geral de veículos automotores em território nacional, percebe-se que o volume de motocicletas cresceu $22,3 \%$ mais do que a frota total. Tal comparação pode ser verificada através da Figura 1.

Figura 1 - Aumento da frota nacional de veículos de duas rodas em comparação com a frota geral de veículos

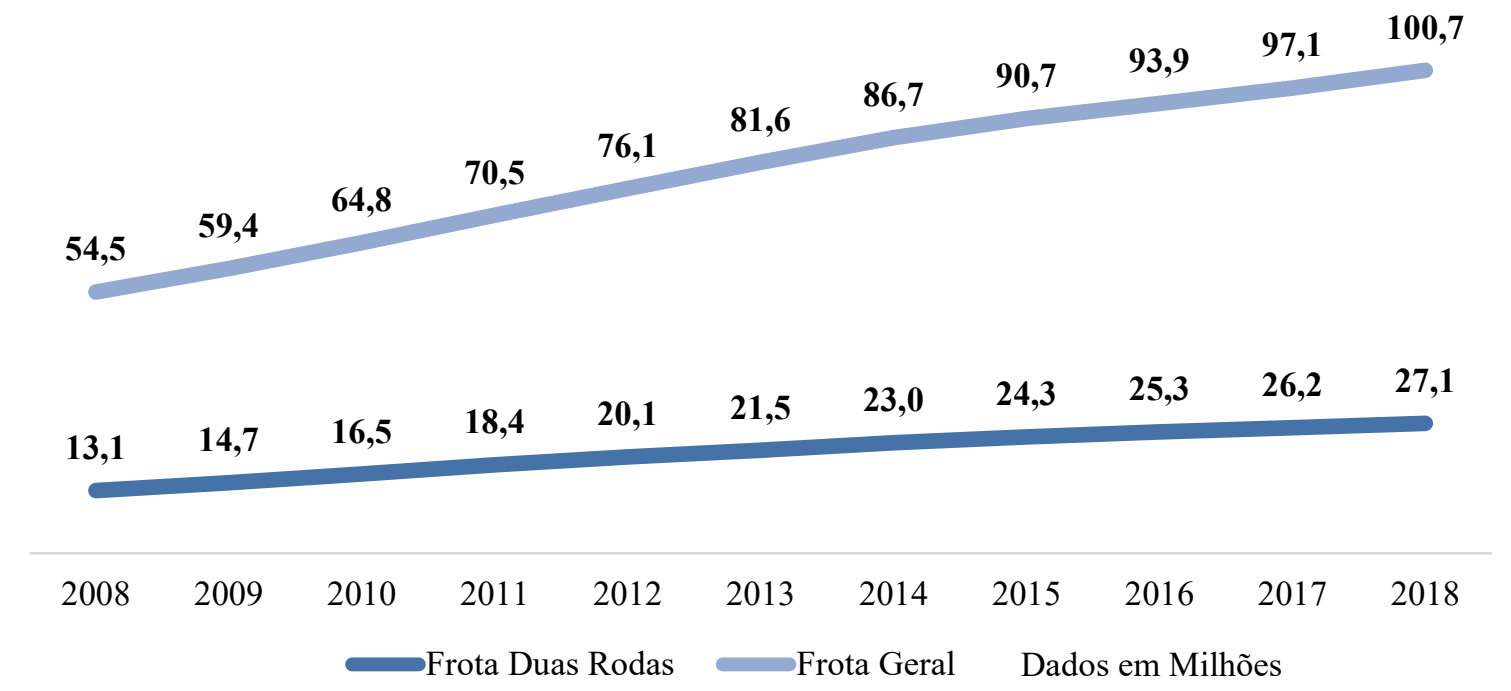

Fonte: ABRACICLO, 2019

Ao observar este tipo de aumento, porém de forma regionalizada, com o intuito de avaliar os locais em que esta expansão ocorreu com maior intensidade, percebe-se que a região Nordeste apresentou progresso no volume total de veículos registrados de forma mais expressiva ao longo dos últimos 10 anos. Com taxa de crescimento superior a $8 \%$, ela se destacou em relação as demais regiões apontando para uma intensificação da escolha do veículo de duas rodas como veículo preferido de sua população, conforme ilustrado pela Figura 2.

De acordo com Ferreira, Santos e Nassi (2014), um dos fatores que pode explicar o crescimento expressivo da frota nessa região, foi o aumento renda per-capita dentro do período estudado, que de acordo com a Pesquisa Nacional por Amostra de Domicílios Continua (PNAD Contínua) desenvolvido pelo IBGE (2019), subiu cerca de 17\%. 
Entretanto, mesmo com a maior taxa de crescimento em relação ao panorama nacional, a região Sudeste se mostra ainda como sendo a região detentora do maior número de emplacamentos registrados.

Figura 2 - Distribuição da frota de veículos automotores de duas rodas por região

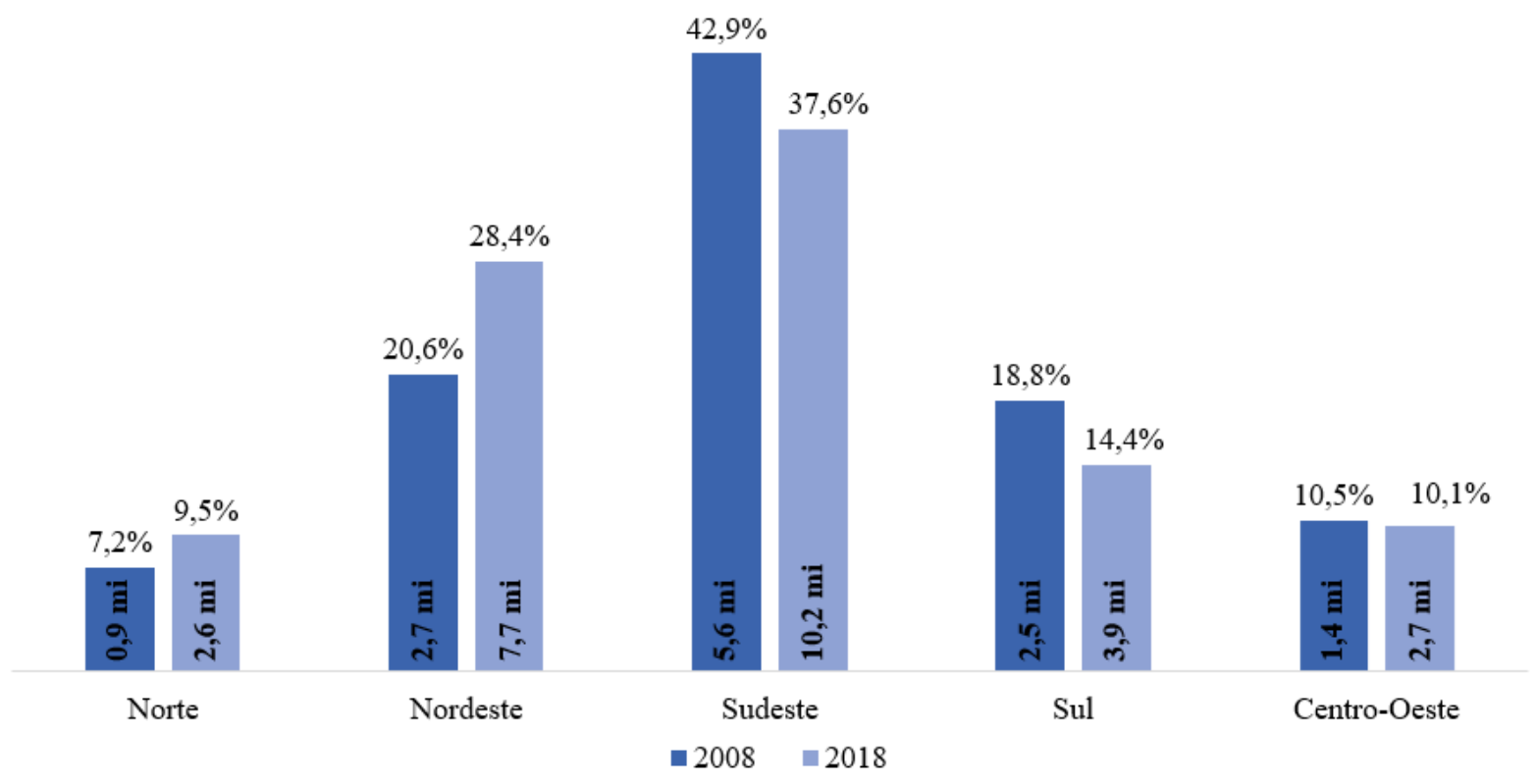

Fonte: ABRACICLO, 2019

Frente a região Nordeste, que apresentou em 2018 uma frota registrada próxima da casa de 7,7 milhões de unidades, a região Sudeste mantém sua vantagem significativa. Com um total de 10,2 milhões de motocicletas, esta região confirma sua hegemonia representando $37,6 \%$ da quantidade total de motocicletas em território nacional.

De forma a aprofundar ainda mais a análise, ao verificar o volume de registros por unidade da federação, confirma-se o estado de São Paulo, como sendo aquele que mais contribui para a formação da frota de motocicletas no Brasil. Com redução próxima de $4 \%$ em sua participação na composição da frota nacional nos últimos 10 anos, o estado paulista ainda foi responsável por registrar em 2018 pouco mais de $20 \%$ da frota nacional. A Figura 3 ilustra essa situação e aponta que este estado, com o volume superior a 5,6 milhões de unidades, confirma sua supremacia frente as demais unidades da federação quando se fala em volume total de motocicletas registradas. 
Figura 3 - Distribuição da frota de veículos automotores de duas rodas na região sudeste

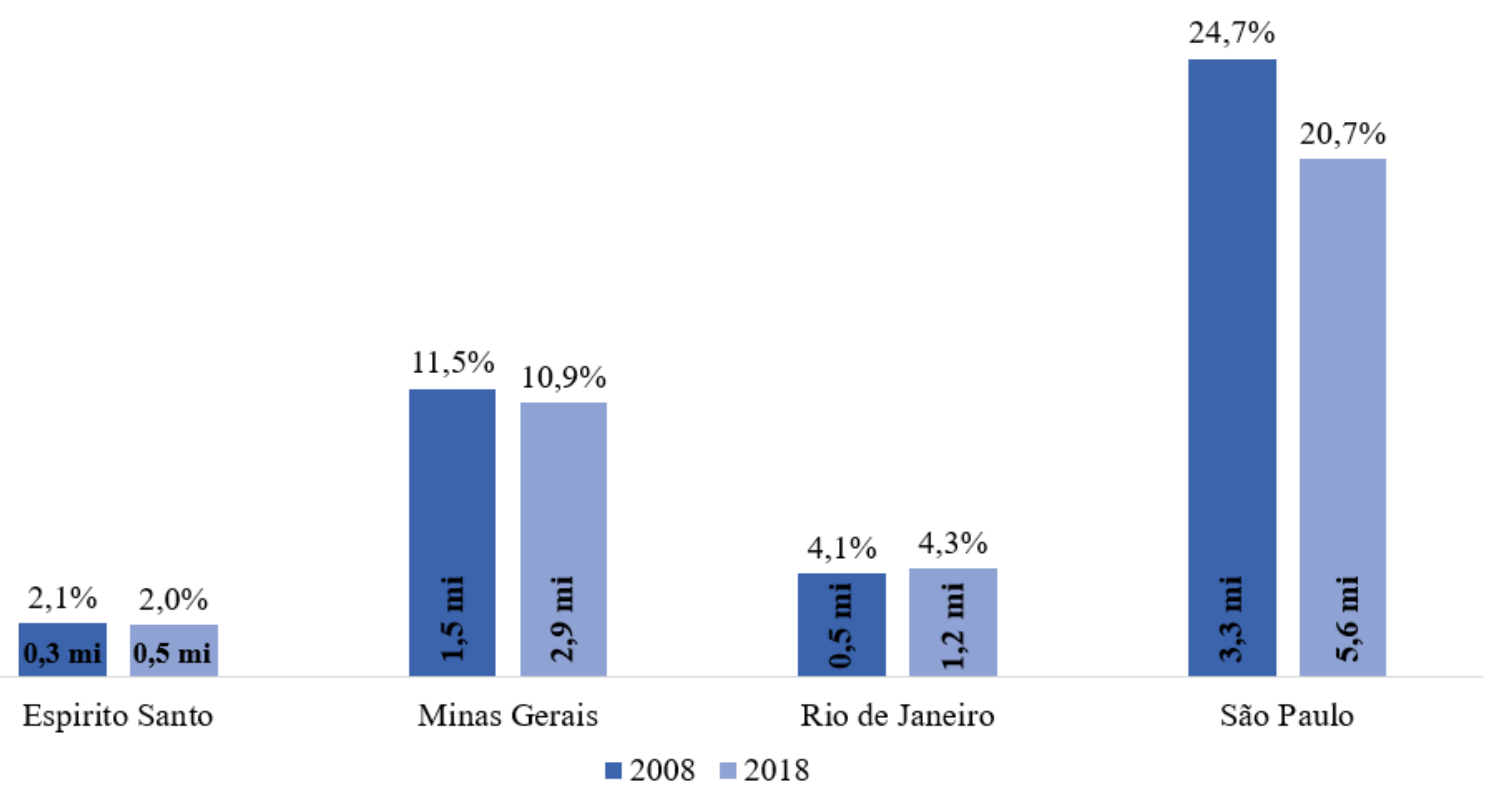

Fonte: ABRACICLO, 2019

Tal hegemonia, deve-se principalmente a centralização da população em grandes centros urbanos e a versatilidade de utilização da motocicleta nestes ambientes, uma vez que a agilidade deste tipo de veículo nas ruas e avenidas movimentadas das grandes capitais certamente é um atrativo de compra importante. Além disso, seu baixo custo de aquisição e manutenção quando comparado aos demais tipos de veículos, posiciona a motocicleta como uma excelente alternativa em relação ao transporte público. De acordo com pesquisas conduzidas pela Associação Internacional dos Fabricantes de Motocicletas (IMMA, 2014), $60 \%$ das vendas de motocicletas no Brasil se dão por conta da busca por uma alternativa frente ao transporte público dos centros urbanos.

Ainda de acordo com ABRACICLO (2019), aponta-se que com o avanço do mercado e popularização deste tipo de veículo, a forma de utilização da motocicleta se mostra diversificada em três segmentos, que conforme ilustrado pela Figura 4, apresentam comportamento perene de distribuição ao longo dos últimos 6 anos. Vale destacar que segundo a associação de fabricantes, a participação total dos três perfis pode ser superior a $100 \%$, uma vez que o uso combinado em mais de uma forma proposta é tecnicamente possível.

De acordo com o gráfico, observa-se que o montante daqueles que se denominaram integrantes da classe de condutores que fazem uso a motocicleta como objeto de trabalho, não supera os 3\%, entretanto, conforme matéria publicada no jornal O Estado de São Paulo, Veiga, (2016), sugere que deve-se compreender que este tipo de profissão, os então denominados 
“motoboys”, vem ganhando cada vez mais espaço na cidade de São Paulo. De acordo com o texto publicado, em 1990 eles representavam cerca de 20.000 profissionais, sendo que de acordo com Vieira (2019), o sindicato dos motofretistas de São Paulo (SINDIMOTOSP), aponta que hoje este número já ultrapassa os 200.000. Fazendo uma comparação deste montante com a frota total de motocicletas registrada na cidade de São Paulo até Agosto de 2019, que segundo Detran-SP (2019), supera os 1,2 milhões de unidades, entende-se que o volume de motocicletas associado a estes profissionais representa cerca de $16 \%$ da frota de motocicletas da maior cidade do pais.

Figura 4 - Forma de aplicação e uso dos veículos de duas rodas

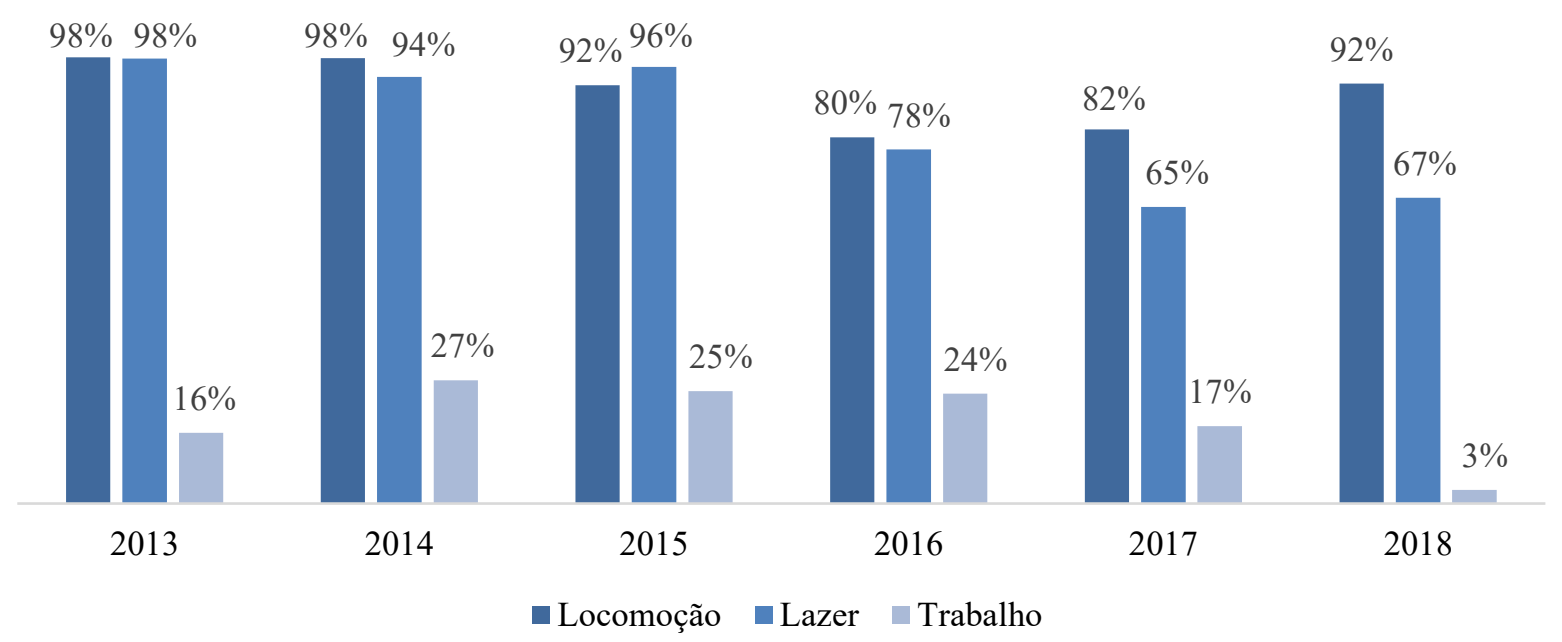

Fonte: ABRACICLO, 2019

Além disso, outro ponto que deve ser observado é que muitos destes profissionais trabalham de forma informal, sem qualquer tipo de registro. Conforme apontado por Silva (2009), a partir de uma pesquisa com 2500 empresas do ramo de motofrete instaladas na cidade de São Paulo, concluiu-se que somente 350 eram regularizadas perante a Prefeitura da cidade. Isso comprova que a real quantificação do montante de profissionais que percorre diariamente as ruas desta metrópole, muitas vezes por mais de 10 horas por dia, é uma tarefa bastante difícil de ser executada com precisão. Neste aspecto, destaca-se também a recente introdução do uso de aplicativos de entregas, que de acordo com Vieira (2019), já emprega hoje cerca de 40.000 motofretistas nesta cidade e contribui ainda mais para o aumento da taxa de informalidade. 


\subsection{A QUESTÃO DA MANUTENÇÃO DO VEÍCULO}

Sabe-se que qualquer tipo de máquina requer a realização de manutenções periódicas para que seu desempenho seja satisfatório. Mais do que isso, a intervenção para a execução de inspeções preventivas é fundamental para que o veículo possa atender os requisitos mínimos de segurança viária. Essa preocupação é ainda mais latente quando se analisa o veículo de duas rodas, uma vez que quando comparado ao automóvel, a grande maioria dos modelos não possuem diversos componentes de segurança passiva, como por exemplo barras de proteção lateral ou sistemas de amortecimento de impacto frontal.

Diante da importância de se assegurar o bom estado de conservação da frota circulante, a maioria dos países desenvolvidos obriga periodicamente que inspeções técnicas sejam realizadas nos veículos que possuem permissão de rodagem em vias públicas. Na Alemanha por exemplo, esta obrigatoriedade vigora desde 1951, sendo que tal exigência é regulamentada a partir do Anexo VIII da "Straßenverkehrs-Zulassungs-Ordnung", ou Regulamentação da Permissão de Trânsito em Vias Públicas (BUNDESMINISTERIUM DER JUSTIZ UND FÜR VERBRAUCHERSCHUTZ, 2012).

A legislação teutônica determina que, para haver permissão de circulação, a inspeção deve ser feita a cada 2 anos por agente certificador autorizado. Uma das empresas mais renomadas neste segmento é a TÜV-SÜD que durante as atividades de inspeção em motocicletas, verifica 46 itens divididos entre os seguintes subsistemas da motocicleta:

a) Condições Gerais (Número do Chassi, Plaqueta de Identificação do Modelo/Fabricante, Placa de Registro etc.);

b) Sistema Elétrico e Iluminação;

c) Sistema de Direção;

d) Freios;

e) Motor/Transmissão, Chassi e Elementos da Carroceria;

f) Sistema de Escapamento (Estanqueidade e Ruído).

Em caso de reprovação, o proprietário tem um mês para resolver as pendências apontadas e retornar para uma nova verificação, caso contrário, a licença de rodagem do veículo fica suspensa. Ao ser aprovado, o veículo recebe uma etiqueta que é aplicada na placa de registro do veículo. Lá ficam identificados o mês e o ano da próxima inspeção obrigatória para que o controle das autoridades de trânsito possa ser executado. Como exemplo, na Figura 5 
ilustra-se a plaqueta fixada a uma placa de identificação de uma motocicleta registrada na Alemanha.

Figura 5 - Placa de uma motocicleta registrada na Alemanha

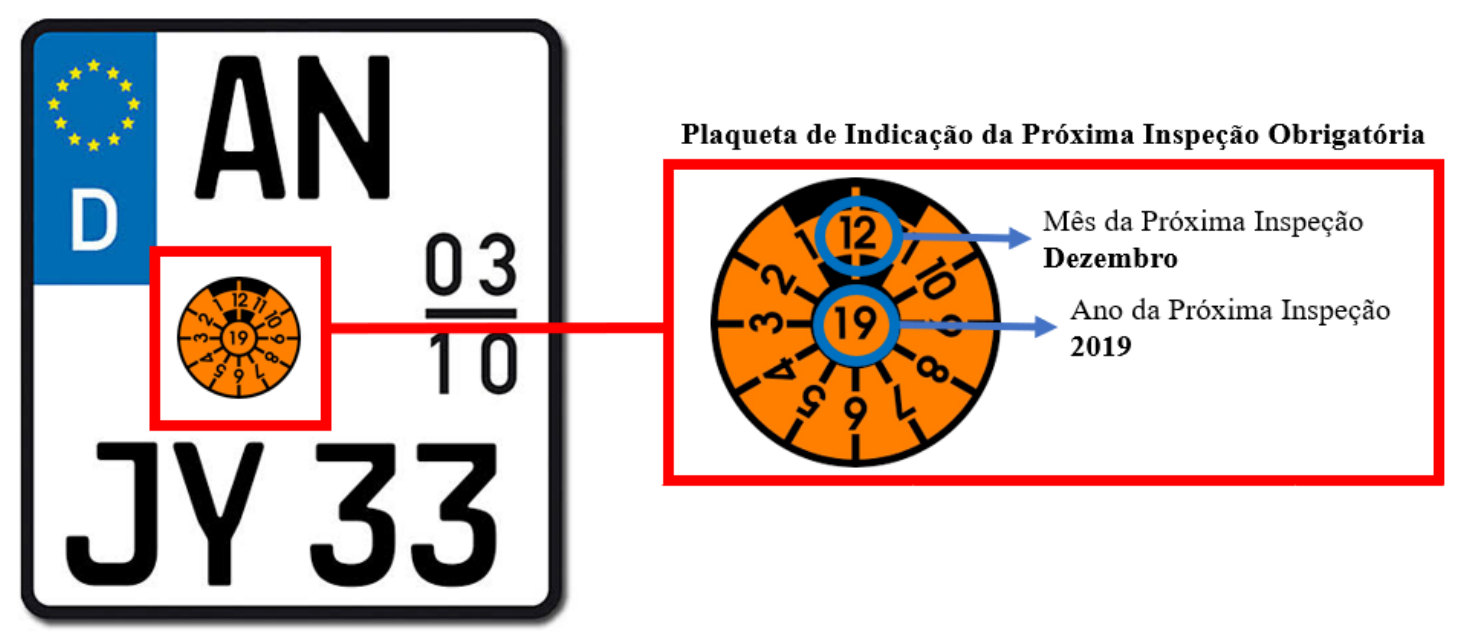

Fonte: Autor "adaptado de" Wechselkennzeichen, 2019

De acordo com o que foi apontado por Alemanha (2019) e ilustrado na Figura 6, nos últimos 10 anos, 82,1\% das motocicletas inspecionadas neste país foram aprovadas sem nenhum tipo de pendência junto aos órgãos certificadores. Isso representa cerca de 13,8 milhões de veículos, de um total de 16,8 milhões de motocicletas verificadas neste período.

Figura 6 - Tipos e quantidades de pendências verificadas durante as inspeções obrigatórias em motocicletas - Alemanha - período de 2009 a 2018

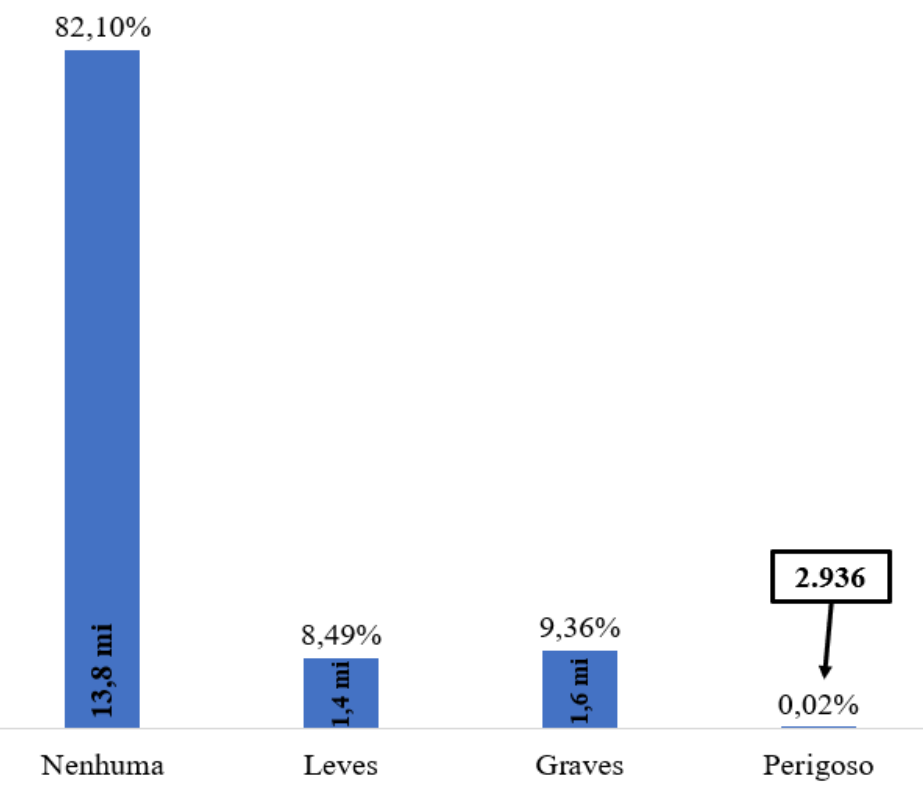

Fonte: Alemanha, 2019 
Verifica-se, portanto, que nos últimos 10 anos de inspeções executadas na Alemanha, menos de $10 \%$ das motocicletas apresentaram pendencias graves ou foram consideradas perigosas para a circulação em vias públicas. De acordo com pesquisas executadas pelo Allgemeiner Deutscher Automobil-Club (ADAC) (2019), os principais problemas observados durante as inspeções foram verificadas no sistema elétrico dos veículos, com maior participação dos itens de iluminação (faróis, indicadores de direção e lanterna/luz de freio/luz de placa), sendo que a Figura 7, ilustra os resultados desta pesquisa.

Figura 7 - Pendencias observadas nas inspeções periódicas distribuídas por grupo construtivo - Alemanha - período de 2009 a 2018

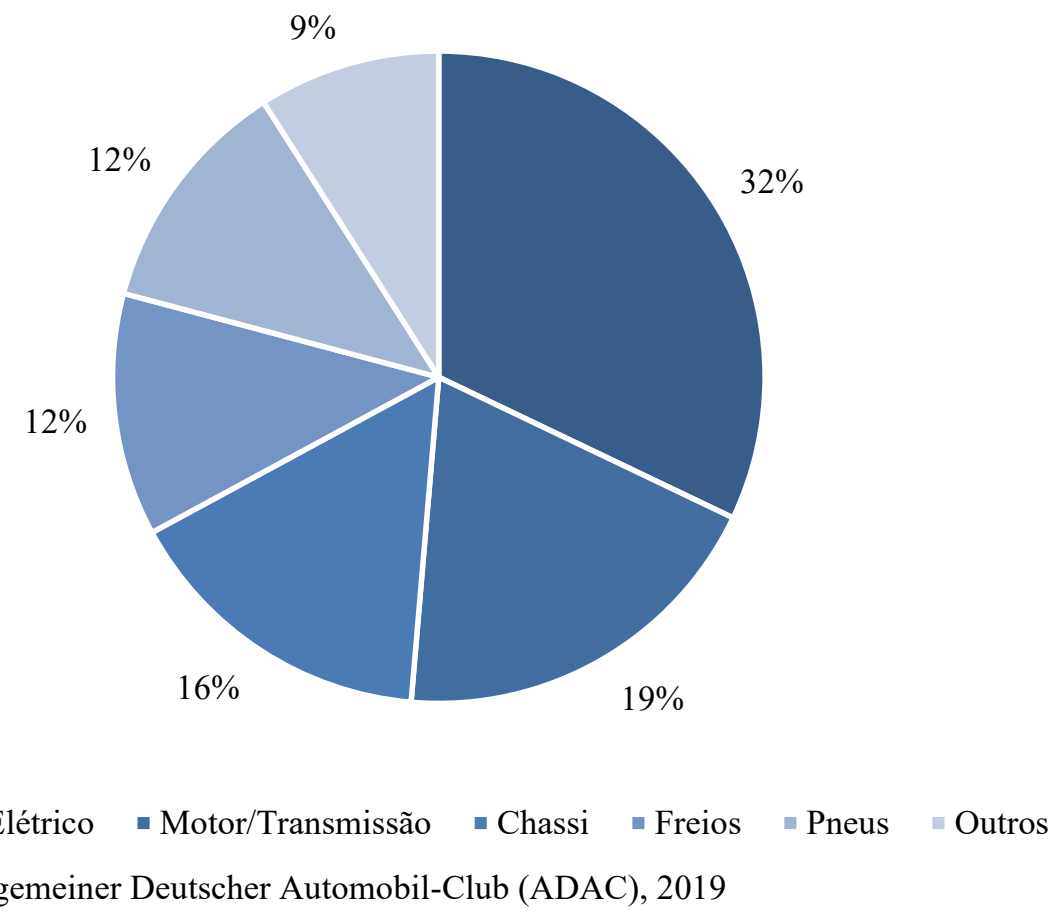

Diferentemente de outros países, o Brasil ainda não executa inspeções técnicas obrigatórias e periódicas em sua frota de veículos. A atual legislação nacional prevê a execução de tais inspeções, de forma que:

a) O artigo 104 da Lei $n^{\circ} 9.503$ de 23 de Setembro de 1997, que instituiu o Código de Transito Brasileiro, regulamenta que

Os veículos em circulação terão suas condições de segurança, de controle de emissão de gases poluentes e de ruído avaliadas mediante inspeção, que será obrigatória, na forma e periodicidade estabelecidas pelo CONTRAN para os itens de segurança e pelo CONAMA para emissão de gases poluentes e ruído. (BRASIL, 1997) 
O Conselho Nacional de Trânsito (CONTRAN), órgão máximo do Sistema Nacional de Trânsito Brasileiro, definiu uma agenda de implementação das inspeções técnicas conforme destacado pela Resolução CONTRAN 716 de 30/11/2017 que:

Estabelece as condições para implantação e operação do programa de inspeção técnica veicular em território nacional, sendo que os órgãos executivos de trânsito de cada estado da federação devem até do dia 31 de dezembro de 2019, implantar o programa de inspeção em sua área de jurisdição. (CONTRAN, 2017)

Entretanto, tal resolução foi suspensa por tempo indeterminado através da Deliberação CONTRAN 170 de 05/04/2018 que manifestou dificuldades para o cumprimento da agenda de implementação. Segundo texto da própria deliberação,

[...]. Necessário se faz que haja definições dos requisitos e sequência de inspeção, além das especificações de sistemas informatizados para agendamento, operacionalização e gestão das atividades. [...]. Desta forma esta CGIT propõe que a Resolução CONTRAN 176/2017 seja suspensa, por edição de Deliberação do CONTRAN, haja visto que o prazo previsto em seu art. 13 não será cumprido pelos órgãos e entidades executivas de trânsito dos Estados e do Distrito Federal [...]. (CONTRAN, 2018)

Já do lado ambiental, o Conselho Nacional do Meio Ambiente (CONAMA), publicou a Resolução 418 de 25/11/2009 que:

\footnotetext{
Dispõe sobre critérios para a elaboração de Planos de Controle de Poluição Veicular - PCPV e para a implantação de Programas de Inspeção e Manutenção de Veículos em Uso - I/M pelos órgãos estaduais e municipais de meio ambiente e determina novos limites de emissão e procedimentos para a avaliação do estado de manutenção de veículos em uso. (CONAMA, 2009)
}

Em seu Artigo $5^{\circ}$, tal resolução aponta que todos os municípios com frota superior a 3 milhões de veículos deveriam dentro de 12 meses após a data de publicação da resolução elaborar, aprovar e publicar o Plano de Controle de Poluição Veicular, sendo que tais atividades ficariam facultadas aos municípios com frota inferior a 3 milhões. Na época da publicação, conforme Brasil (2009), somente o município de São Paulo possuía esta quantidade de veículos, sendo que lá, este tipo de inspeção ocorreu entre 2009 e 2014. (JOÃO... 2018)

Não cabe aqui analisar os motivos pelos quais as inspeções veiculares, sejam elas técnicas ou ambientais não vem mais ocorrendo na cidade de São Paulo, entretanto, destaca-se a diferença entre a forma de abordagem deste assunto perante as instituições de ambos os países aqui mencionados. 
Paralelamente, a Associação Brasileira dos Fabricantes de Motocicletas, Ciclomotores, Motonetas, Bicicletas e Similares, ABRACICLO, executa o MotoCheck Up, maior programa setorial de avaliação gratuita de motocicletas e de conscientização sobre pilotagem segura da América Latina (ABRACICLO, 2017). Em 2019, o programa atingiu a sua $24^{\text {a }}$ edição, sendo que desde o início das avaliações em 2008, mais de 50.000 motocicletas foram inspecionadas em diferentes cidades brasileiras. A Figura 8 ilustra o momento de uma inspeção realizada na $16^{\mathrm{a}}$ edição do evento que ocorreu em Brasília - DF.

Figura 8 - Evento MotoCheck Up (16 Edição) - realizado em Brasília - DF

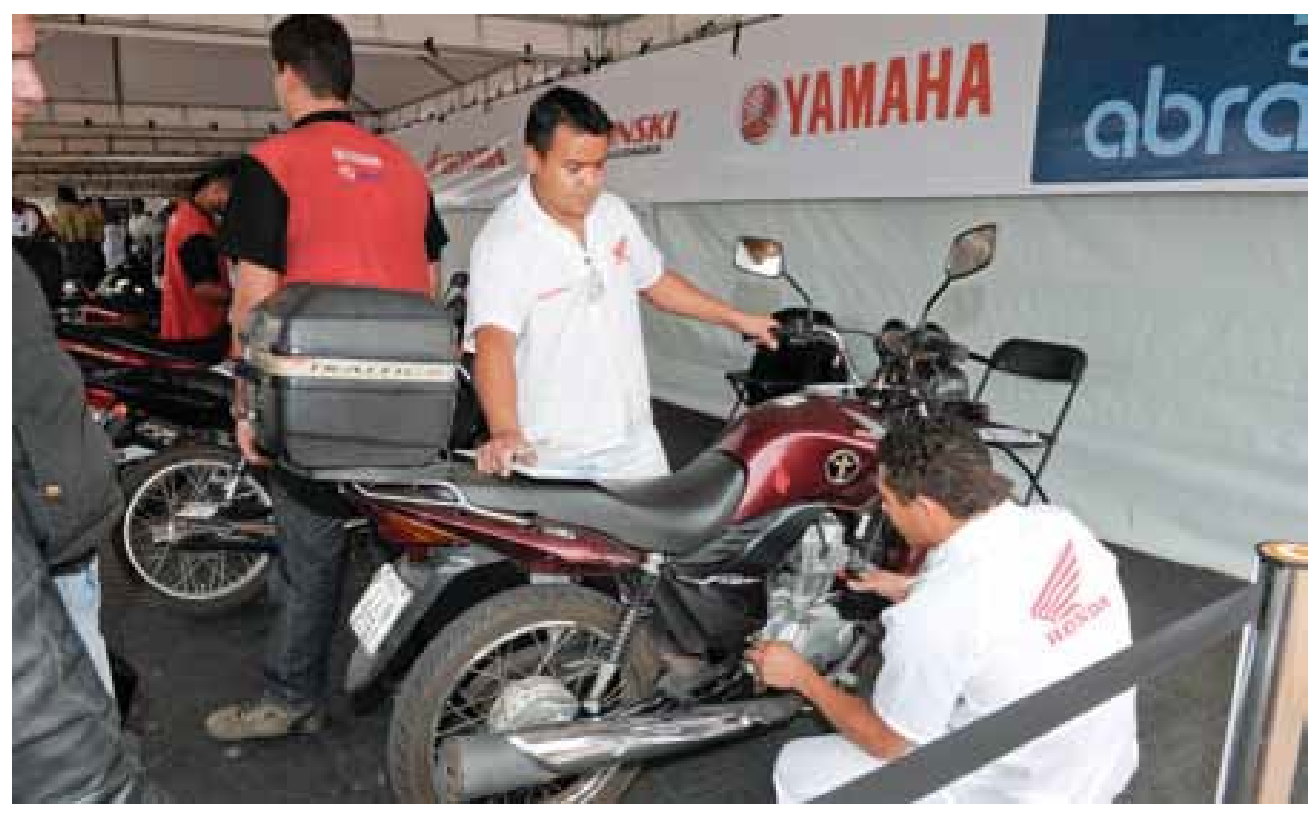

Fonte: em Discussão, 2012

Durante a inspeção, a motocicleta tem 21 itens de segurança verificados, sendo que os dados colhidos ao longo dos últimos 11 anos apontam para uma taxa de sinistralidade de 229 $\%$. Partindo do princípio que uma mesma moto pode ter mais de um componente pendente de manutenção, entende-se que o número de pendencias encontradas ao longo das 24 edições do programa foi mais de duas vezes maior do que o número de motos verificadas.

Isso aponta para uma questão preocupante, a falta de manutenção da frota nacional, principalmente quando se observa itens de segurança.

Ao verificar as pendencias de forma estratificada de acordo com cada item verificado, entende-se que os maiores índices de sinistralidade foram verificados junto aos sistemas do freio traseiro e dianteiro respectivamente, conforme sugere a Figura 9 a seguir. 
Figura 9 - Itens que apresentaram necessidade de manutenção nas 24 edições do projeto Motocheck-up, organizado pela ABRACICLO.

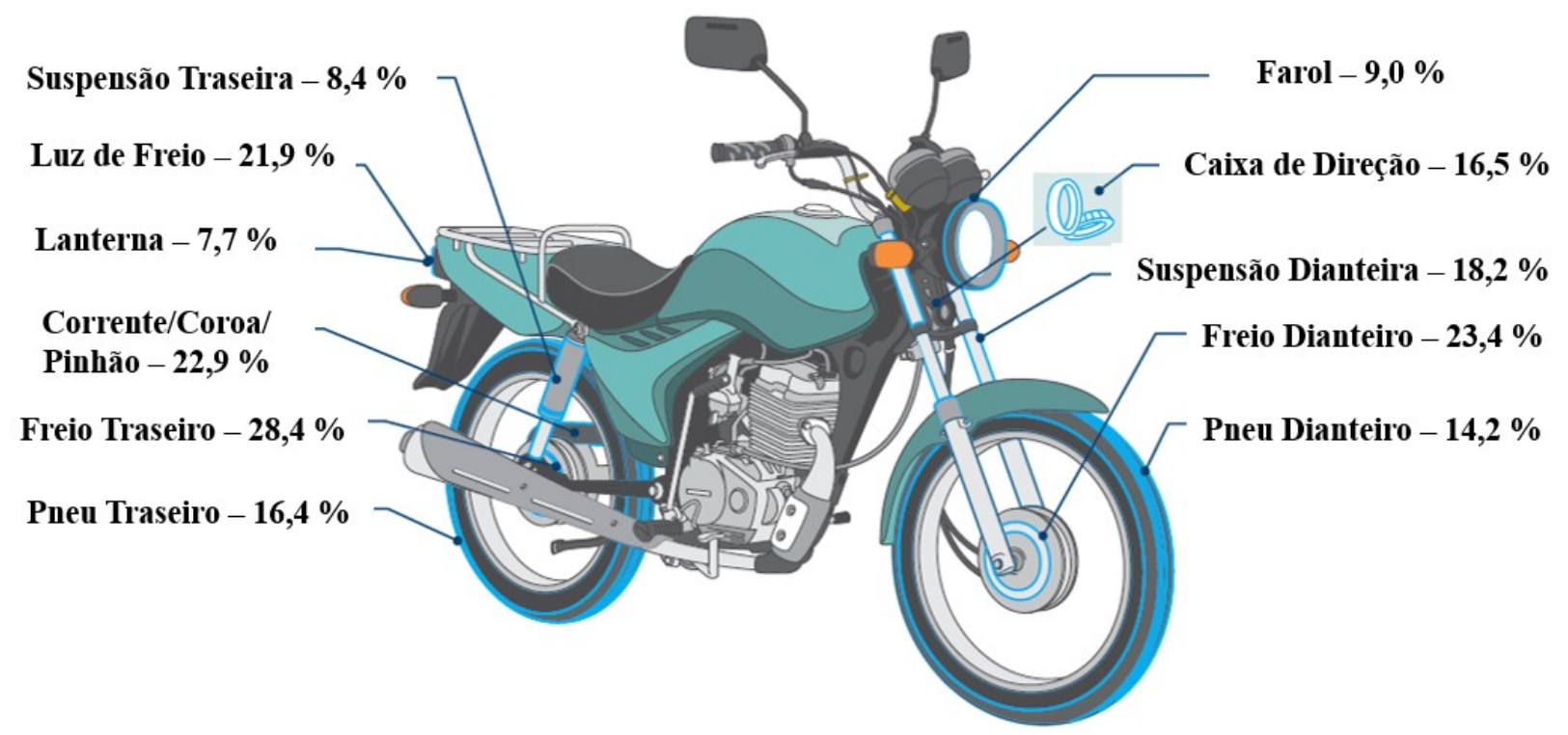

Fonte: Autor “adaptado de” em Discussão, 2012

Desta maneira, entende-se que a questão da manutenção do veículo de duas rodas no Brasil deve ser observada cautelosamente durante qualquer tipo de análise de durabilidade, uma vez que, diferentemente de países mais desenvolvidos, a questão da execução das manutenções preventivas apresenta grandes divergências frente ao que os fabricantes estabelecem como recomendado em seus planos de inspeções periódicas. 


\subsection{A IMPORTÂNCIA DO ESTUDO DA DURABILIDADE NA ENGENHARIA AUTOMOTIVA}

De acordo com Johannesson e Speckert (2014), a durabilidade é a capacidade de um item resistir a sua proposta de uso por um período longo suficiente. Trazendo essa definição para o contexto automotivo, entende-se que o conceito de durabilidade se relaciona com a habilidade de um veículo, sistema ou componente de executar suas funções de serviço durante seu período de vida útil seguindo padrões de manutenção adequados as condições de uso empregadas.

Desta forma, um dos principais objetivos durante o projeto do veículo, é garantir que ele seja robusto e confiável de forma que as expectativas dos clientes sejam atendidas. Para isso, além de definir o tempo de vida de sistemas e componentes, deve-se olhar com atenção para todas as possíveis fontes de carregamentos aplicados no veículo e suas respectivas variações. Os carregamentos aplicados pelo usuário e a resistência estrutural, definirão o tempo de vida de cada componente projetado. Considerando que a resistência estrutural do componente depende somente do material empregado em sua construção e suas características geométricas, o maior desafio do ponto de vista do projetista será o de prever quais serão os carregamentos aplicados pelos usuários e como se darão suas variações. Estas por sua vez são um reflexo do tipo de aplicação do veículo, estilo de condução do piloto e do mercado em que o veículo está inserido.

No ramo das duas rodas, Stoffregen (2010), ressalta que os estudos sobre durabilidade cumprem um papel de destaque dentro do processo de desenvolvimento de novos modelos. Tais análises são conduzidas de acordo com as peculiaridades e experiências de cada montadora, sendo que na maioria dos casos, tais avaliações buscam garantir a que a vida útil do produto exceda os $150.000 \mathrm{~km}$ para o uso de um condutor normal. Para isso, utilizam-se estratégias de testes combinando-se diferentes tipos de carregamentos e formas de utilização com a intenção de acelerar o processo de testes e validação. 
Johannesson e Speckert (2014), destacam ainda que este período probatório, na maioria das vezes acontece em circuitos ou ambientes fechados, que na verdade, submetem o veículo a carregamentos mais severos que aqueles impostos por condutores convencionais. Entretanto, por mais severo que os testes de durabilidade possam ser, estes ambientes ainda podem ser denominados como controlados e que infelizmente, não podem simular todas as possíveis ocorrências e carregamentos que o veículo será exposto durante sua vida útil. Na Figura 10, verifica-se que a intensidade dos carregamentos impostos pelo uso dos condutores normais (clientes que comprarão o veículo) deve ser sempre inferior aos dos carregamentos obtidos durante os testes de durabilidade. Além disso, nota-se também que ambos devem ter intensidade inferior aos limites de resistência estrutural do componente.

Figura 10 - Distribuição de probabilidade dos carregamentos impostos por condutores normais, pistas de teste e resistência estrutural do componente

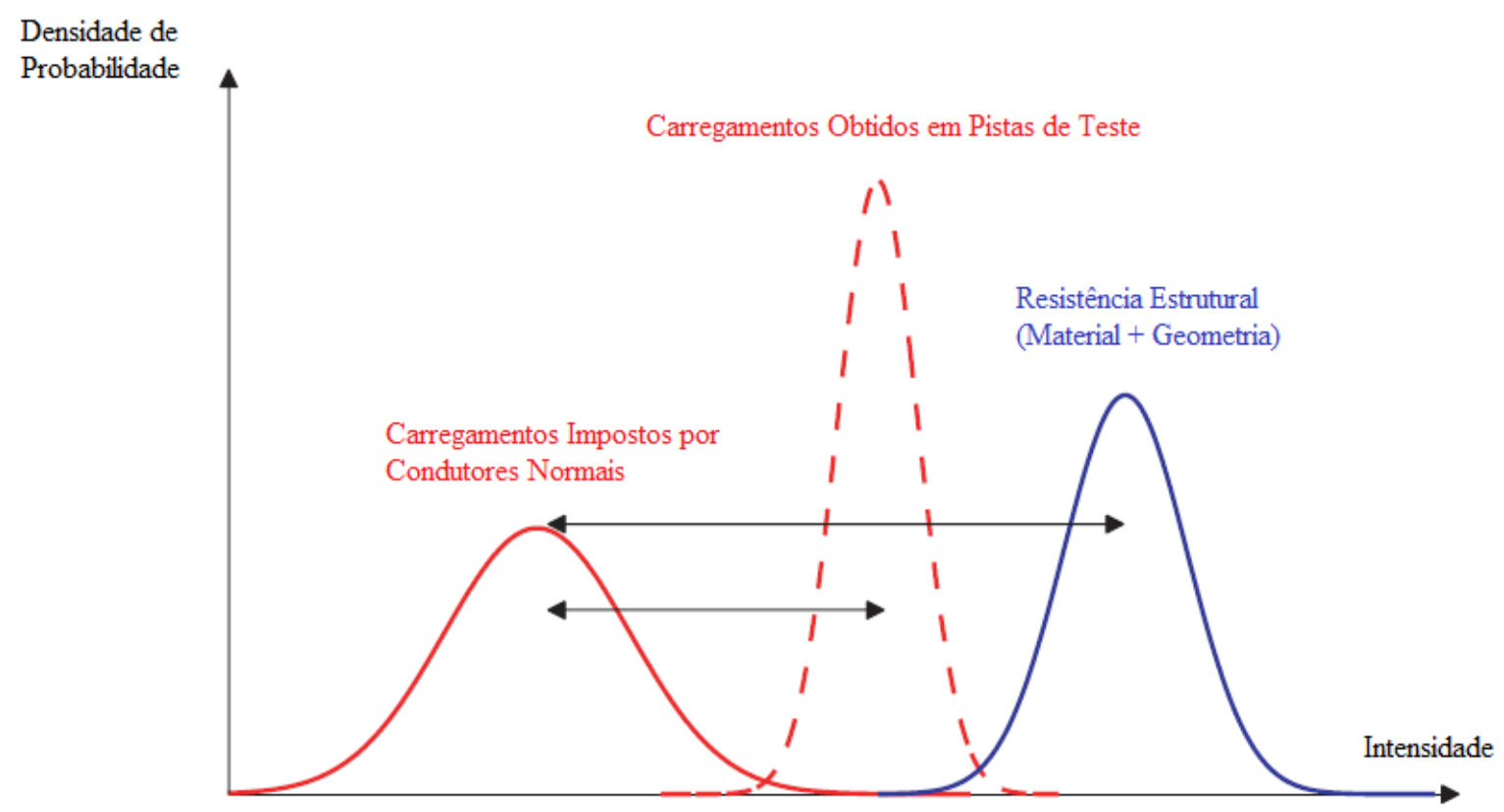

Fonte: Autor “adaptado de" Johannesson e Speckert, 2014

Ainda de acordo com essa literatura, a estratégia para o aumento da confiabilidade dos veículos em desenvolvimento sempre esteve alinhada com a aquisição de informações provenientes dos testes de campo. Estes por sua vez, devem permitir que os motivos das falhas observadas sejam compreendidos, para que então soluções de engenharia sejam desenvolvidas de forma que os impactos de tais falhas sejam evitados ou minimizados. Apesar desta ser a base para a identificação de pontos fracos e subsequente promoção de melhorias técnicas para o incremento da confiabilidade dos componentes ainda em fases iniciais do projeto, esta 
estratégia de aperfeiçoamento contínuo possui limitações, uma vez que ela depende de resultados práticos inerentes da utilização do produto no campo. Isso torna os resultados dos testes possíveis de serem aplicados somente em uma fase terminal do desenvolvimento, em que quaisquer alterações incorrerão em investimentos e prazos consideráveis.

Para que situações como esta sejam evitadas, Weber (2009), aponta que auditores de qualidade altamente qualificados são designados para garantir que todos os sistemas do veículo sejam avaliados durante a fase de desenvolvimento. A queda no número de ocorrências de qualidade ao longo da fase de desenvolvimento, demonstrará o nível de maturidade do projeto ainda em sua etapa inicial. Conforme apresentado na Figura 11, espera-se que durante a construção dos primeiros protótipos, o número de ocorrências de qualidade seja ainda consideravelmente elevado. A evolução dos componentes e processos internos da montadora, deverão ser capazes de garantir a queda no número de ocorrências, até que elas alcancem índices toleráveis de acordo com o volume de produção em série.

Figura 11 - Evolução da qualidade do veículo durante a fase de desenvolvimento

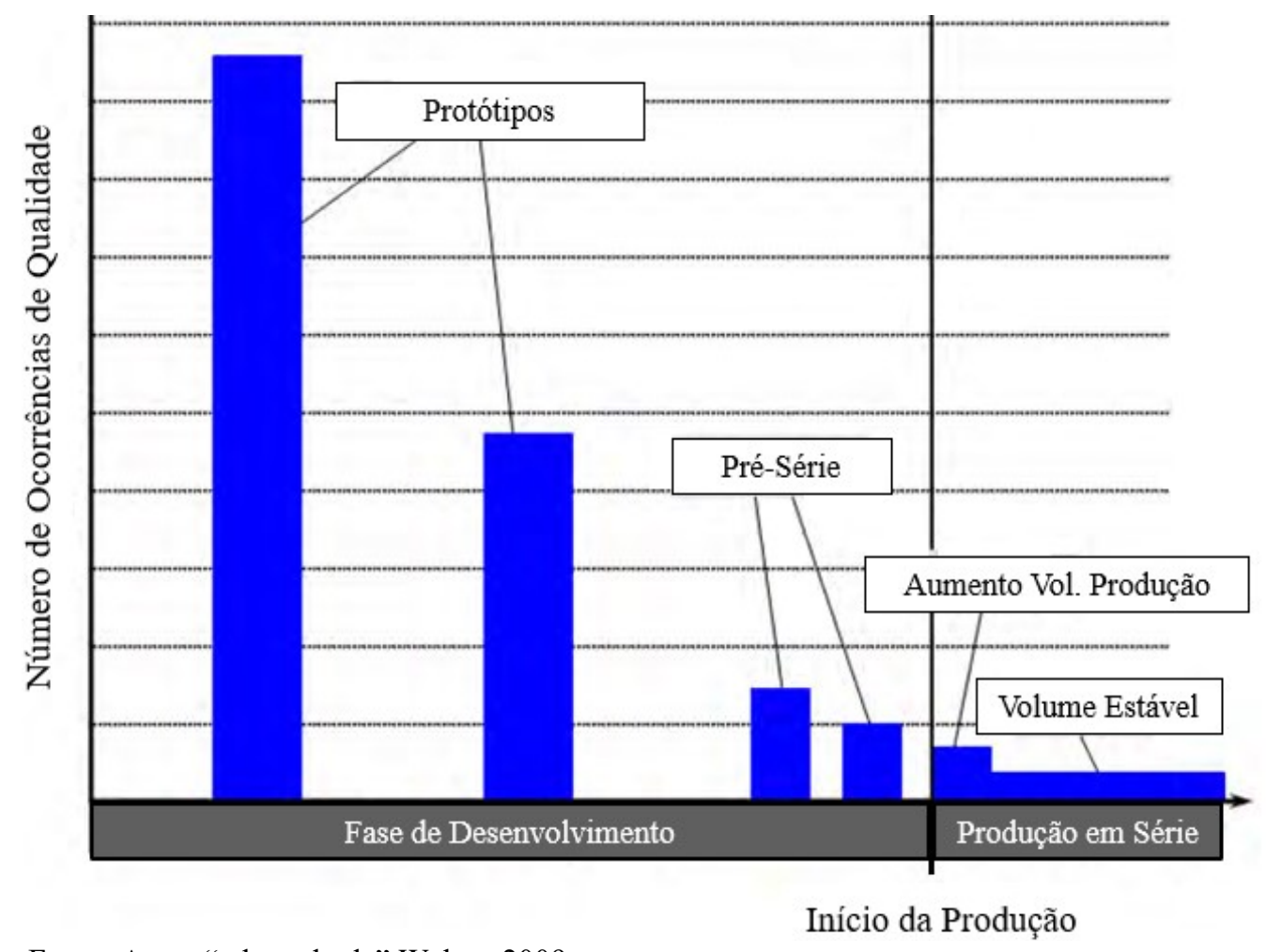

Fonte: Autor “adaptado de” Weber, 2009

Durante o desenvolvimento de projetos de alta complexidade, que demandam constantes verificações e validações, destaca-se também a aplicação de uma outra ferramenta bastante útil denominada "Modelo V". Kneuper (2018), aponta que o Modelo V é um método concebido 
para auxiliar desenvolvedores durante as etapas de validação e verificação de resultados de testes executados durante a fase de projeto. Tal conceito foi primeiramente apresentado no final da década de 1970, com aplicação na área de desenvolvimento de softwares. Sua principal finalidade é a de estabelecer um ciclo de atividades relacionadas e integrantes ao processo de verificação e validação.

Ilustrado a partir da letra "V", primeiramente lista-se no braço esquerdo do caractere as atividades integrantes do processo de desenvolvimento, sendo elas dispostas em sequência, posicionando na parte superior deste braço a atividade de menor complexidade. Para cada uma destas atividades de desenvolvimento, no braço direito da letra, haverá uma atividade correspondente, porém, associada ao processo de validação/integração do projeto.

Além disso, espera-se que haja uma relação de interdependência entre as atividades listadas em cada etapa, de forma que os resultados obtidos em cada passo possam servir de referência para a validação do próximo. De forma prática, espera-se que com a aplicação do Modelo V, o produto final possa ser validado de acordo com os requisitos originais do cliente, sendo que ao adaptar este tipo de ferramenta a realidade em estudo, entende-se que a avaliação dos carregamentos impostos pelos diferentes tipos de condutores e a execução de testes de durabilidade, se apresentam como etapas fundamentais, conforme ilustra a Figura 12.

Figura 12 - Modelo V aplicado ao processo de desenvolvimento de um veículo

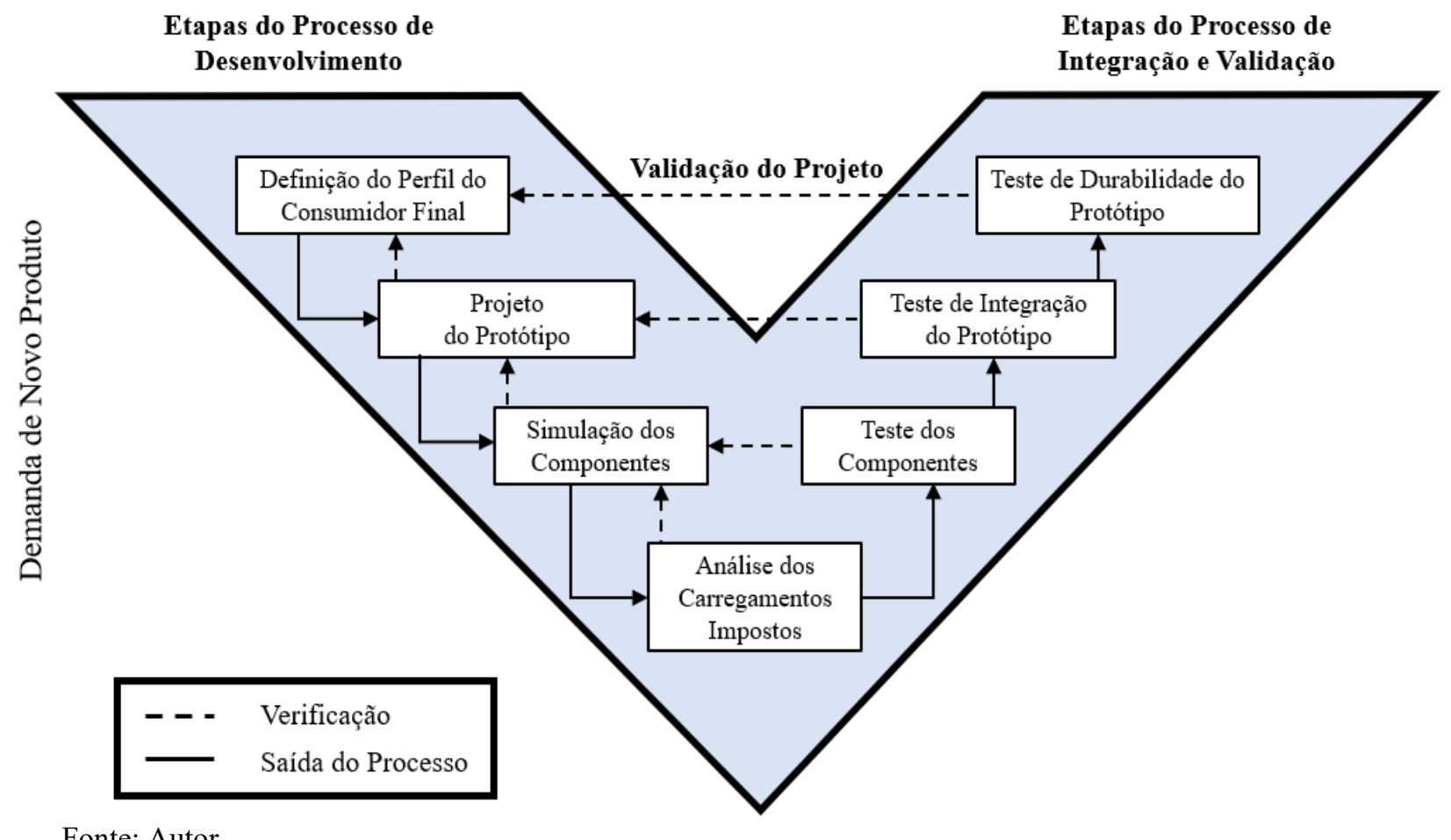

Fonte: Autor 


\subsection{PROCESSO DE TESTES E VALIDAÇÃO}

Para que o processo de evolução do protótipo ocorra de forma mais rápida gerando menos perdas possíveis, entra em cena a importância da execução de ensaios executados através de simuladores dinâmicos, simulações computacionais e testes acelerados. A seguir discute-se cada um destes métodos.

\subsubsection{Simuladores Dinâmicos}

A validação dinâmica, segundo Chindamo et al. (2017) é sem dúvida uma etapa mandatória durante o desenvolvimento na área da engenharia mecânica automobilística. Esses recursos colaboram intensivamente para a redução do tempo e recursos financeiros gastos em testes reais em campo, auxiliando os engenheiros de desenvolvimento durante a tarefa de validação do veículo completo.

Para que este tipo de confirmação seja efetivo, o modelo adotado durante a construção de plataformas para simulações dinâmicas deve ser baseado em modelos matemáticos robustos e confiáveis. Um exemplo deste tipo de equipamento comumente utilizado no segmento automotivo é o dispositivo de ensaio de quatro colunas, já demonstrado por Vaes, Sas e Swevers (2004), conforme ilustrado pela Figura 13.

Figura 13 - Dispositivo de ensaio de quatro colunas

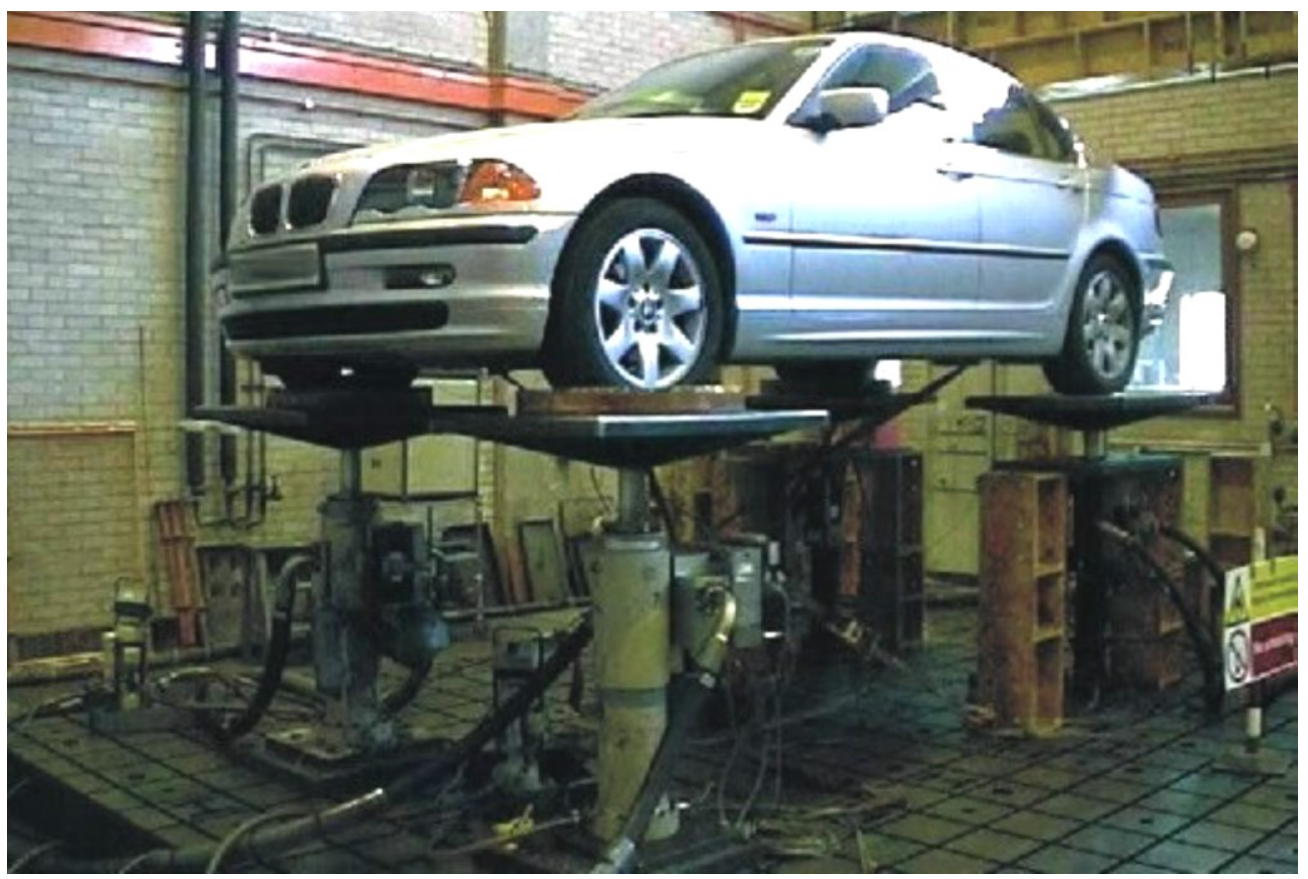

Fonte: Vaes, Sas e Swevers, 2004 
Este tipo de dispositivo, permite que o veículo seja apoiado em quatro atuadores hidráulicos capazes de submeter o automóvel a oscilações de diferentes frequências. As principais aplicações deste tipo de equipamento são voltadas para execução de análises de conforto, investigação de frequências naturais e análises de ruídos e vibrações "NVH”, em que as frequências de oscilação aplicadas nos atuadores hidráulicos são resultantes de análises multivariadas.

Ainda de acordo com Chindamo et al. (2017), este tipo de dispositivo também comprova sua importância durante análises voltadas ao segmento de duas rodas, em que testes de bancada realizados para a avaliação do sistema de suspensão do veículo por exemplo, se mostram como alternativas altamente valiosas para redução do tempo de validação do protótipo.

De forma mais complexa, uma vez que o veículo de duas rodas não é capaz de se auto sustentar, este tipo de equipamento requer adaptações para prover análises do comportamento dinâmico da motocicleta ao mesmo tempo que avaliações quantitativas das interações entre o veículo e pavimento sejam executadas. A Figura 14 ilustra um dispositivo de duas colunas desenvolvido para motocicletas.

Figura 14 - Dispositivo de ensaio de duas colunas para motocicletas

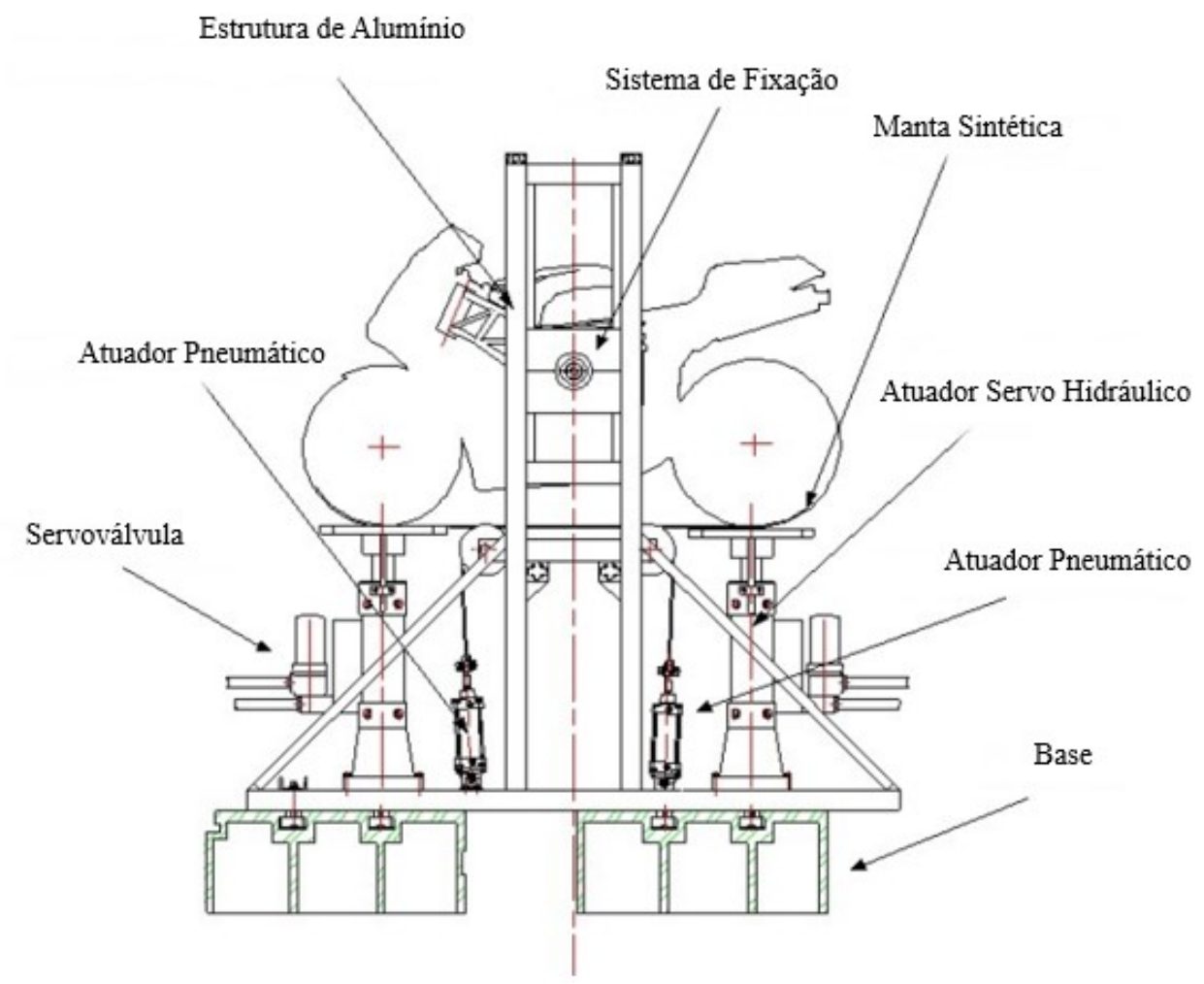

Fonte: Autor "adaptado de" Chindamo et al., 2017 
Atualmente, este tipo de dispositivo, que permite que a forma de fixação do veículo ao equipamento de medição não afete os resultados das análises, raramente pode ser encontrado em nível mundial, sendo que as principais adaptações frente ao sistema utilizado para veículos de 4 rodas requerem que:

a) O sistema de fixação do quadro da moto ao equipamento esteja localizado junto ao centro de massa do veículo;

b) O sistema de fixação seja construído a partir da aplicação de dispositivos móveis e pivôs montados com buchas que permitam baixa resistência ao atrito com a estrutura de alumínio do dispositivo de ensaio;

c) Sejam empregadas mantas de material sintético para oferecer as resistências de tração e frenagem aplicadas aos pneus do veículo durante o ensaio.

Com base nessas premissas, a construção de um dispositivo em escala real, capaz de reproduzir os comportamentos necessários para avaliações da dinâmica vertical de uma motocicleta, foi devidamente desenvolvido, sendo que os resultados obtidos pelos autores se mostraram satisfatórios. A Figura 15 ilustra o dispositivo.

Figura 15 - Dispositivo de ensaio desenvolvido para motocicletas em operação

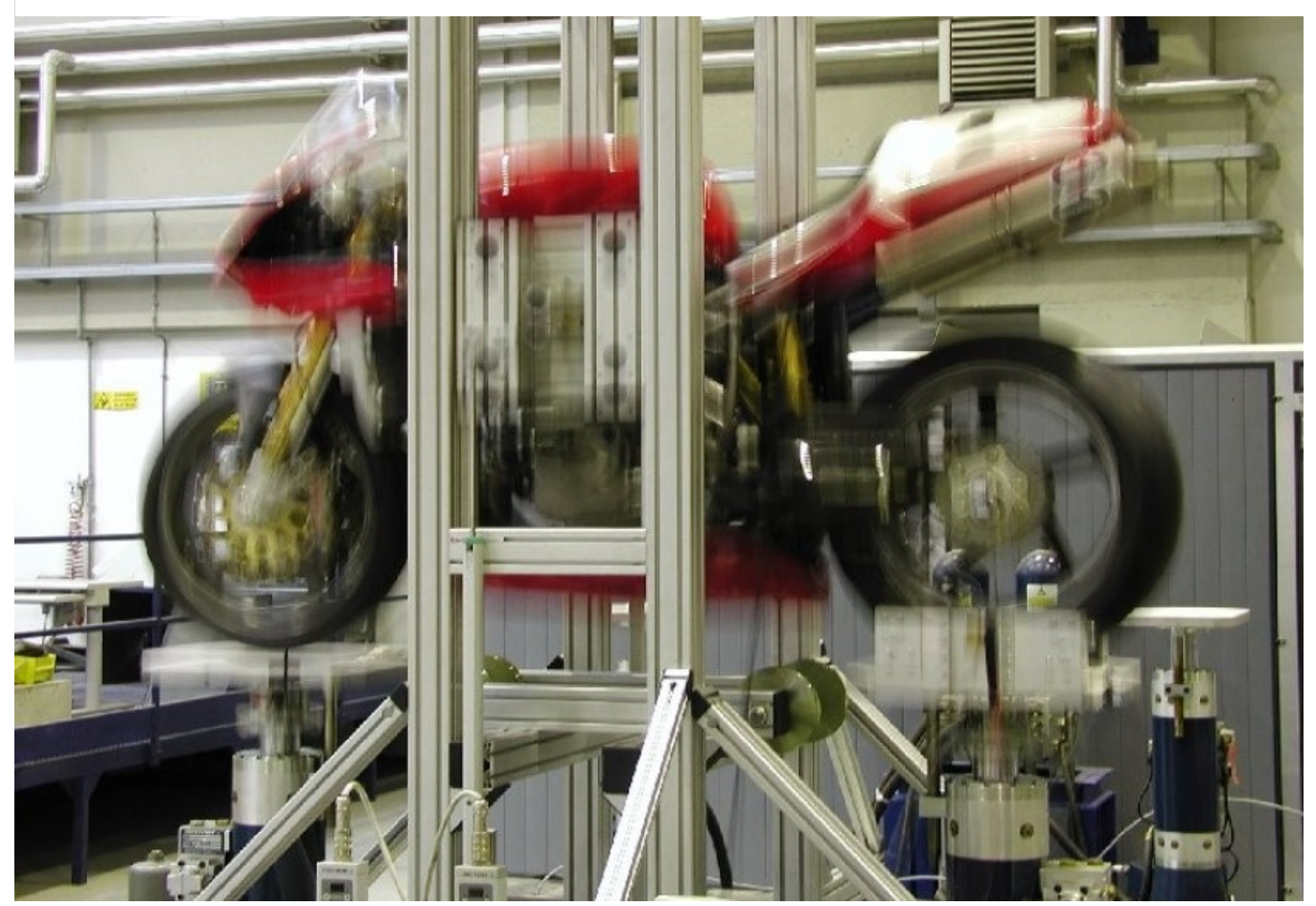

Fonte: Autor “adaptado de” Chindamo et al., 2017 
Chindamo et al. (2017) ainda apontam que as validações se basearam em comparações de frequências (estimadas vs. aferidas) junto as massas não suspensas da motocicleta, sendo que por questões de confidencialidade, os autores não forneceram dados quantitativos dos resultados.

Além disso, análises relacionadas a reprodução do perfil do terreno foram utilizadas para garantir a eficiência do dispositivo de teste. Sessões executadas a partir da comparação com resultados adquiridos em medições conduzidas em terrenos reais, permitiram a execução de testes simulando diferentes velocidades de condução, o que colaborou para a confirmação da fidelidade dos resultados obtidos pelo equipamento.

Isso comprovou a possibilidade da realização de ensaios dinâmicos a partir do uso de simuladores desenvolvidos especificamente para motocicletas, o que certamente se demonstra como uma alternativa bastante atraente para que os departamentos de pesquisa e desenvolvimento das montadoras aperfeiçoem suas estratégias empregadas durante as rotinas de testes e validações de seus produtos.

\subsubsection{Simulações Computacionais}

Conforme já destacado, testes executados em simuladores dinâmicos proporcionam soluções bastante atraentes durante a execução de ensaios para validações de novos produtos. Entretanto, conforme apresentado por Shi et al. (2009) a manutenção de equipamentos conforme aquele introduzido por Chindamo et al. (2017) pode impactar sensivelmente nos custos dos projetos, uma vez que uma série de alterações são necessárias para que cada veículo seja devidamente ensaiado junto ao dispositivo. Além disso, a técnica aplicada durante o setup do maquinário requer tempo e conhecimentos específicos, uma vez que cada tipo de motocicleta diferente demandará uma série de ajustes no equipamento antes do início dos testes. De maneira análoga, caso haja alterações estruturais ou dinâmicas durante a evolução do projeto em teste, o sistema de ensaio precisará ser recalibrado. Dependendo da urgência vinculada aos prazos acordados para o início da produção em massa (S.O.P.), isso pode fazer com que o departamento de pesquisa e desenvolvimento se torne refém de seu próprio dispositivo de ensaio.

Para que entraves como estes sejam minimizados, Shi et al. (2009), apontam que testes simulados são aplicados desde a década de 1930 junto a indústria aeroespacial. Na indústria automotiva, este tipo de experimentação vem sendo aplicada desde 1948. Com o avanço na área computacional, softwares como CATIA ${ }^{\circledR}$, ADAMS $^{\circledR}$ e NASTRAN ${ }^{\circledR}$, vem proporcionando aos 
engenheiros automotivos resultados bastante satisfatórios com simulações que independem do protótipo físico já acabado. Como exemplo, Shi et al. (2009), desenvolveu um modelo digital para análises dinâmicas, em que o perfil do solo utilizado pôde ser aferido através de simulações reais e posteriormente aplicado ao protótipo virtual, com o intuito de se obter a validação estrutural do quadro do protótipo. Para isso, um dispositivo de duas colunas foi desenvolvido em ambiente computacional conforme ilustrado na Figura 16 e posteriormente aferido por um sistema real com o intuito de garantir a eficácia do modelo.

Figura 16 - Quadro e dispositivo de duas colunas desenvolvidos em ambiente computacional

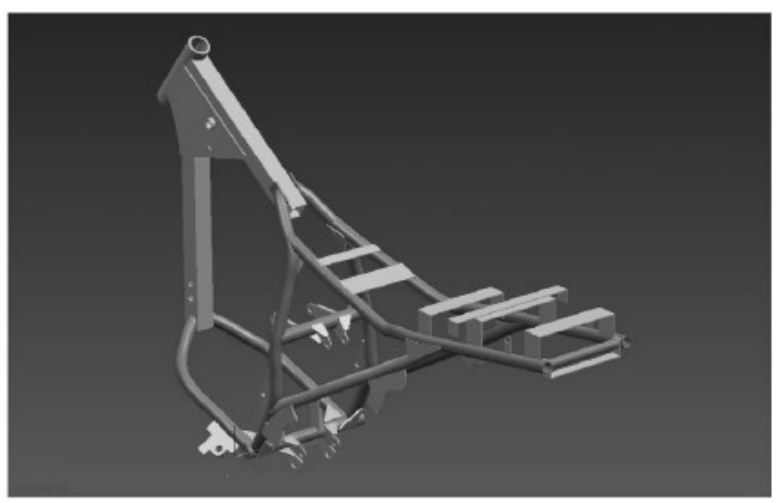

Fonte: Shi et al., 2009

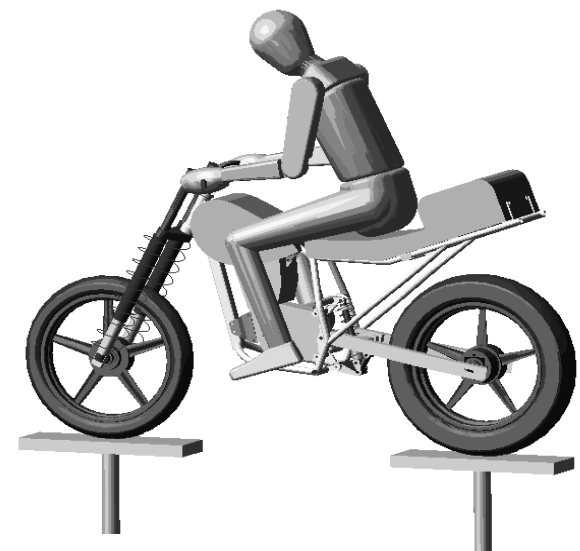

De maneira análoga, Subbu, Anthonysamy e Sharma (2015) desenvolveram um modelo virtual (Figura 17) para que análises e correções de problemas observados no campo pudessem ser desenvolvidas. Com o intuito de se eliminar falhas evidenciadas por trincas no paralama dianteiro de uma motocicleta, um modelo computacional para análise de tensões foi calibrado e posteriormente validado através de medições feitas durante a condução da motocicleta real em terrenos indianos. 
Figura 17 - Modelo computacional para análises de tensões principais máximas em determinadas frequências de interesse no paralama dianteiro de uma motocicleta

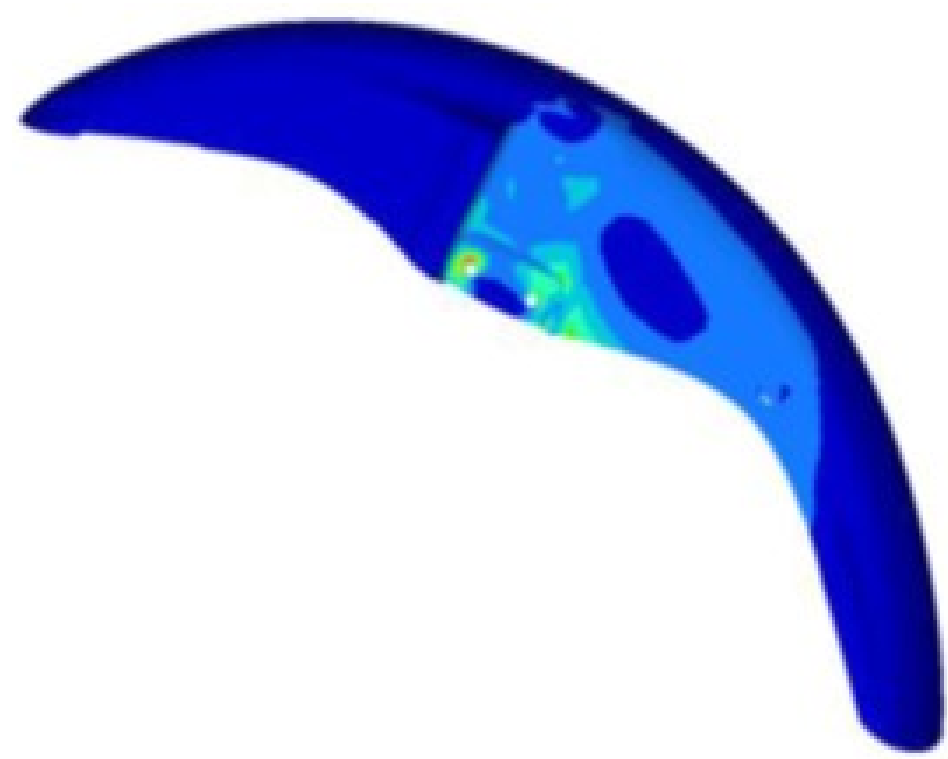

Fonte: Subbu, Anthonysamy e Sharma, 2015

Tal tipo de análise permite ao departamento de desenvolvimento realizar ajustes importantes no projeto de novos modelos, proporcionando um maior alinhamento entre as atividades de desenvolvimento e monitoramento da satisfação de clientes finais, o que evidencia um processo de desenvolvimento mais eficiente. 


\subsubsection{Testes Acelerados}

O desenvolvimento de testes acelerados contribui para que situações práticas de utilização sejam ensaiadas sem que um veículo completo esteja já disponível. Como exemplo, pode-se destacar a importância dos ensaios dinâmicos de corrosão, executados de forma a combinar esforços mecânicos, térmicos e químicos em componentes potencialmente sensíveis do veículo. Weber (2009), aponta que estes ensaios são executados em três fases distintas:

a) A preparação do veículo consiste em remover a camada de proteção superficial destes componentes expondo a superfície metálica que será ensaiada;

b) O pré-condicionamento permite que seja criado um certo nível de stress e danos preliminares expondo o componente ensaiado a condições térmicas, mecânicas e químicas extremas, como torção em ambientes muito frios, impactos em terrenos fora de estrada, pulverização de água salina e areia ou condução severa em terrenos esburacados e altamente sinuosos;

c) O teste de corrosão em si, considerando o processo de desenvolvimento adotado pela BMW, ocorre em 50 ciclos, sendo que cada um dura 24 horas e é dividido em 4 fases:

- Fase 1 - Condução em climas corrosivos e úmidos;

- Fase 2 - Borrifação de solução de água com sal;

- Fase 3 - Condensação a $45^{\circ} \mathrm{C}$;

- Fase 4 - Incubação.

Desta maneira, em um período de três meses, este teste permite que uma ideia do estado de conservação ao final da vida útil do componente, quando operado por um possível futuro cliente, seja possível de ser avaliado. A Figura 18 compara o estado de conservação de um diferencial após 50 dias exposto ao ensaio dinâmico de corrosão (foto superior) e outro componente avaliado após 7 anos $(200.000 \mathrm{~km})$ de uso regular (foto inferior). Através da comparação das imagens, entende-se que o ensaio dinâmico de corrosão cumpre com seu papel durante as fazes de validação do protótipo. Tal afirmação pode ser feita, uma vez que os níveis de corrosão verificados pelo teste foram ainda mais severos do que aqueles apresentados pelo componente após um período de tempo considerável de uso em condições reais de utilização. 
Figura 18 - Diferencial exposto a 50 dias de teste dinâmico de corrosão e diferencial após 7 anos de uso $(200.000 \mathrm{~km})$

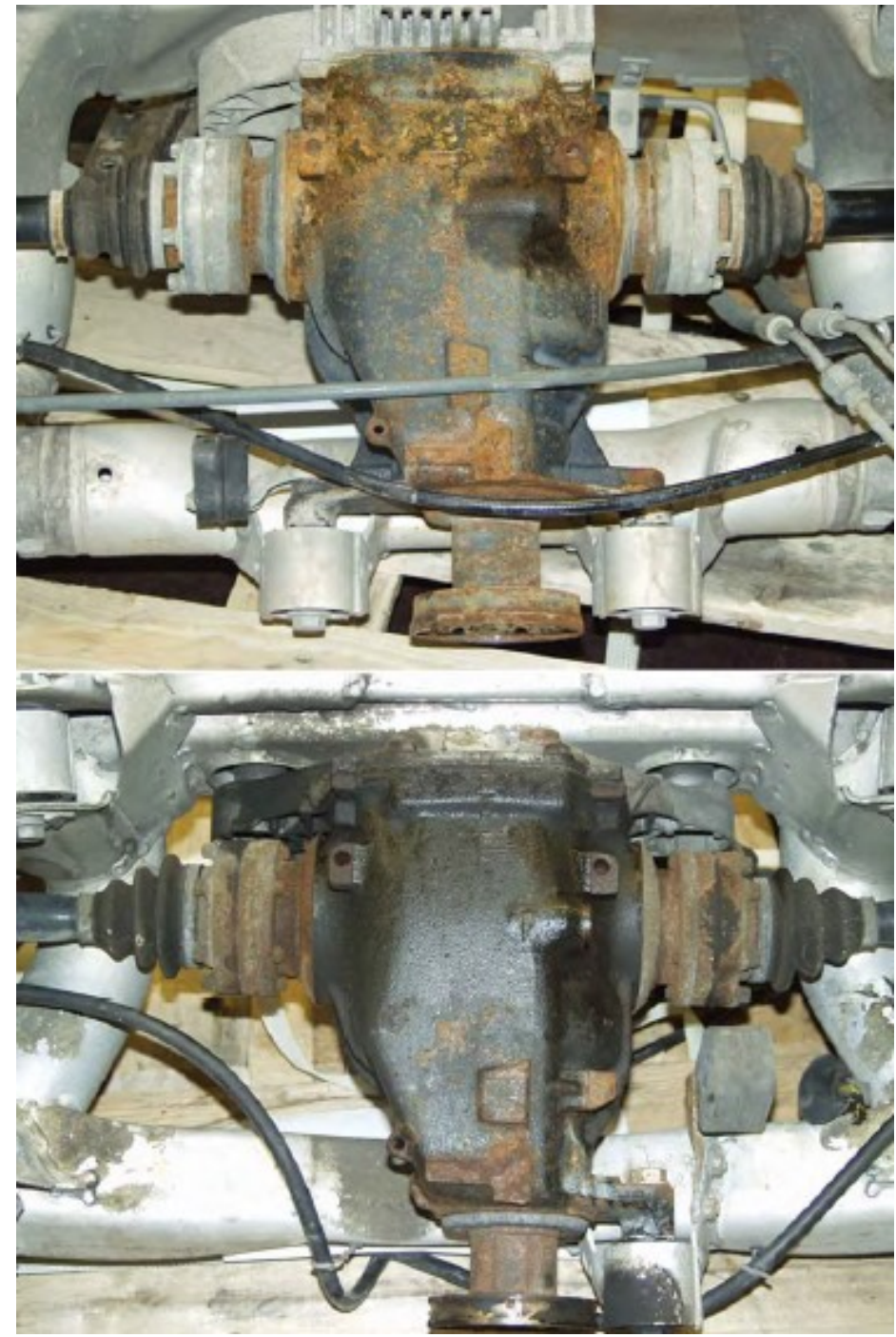

Fonte: Weber, 2009

Além deste tipo de ensaio voltado para a avaliação da resistência a corrosão, Lin, Hwang e Chang (2009) demonstraram a possibilidade de se estudar análises estruturais aceleradas em peças de motocicletas. O trabalho destes autores promoveu o desenvolvimento de testes de fadiga em componentes soldados de forma a permitir a comprovação da eficiência da aceleração de avaliações de durabilidade através do auxílio de dispositivos servo-hidráulicos.

Suas avaliações, primeiramente executadas em um guidão de motocicleta, conforme exposto na Figura 19, comprovaram que as falhas obtidas durante os testes acelerados foram quase idênticas aquelas verificadas após as rodagens em diferentes tipos de terreno. 
Figura 19 - Comparação entre trinca obtida durante teste acelerado em bancada (esquerda) e trinca obtida durante rodagem (direita)
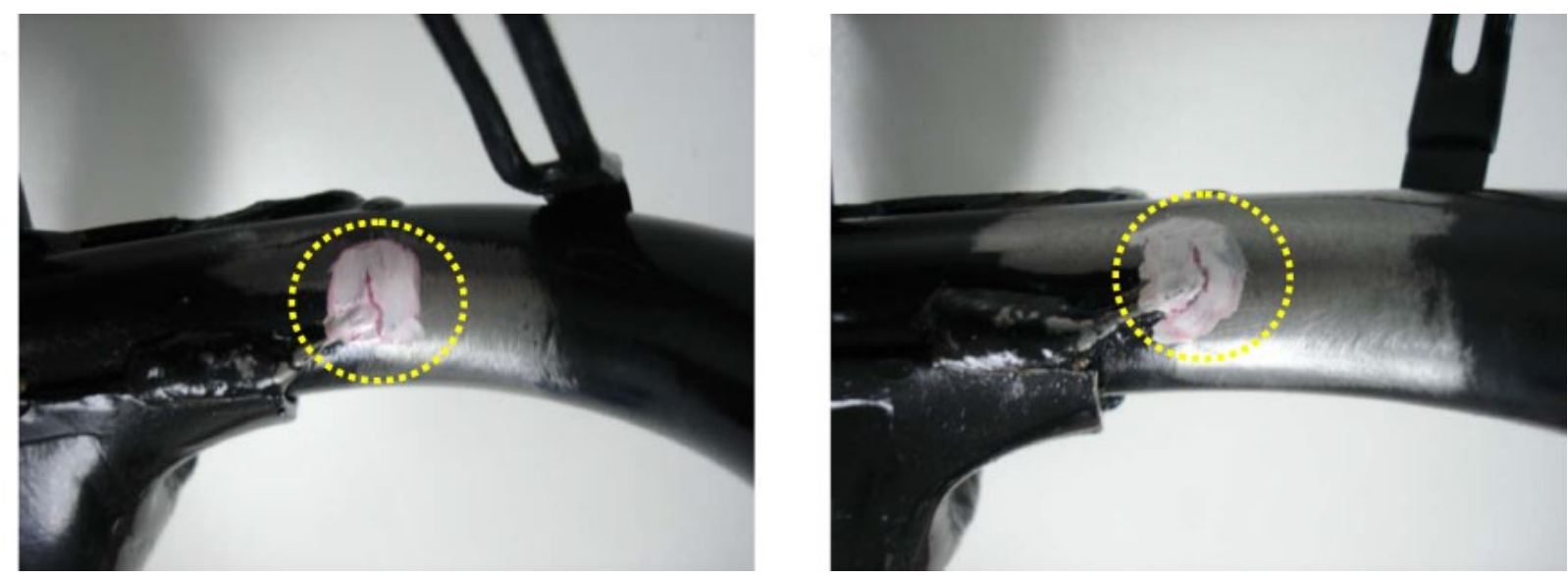

Fonte: Lin, Hwang e Chang, 2009

\subsubsection{A Importância dos Ensaios Reais em Campo}

Apesar do grande desenvolvimento da tecnologia relacionada a avaliações dinâmicas, simulações computacionais e testes acelerados de durabilidade, deve-se destacar que a condução de uma motocicleta é um processo bastante complexo e de difícil simulação. Mesmo com a tecnologia computacional em constante desenvolvimento, a necessidade de executar testes de rodagem em campo para validação e confirmação sobre a qualidade do produto, conforme ilustrado pela Figura 20, se mantém como uma atividade extremamente importante durante o desenvolvimento do veículo.

Figura 20 - Teste de durabilidade de motocicletas em ambiente real de utilização (vias públicas)

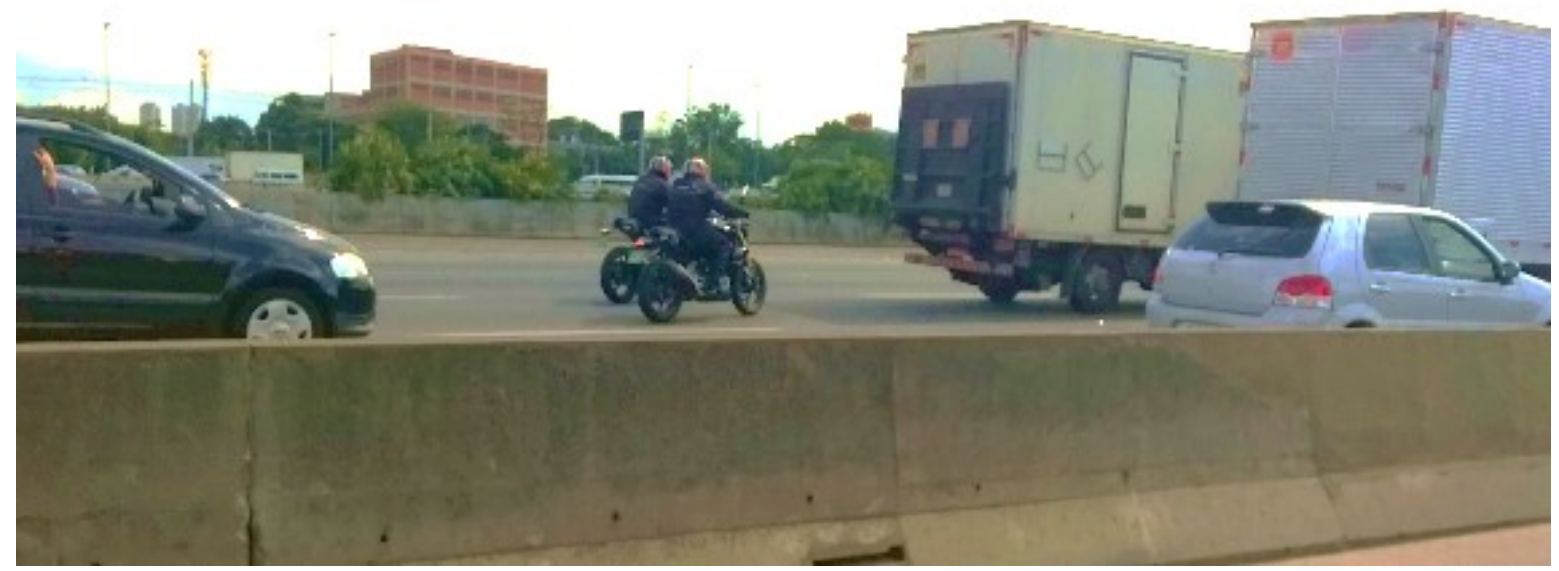

Fonte: Autor 
Somente a partir de ensaios práticos reais, realizados por condutores experientes e conduzidos em ambientes reais de utilização, é que o produto poderá ser realmente validado. Sabendo disso, as montadoras investem grande parte de seus recursos destinados ao desenvolvimento, para construção e manutenção de campos de provas com diferentes tipos de pavimentos e traçados, assim como aquele ilustrado na Figura 21, de forma a permitir que seus veículos sejam avaliados e testados de acordo com suas exigências específicas.

Figura 21 - Campo de provas de Miramas (BMW)

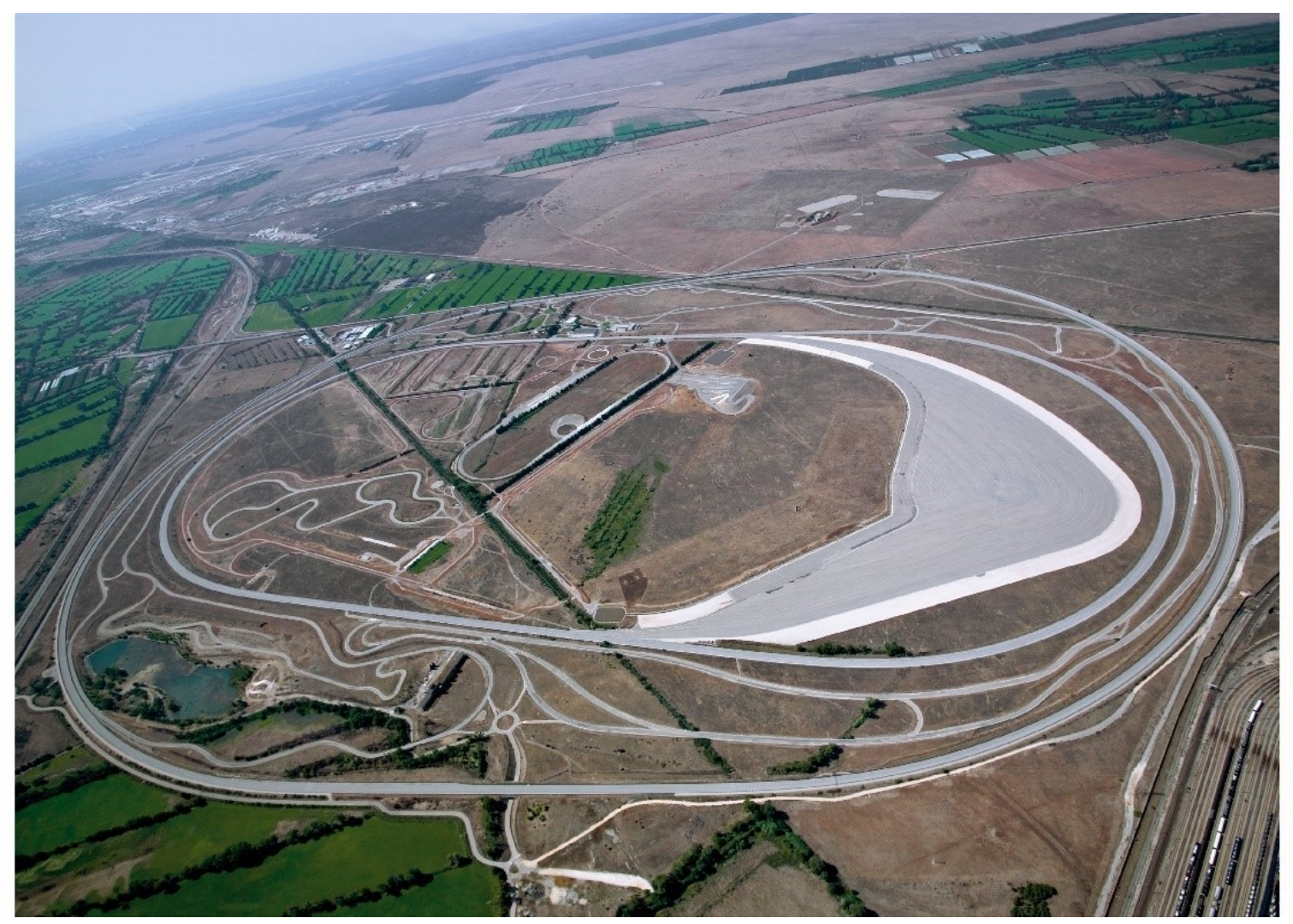

Fonte: BMW, 2008

A construção de pistas especiais com diferentes tipos de relevo e pavimentação, permite aos fabricantes executarem diferentes tipos de testes com focos distintos em um mesmo local geográfico, o que garante economia de tempo e dinheiro durante as fases de validação dos produtos.

Dependendo do tipo de veículo e sua respectiva aplicação, o interesse em avaliá-lo em terrenos mais específicos, pode ser um diferencial durante o desenvolvimento do projeto. Parece bastante lógico afirmar que um veículo esportivo, deverá ser mais intensamente testado em pistas com traçados que proporcionam a condução em alta velocidade e dinâmica de condução esportiva, como os visíveis na pista de Miramas, por exemplo. Já motocicletas destinadas a 
aplicação em todo o terreno, requerem avaliações diferentes. Para isso, além dos testes executados em terrenos fora de estrada, destacam-se os testes executados em pistas especiais. Basicamente, pode-se destacar 3 tipos mais usuais de pistas especiais comumente utilizadas durante a execução de testes de durabilidade. A Figura 22 ilustra esses tipos de pista, que são:

Figura 22 - Pistas especiais - a) Pot Holes, b) Cobblestones e c) Body Twist)

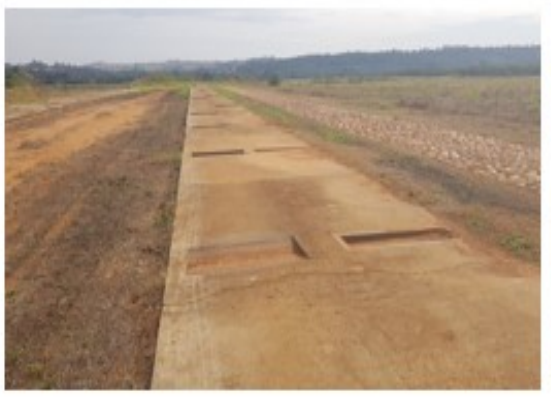

a)

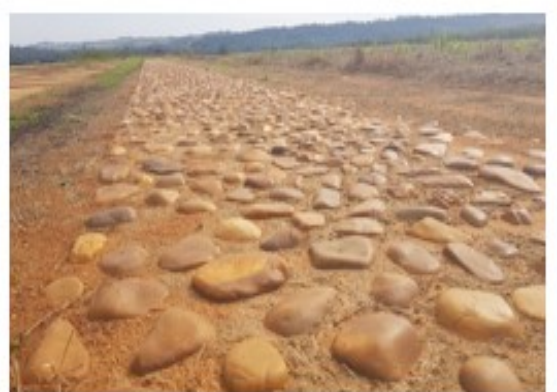

b)

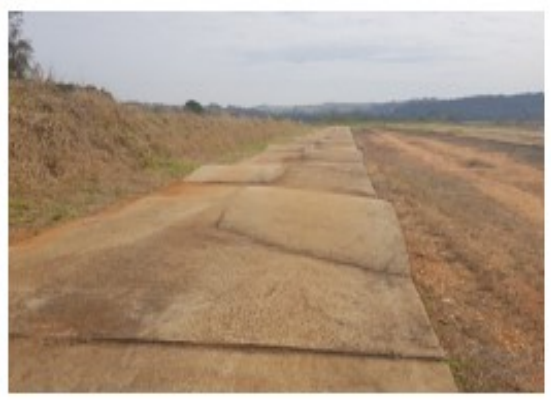

c)

Fonte: Tatuí Motors Test, 2019

a) Pista de Buracos e Obstáculos "Pot Holes":

- Ideal para a execução de testes de durabilidade acelerados com a intenção de expor os sistemas do veículo a impactos de baixas frequências e grandes amplitudes. Principalmente utilizada para garantir a durabilidade dos sistemas de suspensão e direção;

b) Pista de Pedras de Rio "Cobblestones":

- Desenvolvida para execução de ensaios estruturais acelerados, avaliação de ruídos, desempenho dos sistemas de suspensão e direção, avaliação de ruídos e vibrações "NVH" e estudos relacionados ao conforto veicular;

c) Pista de Torção "Body Twist":

- Desenvolvida para execução de ensaios estruturais do conjunto do chassi e carroceria, proporcionar grandes deflexões do conjunto da suspensão do veículo e permitir a verificação do comportamento dinâmico do veículo.

Stoffregen (2010), ressalta que mesmo após a execução dos testes em laboratórios, simulações dinâmicas e computacionais como as mencionadas anteriormente, o teste no campo é essencial para que a validação do produto ocorra de forma bem-sucedida. As simulações e demais testes independentes, executados para componentes específicos, não são capazes de simular todas as interações entre os componentes e variáveis observadas no campo, como por 
exemplo, variações de temperatura, pressão atmosférica, vento, umidade, poeira, sujeira, perfis de condução diferentes e terrenos distintos.

Isto faz com que os testes reais em campo tenham a missão de expor as situações que nenhum dos diversos testes e simulações anteriores puderam apresentar, evitando que qualquer falha não conhecida possa ser apresentada nas mãos dos clientes após o término da fase do projeto.

\subsection{A IMPORTÂNCIA DE SE CONHECER O PERFIL DE UTILIZAÇÃO}

Além de garantir a durabilidade do produto do ponto de vista técnico por meio de diversos tipos de testes e avaliações executadas pela montadora, a forma como os clientes finais realmente irão utilizar o produto é um fator extremamente importante e de certa forma pouco conhecido. Diversas sugestões e suposições são concebidas a partir de estudos preliminares sobre os possíveis perfis de futuros clientes, entretanto, pouco se sabe de fato sobre a forma real que estes indivíduos adotarão quando o produto for a eles entregue.

De acordo com Weber (2009), o grande desafio na engenharia automotiva durante o processo de validação e análise de confiabilidade, é saber antecipar a forma como o veículo será utilizado pelo usuário e como considerar essas informações durante o processo de desenvolvimento e dimensionamento do produto. Segundo ele, a investigação para compreensão destes dados deve ser dividida em três áreas de pesquisa:

a) Carregamentos Térmicos e Mecânicos:

- O veículo será conduzido de forma amena ou severa?;

- Ele será aplicado em superfícies irregulares fora de estrada ou somente em estradas pavimentadas?;

- O veículo será projetado para uso em longas distâncias ou terá foco urbano considerando pequenos deslocamentos?;

- Na maioria do tempo ele será conduzido totalmente carregado ou somente deverá transportar o peso do condutor e pequenas bagagens?; 
b) Condições Ambientais:

- Normalmente o veículo será conduzido em ambientes secos, quentes e áridos?;

- A utilização em ambientes urbanos com excesso de poluição deve ser considerada?;

- A aplicação em condições úmidas, frias com terrenos salinos também deve ser prevista?;

c) Condições Operacionais:

- Quais são as funções que o piloto e/ou passageiro utilizam?;

- Quais delas são utilizadas ao mesmo tempo?;

- Como o piloto e/ou passageiro operam e utilizam essas funções?;

Muito se tem evoluído neste ambiente com o avanço da conectividade empregada no setor automotivo, sendo que hoje em dia, a aquisição de dados para monitoramento do perfil de utilização do veículo pelos clientes finais vem se tornando uma atividade mais viável graças ao constante desenvolvimento da tecnologia embarcada nos veículos, que em alguns casos, permite até a troca de informações em tempo real entre o veículo e aparelhos de comunicação pessoal, como smartphones por exemplo. De acordo com pesquisas realizadas pela Agência Nacional de Segurança Viária Norte Americana (NHTSA), hoje em dia, grande parte das montadoras já são capazes de coletar vários tipos de dados do veículo e de seu usuário durante sua condução ou utilização.

De acordo com GAO (2017), a tecnologia embarcada em veículos atuais que dispõem de sistemas de conectividade, permite que dados referentes a localização do veículo em tempo real, forma de uso, estado de conservação do veículo e um conglomerado de dados armazenados pelo sistema de infotainment, incluindo até mesmo informações pessoais, sejam armazenadas. A Figura 23, resume a grande capacidade dos veículos atuais em coletar e armazenar dados que podem ser bastante interessantes para o monitoramento do padrão de utilização dos clientes. Além disso, informações sobre o estado técnico do veículo, que compreendem dados referentes a possíveis falhas registradas pelos sistemas eletrônicos, auxiliam as montadoras a rapidamente identificar possíveis problemas mais graves e adotar estratégias corretivas imediatas para a melhoria da qualidade de seus produtos e até mesmo segurança de seus usuários. Estas informações sem dúvida são de grande valia para o estudo e monitoramento dos perfis de utilização dos clientes, sendo que sua aquisição em tempo real, demonstra uma quebra de 
paradigma proporcionada pela tecnologia moderna para o auxílio no processo de desenvolvimento dos veículos.

Figura 23 - Como veículos atuais geram e armazenam diferentes tipos de dados

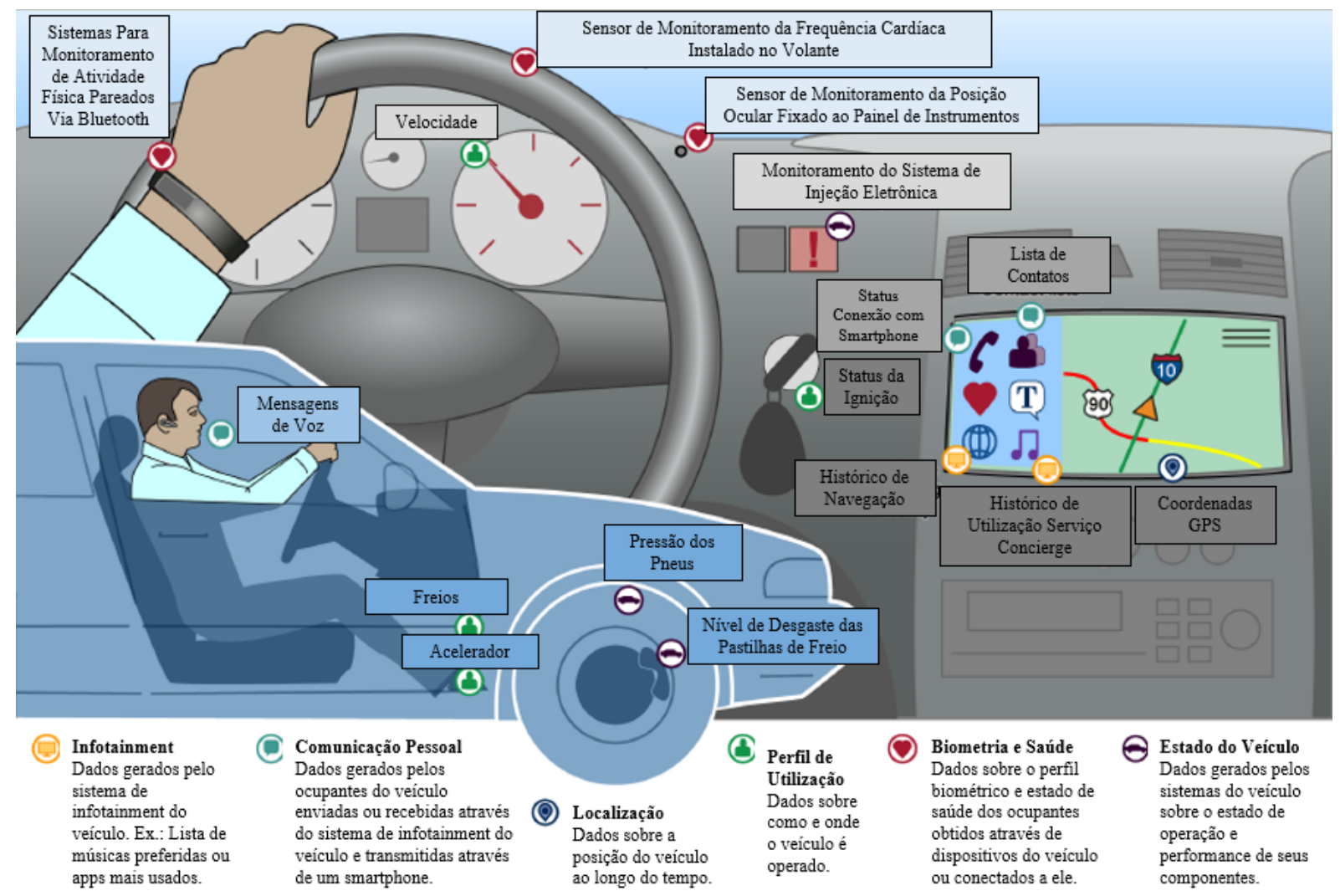

Fonte: Autor "adaptado de" GAO, 2017

Não obstante, por conta da preocupação com o sigilo e privacidade dos dados, muitas destas informações disponíveis ainda não são utilizadas pelas montadoras. Segundo GAO (2017), pesquisas sobre a privacidade de dados armazenados em veículos atuais vêm ganhando o interesse das autoridades, uma vez que o risco de exposição de dados pessoais é um fator sensivelmente preocupante. Assim, mesmo sendo capazes de coletarem uma grande quantidade de informações tecnicamente relevantes, porém altamente sensíveis para a manutenção da privacidade, todas as 13 montadoras avaliadas pelo comitê de segurança da informação (segundo pesquisas conduzidas pela NHTSA), vide GAO (2017), afirmaram coletar somente dados vinculados ao perfil de utilização do cliente e estado do veículo (para fins de pesquisa e desenvolvimento). Essa mesma pesquisa, também revelou que três das 13 montadoras, atualmente coletam dados associados ao sistema de infotainment (para fins de melhoria dos serviços prestados, como por exemplo, serviço de concierge). A Figura 24, ilustra os resultados 
desta pesquisa e aponta a crescente tendência de coleta de dados associados aos sistemas de conectividade de veículos atualmente em comercialização.

Figura 24 - Tipos de dados coletados pelas montadoras em veículos equipados com sistemas de conectividade

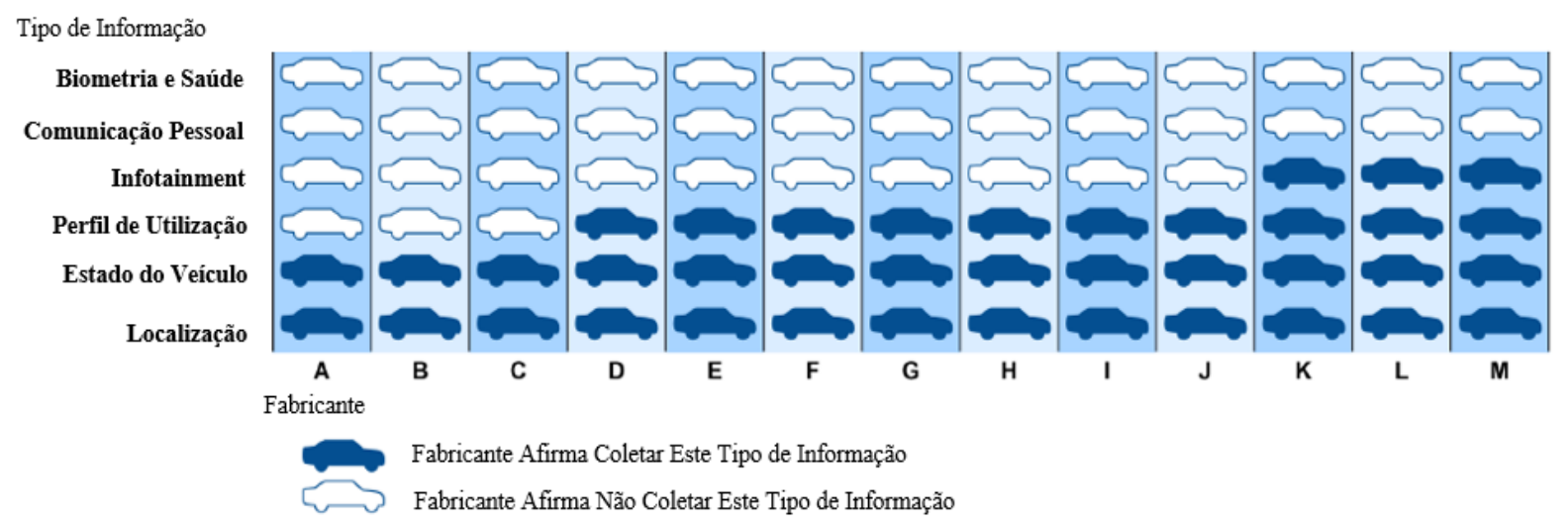

Fonte: Autor "adaptado de" GAO, 2017

No tocante ao setor de motocicletas, essa tendência no aumento da aquisição de dados para monitoramento das condições de utilização também vem se desenvolvendo nos últimos anos. Gorges, Öztürk e Liebich, (2017) comprovaram a possibilidade de executar aquisição de dados online de veículos de duas rodas a partir das informações disponíveis na rede de bordo do veículo. Estes dados por sua vez permitem aos engenheiros de desenvolvimento do veículo conhecerem em tempo real as características de utilização do veículo e determinar a ocorrência de eventos especiais durante a pilotagem. Estes eventos são na maioria das vezes as causas de danos em componentes do veículo e são causados por aplicações severas, mau uso ou condições não previstas como impactos causados por buracos ou outros obstáculos na via.

Hoje, dados sobre as condições de pilotagem já são obtidos de maneira offline com a intenção de se observar as características de pilotagem adotadas pelos usuários. Essa coleta acontece normalmente quando o veículo é conduzido a executar manutenções nas redes de concessionários das montadoras. Dados obtidos a partir das unidades de comando do veículo e armazenados nestes componentes, registram o histórico das informações e os transferem através do servidor do concessionário para os servidores da matriz da montadora, normalmente localizado no país de origem da empresa. Essas informações têm como principal objetivo fornecer dados sobre a forma de uso adotada pelo consumidor e auxiliar a montadora em situações mais delicadas, como durante avaliações de solicitações de garantia por exemplo. De forma a verificar os dados sobre o uso do cliente, a montadora pode então compreender se de 
fato ocorreram falhas inesperadas associadas a falta de qualidade em componentes específicos, ou se porventura os problemas reclamados pelo cliente são oriundos de aplicações severas ou decorrentes de falhas causadas por eventos especiais.

Como exemplo deste tipo de análise já realizada por fabricantes, incluindo as do setor de duas rodas, a Figura 25 ilustra dados colhidos através dos servidores dos concessionários durante a execução de manutenções em um modelo específico de motocicleta. Por questões envolvendo a confidencialidade dos dados, os valores numéricos das velocidades médias foram aqui substituídos por valores arbitrários (v1, v2, v3 etc.), sendo que tais informações se referem a parte de um estudo executado para se comparar o perfil de utilização deste determinado modelo pelos diferentes usuários espalhados mundo a fora. Neste momento, verificou-se a distribuição das velocidades médias adotadas pela maioria dos clientes em cada um de seus respectivos mercados, sendo que os dados são ilustrados através de um diagrama de caixa, também chamado de boxplot. Mais informações sobre este tipo de gráfico poderão ser encontradas na seção 6.1.2.1. Neste caso em específico, chama-se a atenção para o fato do Brasil ser o país que apresenta a maior amplitude em relação ao primeiro e últimos quartis do diagrama, o que aponta para uma grande variabilidade da velocidade média adotada pelos condutores locais durante a condução deste determinado modelo de motocicleta.

Figura 25 - Distribuição da velocidade média adotada por condutores de diferentes mercados para um determinado modelo de motocicleta

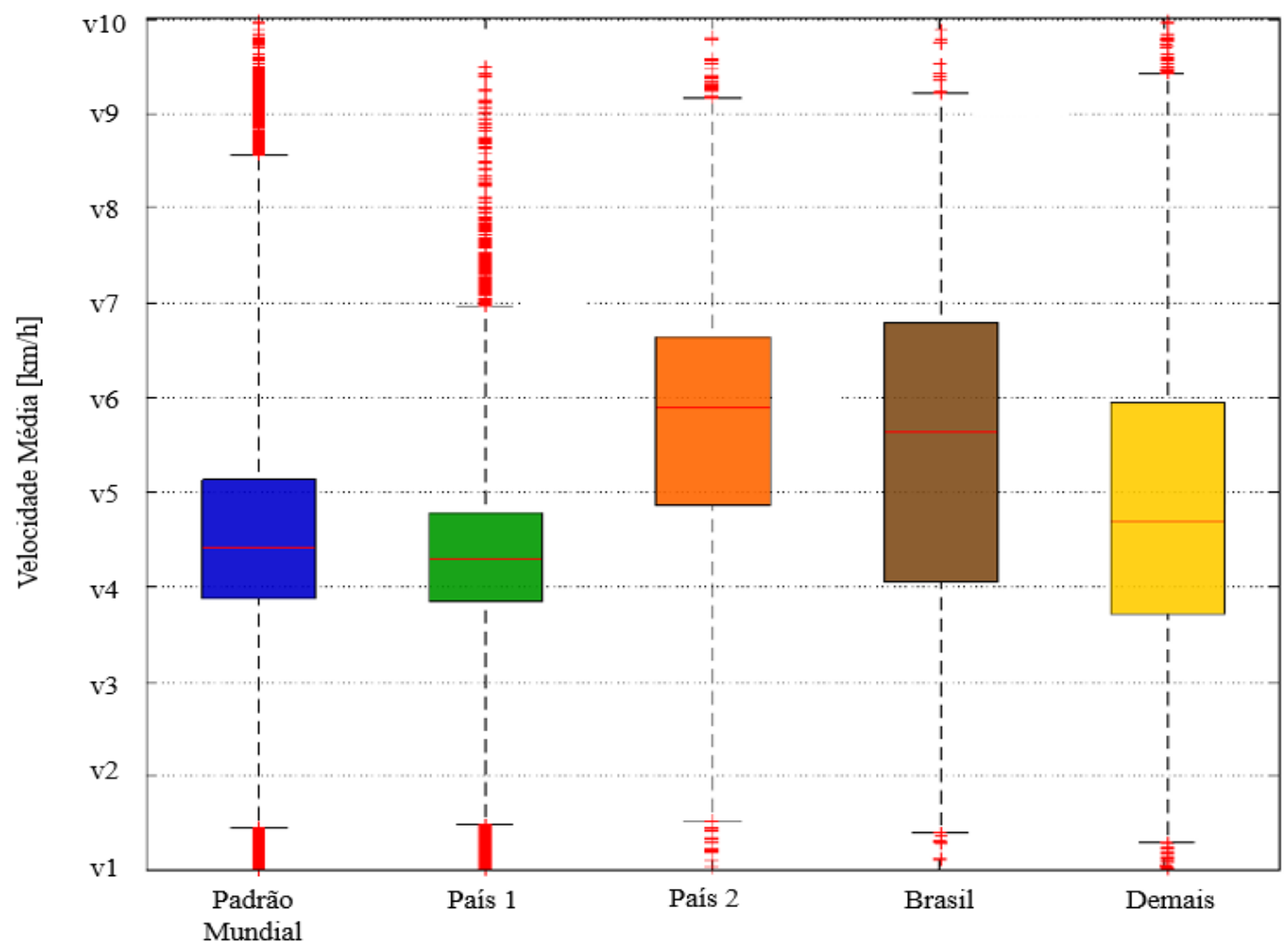


Informações como esta, sinalizam para a ocorrência de peculiaridades locais em relação a forma de uso deste tipo de motocicleta, sendo muito úteis para a execução de futuros novos projetos ou até mesmo melhorias em modelos correntes.

Destaca-se também a relevância da coleta deste tipo de informação para o aperfeiçoamento dos testes de durabilidade, que como visto, têm como objetivo garantir que o produto, muitas vezes desenvolvido longe do seu local de venda, possa ser testado de acordo com os padrões locais de utilização.

\subsection{OS CUSTOS ASSOCIADOS COM A QUESTÃO DA DURABILIDADE}

De acordo com Weber (2009), todas as montadoras almejam construir veículos com a máxima qualidade e durabilidade possíveis, entretanto, a maior questão que paira sobre os responsáveis destas empresas é decidir qual será o custo envolvido com a busca deste objetivo. Sendo assim, para melhor se definir o quanto será investido em um determinado projeto, tornase necessário compreender o custo total de qualidade, que pode ser dividido em duas áreas fundamentais:

\subsubsection{Custos de não conformidade}

São definidos como aqueles gastos que desapareceriam se o produto e os processos internos da montadora fossem perfeitos. Dependendo da área que a não conformidade ocorre, estes custos por sua vez, se subdividem em:

a) Custos de falhas internas: vinculados a situações e problemas detectados dentro do ambiente da montadora antes da entrega aos clientes finais. Exemplos típicos são custos gerados por retrabalho, alterações em projetos já em andamento, atraso do início de produção em massa, repetição de testes para nova validação, scrap etc.;

b) Custos de falhas externas: associados a falhas que ocorrem e são detectadas após a entrega do veículo aos clientes finais. Estes por sua vez podem ser exemplificados pelos gastos gerados por recalls, garantias, cortesias, redução do volume de vendas de novos veículos e demais custos associados com o gerenciamento das reclamações dos clientes finais. 


\subsubsection{Custos de conformidade}

Para que o produto esteja conforme no momento de seu lançamento, várias medidas devem ser tomadas, sendo que todos os custos associados com estas atividades são associados aos custos de conformidade. Dependendo do momento em que as contramedidas de qualidade são tomadas, os custos associados a conformidade podem também ser subdivididos em:

a) Custos de prevenção: associados a medidas proativas para evitar defeitos incluindo manutenções preventivas. Exemplos típicos são as atividades associadas com o planejamento de qualidade (métodos de prevenção, reorganização ou reestruturações organizacionais para melhorias nos processos e produtos), documentação (revisão de instruções de trabalho, instruções técnicas etc.), treinamento, avaliação de fornecedores, avaliação de erros e avaliações de capabilidade;

b) Custos de avaliação: atribuídos as medidas tomadas para encontrar defeitos de qualquer tipo através de qualquer procedimento de avaliação. Exemplos típicos estão associados aos procedimentos de inspeção final, testes em componentes e peças acabadas, testes de campo, auditorias de qualidade (internas e externas), inspeções (em veículos acabados, equipamentos, infraestrutura e pessoas), calibrações em equipamentos de medição etc.

Weber (2009) ainda afirma que investimentos em processos de avaliação e prevenção são a chave para redução de custos totais de qualidade. A progressão dos quatro tipos de custos ao longo do processo de desenvolvimento da qualidade pode ser ilustrada a partir da Figura 26, que justifica o investimento em ferramentas de avaliação e prevenção de forma a poupar recursos financeiros a longo prazo. A figura esclarece que mediante a aplicação de processos e metodologias para a avaliação contínua e prevenção de falhas, os custos mais elevados, justamente atrelados as falhas internas ou externas podem ser sensivelmente reduzidos.

Naturalmente, os custos vinculados as falhas externas se demonstram como sendo a principal preocupação das montadoras após a introdução de novos produtos no mercado, sendo que o constante monitoramento e avaliação da evolução destes valores se destaca como uma das atividades mais importantes para o correto monitoramento da qualidade do produto e satisfação dos clientes. 
Figura 26 - Progressão dos custos totais de qualidade ao longo do processo de desenvolvimento da qualidade

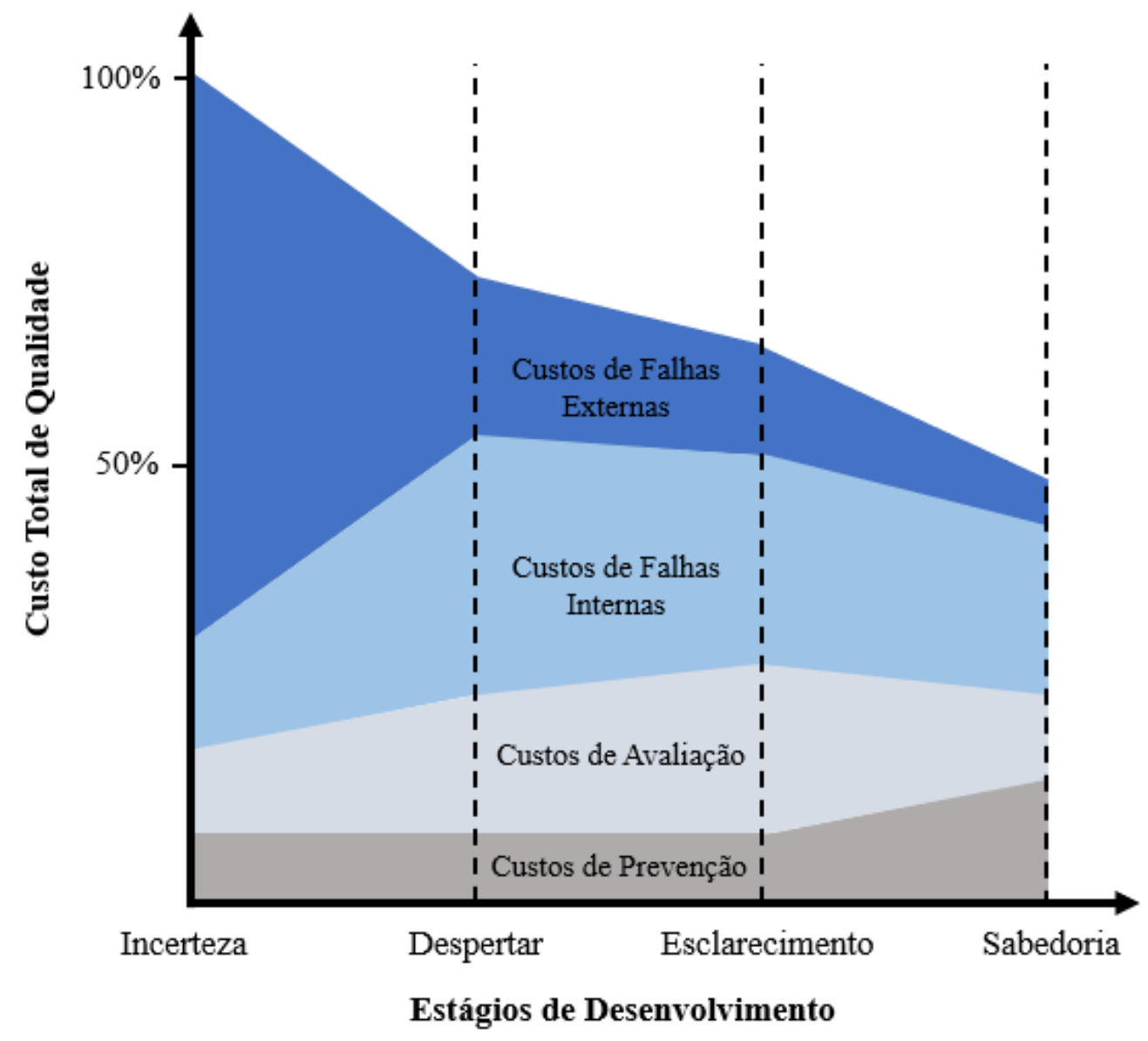

Fonte: Autor “adaptado de" Weber, 2009

Neste estágio, ressalta-se também a possibilidade de verificação de evidências sobre a diferença do comportamento do veículo em diferentes mercados, uma vez que se o produto demandar mais atendimentos em garantia em uma determinada região, entende-se que possíveis solicitações ou aplicações não previstas durante a fase de desenvolvimento pode estar ocorrendo nestes ambientes. Desta forma, cabe as montadoras buscarem metodologias constantes de avaliação e monitoramento destas informações, para que conforme visto anteriormente, os investimentos em custos de avaliação e prevenção possam ser destinados a permitir que tais situações sejam evitadas em novas versões ou novos projetos.

A Figura 27 ilustra o comportamento de dois segmentos de produtos diferentes e seus respectivos custos de garantia por unidade vendida dentro de um período de 6 meses. Por questões estratégicas os valores não podem ser ilustrados, mas o principal objetivo é evidenciar que produtos diferentes, apresentam comportamentos distintos em cada mercado. Por isso, 
avaliações locais mais detalhadas para se compreender tais particularidades podem ser desenvolvidas para se determinar a origem destes custos e propor estratégias para sua redução.

Figura 27 - Comparação entre os custos de garantia por unidade vendida entre dois segmentos de produto em diferentes mercados
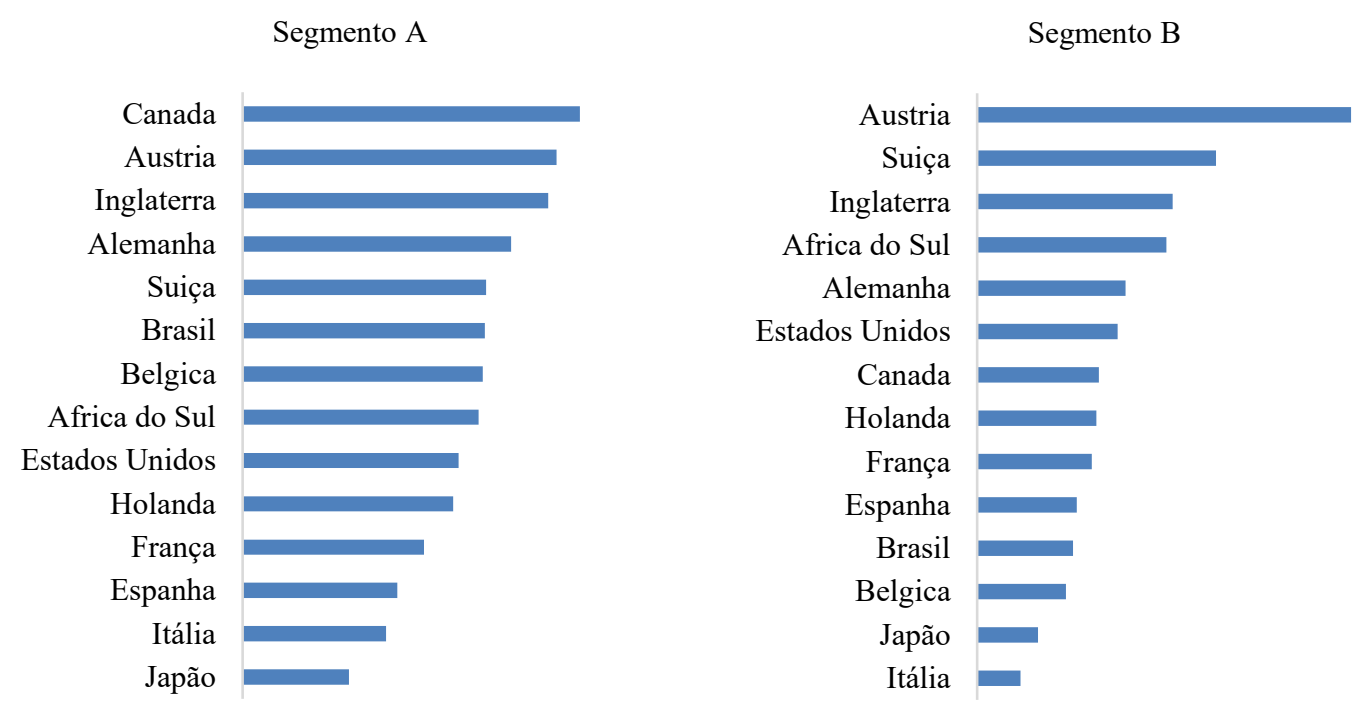

Fonte: Autor

\subsection{ANÁLISE DE DADOS PARA AVALIAÇÃO DA DURABILIDADE}

Conforme já apresentado nas seções anteriores, a falta de durabilidade não deve ser compreendida como um problema que afeta unicamente o cliente. Estas situações reduzem a lucratividade das companhias, principalmente por conta dos custos atribuídos as garantias, recalls e demais despesas designadas para gestão da satisfação dos clientes afetados por problemas vinculados a falta de durabilidade (cortesias). Sendo assim, é natural que os estudos associados ao desenvolvimento da qualidade dos produtos, para fins de maior durabilidade, sejam de grande interesse das montadoras, afinal, conforme já discutido, quanto menores foram os custos associados a falhas externas e internas, maior será a chance de determinado modelo de veículo ser bem sucedido de acordo com a ótica financeira da montadora.

A partir de agora, discutir-se-á as principais formas de estudo dedicados a avaliação da durabilidade em veículos automotores, sendo que de acordo com Johannesson e Speckert (2014), o estudo sobre a teoria de fadiga, se faz estritamente necessário para que qualquer tipo de análise futura sobre a influência do perfil de diferentes condutores seja executada. 


\subsubsection{A Importância do Estudo da Fadiga}

Conforme sugerido por Callister Junior (2008) o termo fadiga aplicado no estudo da engenharia mecânica, pode ser definido como uma falha que ocorre em componentes sujeitos a tensão cíclica e oscilante, sendo que em tais condições, podem ocorrer falhas mecânicas (trincas, fraturas ou demais danos) mesmo quando os níveis de tensão aplicados ao componente estão abaixo do limite de escoamento do material empregado para sua construção quando submetido a cargas estáticas.

De acordo com Beer et al. (2011), a fadiga deve ser levada em conta no projeto de todos os componentes estruturais e de máquinas submetidos a cargas repetidas ou flutuantes, sendo que o número de ciclos de carregamento que se pode esperar durante a vida útil de um componente varia grandemente. $\mathrm{O}$ virabrequim de um motor por exemplo, poderá ser carregado por aproximadamente meio bilhão de vezes se o veículo alcançar $300.000 \mathrm{~km}$ rodados.

O número de ciclos de carregamento necessário para provocar a falha de um corpo de prova por meio de cargas cíclicas pode ser determinado experimentalmente para determinado nível de tensão máxima. Se forem executados uma série de ensaios utilizando-se diferentes níveis de tensão máxima, os dados resultantes podem ser apresentados graficamente, conforme apontado por Qq et al. (2018), sendo que tal diagrama se denomina curva S-N ou curva de Wöhler. Este gráfico é definido como uma regressão dos níveis de tensão em função dos ciclos necessários para observação de danos causados pela fadiga do material. A Figura 28 ilustra um exemplo para o aço SCM 435 temperado a $300{ }^{\circ} \mathrm{C}$, por um período de 60 minutos, material este aplicado na construção de eixos dianteiros de motocicletas.

Nota-se a partir da observação da imagem, que quanto mais alta for a tensão máxima, menor será o número de ciclos necessários para que a ruptura do componente seja observada. À medida que a intensidade da tensão máxima é reduzida, o número necessário de ciclos para provocar a ruptura aumenta até ser alcançada uma tensão conhecida como limite de resistência a fadiga $\sigma_{f}$, que é a tensão para qual não ocorre falha, mesmo para um número infinitamente grande de ciclos de carregamento. $\mathrm{O}$ modelamento apresentado na figura pode ser determinado pela relação exponencial:

$$
\sigma_{a}=\sigma_{f}\left(2 N_{f}\right)^{b}
$$


Figura 28 - Diagrama S-N para o Aço SCM 435 temperado a $300{ }^{\circ} \mathrm{C}$ por 60 minutos

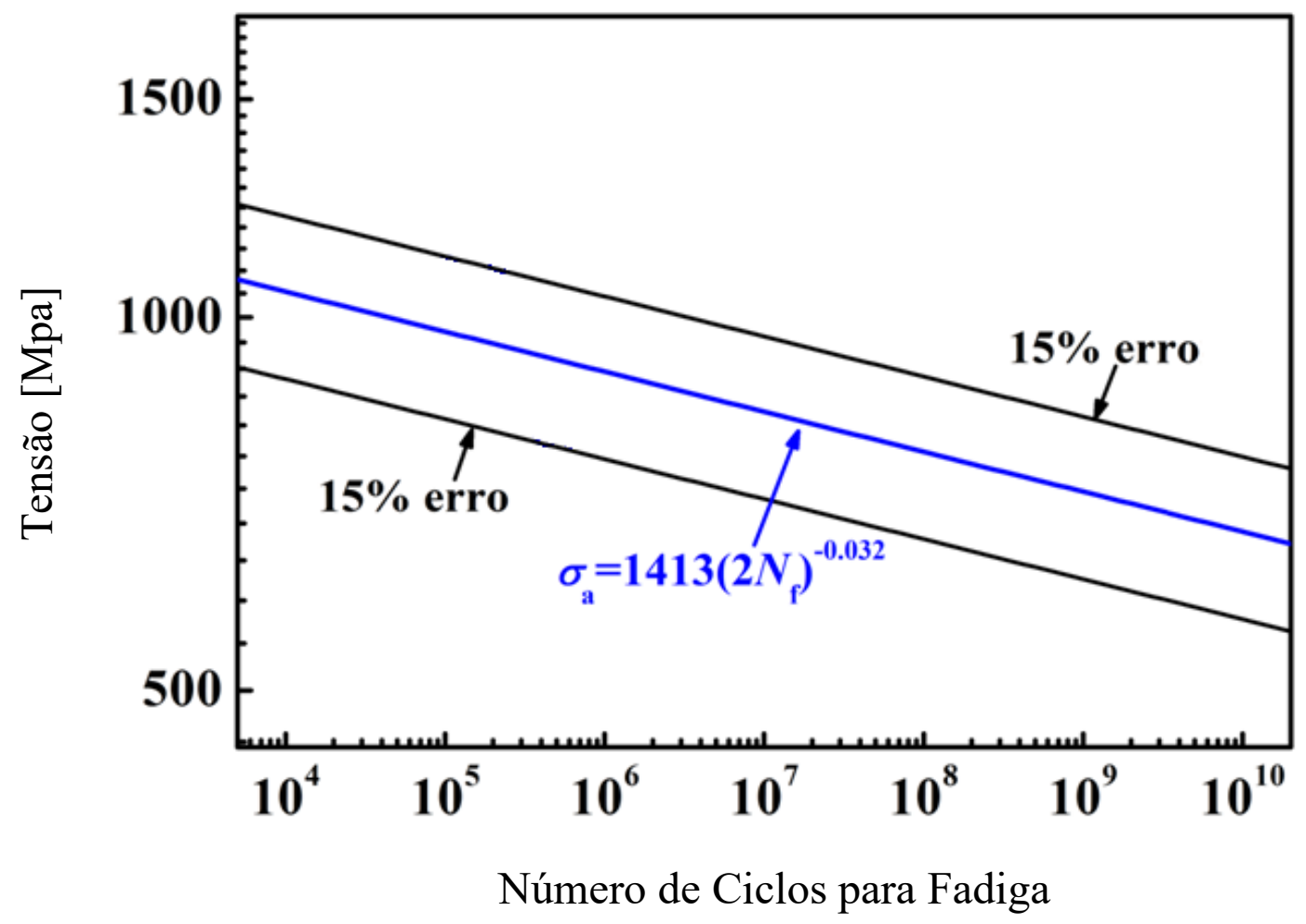

Fonte: Autor “adaptado de" Qq et al., 2018

que deriva da forma logarítmica primeiramente proposta por Basquin em 1910, conforme exposto a seguir

$$
\log \sigma_{a}=\log \sigma_{f}+b \log 2 N f
$$

em que, $\sigma_{a}$ representa a amplitude da tensão, $\sigma_{f}$ o coeficiente de resistência a fadiga, determinado pela tensão em que ocorre a fratura quando o número de ciclos é $2 N_{f}=1$, e $b$ é o expoente de Basquin determinado a partir da curva de Wöhler para o material em estudo.

\subsubsection{Análises de Fadiga em Carregamentos Reais}

Para que a discussão sobre as aplicações da teoria de fadiga seja possível de ser executada em situações reais, Johannesson e Speckert (2014), apontam para a importância de se compreender os tipos de carregamento em estudo, sendo que estes podem se apresentar das seguintes formas: 


\subsubsection{Carregamentos de Amplitude Constante}

São exemplificados pelo tipo mais simples de carregamento que, conforme o próprio nome sugere, apresenta amplitude constante. Como exemplo, menciona-se o carregamento ilustrado na Figura 29 (a) fruto da aplicação de um carregamento com amplitude $\sigma_{a}$ assim como aquele utilizado para construção da curva de Wöhler descrita no tópico anterior.

\subsubsection{Carregamentos por Blocos}

O próximo tipo de carregamento é aquele que se divide em blocos que apresentam amplitudes constante ao longo de sua distribuição. Quando agrupados, estes blocos representam a integridade do carregamento em estudo assim como ilustrado na Figura 29 (b).

\subsubsection{Carregamentos com Amplitudes Variáveis}

Os tipos de carregamentos presentes em estruturas veiculares quando experimentadas em condições de serviço, normalmente se apresentam como carregamentos de amplitude variável, que por sua vez, podem ser divididos em carregamentos de faixa estreita (Figura 29 (c)) ou faixa ampla (Figura (d)).

Figura 29 - Tipos distintos de carregamentos
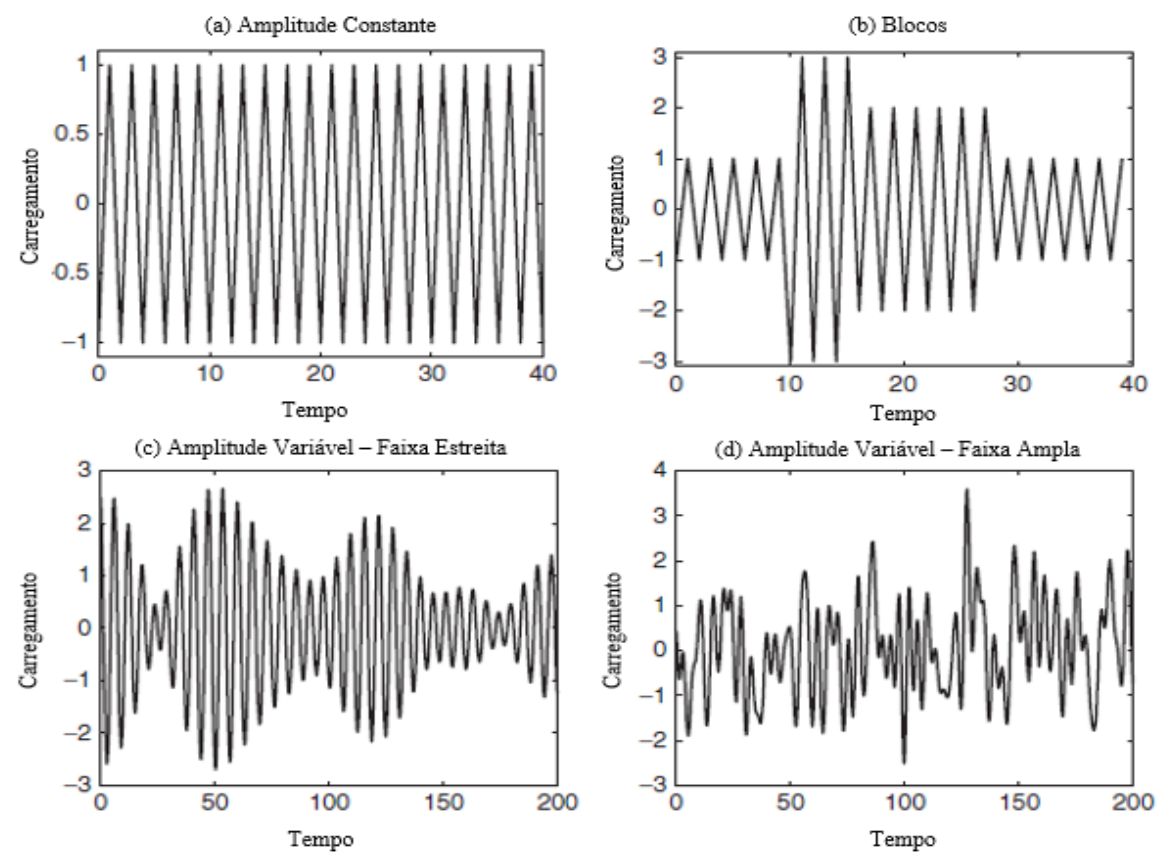

Fonte: Autor "adaptado de“ Johannesson e Speckert, 2014 
Realizando-se uma comparação dos diferentes tipos de carregamento apresentados na Figura 29, com resultados calculados a partir da coleta de sinais em campo com frequência de aquisição de $250 \mathrm{~Hz}$, (vide seção 4.8 .3 para maiores detalhes), fica evidente que dos tipos apresentados anteriormente, aquele que deverá ser mais profundamente estudado será o carregamento de amplitude variável com faixa ampla. De forma a esclarecer o motivo da escolha, a Figura 30 ilustra o resultado obtido durante o cálculo da força vertical atuante na roda dianteira de uma motocicleta e comprova que o carregamento em questão se comporta como aquele apresentado na Figura 29 (d).

Figura 30 - Exemplo de carregamento real obtido a partir da coleta de sinais

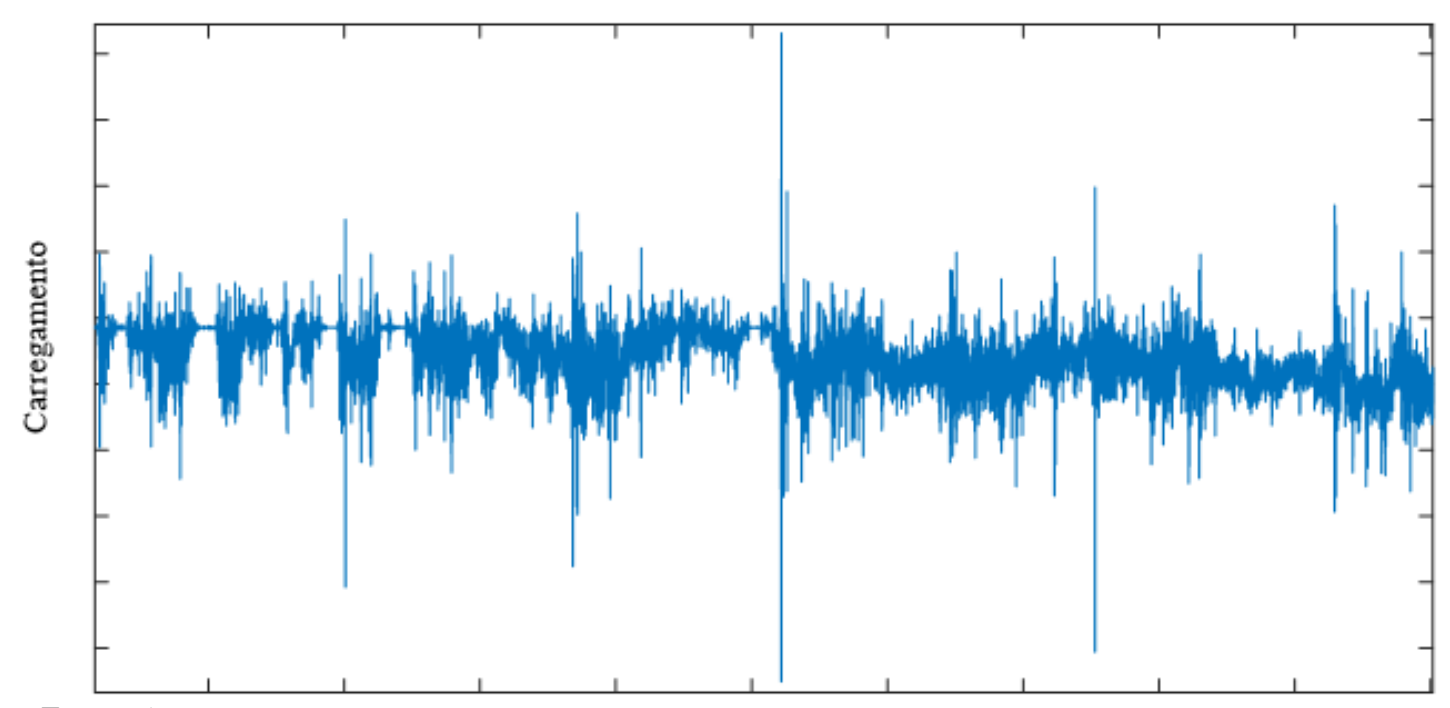

Fonte: Autor

\subsubsection{Carregamentos com Amplitude Variável, Ciclo de Fadiga e o Método Rainflow}

De acordo com Johannesson e Speckert (2014), uma forma de se avaliar carregamentos com amplitudes variáveis, como os expostos na figura anterior, envolve a identificação de ciclos individuais de fadiga e então aplicar a metodologia de acúmulo de danos. Para isso se faz necessário em um primeiro momento, determinar o ciclo individual de fadiga e esclarecer as partes que o compõe.

A Figura 31 ilustra este ciclo e apresenta as definições dos conceitos de amplitude, variação e média do ciclo, conforme exposto a seguir: 
a) Amplitude $=($ Máximo - Mínimo $) / 2$;

b) Variação = Máximo - Mínimo;

c) Média $=($ Máximo + Mínimo $) / 2$.

Desta maneira, pode-se determinar um ciclo como sendo o par composto de um ponto de mínimo e máximo, em que sua variação se denota como a característica mais relevante para estudos envolvendo fadiga.

Figura 31 - Ciclo de Fadiga

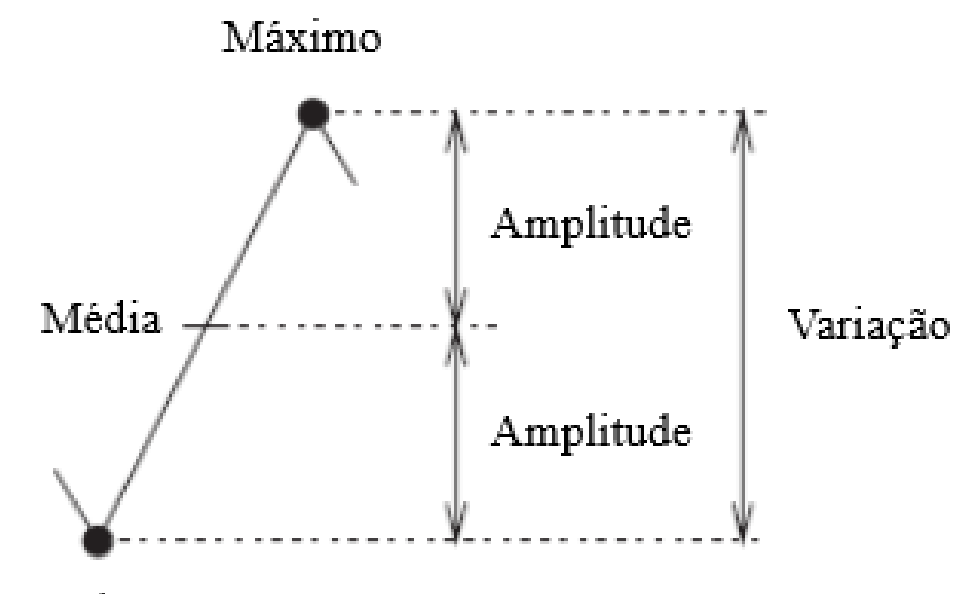

\section{Mínimo}

Fonte: Autor "adaptado de“ Johannesson e Speckert, 2014

Espera-se que o número de variações verificadas durante a análise de um carregamento real seja significativamente grande, o que torna a análise individual de cada variação observada praticamente inexequível. Desta forma, faz-se necessária a introdução da teoria de identificação de ciclos individuais de fadiga por meio do método Rainflow.

Este método foi primeiramente apresentado por Tatsuo Endo em 1967, conforme descrito por Murakami (1992) e utiliza como analogia a queda de gotas de chuva por telhados de estilo japonês, que conforme apresentado por Angelo (2007), permitem que o trajeto da gota não seja alterado mesmo passando por pequenas elevações de nível através dos diversos planos do telhado.

Uma outra definição do método Rainflow, foi proposta por Rychlik e Leadbetter (1997), e pode ser apresentada de forma gráfica (Figura 32), colaborando para uma melhor compreensão da teoria aplicada no desenvolvimento deste útil algoritmo matemático. Essa definição propõe que para cada máximo local $M_{k}$, deverá haver um ponto acima deste mesmo 
nível tanto à esquerda como à direita com o menor desvio possível. Após tendo determinado este ponto de máxima, deverão ser definidos ambos os pontos de mínimo $\left(m_{k}{ }^{-}\right.$e $\left.m_{k}{ }^{+}\right)$ localizados de forma imediatamente adjacentes ao máximo $M_{k}$.

O ciclo Rainflow será então composto pelo ponto de máxima $M_{k}$ e o mínimo de maior valor absoluto, denominado $m_{k}^{r f c}=\max \left(m_{k}{ }^{-}, m_{k}{ }^{+}\right)$. Sendo assim, para o exemplo em avaliação, define-se como ciclo Rainflow o par ordenado $\left(m_{k}^{r f c}, M_{k}\right)$.

Figura 32 - Definição do método Rainflow proposta por Rychlik (1987)

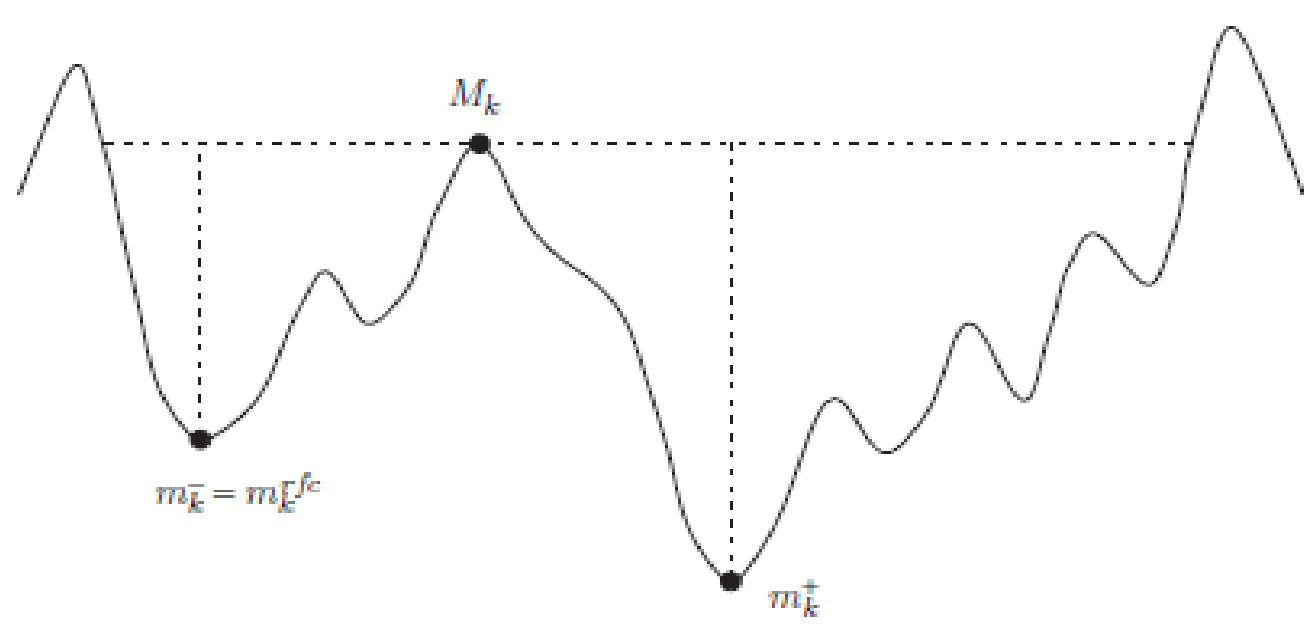

Fonte: Johannesson e Speckert, 2014

\subsubsection{A Contagem de Ciclos Rainflow}

A principal ideia por trás da aplicação da metodologia de contagem de ciclos Rainflow se baseia na contagem de ciclos de histerese causados pelo carregamento em estudo. Nesta seção, apresentar-se-ão as ideias básicas relacionadas aos modelos de histerese que justificam a aplicação da contagem de ciclos Rainflow no estudo da fadiga.

Conforme apontado por Haus (2011), o conceito de histerese em metais foi primeiramente apresentado por Bauschinger em 1886. De acordo com Yan (1998), quando os materiais são carregados em uma direção axial (por exemplo, tração) no regime plástico, descarregados e, em seguida, recarregados no sentido inverso (por exemplo, compressão), eles podem produzir durante a recarga, um nível de tensão mais baixo do que o do carregamento realizado no sentido original. Esta dependência do sentido do carregamento e o comportamento assimétrico das tensões, são conhecidos como efeito Bauschinger, conforme ilustra a Figura 33. 
Figura 33 - Representação esquemática do comportamento uniaxial tensãodeformação de muitos materiais durante a deformação no sentido inicial e reverso, mostrando o efeito Bauschinger

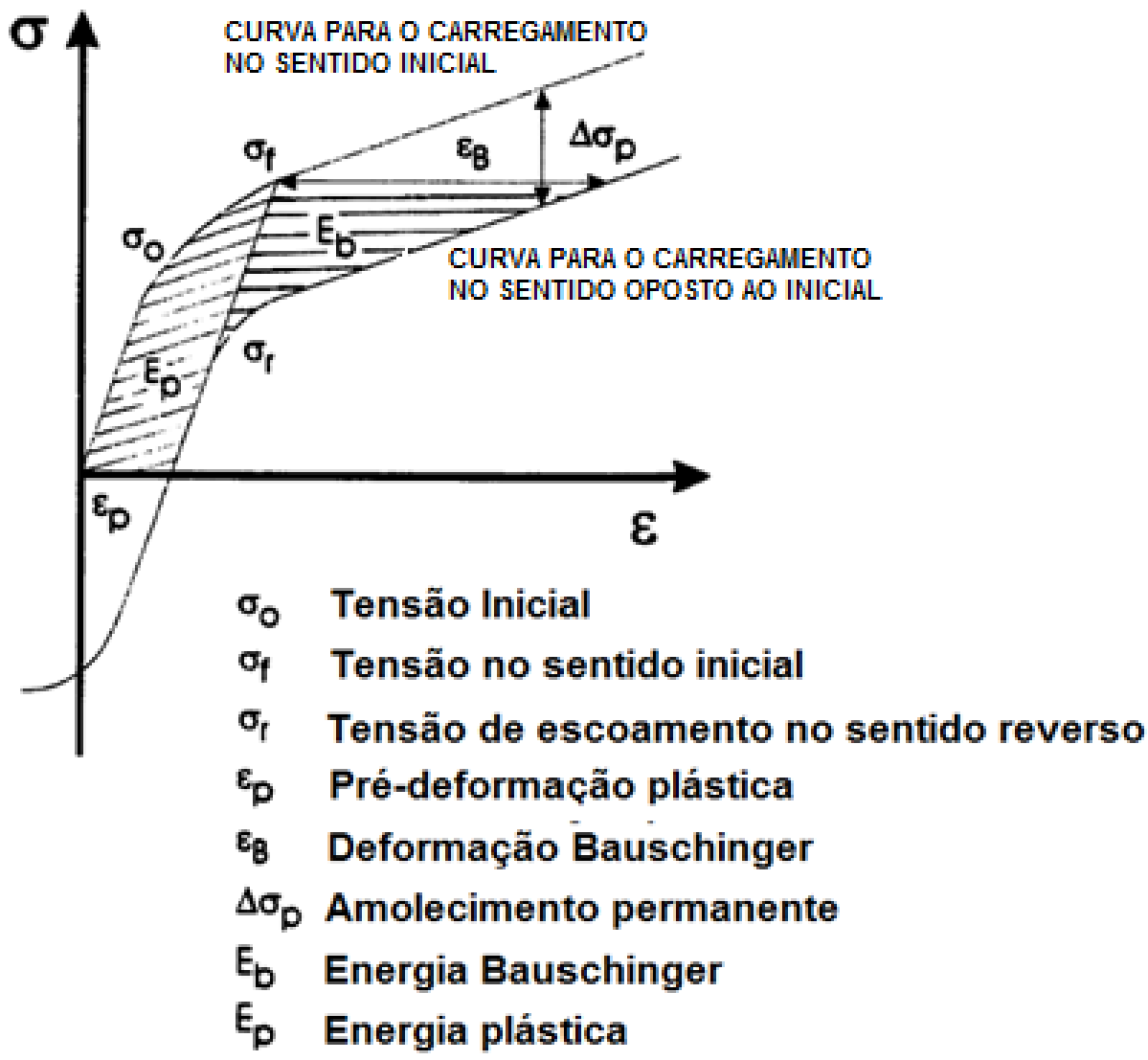

Fonte: Haus, 2011

Conhecendo o conceito de histerese, deve-se agora avaliar a forma como tais fenômenos se desenvolvem no plano da tensão-deformação ao longo do tempo. Para isso, Johannesson e Speckert (2014) reforçam que diversos autores propuseram teorias alinhadas com a tratativa da contagem de ciclos de histerese, entretanto, aquele que obteve melhor desempenho prático nesta área foi Masing (1941) que desenvolveu trabalhos descrevendo a evolução de ciclos de histerese no plano da tensão-deformação a partir da avaliação do comportamento da tensão ou deformação ao longo do tempo.

A teoria de Masing, é um modelo empírico desenvolvido para a avaliação do comportamento dos ciclos de histerese em regimes uniaxiais de tensão-deformação e se baseia na equação de Ramberg-Osgood

$$
g(\sigma)=\varepsilon=\frac{\sigma}{E}+K\left(\frac{\sigma}{E}\right)^{n}
$$


em que $\sigma$ e $\varepsilon$ representam o par tensão deformação, $E$ simboliza o módulo de elasticidade do material e o par $K$ e $n$ são constantes que dependem das propriedades físicas do material que está sendo aplicado.

Desta maneira, Masing descreve que a partir da aplicação das seguintes regras, pode-se então descrever a evolução do comportamento da tensão ao longo do tempo:

a) Iniciando-se com deformação nula, calcula-se o valor da tensão a partir da equação (3) até que o primeiro máximo ou mínimo local de deformação $\varepsilon$ seja atingido. No próximo ponto de inflexão da deformação, os sucessíveis incrementos nos valores de tensão serão possíveis de ser calculados a partir da regra de Masing

$$
\frac{|\Delta \varepsilon|}{2}=g\left(\frac{|\Delta \sigma|}{2}\right)
$$

até que o próximo ponto de inflexão, o ramo de histerese ou ciclo de tensão-deformação seja encontrado de acordo com as regras, denominadas "regras da memória de Masing" conforme a seguir:

- $1^{a}$ Regra da memória: se o ramo de histerese encontrar um ciclo de tensãodeformação, a curva de tensão-deformação cíclica deverá ser seguida;

- $\quad 2^{\mathrm{a}}$ Regra da memória: se o ramo de histerese encontrar um outro ciclo de histerese, este novo ciclo deverá ser seguido;

- $3^{a}$ Regra da memória: se o ramo de histerese encontrar um ciclo de tensãodeformação, no quadrante oposto, a curva de tensão-deformação cíclica (oposta) deverá ser seguida.

A Figura 34, adaptada de Johannesson e Speckert (2014), exemplifica a aplicação da teoria de Georg Masing, que de acordo com as definições apresentadas, aponta que os ciclos de histerese dependem da sequência de valores máximos extremos do par tensão-deformação. Estes por sua vez, podem ser encontrados a partir do cálculo proposto pelas equações (3) e (4) aplicadas a partir do conhecimento do comportamento da tensão ou deformação ao longo do tempo. 
Figura 34 - Exemplo de aplicação da teoria de Masing
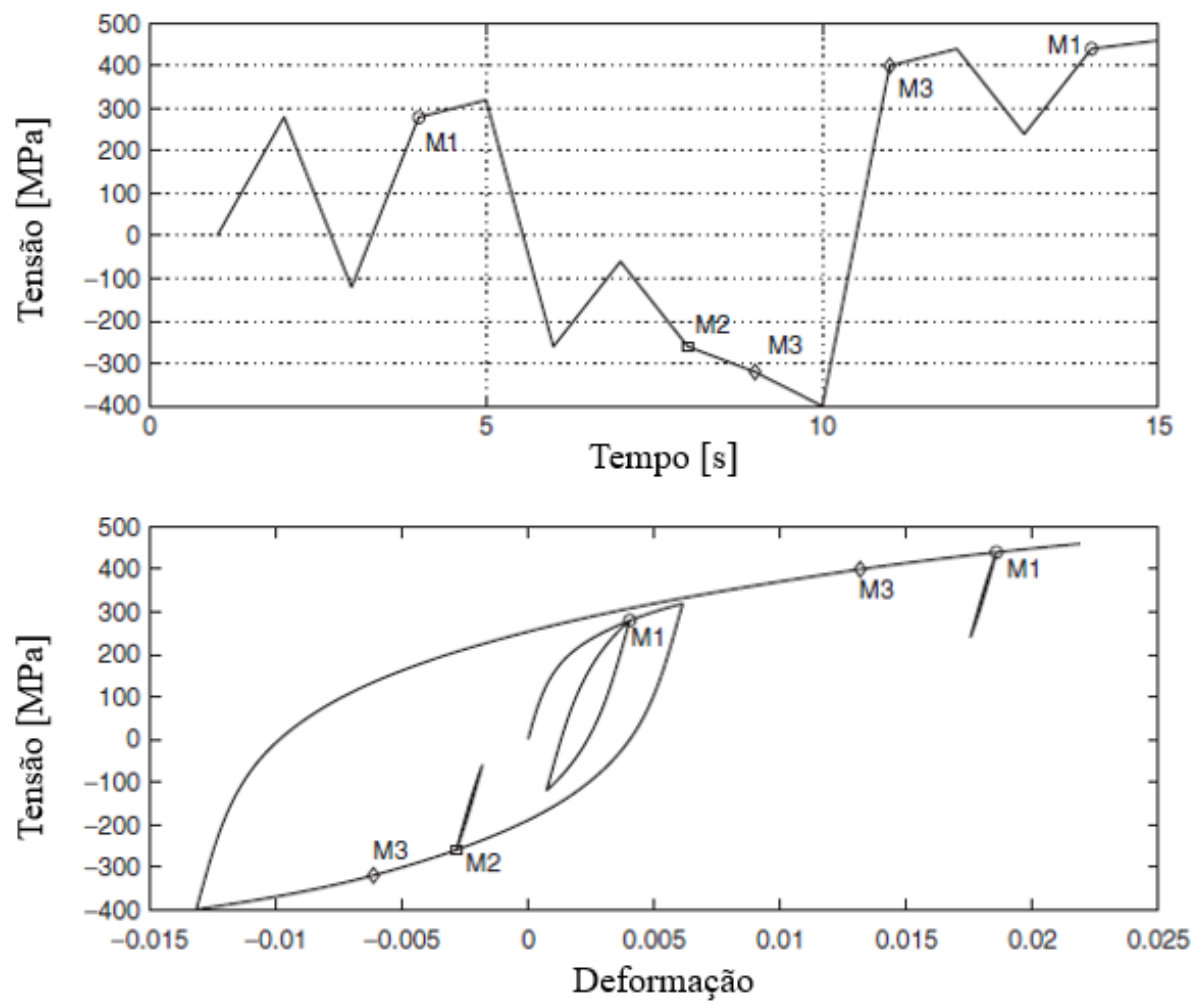

Fonte: Autor "adaptado de“ Johannesson e Speckert, 2014

A figura propõe que existem três ciclos fechados, sendo que os pontos em que foram aplicadas as diferentes regras da memória de Masing, se mostram identificados pelos pontos M1, M2 e M3. Observa-se então, que o ciclo de histerese ilustrado na parte inferior esquerda da figura não coincide com o gráfico da tensão-deformação antes de atingir o ponto M3, localizado na ordenada de $400 \mathrm{MPa}$. Os pontos M1 ou M2 são os pontos em que os 3 ciclos se fecham.

Dessa forma, os ciclos de histerese presentes no percurso tensão-deformação dependem somente da sequência dos pontos extremos locais do sinal da tensão ou deformação ao longo do tempo. Tendo tais ciclos como os eventos mais relevantes para fadiga, as análises de carregamentos apresentadas de aqui em diante deverão considerar somente estes pontos extremos locais, o que justifica a aplicação dos métodos de contagem através da teoria de contagem de ciclos Rainflow.

Para que essa contabilização possa ser executada, diversos tipos de algoritmos são recomendados pela literatura, sendo que por conta de sua complexidade, maiores detalhes sobre o desenvolvimento de tais ferramentas computacionais não serão aqui abordados. 
De forma geral, sabe-se que todos os algoritmos que possuem esta finalidade são capazes de interpretar os sinais de tensão ou deformação ao longo do tempo e extrair deles a contagem de ciclos de histerese, que podem então ser armazenados em forma de matriz. A matriz de Rainflow, como é denominada, é uma Matriz $i$ x $j$ que permite o armazenamento do número de ciclos de histerese. Tais ciclos são armazenados através de seus pares ordenados (valores de mínimo e máximo), sendo que ao plotar a matriz, tem-se no eixo das ordenadas, o valor mínimo de cada ciclo Rainflow, e no eixo das abcissas, os valores de máximo. A Figura 35 ilustra um exemplo, sendo que a paleta de cores auxilia na compreensão do número de vezes que determinado par ordenado se repete durante a análise de carregamento. As cores quentes simbolizam uma maior frequência de ocorrência para as determinadas amplitudes já as cores frias, apontam para frequências menores de observação das respectivas amplitudes observadas.

Figura 35 - Exemplo de matriz de Rainflow

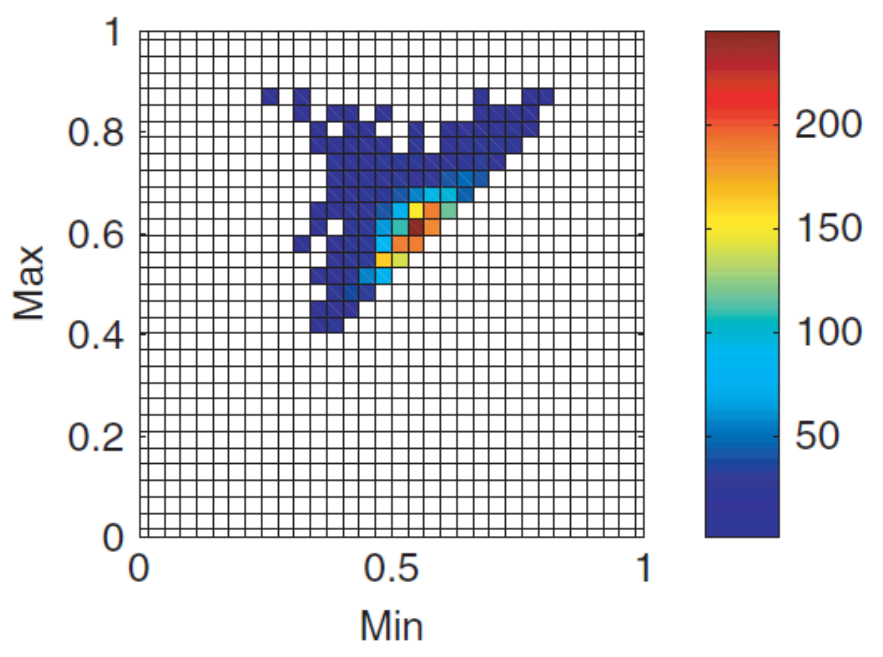

Fonte: Johannesson e Speckert, 2014

Conforme apontado por Wafo (2011), a implementação da ferramenta computacional Rainflow pode ser desenvolvida a partir de códigos MATLAB ${ }^{\circledR}$. Fragmentos de códigos já previamente desenvolvidos e validados, permitem que a análise de carregamentos reais possa ser facilmente conduzida. Maiores detalhes sobre esse tipo de implementação serão apresentados no Capítulo 6. 


\subsubsection{O Acúmulo de Danos e o Conceito de Pseudo-Dano}

De acordo com Johannesson e Speckert (2014), a análise de dados relacionados a carregamentos reais deve se basear em métodos robustos capazes de extrair os aspectos mais importantes relacionados a análise de fadiga. Um dos modelos mais utilizados para avaliações deste tipo, é o método denominado de pseudo dano. Este conceito, contempla a aplicação dos conceitos da curva de Wöhler (vide seção 4.7.1) em conjunto com a teoria de contagem de ciclos Rainflow (vide seção 4.7.4).

A partir da obtenção da matriz de Rainflow, em que a contribuição de dano causada por um ciclo de amplitude $S_{i}$ é igual a $1 / N_{i}$, deseja-se obter o valor referente a contribuição de todos os ciclos daquela determinada contagem de ciclos Rainflow. Para isso, Risitano, Corallo e Risitano (2012) sugerem a aplicação da teoria do acúmulo de danos proposta por PalmgrenMiner, em que a contribuição de todos os ciclos em estudo pode ser determinada por

$$
d=\sum_{i} S_{i}^{\beta}
$$

em que $\beta$, diferentemente do coeficiente de Basquin, que conforme apresentado na seção 4.7.1 tem relação com o material aplicado na peça, neste caso, dependerá do tipo de processo de fabricação do componente que está sendo analisado. Do ponto de vista prático, recomenda-se a escolha de um destes valores para sua respectiva aplicação:
a) $\beta=3 \rightarrow$ componentes soldados;
b) $\beta=5 \rightarrow$ componentes automotivos com acabamento grosseiro;
c) $\beta=7 \rightarrow$ componentes automotivos com acabamento fino.

Neste ponto, Johannesson e Speckert (2014) chamam a atenção para o fato de não haver neste momento o interesse em se calcular o limite de fadiga, mas sim, reduzir os diversos dados coletados a partir da metodologia de contagem de ciclos Rainflow em um único escalar. Este valor, servirá então como primeira referência para simbolizar os aspectos mais relevantes do estudo de fadiga para os dados coletados. 


\subsubsection{Amplitude Equivalente}

$\mathrm{Na}$ maioria dos casos, os números obtidos a partir do cálculo relacionado ao pseudo dano podem ser difíceis de serem interpretados do ponto de vista físico. Isso ocorre porque normalmente os valores mais comuns para este escalar podem chegar a uma ordem de grandeza de $1.10^{13} k N^{5}$, o que torna a interpretação desse valor de certa forma complexa para avaliações de engenharia. Desta forma, após a determinação do valor para o pseudo dano, o cálculo da amplitude equivalente pode facilitar a interpretação dos valores obtidos com as medições, permitindo então que comparações entre pilotos possam ser executadas. Johannesson e Speckert (2014) apresentam a equação da amplitude equivalente da seguinte forma

$$
A_{e q}=\left(\frac{K \cdot d}{N_{0}}\right)^{\frac{1}{\beta}}
$$

em que $A_{e q}$ corresponde ao valor da amplitude equivalente, $K$ equivale ao valor de extrapolação obtido através da relação entre a quilometragem total planejada para a vida útil do veículo e a quilometragem do percurso de medição, $d$ o valor do pseudo dano obtido de acordo com a equação (5) e $N_{0}$ o número de ciclos, que depende do regime de operação da peça. Para aplicações em regime de alta frequência, expostos a níveis elevados de fadiga, recomenda-se a seleção de $N_{0}=10^{6}$, já para regimes de baixa frequência, expostos a níveis mais baixos de fadiga, recomenda-se adotar $N_{0}=10^{3}$.

\subsubsection{Avaliação de Carregamentos Impostos pelo Usuário}

Conforme apresentado anteriormente, quando um veículo está em fase de desenvolvimento, deve-se conhecer previamente os tipos e magnitudes dos carregamentos que ele será exposto durante seu uso pelos clientes finais.

As características construtivas do novo protótipo são adotadas de acordo com as estimativas desenvolvidas pelas montadoras sobre como deverá ser a forma de utilização pelos usuários. A experiência em projetos anteriores é uma das principais fontes para o desenvolvimento destas estimativas, uma vez que os resultados dos testes já conduzidos em 
campo de provas e análises computacionais para projetos passados, certamente auxiliam o departamento de pesquisa e desenvolvimento a projetar novos veículos.

Entretanto, por conta do acirramento da competitividade entre as montadoras, cada vez mais observa-se o aumento da internacionalização dos produtos, fenômeno este, que pode ser verificado quando o mesmo veículo, contendo exatamente as mesmas características técnicas é comercializado a nível mundial. Por um lado, tal situação colabora para a padronização dos processos de desenvolvimento e manufatura, o que acarreta grandes otimizações e evita perdas financeiras expressivas. Já por outro, verifica-se a necessidade de se conhecer exatamente as características de carregamento que serão aplicadas pelos diferentes usuários e ambientes ao redor do globo.

Isso significa que um projeto devidamente adequado para um determinado mercado em que o ambiente e os padrões de condução são altamente hostis, poderá ser superdimensionado para outros em que tais condições são mais amenas. De forma análoga, um projeto dimensionado para solicitações intermediárias poderá ser considerado como subdimensionado quando aplicado naqueles ambientes em que as solicitações são mais severas.

É evidente que um projeto individualizado para cada mercado e tipo de público alvo é economicamente impossível, sendo assim, um dos desafios que se mostra pertinente, é o de se agrupar perfis de carregamentos impostos por usuários semelhantes de forma a permitir que um projeto especifico, porém economicamente viável para cada um destes grupos, seja desenvolvido.

Desta maneira, define-se como principal meta a descrição e compreensão dos carregamentos impostos pelos diferentes usuários e suas variações, o que compreende a variação entre condutores, ambientes etc.

\subsubsection{Comparação entre Condutores}

De forma a permitir a comparação entre diferentes perfis de condução e avaliar a influência destas diferenças na durabilidade do veículo, a comparação entre medições de carregamentos colhidos a partir de diferentes pilotos deve ser executada. Para isso, a primeira medida a ser tomada é a de se determinar o tipo de amostra de pilotos que será utilizada para a coleta de dados. Johannesson e Speckert (2014) apontam para a importância de se escolher uma amostra randômica de usuários para cada tipo de população estudada. Essa escolha deve ser feita sem restrições de idade, perfil social, sexo, grau de instrução, tempo de experiência de 
condução, porte etc., o que torna a avaliação dos resultados a mais apropriada e condizente com a realidade possível.

Quando se observa diferentes populações, um fator importante para a posterior comparação de dados é estabelecer uma quantidade fixa para o número de amostras dentro de cada população. Isso evita que atribuições de pesos e demais cálculos de probabilidade sejam necessários para se equiparar a significância das amostras em cada população. Portanto, recomenda-se que todas as diferentes populações estudadas, tenham o mesmo número de amostras, sendo que, o ponto mais importante é o de se definir a população de forma adequada para que todos os membros possam ser considerados na análise com o mesmo nível de relevância.

\subsubsection{Análise Estatística da População}

Considerando-se uma população randômica de tamanho $M$, em que cada condutor integrante a esta população é representado pela letra $n$, pode-se dizer que a probabilidade que cada integrante tem de aparecer nesta população é igual a $n / M$.

Este tipo de amostragem segundo Johannesson e Speckert (2014) é utilizado quando não se tem muitas informações disponíveis sobre onde executar as medições e o custo para executar coletas de dados para cada condutor é significativamente baixo. As principais vantagens deste tipo de avaliação é que apesar de sua simplicidade, as análises se demonstram altamente convincentes e eficazes.

Para que este tipo de estudo seja executado, deve-se introduzir os conceitos de média e variância, sendo que para isso, adota-se que os diferentes condutores envolvidos na população são numerados conforme a seguir $1,2,3,4 \ldots, M$, sendo que para cada número $i$ haverá um determinado valor associado ao carregamento aferido $y_{i}$ para aquele determinado condutor. Desta forma, obtém-se uma população para os valores associados aos carregamentos $y_{1}, y_{2}, y_{3}, \ldots, y_{M}$, com valor médio associado a população $\left(\bar{y}_{U}\right)$ e variância $\left(S^{2}\right)$ que podem ser calculados conforme exposto a seguir

$$
\bar{y}_{U}=\sum_{i=1}^{M} y_{i} / M
$$




$$
S^{2}=\sum_{i=1}^{M}\left(y_{i}-\bar{y}_{U}\right)^{2} /(M-1)
$$

Considerando agora uma amostra aleatória de tamanho $n$, o valor médio da amostra $(\bar{y})$ será então

$$
\bar{y}=\sum_{i=1}^{n} y_{i} / n
$$

com variância $\left(s^{2}\right)$

$$
s^{2}=\sum_{i=1}^{n}\left(y_{i}-\bar{y}\right)^{2} /(n-1)
$$

e desvio padrão $(s)$

$$
s=\sqrt{\sum_{i=1}^{n}\left(y_{i}-\bar{y}\right)^{2} /(n-1)}
$$

Para que o tamanho mínimo da amostra necessária para avaliação das possíveis diferenças entre os condutores em estudo seja determinado, Johannesson e Speckert (2014), propõem que o desvio corrigido da média da amostra $S E(\bar{y})$ seja avaliado, sendo que sua fórmula pode ser definida por

$$
S E(\bar{y})=\sqrt{\frac{S^{2}}{n}\left(1-\frac{n}{M}\right)} .
$$

Destaca-se ainda que em estatística, intervalo de confiança (IC) é um tipo de estimativa por intervalo de um parâmetro populacional desconhecido. Introduzido na estatística por Neyman (1937), define-se como sendo um intervalo observado (calculado a partir de observações) que pode variar de amostra para amostra e que com dada frequência, (nível de confiança) inclui o parâmetro de interesse. Dentro do contexto em estudo, o valor do intervalo de confiança para a amostra $n$ é importante para que possamos compreender a influência que cada medição adicional colabora para a diminuição do intervalo. Quanto menor ele for, maior será a confiabilidade dos resultados obtidos. 
Desta forma, para uma amostra de tamanho $n=3$, por exemplo, a variação do desvio calculado a partir da equação (12) nos aponta que quando uma medição adicional é realizada, o intervalo de confiança apresenta uma variação de tamanho, indo de $86,5 \%$ quando se tem somente 3 amostras e chegando a um patamar de 89,5\% quando se tem 4 amostras. De acordo com estas informações, constrói-se o gráfico apresentado na Figura 36, que nos sugere que uma amostra de tamanho $n=10$, pode nos proporcionar um intervalo de confiança suficientemente significativo com precisão superior a 95\%.

Figura 36 - Variação do tamanho do intervalo de confiança em relação ao tamanho da amostra

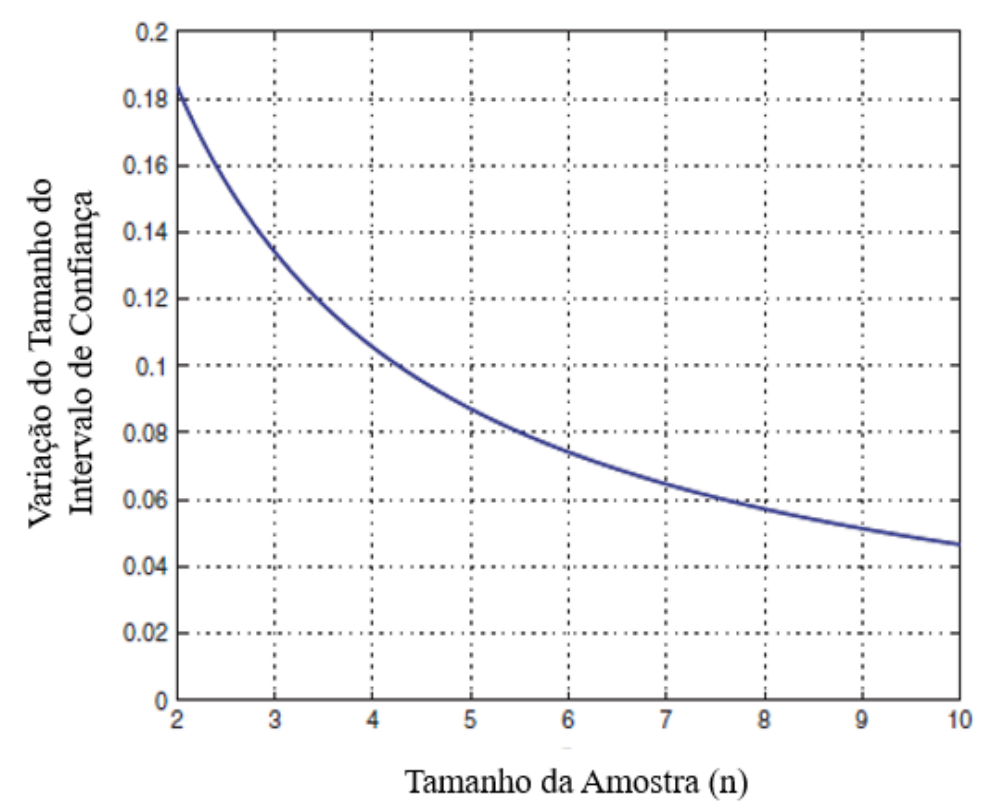

Fonte: Autor "adaptado de" Johannesson e Speckert, 2014

\subsubsection{Caracterização da População}

De forma padrão, Johannesson e Speckert (2014), apontam que uma determinada população de condutores pode ser aproximada por uma distribuição estatística de acordo com o padrão dos dados de carregamento obtidos para cada uma destas populações. Normalmente, a intensidade de carregamentos veiculares está associada a distribuições do tipo Normal, Weibull ou Log-normal.

Seguindo os padrões apresentados por esta literatura, a distribuição log-normal será utilizada por se demonstrar mais conveniente do ponto de vista matemático, sendo que a Figura 37, mostra as distribuições relacionadas aos valores da amplitude equivalente, calculadas a 
partir dos valores de pseudo dano (conforme equação 6) para uma determinada população de condutores a partir dos valores da média, desvio padrão e intervalo de confiança (95\%) da média e desvio padrão.

$$
\mu^{*}=\frac{1}{n} \sum_{i=1}^{n} \ln A_{e q, i}, \quad s^{2}=\frac{1}{n-1} \sum_{i=1}^{n}\left(\ln A_{e q, i}-\mu^{*}\right)^{2}
$$

$$
I_{\mu}=\left[\mu^{*}-2 s / \sqrt{n} ; \mu^{*}+2 s / \sqrt{n}\right]
$$

$$
I_{\sigma}=\left[S \sqrt{\frac{n-1}{b}} ; s \sqrt{\frac{n-1}{a}}\right]
$$

Em que $a=\chi_{0,025}^{2}(n-1)$ e $b=\chi_{0,095}^{2}(n-1)$ são quantis da distribuição chiquadrado com $n-1$ graus de liberdade e o fator 2 descrito na Figura 37 (a), corresponde ao quantil de 97,5\% da distribuição normal. Desta maneira, calcula-se o intervalo de confiança (95\%) $I_{\theta}$, para a mediana da amplitude equivalente $A_{e q}$, denominada $\theta$.

$$
I_{\theta}=\left[e^{\mu^{*}-2 s / \sqrt{n}} ; e^{\mu^{*}+2 s / \sqrt{n}}\right]
$$

Figura 37 - Distribuição normal para $\log A_{e q} / k N$ (a) e histograma estimado para densidade de probabilidade log-normal (b)

(a) Gráfico de Probabilidade Normal

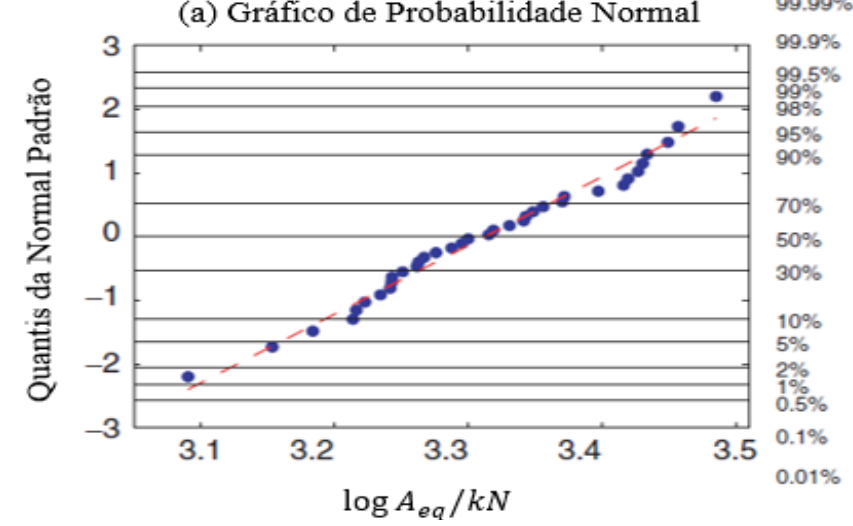

Fonte: Autor "adaptado de" Johannesson e Speckert, 2014 (b) Distribuição Log-Normal

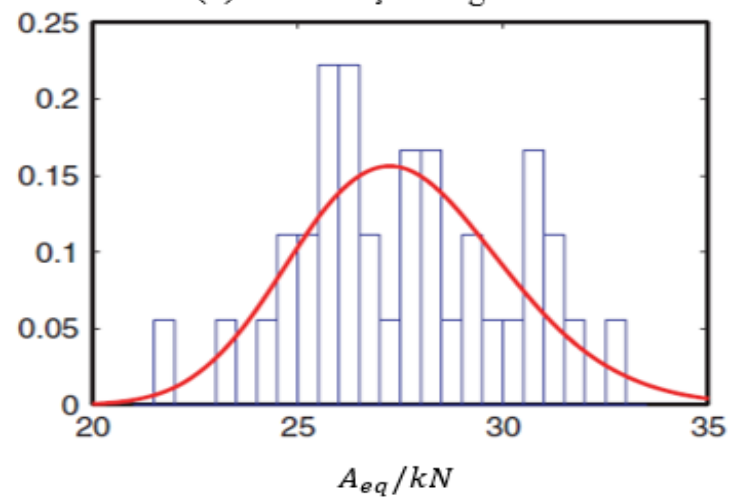




\subsubsection{Comparação Entre Diferentes Populações}

Com base nestas definições anteriores, pode-se então estipular uma metodologia para se comparar diferentes populações que impõem diferentes níveis de carregamentos. De forma geral, deseja-se buscar uma maneira de definir se um tipo de população atribui carregamentos mais severos ou amenos que outra e inclusive, quantizar essas diferenças. Sendo assim, para que isso seja feito, pode-se utilizar um intervalo de confiança, associado ao quociente de severidade média

$$
I_{\theta_{2} / \theta_{1}}=\left[\frac{\theta_{2}^{*}}{\theta_{1}^{*}} e^{-2 s \sqrt{1 / n_{2}+1 / n_{1}}} ; \frac{\theta_{2}^{*}}{\theta_{1}^{*}} e^{+2 s \sqrt{1 / n_{2}+1 / n_{1}}}\right]
$$

em que $\theta_{1}^{*}$ e $\theta_{2}^{*}$ são as medianas estimadas obtidas a partir das medias $\ln \theta_{1}^{*}$ e $\ln \theta_{2}^{*}$ obtidas a partir de $n_{1}$ e $n_{2}$ respectivamente. Já o parâmetro $s$ pode ser obtido a partir do desvio padrão. Se esse intervalo de confiança não cobrir o valor 1 , pode-se determinar com $95 \%$ de confiança que existe de fato uma diferença entre estas populações. Entretanto, se o intervalo contiver a unidade, verifica-se que não ocorre diferença com um grau de confiança de 95\%. Isso pode ser dito pois quando o intervalo de confiança contém o valor 1, pode-se dizer que em algum momento, $\theta_{1}^{*}=\theta_{2}^{*}$, o que justifica a interpretação de que nesta situação não deve ocorrer semelhança entre as populações avaliadas.

Desta forma, verifica-se a possibilidade de executar uma análise técnica e estatística para os dados obtidos a partir do estudo do pseudo dano, sendo que a sequência de atividades para se determinar a diferença entre as populações de condutores envolve o seguinte passo a passo:
a) Aquisição dos dados reais;
b) Tratamento dos dados;
c) Contagem de ciclos de fadiga através do método Rainflow;
d) Determinação do pseudo dano $d$;
e) Cálculo da amplitude equivalente $A_{e q}$;
f) Executar a avaliação estatística das populações; 
g) Determinar os intervalos de confiança associados aos quocientes de severidade média $I_{\theta_{2} / \theta_{1}}$ entre as populações.

A partir da determinação da metodologia necessária para a avaliação de uma possível diferença entre a severidade de uso do veículo por diferentes populações, resta agora avaliar quais serão os dados colhidos do veículo para que os estudos até então apresentados possam ser devidamente conduzidos. Desta forma, dedica-se a partir deste momento, uma atenção maior para a metodologia recomendada pela literatura para que a aquisição e tratamento dos dados obtidos seja devidamente realizada.

\subsection{AQUISIÇÃO E TRATAMENTO DE DADOS PARA AVALIAÇÕES DE DURABILIDADE EM VEÍCULOS AUTOMOTORES}

Os primeiros estudos sobre aquisição de dados em veículos automotores com o intuito de se estudar a forma de operação do veículo, foi apresentado por Daimlerchrysler Corporation (2001). Estes estudos foram desenvolvidos com o intuito de permitir aos engenheiros de desenvolvimento dos sistemas de injeção eletrônica a poderem adquirir dados reais do sistema de gerenciamento eletrônico do motor do veículo para que então, um aperfeiçoamento dos sistemas pudesse ser executado. A partir daí, surgiram os primeiros sistemas de telemetria, que de acordo com Carden, Jedlicka e Henry (2002), é um sistema eletrônico de monitoramento construído para rastrear, medir ou enviar comandos a algum equipamento que esteja distante ou em constante movimento.

Figura 38 - Exemplo de sistema de aquisição de dados veiculares

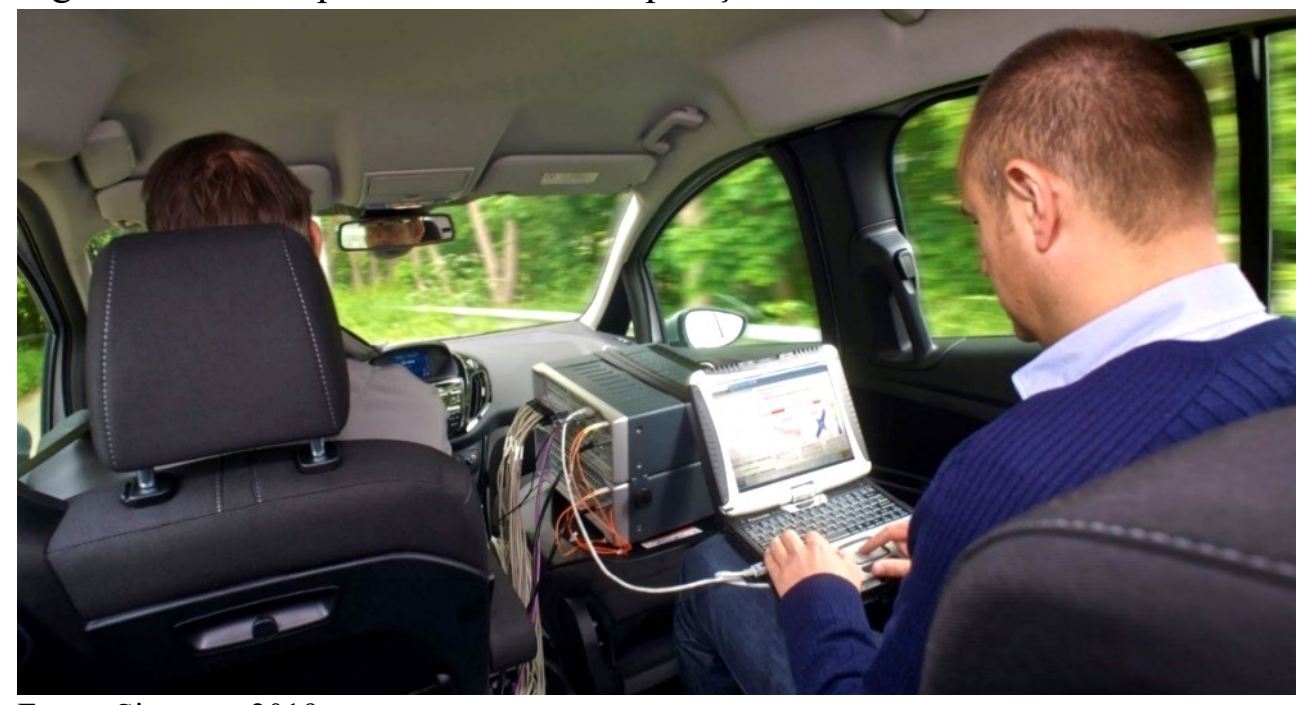

Fonte: Siemens, 2019 
Uma das principais funções de um sistema de telemetria, é permitir que os dados coletados em diversos tipos de ambientes e condições de utilização possam ser posteriormente avaliados de acordo com as necessidades de pesquisa do usuário do sistema.

Desta maneira, os sistemas de telemetria para aquisição de dados veiculares, permitem que diferentes informações oriundas da utilização do veículo em tempo real, possam ser salvas em um dispositivo de armazenamento de dados. Este dispositivo poderá ser posteriormente acessado com o intuito de permitir ao engenheiro responsável pela pesquisa verificar e estudar os dados adquiridos e a partir de então, aplicar diferentes metodologias de análise e avaliações estatísticas para que conclusões a respeito das medições sejam extraídas. Conforme apresentado na Figura 38, estes sistemas podem envolver vários componentes, que normalmente são altamente complexos e custosos, demandando a aplicação de mão-de-obra altamente especializada para sua instalação, operação e posterior interpretação dos resultados obtidos durante as medições.

\subsubsection{A Aplicação de Sistemas de Coleta de Dados em Motocicletas}

Por conta da diferença evidente que existe entre o packaging de um automóvel e o de uma motocicleta, entende-se que os desafios que envolvem a instrumentação e instalação de um sistema de coleta de dados em um veículo de duas rodas são ligeiramente maiores do que em um automóvel. Isto pois além da questão do espaço reduzido, em uma motocicleta, os sistemas do veículo e consequentemente os dispositivos integrantes ao sistema de instrumentação ficarão mais expostos as intempéries e agentes externos presentes no ambiente.

Sendo assim, uma série de cuidados adicionais devem ser tomados para que tais componentes sejam empregados neste tipo de veículo.

Apesar das particularidades envolvidas, pode-se dizer que a aquisição de dados em motocicletas é totalmente viável. Yuen, Karim e Saifizul (2014) comprovaram tal possibilidade quando executaram seus trabalhos voltados para aquisição de dados em uma motoneta de baixa cilindrada. Um de seus trabalhos, foi desenvolvido com o intuito de se verificar as diferentes reações de um grupo de condutores distintos quando eles pilotavam esta motocicleta em uma curva.

Para que tais estudos fossem possíveis, os autores equiparam o veículo escolhido com um sistema de aquisição de dados e uma série de sensores, cujo intuito, era o de monitorar o perfil de utilização dos diversos condutores em tempo real quando eles pilotavam no trecho de entrada da curva adotada como local de estudo. 
A Figura 39 ilustra este conjunto de dispositivos, sendo que após o tratamento e avaliação dos dados coletados, o autor foi capaz de estabelecer uma equação linear que explicava a taxa de redução da velocidade observada para cada condutor em função do ponto de entrada da curva.

Figura 39 - Exemplo de sistema de aquisição de dados veiculares instalados em uma motoneta

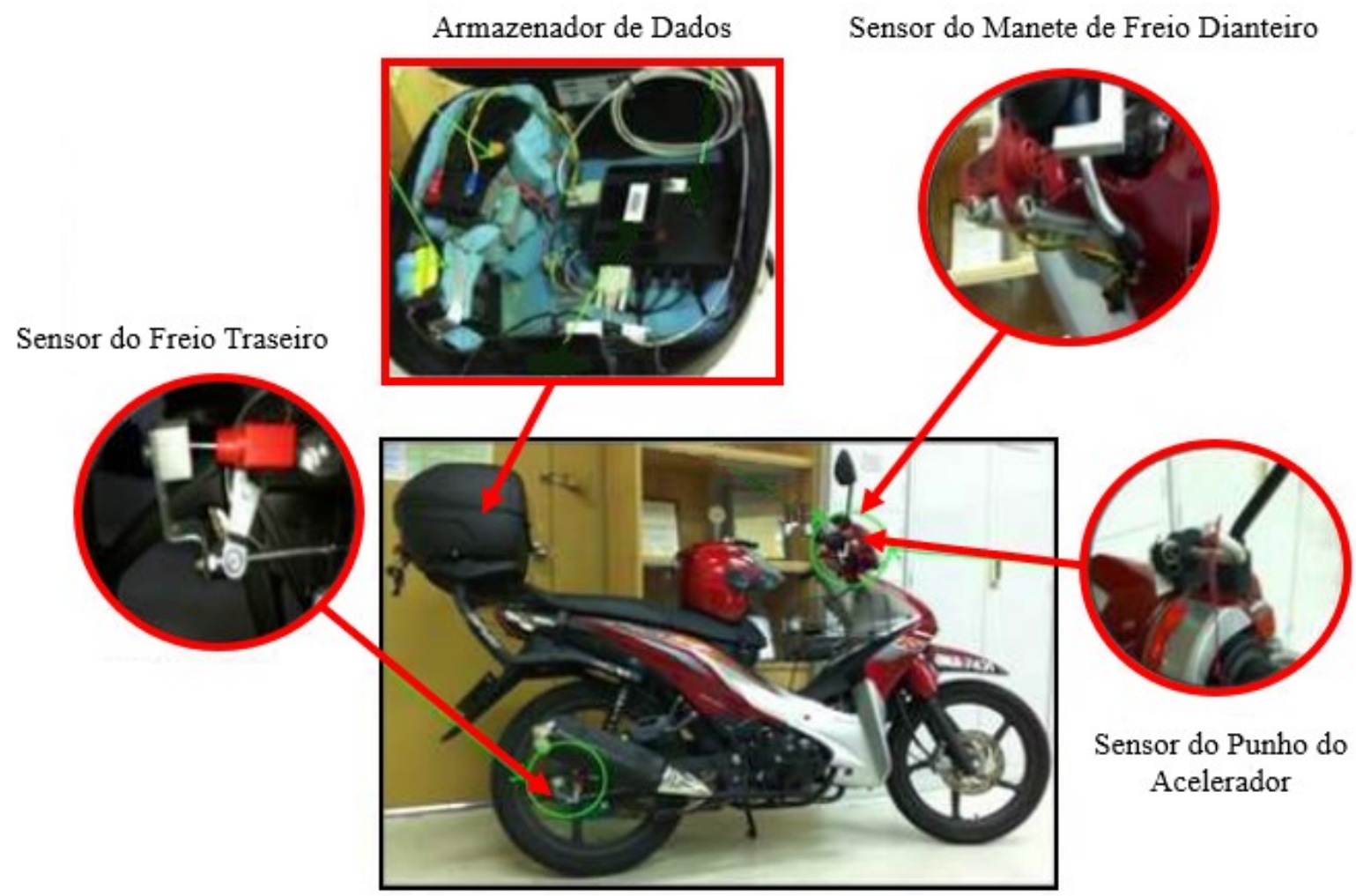

Fonte: Autor "adaptado de” Yuen, Karim e Saifizul., 2014

Tais informações, segundo o autor, foram úteis para que engenheiros de tráfego locais, pudessem compreender de maneira mais efetiva a forma de reação dos condutores deste tipo de veículo, o que proporcionou a avaliação e desenvolvimento de futuros estudos sobre a redução de acidentes de trânsito envolvendo motocicletas.

De maneira análoga Gorges, Öztürk e Liebich, (2017) conduziram pesquisas no ramo da área automotiva voltadas para o segmento de duas rodas. Um de seus trabalhos determinou que os carregamentos impostos por condutores poderiam ser calculados através das informações já armazenadas pelos módulos eletrônicos originais do veículo, sendo que, neste estudo, foram utilizados equipamentos auxiliares (instrumentação) para comparar a eficácia do algoritmo desenvolvido pelo autor e ratificar que os dados colhidos através dos módulos 
originais pudessem realmente ser utilizados para calcular os esforços em ambas as rodas da motocicleta adotada para a condução da pesquisa.

A Figura 40 ilustra os resultados obtidos para a força resultante calculada em ambas as rodas do veículo por meio do algoritmo desenvolvido por Gorges, Öztürk e Liebich, (2017). Os dados ilustrados se referem a uma janela de 20 segundos de dados coletados, em que ocorreu a frenagem e logo em seguida a aceleração do veículo por parte do condutor. Além de ilustrar os resultados, a imagem também os compara com os dados colhidos a partir da medição das forças através de transdutores instalados nos cubos das rodas do veículo.

Figura 40 - Valores da força resultante em ambas as rodas de uma motocicleta

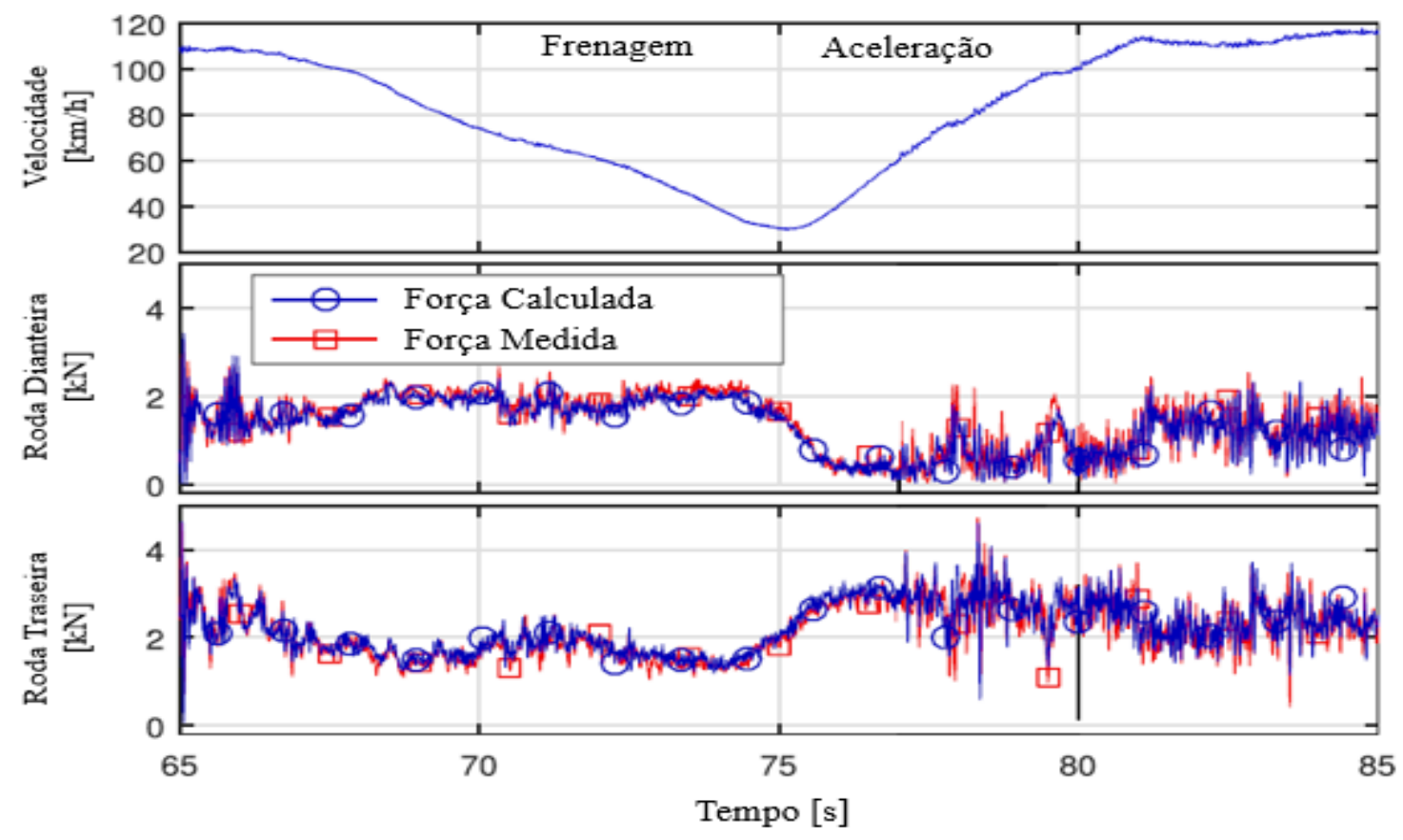

Fonte: Autor “adaptado de” Gorges, Öztürk e Liebich, (2017)

De acordo com o exposto na figura, os resultados obtidos a partir dos cálculos executados pelo algoritmo foram bem próximos daqueles aferidos através dos transdutores. Isso comprovou a eficácia da rotina computacional aplicada para o cálculo das forças nas rodas, que se baseou somente em dados disponibilizados a partir dos módulos originais da motocicleta utilizada pelo autor. 


\subsubsection{Aquisição de Dados Via Rede CAN (Controller Area Network)}

Conforme exposto anteriormente, comprovou-se a possibilidade de utilizar informações provenientes dos módulos eletrônicos de veículos automotores para que estudos sobre a avaliação das forças nas rodas do veículo em tempo real pudessem ser realizados. Tal tipo de estudo só é possível graças ao protocolo de comunicação CAN sigla em inglês para Controller Area Network. Este tipo de protocolo foi inicialmente desenvolvido pela empresa Robert Bosch Ltda. no início dos anos 80 com o intuito de promover uma rede de comunicação de baixo custo para aplicação no segmento automotivo. Hoje em dia, segundo Natale et al. (2012), por conta de sua eficácia, este tipo de tecnologia é aplicada em diversas áreas como por exemplo, automação industrial, robótica, dispositivos médicos e aviação.

Esta plataforma de comunicação é transmitida em um barramento digital projetado para operar entre velocidades de $20 \mathrm{kbit} / \mathrm{s}$ até $1 \mathrm{Mbit} / \mathrm{s}$, sendo que a taxa de transmissão de dados depende do tamanho do barramento e da velocidade dos transmissores e receptores. Além do seu baixo custo de aplicação, a simplicidade do protocolo e a arquitetura de detecção de falhas com posterior retransmissão das informações, são fatores que tornam este tipo de rede bastante atrativa aos olhos das montadoras de veículos, sendo que hoje em dia, este tipo de ferramenta já substitui grande parte dos sistemas elétricos automotivos ponto a ponto.

O barramento em si pode ser constituído por fios elétricos (meio de transmissão de dados), sendo que de acordo com Robert Bosch GmbH (2011) existem três formas de se constituir um barramento CAN. As redes com 2 e 4 fios trabalham com os sinais de dados (CAN High) e (CAN Low).

No caso dos barramentos com 4 fios, além dos sinais de dados, um fio com tensão para alimentação e outro com 0 Volts (massa) são empregados. As redes com apenas 1 fio operam somente com este filamento, chamado exclusivamente de linha CAN. Outro ponto importante é que além dos módulos presentes como transmissores e receptores de dados, existem também os terminadores. Essa nomenclatura dada aos resistores com valores de 120 a 124 ohms conectados na rede para que os sinais possam ser corretamente propagados. Eles normalmente ficam instalados no começo e no final da rede e garantem que os sinais sejam refletidos de forma a permitir o correto funcionamento da rede de dados. A Figura 41, ilustra uma representação de uma arquitetura CAN aplicada em uma motocicleta, sendo que neste caso, aplica-se uma rede CAN de 2 fios (CAN High) e (CAN Low), e os módulos (emissores e receptores de sinais) são os denominados Painel (painel de instrumentos), ABS (módulo de 
controle eletrônico do sistema de freio antitravamento das rodas) e DME (módulo de gerenciamento eletrônico do motor).

Figura 41 - Exemplo de arquitetura CAN aplicada em uma motocicleta

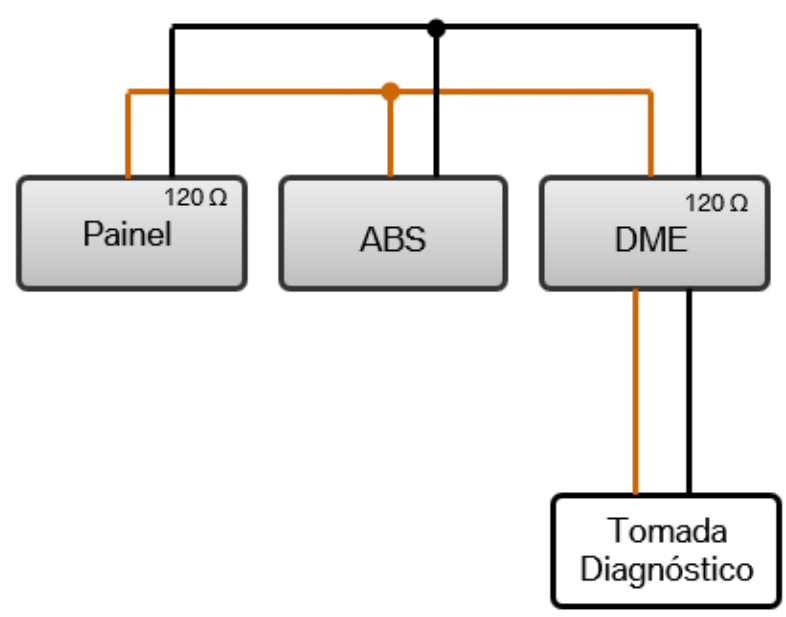

Fonte: Autor

O número de módulos integrantes ao sistema pode variar, sendo que em veículos mais complexos, esta quantidade pode superar uma centena de unidades de comando. Dentro deste contexto, destaca-se a importância deste tipo de rede de comunicação junto ao avanço da tecnologia automotiva. De acordo com Navet e Simonot-lion (2009), a rede CAN proporcionou a diminuição expressiva da quantidade de fios aplicados para a conexão de sistemas elétricos do veículo. Como exemplo, verificou-se uma redução de 40\%, indo de 635 para 370 fios diferentes incluídos no chicote do Peugeot 307, que já possui rede CAN de 2 fios em comparação com o mesmo veículo não multiplexado (Peugeot 306).

Sabendo ainda que diversos dados são fornecidos aos módulos em tempo real, como por exemplo, velocidade das rodas, velocidade do veículo, porcentagem de abertura do acelerador, entre outros, tais informações podem ser coletadas e posteriormente salvas em dispositivos de armazenamento de dados conforme já fora explorado em seções anteriores. Na prática, o registrador de dados, deverá ser compatível com o barramento de comunicação CAN aplicado no veículo, além disso, ele deve ser capaz de armazenar as informações coletadas ao longo do trajeto escolhido para o teste (memória suficiente). Para que sua conexão com a rede do veículo seja executada, deve-se escolher um dos módulos do veículo como o intercomunicador com o armazenador de dados. Normalmente, escolhe-se o módulo que inicia ou termina a rede de 
comunicação (no caso do diagrama acima, o que inicia o barramento é o painel e o que termina módulo DME.

\subsubsection{Tratamento e Pré-Processamento de Sinais}

De acordo com Johannesson e Speckert (2014), após a aquisição de sinais oriundos de medições dinâmicas, é essencial que uma fase de pré-processamento de dados seja executada. Diversos tipos de dados indesejados podem prejudicar as análises futuras e caso isso não seja feito, os resultados poderão ser distorcidos a ponto de inutilizar as avaliações para o determinado estudo em desenvolvimento.

Além disso, ajustes aplicados aos sinais também são de suma importância, para que ruídos indesejados possam ser eliminados. Para isso, análises espectrais, com o intuito de se descobrir possíveis ruídos em determinadas faixas de frequência podem ser úteis para que os sinais possam ser de fato aproveitados com sua devida significância.

Do ponto de vista da análise estrutural e fadiga, as propriedades essenciais que devem ser preservadas durante o pré-processamento estão relacionadas com as amplitudes do carregamento ao longo do tempo. Isto pode ser dito, uma vez que como já apresentado anteriormente, a avaliação das amplitudes é muito importante para que os ciclos Rainflow possam ser devidamente contabilizados.

A Figura 42 ilustra um sinal oriundo de uma medição de força vertical na roda de um veículo pesado. Este sinal, passou por três tipos de tratamento, de forma a se analisar a influência da aplicação dos diferentes tipos de filtros. Os sinais ilustrados a esquerda, se referem ao sinal original após extração de dados do sistema de armazenamento, já os diferentes sinais expostos a direita, apontam para o mesmo trecho de 0,5 segundos após a aplicação dos diferentes tipos de filtros. 
Figura 42 - Comparação do efeito de três tipos de filtros aplicados em um sinal

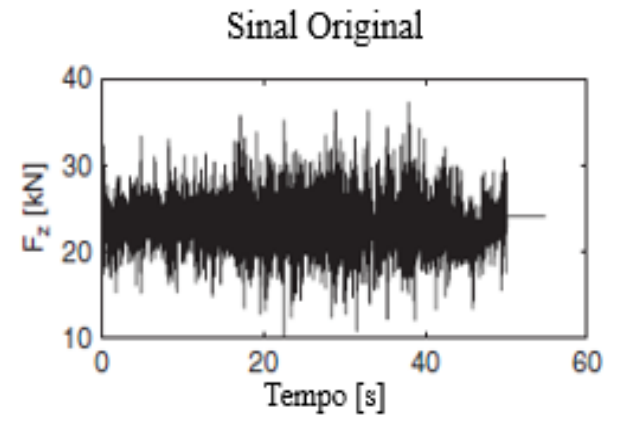

Sinal Original

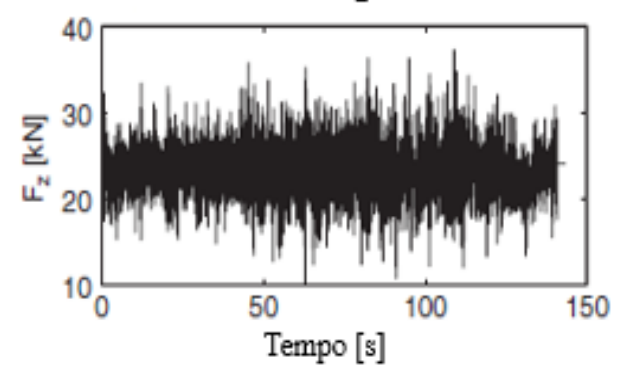

Sinal Original

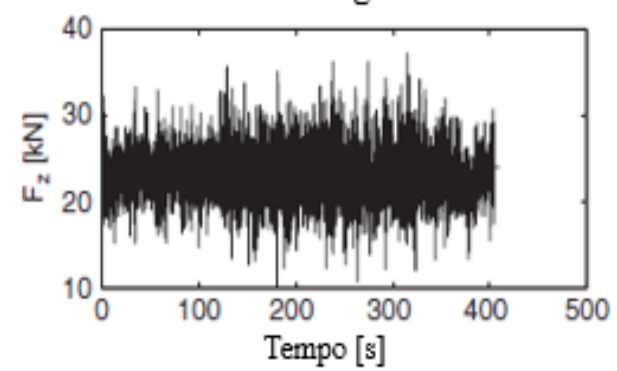

Filtro 1

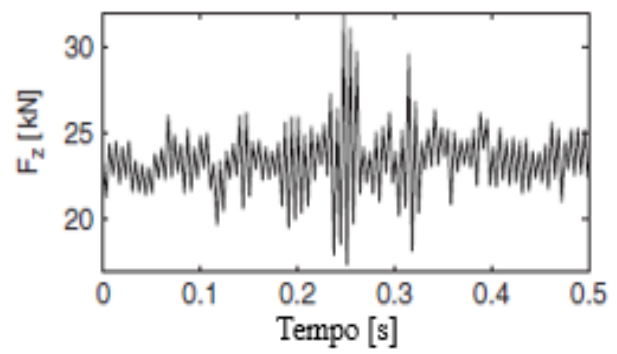

Filtro 2

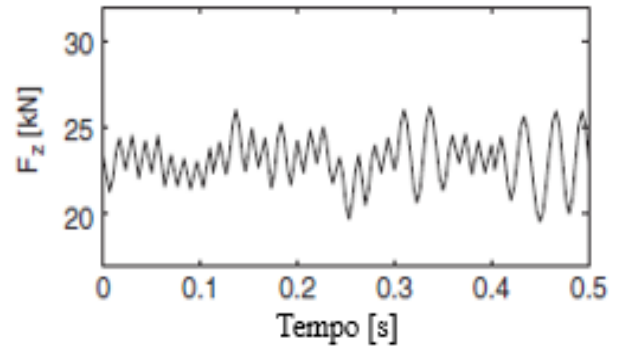

Filtro 3

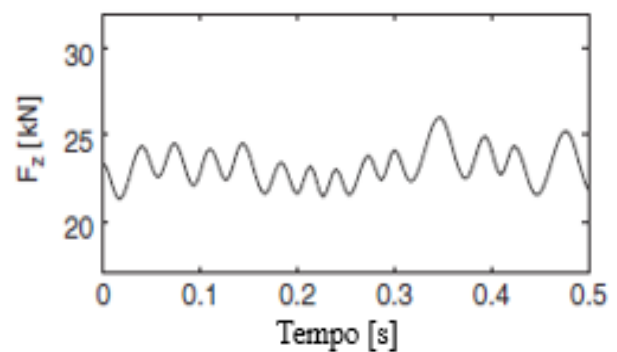

Fonte: Autor “adaptado de” Johannesson e Speckert, 2014

Após a análise da imagem, identifica-se uma queda no número de dados disponíveis após a filtragem, sendo aquela executada pelo filtro 3 a que mais removeu dados, deixando o sinal mais suave quando comparado com aquele resultante da filtragem do primeiro e do segundo filtro. Entretanto, justamente por conta da grande quantidade de dados que foram removidos pelo filtro 3 entende-se que possivelmente este pode fornecer resultados não associados com a realidade que se deseja estudar.

Assim, sabe-se que variação no resultado apresentado por de cada filtro se dá pela frequência de filtragem, que varia de filtro para filtro, sendo que para uma compreensão mais adequada da teoria de filtros aplicados em sinais digitais, se faz necessária a aplicação das séries de Fourier. 


\subsubsection{Aspectos Elementares das Séries de Fourier}

De acordo com Angelo (2007), a transformada de Fourier (TF) é a principal ferramenta aplicada na análise de sinais, sendo que ela não altera o sinal em avaliação, mas apenas transforma a informação por ele vinculada em outra mais fácil de ser interpretada. De forma prática, a transformada de Fourier é capaz de transferir um sinal descrito no domínio do tempo para o domínio da frequência a partir da seguinte expressão,

$$
T F(x(t))=X(f)=\int_{-\infty}^{+\infty} x(t) e^{-2 \pi i f t} d t
$$

em que $x(t)$ representa um sinal qualquer descrito no domínio do tempo e $f$ tem unidade descrita em $\mathrm{Hz}$ ou $1 / \mathrm{seg}$.

De forma a ilustrar os resultados obtidos através da aplicação da transformada de Fourier, a imagem superior exibida na Figura 43 ilustra o sinal da aceleração do centro de massa (em relação a Z) de um veículo de duas rodas ao longo do tempo. Este sinal foi captado com uma taxa de aquisição de $250 \mathrm{~Hz}$, sendo que após a aplicação da transformada de Fourier, verifica-se este mesmo sinal descrito na parte inferior da figura, agora, exibido no domínio da frequência.

Ao analisar a figura, verifica-se na imagem inferior que o sinal mencionado teve um pico de dados na faixa dos $15 \mathrm{e} 30 \mathrm{~Hz}$, sendo que, de acordo com os estudos desenvolvidos por Gorges, Öztürk e Liebich, (2017), filtros passa baixa devem ser aplicados a uma determinada frequência de interesse $f_{c}$, para que o tratamento dos dados seja devidamente realizado.

Desta forma, a partir da análise dos sinais transformados para o domínio da frequência, pode-se verificar exatamente quais são as frequências mais representativas em relação a quantidade de dados colhidos durante as medições realizadas. 
Figura 43 - Sinais da aceleração angular do centro de massa de um veículo de duas rodas em relação a Z. Imagem superior - sinal descrito no dominio do tempo. Imagem inferior - sinal descrito no dominio da frequência
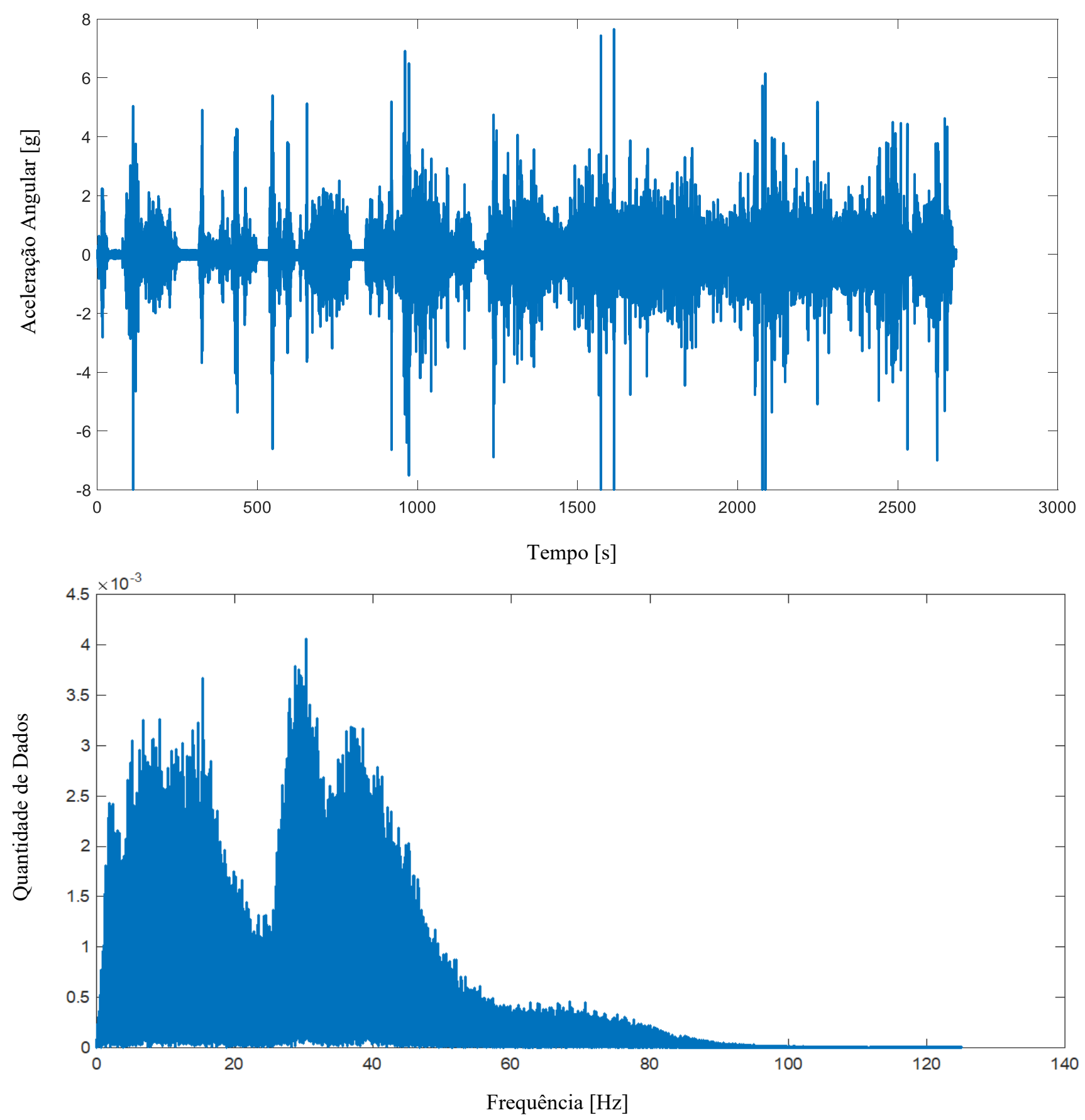

Fonte: Autor 


\subsubsection{Filtros Para o Cálculo da Força Vertical na Roda Dianteira}

De posse dos sinais colhidos junto ao sistema de aquisição de dados e suas respectivas conversões para o domínio da frequência, uma análise espectral pode ser executada. Gorges, Öztürk e Liebich, (2017) sugerem que para o cálculo da força na roda dianteira de uma motocicleta, os sinais relacionados as acelerações e velocidades angulares do centro de massa do veículo sejam filtrados a partir de um filtro passa-baixa com frequência de corte de $5 \mathrm{~Hz}$.

Isso se faz necessário, uma vez que as frequências acima de determinada faixa de frequência, denominada $f_{c}$ estão relacionadas com forças induzidas a partir de oscilações estocásticas atreladas as ondulações e irregularidades do pavimento, que neste momento, devem ser desprezadas. A explicação para esta premissa incorre da necessidade de se avaliar as forças induzidas pelos pilotos e suas respectivas formas de pilotagem, sendo que este grupo de sinais de interesse, fazem parte daqueles com faixa de frequência inferior a $f_{c}$.

A Figura 44 ilustra o resultado da aplicação deste determinado filtro para o sinal da aceleração do centro de massa do veículo em relação a $\mathrm{X}, a_{v e h, x}^{C G}$, sendo que o sinal descrito em vermelho representa o sinal após a aplicação do filtro e o ilustrado em azul, o sinal original.

Figura 44 - Filtragem do sinal da aceleração angular do centro de massa de um veículo de duas rodas em relação a $\mathrm{X}$

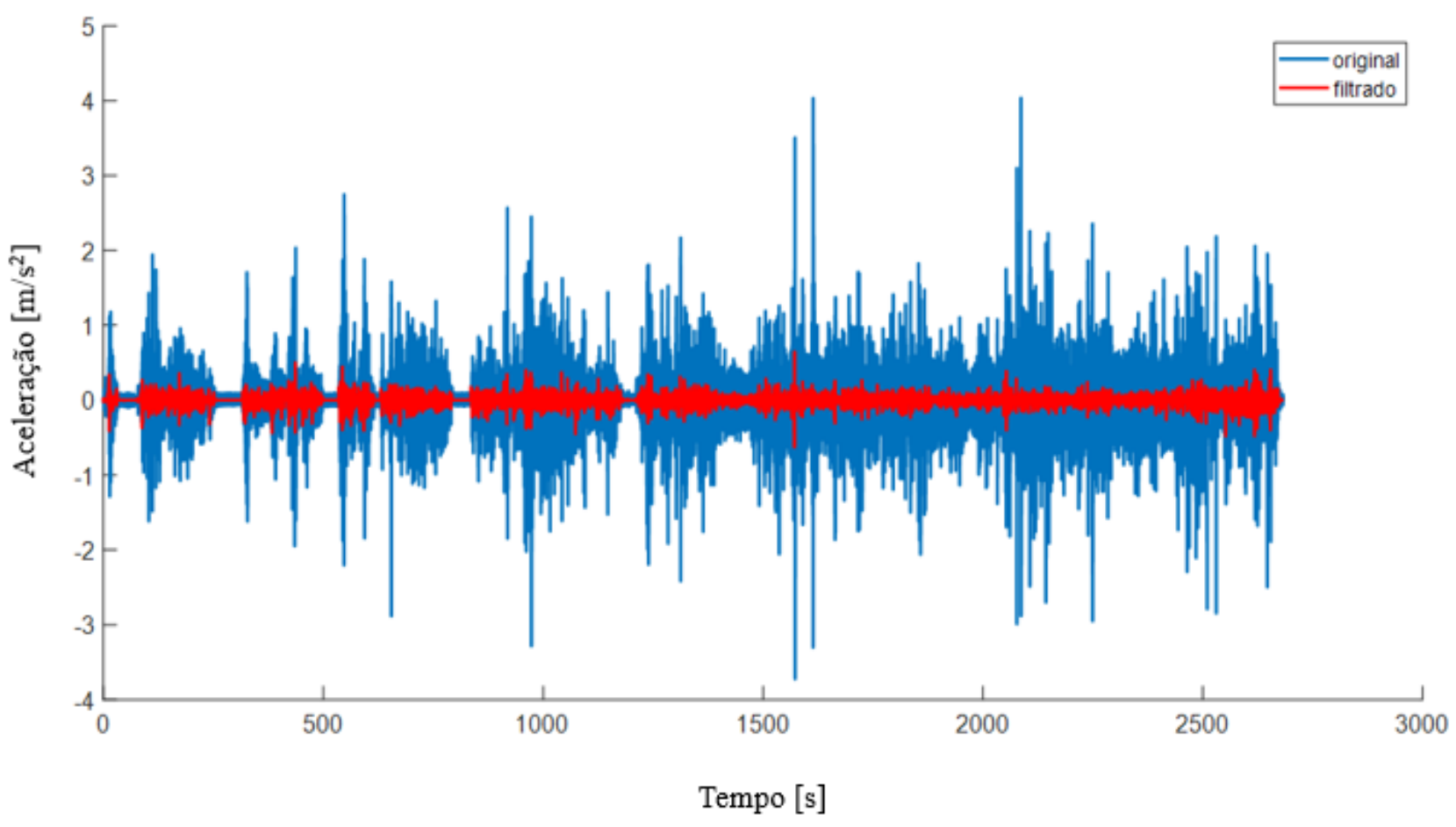

Fonte: Autor 


\section{MATERIAIS E MÉTODOS}

Neste capítulo, apresentam-se os principais recursos empregados durante a condução da pesquisa, como por exemplo, a motocicleta e os instrumentos de medição empregados. Adicionalmente, discute-se a metodologia utilizada para coleta dos dados junto aos pilotos participantes e cálculos aplicados para determinação da força vertical no eixo da roda dianteira.

\subsection{ELEMENTOS ENVOLVIDOS}

Os elementos materiais aplicados, resumem-se ao veículo (motocicleta) e instrumentos de medição aplicados a mesma. Sendo assim a seguir discorre-se sobre tais sistemas/componentes.

\subsubsection{O Veículo Utilizado}

A Figura 45 ilustra o veículo em estudo, que é uma motocicleta da marca BMW modelo G 310 R fabricada no polo industrial de Manaus. Este veículo tem características construtivas para melhor se adaptar aos centros urbanos, como por exemplo, pequena distância entre eixos e posição do centro de gravidade voltada para a frente do veículo, o que facilita sua manobrabilidade em baixas velocidades. Na tabela a seguir são fornecidos os principais dados técnicos do veículo.

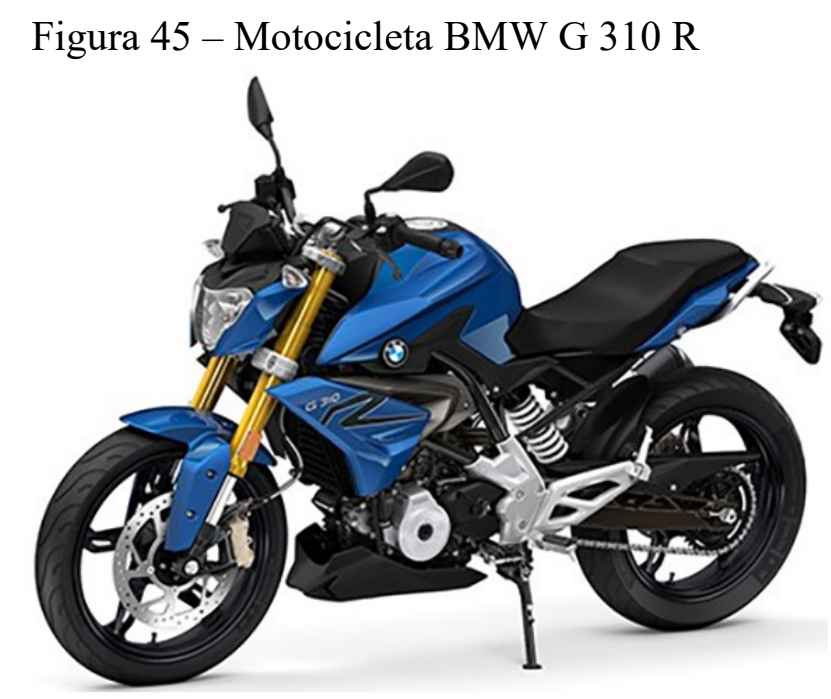

Fonte: Arquivo Pessoal 
Tabela 1 - Principais dados técnicos do modelo BMW G 310 R

\begin{tabular}{l|l}
\hline Potência Nominal & $25 \mathrm{~kW} @$ 9,500 rpm \\
\hline Torque Max. (motor) & $28 \mathrm{~N} . \mathrm{m} @$ @,500 rpm \\
\hline Cilindrada & $313 \mathrm{~cm}^{3}$ \\
\hline Entre-Eixos & $1366 \mathrm{~mm}$ \\
\hline Trail & $103 \mathrm{~mm}$ \\
\hline Peso em Ordem de Marcha & $158 \mathrm{~kg}$ \\
\hline Peso Bruto Total & $345 \mathrm{~kg}$ \\
\hline
\end{tabular}

Fonte: Autor “adaptado de” BMW Motorrad, 2016

\subsubsection{Instrumentação}

O sistema de aquisição de dados instalado ao veículo, funciona com uma taxa de aquisição de dados de $250 \mathrm{~Hz}$ e opera de acordo com a tecnologia de transmissão de dados entre unidades de comando denominada CAN (Controller Area Network), conforme descrito na seção 4.8.2. O objetivo do sistema é o de adquirir informações enviadas e recebidas pelas unidades de comando do veículo, que no caso estudado, são 3:

a) Painel de Instrumentos e Gerenciamento do Sistema de Iluminação;

b) Módulo de Gerenciamento Eletrônico do Sistema ABS;

c) Módulo de Gerenciamento Eletrônico do Motor (DME).

O registrador de dados utilizado é capaz de acessar remotamente as informações destes módulos eletrônicos e coletar os dados dos demais sensores instalados manualmente no veículo, sendo que através da rede CAN, os seguintes dados foram coletados em tempo real durante cada sessão de medição realizada por piloto avaliado:

a) Rotações do Motor [RPM];

b) Porcentagem de Abertura da Borboleta do Acelerador [\%];

c) Velocidade do Veículo $[\mathrm{km} / \mathrm{h}]$;

d) Velocidade da Roda Dianteira $[\mathrm{km} / \mathrm{h}]$;

e) Velocidade da Roda Traseira $[\mathrm{km} / \mathrm{h}]$;

f) Consumo Instantâneo $[\mathrm{ml} / \mathrm{s}]$;

g) Temperatura do Ar de Admissão $\left[{ }^{\circ} \mathrm{C}\right]$;

h) Temperatura do Motor $\left[{ }^{\circ} \mathrm{C}\right]$. 
Além dos dados adquiridos via rede CAN, um total de 4 sensores foram anexados ao veículo para outras informações relevantes também pudessem ser extraídas durante a coleta de dados.

\subsubsection{GPS}

O sistema GPS foi montado para garantir o controle da rota percorrida pelo piloto e validar a velocidade percorrida pelo condutor durante a execução do trajeto padronizado.

\subsubsection{Sensores de Posição da Suspensão Dianteira e Traseira}

Com o intuito de se aferir o curso das suspensões e respectivas variações, foram montados dois sensores digitais de medição por contato de alta precisão (LVDT) capazes de aferir em tempo real a variação do curso das suspensões do veículo. Na prática, o principal benefício do uso destes sensores é o de se permitir uma avaliação das características do asfalto e pincipalmente, do comportamento do piloto durante situações de frenagem e aceleração. Durante uma frenagem mais brusca, espera-se verificar um aumento significativo do curso do amortecedor traseiro (extensão) e uma redução no curso da suspensão traseira (compressão).

\subsubsection{Analog Box (Acelerômetros)}

Sistema de aquisição eletromecânico, capaz de avaliar a aceleração da motocicleta nos três eixos X (rolagem), Y (arfagem), Z (guinada) transferindo os dados para o sistema de aquisição para que eles sejam apresentados em função da aceleração da gravidade $g$.

A Figura 46 ilustra os componentes envolvidos na instrumentação e seus locais de instalação na motocicleta. 
Figura 46 - Detalhes da instrumentação instalada na motocicleta em estudo

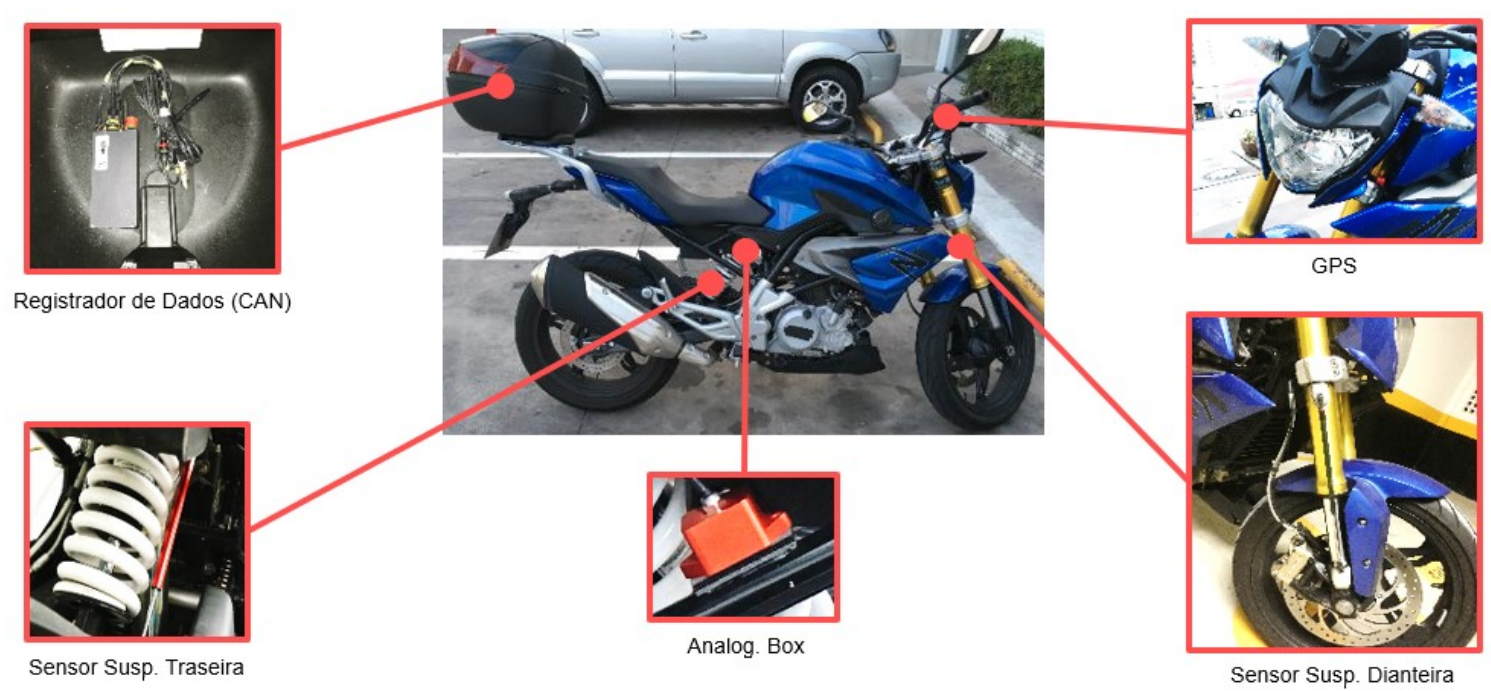

Fonte: Autor

Pelo fato de o veículo de duas rodas ser tecnicamente exposto as condições climáticas e demais agentes externos, cuidados adicionais no tocante a proteção dos componentes eletrônicos foram tomados. Por isso, fez-se o uso de um bagageiro para armazenar o sistema de aquisição de dados.

\subsubsection{O Trajeto}

De forma a permitir uma máxima abrangência de situações reais de pilotagem, adotouse durante o estudo um trajeto contendo 35,2 quilómetros de vias públicas da cidade de São Paulo. Este trajeto envolveu algumas das principais vias coletoras e arteriais da cidade, sendo que entre elas, destaca-se como ponto de aglomeração de veículos a Avenida 9 de Julho, local em que comumente encontram-se motociclistas disputando espaço entre os demais veículos, conforme ilustrado na Figura 47. 
Figura 47 - Avenida 9 de Julho - São Paulo - SP

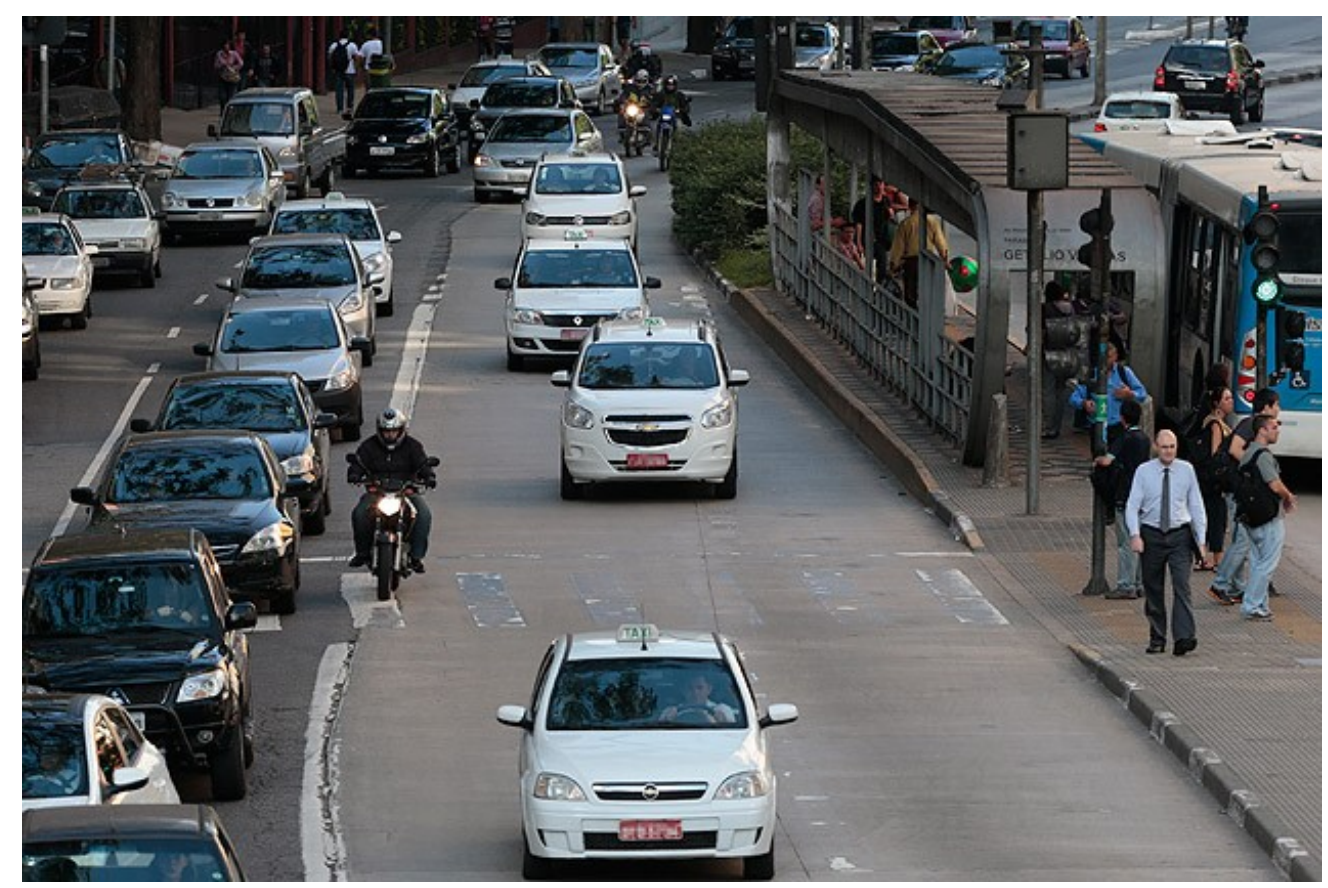

Fonte: Folha de São Paulo, 2015

Todas as medições foram realizadas entre segunda a quarta-feira, sempre entre as 16:00 e 18:00 horas. Isso foi feito para que a influência de diferentes condições de tráfego fosse minimizada, uma vez que conforme já esclarecido, o intuito da pesquisa foi o de se avaliar as diferentes formas de condução adotadas pelos pilotos, desprezando as variações e particularidades inerentes ao meio. Além disso, todas as sessões para coleta de dados foram realizadas com tempo seco para que uma uniformidade nas condições oferecidas aos pilotos pudesse ser obtida.

Antes do início da aquisição dos dados, os pilotos percorreram um trajeto de 4 quilómetros com a motocicleta para que eles pudessem se habituar com os comandos e com o comportamento dinâmico do veículo instrumentado. Este trajeto compôs basicamente as vias públicas entre o local de estacionamento da motocicleta até o trecho inicial do percurso padrão.

A Figura 48, destaca o trajeto com suas vias e respectivos limites de velocidade para cada trecho, sendo que na Figura 49, ilustra-se a distribuição em porcentagem de tais limites em relação a composição total do percurso. 
Figura 48 - Trajeto escolhido durante o levantamento dos dados

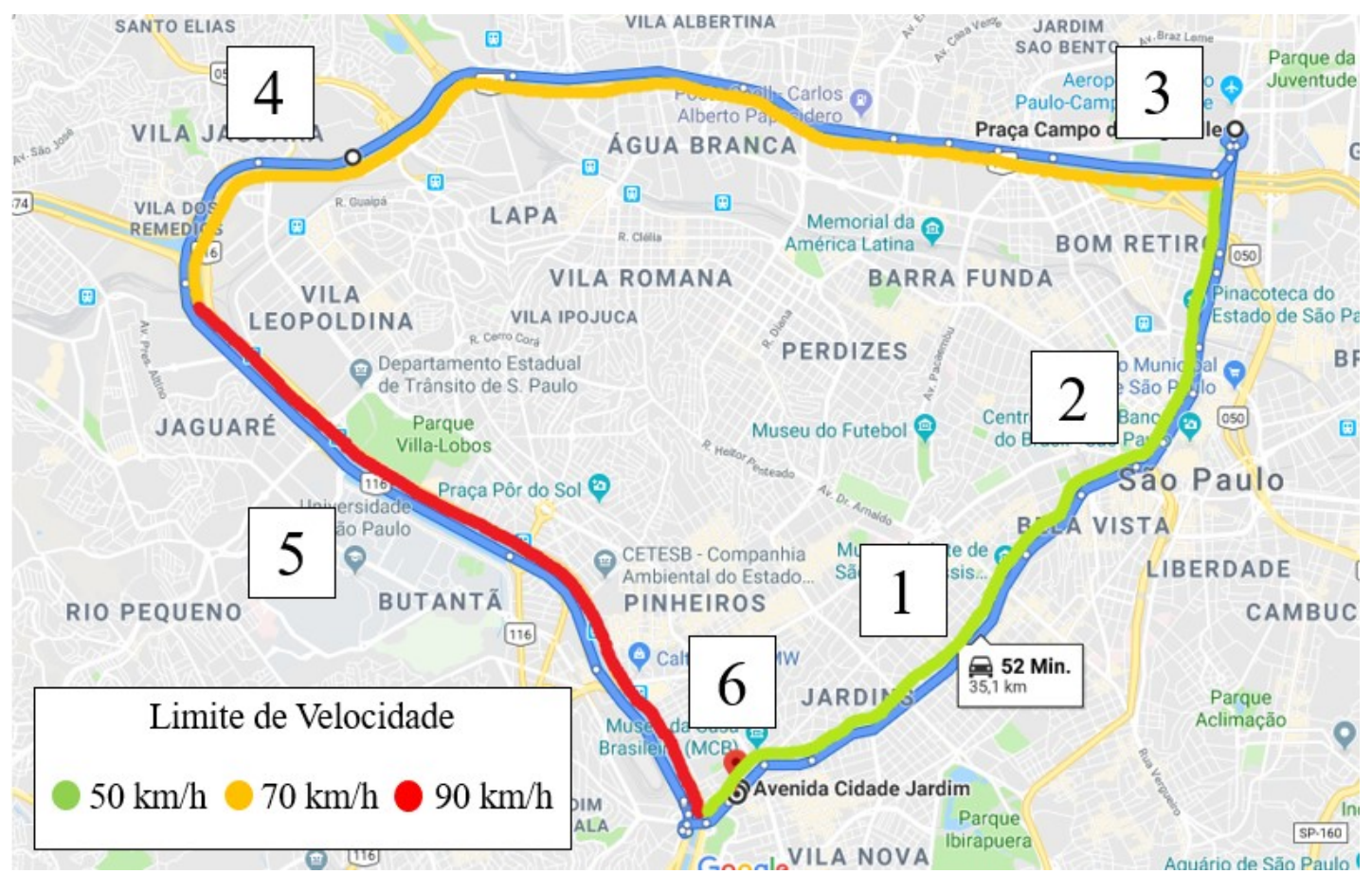

Fonte: Autor "adaptado de" Maps

Legenda:

1. Avenida Cidade Jardim

2. Avenida 9 de Julho

3. Praça Campos de Bagatelle

4. Marginal Tietê

5. Marginal Pinheiros

6. Avenida Cidade Jardim

Percebe-se que o limite variou entre 50 e $90 \mathrm{~km} / \mathrm{h}$, sendo que de forma geral, a distribuição entre os diferentes limites se mostrou sensivelmente igualitária com uma leve minoria em extensão daquelas vias com limites de $90 \mathrm{~km} / \mathrm{h}$.

Figura 49 - Distribuição dos limites de velocidade para o trajeto escolhido

Fonte: Autor

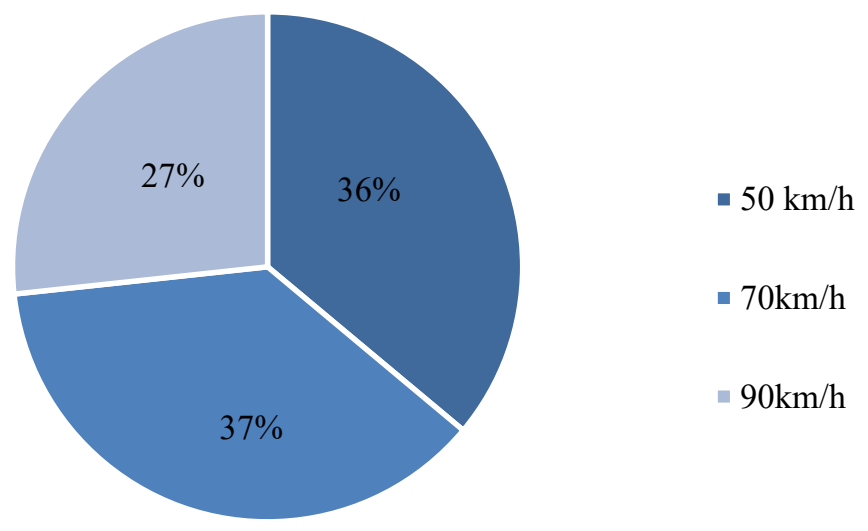




\subsubsection{Os Condutores}

Um total de 30 condutores, todos escolhidos aleatoriamente e portando carteira nacional de habilitação para a categoria A válida, realizaram a condução da motocicleta instrumentada ao longo do trajeto proposto. Durante a execução dos testes, os pilotos foram orientados a conduzir de acordo com sua forma/padrão normal de pilotagem. O intuito de se aferir as diferentes formas de pilotagem foi esclarecido pelo pesquisador, de forma a conscientizar os pilotos da importância da não alteração do perfil no momento do teste, ou seja, os pilotos foram fortemente recomendados a pilotar da forma como estão acostumados a fazer durante o uso que normalmente fazem do veículo de 2 rodas.

A partir do número total de pilotos convidados, foi feita uma pré-seleção para que a medição pudesse ser feita com 10 pilotos que fazem o uso da motocicleta durante o deslocamento urbano, 10 profissionais do ramo de moto frete e 10 pilotos que fazem o uso do veículo de 2 rodas somente para passeio/lazer. Isso permitiu que uma rotulagem dos dados fosse executada, para que então, uma estratégia de avaliação supervisionada fosse desenvolvida.

Para que o grupo de motofretistas pudesse ser composto somente por profissionais da área, um contato com a empesa Itaim Express foi executado. O intuito foi o de envolver profissionais registrados legalmente para a execução da profissão de moto frete, sendo que a legalização e regulamentação desta profissão, faz parte de um dos pilares desta renomada empresa atuante neste setor desde 2001.

Na Tabela 2 a seguir, apresentam-se algumas das principais informações sobre os condutores selecionados durante a participação das medições, que foram executadas entre os dias 07/04/2018 e 26/03/2019. As informações foram obtidas através do questionário apresentado no Apêndice A. 
Tabela 2 - Dados dos condutores participantes da pesquisa

\begin{tabular}{|c|c|c|c|c|c|c|c|c|}
\hline Piloto & Idade & Sexo & Estado Civil & Renda Mensal & Nível de Instrução & $\begin{array}{c}\text { Anos de } \\
\text { Experiencia }\end{array}$ & $\begin{array}{l}\mathbf{K m} / \\
\text { mês }\end{array}$ & Tipo de Uso \\
\hline 1 & 29 & Masculino & Casado & Até $\mathrm{R} \$ 10.000,00$ & Superior Completo & 14 & 720 & Locomoção Urbana \\
\hline 2 & 39 & Masculino & Casado & Até $\mathrm{R} \$ 10.000,00$ & Superior Completo & 21 & 3900 & Locomoção Urbana \\
\hline 3 & 39 & Masculino & Casado & Até $\mathrm{R} \$ 10.000,00$ & Superior Completo & 18 & 1400 & Locomoção Urbana \\
\hline 4 & 37 & Masculino & Casado & Acima de $\mathrm{R} \$ 10.000,00$ & Superior Completo & 19 & 1200 & Locomoção Urbana \\
\hline 5 & 38 & Masculino & Casado & Acima de $\mathrm{R} \$ 10.000,00$ & Ensino Médio & 20 & 3000 & Locomoção Urbana \\
\hline 6 & 25 & Masculino & Solteiro & Acima de $\mathrm{R} \$ 10.000,00$ & Superior Completo & 9 & 440 & Locomoção Urbana \\
\hline 7 & 31 & Masculino & Casado & Acima de $\mathrm{R} \$ 10.000,00$ & Superior Completo & 8 & 1150 & Locomoção Urbana \\
\hline 8 & 39 & Masculino & Casado & Acima de $R \$ 10.000,00$ & Superior Completo & 26 & 1400 & Locomoção Urbana \\
\hline 9 & 54 & Masculino & Casado & Acima de $R \$ 10.000,00$ & Superior Completo & 40 & 400 & Locomoção Urbana \\
\hline 10 & 34 & Masculino & Casado & Acima de $\mathrm{R} \$ 10.000,00$ & Superior Completo & 11 & 600 & Locomoção Urbana \\
\hline 11 & 28 & Masculino & Casado & Até $\mathrm{R} \$ 5.000,00$ & Superior Incompleto & 14 & 4000 & Moto Fretista \\
\hline 12 & 38 & Masculino & Casado & Até $\mathrm{R} \$ 5.000,00$ & Superior Incompleto & 20 & 850 & Moto Fretista \\
\hline 13 & 38 & Masculino & Casado & Até $\mathrm{R} \$ 2.000,00$ & Ensino Médio & 21 & 2400 & Moto Fretista \\
\hline 14 & 37 & Masculino & Casado & Até $\mathrm{R} \$ 5.000,00$ & Ensino Fundamental & 19 & 4000 & Moto Fretista \\
\hline 15 & 42 & Masculino & Solteiro & Até $\mathrm{R} \$ 5.000,00$ & Ensino Fundamental & 22 & 3700 & Moto Fretista \\
\hline 16 & 37 & Masculino & Solteiro & Até $\mathrm{R} \$ 2.000,00$ & Ensino Médio & 24 & 7500 & Moto Fretista \\
\hline 17 & 36 & Masculino & Divorciado & Até $\mathrm{R} \$ 5.000,00$ & Ensino Fundamental & 18 & 4000 & Moto Fretista \\
\hline 18 & 43 & Masculino & Solteiro & Até $\mathrm{R} \$ 5.000,00$ & Ensino Médio & 25 & 5000 & Moto Fretista \\
\hline 19 & 41 & Masculino & Casado & Até $R \$ 5.000,00$ & Superior Incompleto & 24 & 5000 & Moto Fretista \\
\hline 20 & 30 & Masculino & Casado & Até $\mathrm{R} \$ 5.000,00$ & Ensino Médio & 12 & 5000 & Moto Fretista \\
\hline 21 & 33 & Masculino & Casado & Até $\mathrm{R} \$ 10.000,00$ & Superior Incompleto & 19 & 300 & Lazer \\
\hline 22 & 42 & Masculino & Casado & Acima de $\mathrm{R} \$ 10.000,00$ & Superior Completo & 28 & 450 & Lazer \\
\hline 23 & 51 & Masculino & Casado & Acima de $R \$ 10.000,00$ & Superior Completo & 39 & 250 & Lazer \\
\hline 24 & 36 & Masculino & Casado & Até $\mathrm{R} \$ 10.000,00$ & Superior Completo & 8 & 150 & Lazer \\
\hline 25 & 49 & Masculino & Casado & Acima de $R \$ 10.000,00$ & Superior Completo & 35 & 250 & Lazer \\
\hline 26 & 32 & Masculino & Solteiro & Até $\mathrm{R} \$ 10.000,00$ & Superior Completo & 1 & 0 & Lazer \\
\hline 27 & 24 & Masculino & Solteiro & Até $\mathrm{R} \$ 10.000,00$ & Superior Completo & 4 & 150 & Lazer \\
\hline 28 & 28 & Masculino & Solteiro & Até $\mathrm{R} \$ 5.000,00$ & Superior Completo & 10 & 700 & Lazer \\
\hline 29 & 65 & Masculino & Casado & Acima de $\mathrm{R} \$ 10.000,00$ & Superior Incompleto & 46 & 500 & Lazer \\
\hline 30 & 47 & Masculino & Casado & Acima de $R \$ 10.000,00$ & Superior Completo & 27 & 500 & Lazer \\
\hline
\end{tabular}

Fonte: Autor

\subsubsection{Metodologia Aplicada para Cálculo da Força Vertical na Roda Dianteira}

A partir dos estudos apresentados por Gorges, Öztürk e Liebich, (2017), verifica-se a possibilidade de se calcular a força nas rodas do veículo a partir de dados coletados da rede de bordo (CAN) e demais sensores conectados diretamente a um armazenador de dados instalado na motocicleta. $\mathrm{O}$ modelo de cálculo proposto pelos pesquisadores sugere que a força total nas 
rodas pode ser calculada através de suas respectivas decomposições nos 3 eixos (X, Y e Z), sendo que após obtenção dos valores individuais, a força total resultante pode ser calculada.

Conforme apresentado pelos estudos relacionados a fadiga com posterior contagem de ciclos Rainflow (vide seção 4.7.3), interessar-se-á neste momento somente na força vertical da roda dianteira denominada $F_{Z, f}$, que posteriormente, será utilizada para que o pseudo dano, amplitude equivalente e intervalo de confiança associado ao quociente de severidade média possam ser calculados para cada classe de condutores. Para que isso seja possível, deve-se então compreender quais são as componentes da força vertical na roda dianteira e quais são os parâmetros necessários para que elas possam ser calculadas a partir das grandezas aferidas durante a pilotagem da motocicleta.

A partir de um diagrama de corpo livre, aplicado ao veículo instrumentado, verifica-se um total de 5 forças relevantes para o cálculo da força vertical no eixo dianteiro. Tais grandezas estão ilustradas na Figura 50 e serão discutidas individualmente a seguir. Na figura, identificase em cor verde os dados obtidos através de parâmetros construtivos do veículo, tais como

$$
\begin{aligned}
& h_{c g} \rightarrow \text { posição vertical do centro de massa do veículo [m] } \\
& l_{c g} \rightarrow \text { posição horizontal do centro de massa do veículo [m] } \\
& p \rightarrow \text { distância entre eixos [m] }
\end{aligned}
$$

Figura 50 - Diagrama de corpo livre para cálculo da força na roda dianteira

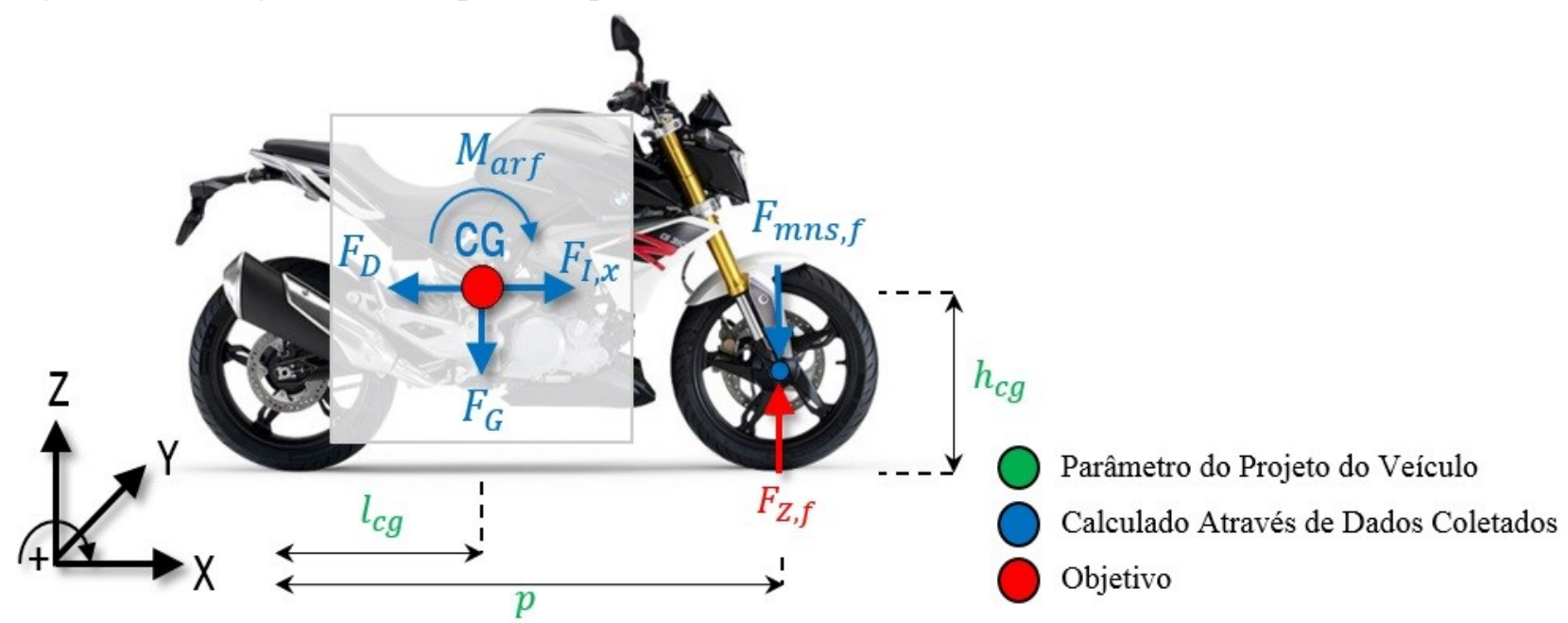

Fonte: Autor “adaptado de” Gorges, Öztürk e Liebich, (2017)

Em azul, ilustram-se as forças calculadas a partir dos dados coletados junto a rede de bordo e outros sensores instalados no veículo, sendo que tais forças podem ser descritas como 
$F_{G} \rightarrow$ Força de gravidade aplicada no centro de massa do veículo [N]

$$
\boldsymbol{F}_{\boldsymbol{G}}=m_{v e h}\left(a_{v e h, z}^{C G}+g\right)
$$

$F_{D} \rightarrow$ Força aerodinâmica aplicada no centro de pressão do veículo ${ }^{1}[\mathrm{~N}]$

$$
\boldsymbol{F}_{\boldsymbol{D}}=\frac{1}{2} \rho c_{x} A v_{v e h}^{2}
$$

$F_{I, x} \rightarrow$ Força de inércia (em relação a $\mathrm{X}$ ) aplicada no centro de massa do veículo [N]

$$
\boldsymbol{F}_{\boldsymbol{I}, \boldsymbol{x}}=-m_{v e h} a_{v e h, x}^{C G}
$$

$M_{\text {arf }} \rightarrow$ Momento de arfagem (rolagem longitudinal) aplicado no centro de massa do veículo [N.m]

$$
\boldsymbol{M}_{\text {arf }}=I_{v e h, y y} \dot{\omega}_{v e h, y}
$$

$F_{m n s, f} \rightarrow$ Força da massa não suspensa do conjunto dianteiro, aplicado no eixo [N].

$$
\boldsymbol{F}_{\boldsymbol{m n s}, f}=m_{n s, f} \ddot{S}_{\text {roda,diant }}
$$

De forma a facilitar o entendimento, agrupam-se os produtos das fórmulas descritas anteriormente em uma tabela, para que então um olhar mais detalhado a respeito das grandezas e suas respectivas unidades seja executado. Além disso, apresenta-se na Tabela 3, a origem de cada um dos dados, para que o leitor compreenda como que tal grandeza pôde ser adquirida para o cálculo das forças descritas anteriormente.

\footnotetext{
${ }^{1}$ Neste caso adotou-se a posição do centro de pressão coincidente com a posição do centro de gravidade do veículo.
} 
Tabela 3 - Grandezas necessárias para o cálculo da força na roda dianteira

\begin{tabular}{l|c|c|c}
\hline Descrição & Representação & Unidade & Origem \\
\hline Massa do veículo (peso em ordem de marcha) & $m_{v e h}$ & $\mathrm{~kg}$ & Dado de Projeto \\
\hline Aceleração do centro de massa (em relação a Z) & $a_{v e h, z}^{C G}$ & $\mathrm{~m} / \mathrm{s}^{2}$ & $\begin{array}{c}\text { Rede de Bordo } \\
\text { (sensor instalado) }\end{array}$ \\
\hline Aceleração do centro de massa (em relação a X) & $a_{v e h, x}^{C G}$ & $\mathrm{~m} / \mathrm{s}^{2}$ & $\begin{array}{c}\text { Rede de Bordo } \\
\text { (sensor instalado) }\end{array}$ \\
\hline Aceleração da gravidade & $g$ & $\mathrm{~m} / \mathrm{s}^{2}$ & - \\
\hline Densidade do ar & $\rho$ & $\mathrm{kg} / \mathrm{m}^{3}$ & - \\
\hline Coeficiente de arrasto aerodinâmico & $c_{x} A$ & $\mathrm{~m}^{2}$ & Dado de Projeto \\
\hline Velocidade do veículo & $v_{v e h}$ & $\mathrm{~km} / \mathrm{h}$ & Rede de Bordo \\
(ABS)
\end{tabular}

Fonte: Autor

Tendo-se em mãos os valores das forças individuais, pode-se então calcular o valor da resultante vertical no eixo dianteiro.

$$
\boldsymbol{F}_{\boldsymbol{Z}, \boldsymbol{f}}=\frac{\boldsymbol{F}_{\boldsymbol{G}} l_{c o g}}{p}-\frac{\boldsymbol{F}_{\boldsymbol{D}} h_{\operatorname{cog}}}{p}+\frac{\boldsymbol{F}_{\boldsymbol{I}, \boldsymbol{x}} h_{\text {cog }}}{p}+\frac{\boldsymbol{M}_{\boldsymbol{a r f}}}{p}+\boldsymbol{F}_{\boldsymbol{m} \boldsymbol{n}, \boldsymbol{f s}} \cos \varphi_{v e h, x}
$$

Sendo que $\varphi_{v e h, x}$, se refere ao ângulo de inclinação da motocicleta em relação ao plano horizontal (X), conforme apresentado na Figura 51. 
Figura 51 - Ângulo de inclinação da motocicleta em relação ao plano horizontal

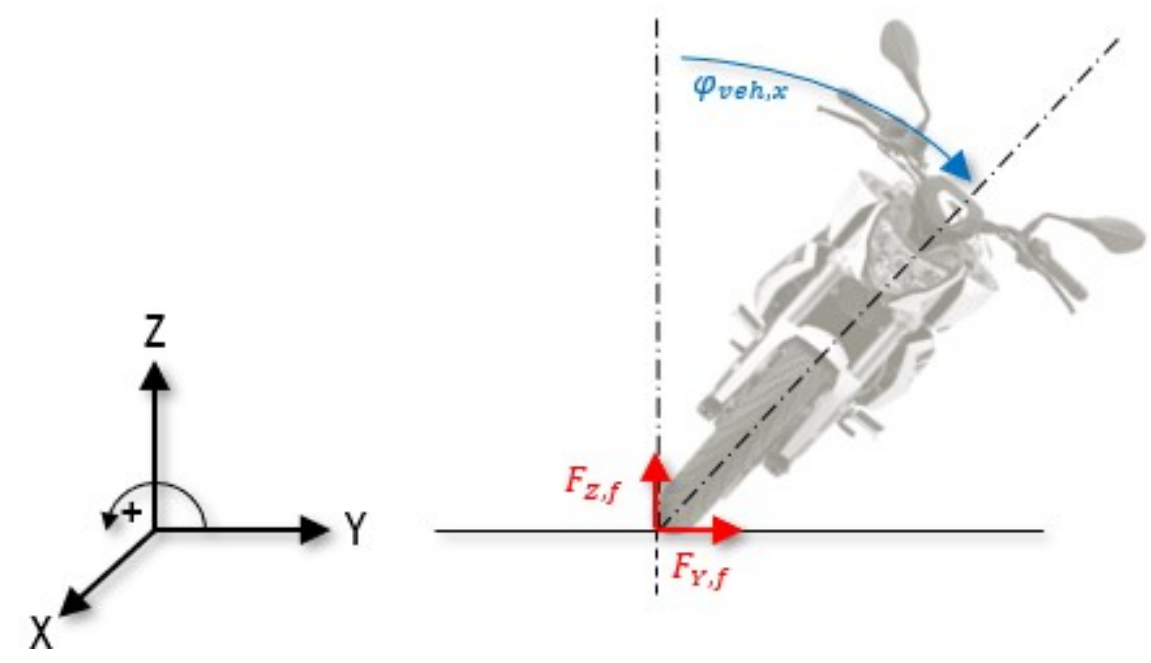

Fonte: Autor “adaptado de" Gorges, Öztürk e Liebich, (2017)

Sabe-se que este ângulo é bastante importante para a descrição da dinâmica veicular de uma motocicleta, sendo denominado por Cossalter (2006) como ângulo de rolagem, capaz de ser calculado através da seguinte expressão:

$$
\varphi_{v e h, x}=\tan ^{-1}\left(\frac{v_{v e h}^{2}}{g R_{c}}\right)+\sin ^{-1} \frac{t \sin \left(\tan ^{-1}\left(\frac{v_{v e h}^{2}}{g R_{c}}\right)\right)}{h_{c g}-t}
$$

em que $R_{c}$ e $t$ podem ser descritos respectivamente como sendo o raio de curvatura do trajeto circular percorrido e o raio da seção transversal do pneu, ambos dados em metros.

Nota-se então, que o ângulo de rolagem é diretamente proporcional ao quadrado da velocidade do veículo, sendo que, em conjunto com o ângulo de esterçamento $\delta$, compõem o principal componente direcional do veículo duas rodas. A Figura 52 ilustra esta composição para o fenômeno de esterçamento de uma motocicleta.

Além destes ângulos, os escorregamentos dos eixos traseiro e dianteiro cumprem papel fundamental para o controle direcional, que conforme apresentado a seguir, pode ser determinado pelo ângulo de esterçamento efetivo $\Delta^{*}$

$$
\Delta^{*} \cong \frac{\cos \varepsilon}{\cos \varphi} \delta+\lambda_{r}+\lambda_{f}
$$


em que $\varepsilon$ representa o ângulo de cáster e $\lambda_{r}, \lambda_{f}$ se referem aos valores de escorregamento para os eixos traseiro e dianteiro, respectivamente.

Figura 52 - Composição do movimento de esterçamento de um veículo de duas rodas

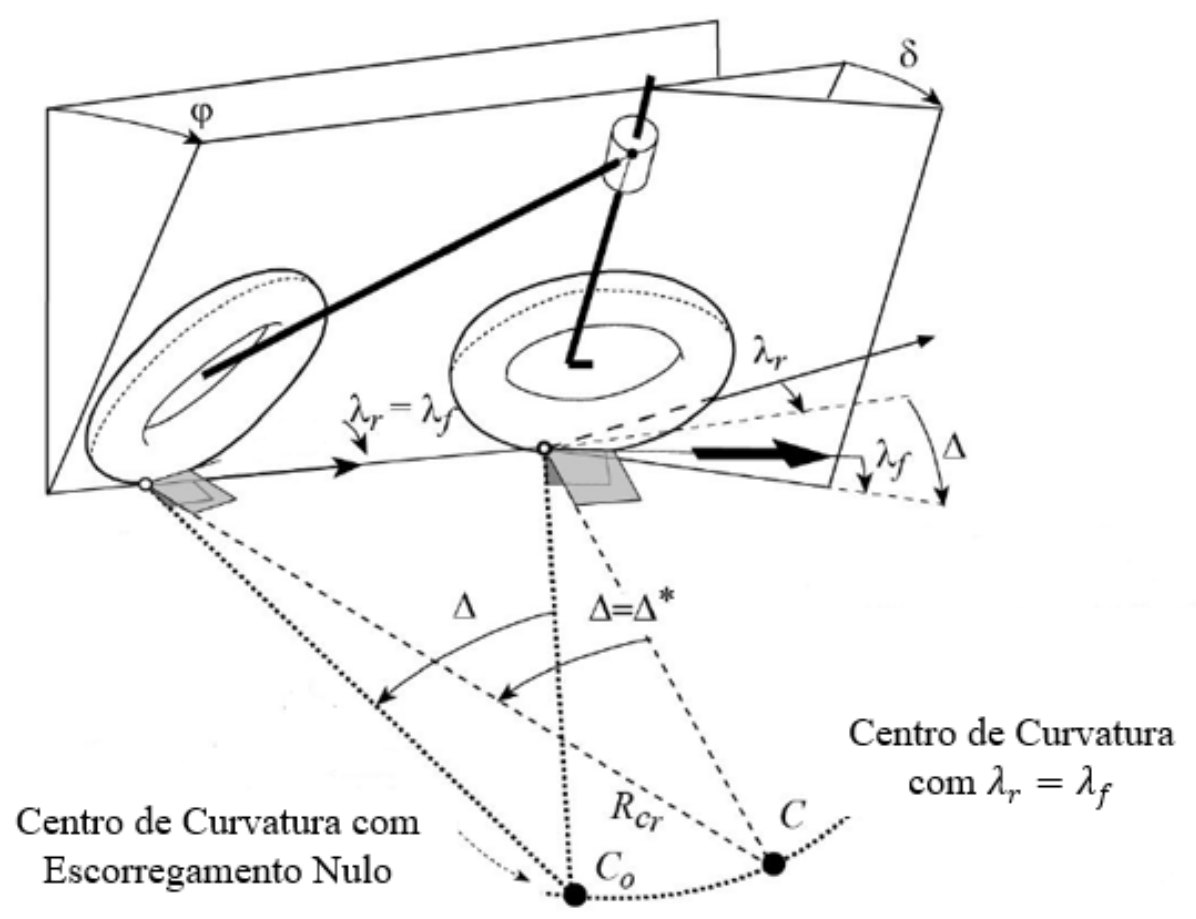

Fonte: Autor "adaptado de" Cossalter, 2006

Para condução do veículo em trajetos urbanos, em que, durante a maior parte do tempo predominam-se as baixas velocidades, entende-se que a magnitude de $\varphi_{v e h, x}$ é bastante pequena quando comparada com $\delta$. Ou seja, em baixas velocidades, entende-se que a contribuição do ângulo de esterçamento para controle direcional do veículo, é significativamente maior do que o ângulo de rolagem.

Partindo desta condição simplificadora, pode-se dizer que quando se avalia a magnitude da força vertical no eixo dianteiro em trajetos urbanos, em que a motocicleta permanece em posição vertical em sua maior parte do tempo, pode-se assumir $\cos \varphi_{v e h, x}=1$, o que torna o valor da força vertical no eixo dianteiro capaz de ser calculado da seguinte maneira:

$$
\boldsymbol{F}_{\boldsymbol{Z}, \boldsymbol{f}}=\frac{\boldsymbol{F}_{\boldsymbol{G}} l_{c o g}}{p}-\frac{\boldsymbol{F}_{\boldsymbol{D}} h_{c o g}}{p}+\frac{\boldsymbol{F}_{\boldsymbol{I}, \boldsymbol{x}} h_{c o g}}{p}+\frac{\boldsymbol{M}_{\boldsymbol{a r f}}}{p}+\boldsymbol{F}_{\boldsymbol{m} \boldsymbol{n}, \boldsymbol{f} \boldsymbol{s}}
$$




\section{RESULTADOS E ANÁLISES}

A partir da coleta dos dados, avaliações preliminares foram desenvolvidas com o objetivo de se observar os sinais de saída do data logger. Os dados foram colhidos através de um sistema de aquisição de dados Weber Technologies, desenvolvido especificamente para o sistema aplicado ao veículo em estudo. A transferência dos arquivos do sistema de aquisição para a estação de trabalho foi feita através de rede wi-fi, em que todos os dados gravados durante uma sessão de medição eram transmitidos rapidamente para a estação de trabalho e posteriormente importados para o ambiente MATLAB ${ }^{\circledR}$.

Após análises preliminares, os dados referentes as velocidades e perfil de utilização do acelerador da motocicleta foram avaliados através de dois algoritmos (Apêndices B e C). Em seguida, um novo algoritmo para a execução dos cálculos propostos pelo modelo ilustrado na seção 5.1 .5 foi então desenvolvido, (Apêndice D), com o intuito de se calcular o valor da força vertical na roda dianteira em função do tempo. Após esta etapa, a metodologia para a contagem de ciclos Rainflow, conforme descrito na seção 4.7.4, foi implementada. Por fim, as estratégias de comparação do pseudo dano e amplitude equivalente dos carregamentos aferidos para as diferentes amostras da população foi executada. O objetivo, foi o de se obter conclusões sobre a influência dos diferentes perfis de condução em estudo, junto aos parâmetros de durabilidade do veículo instrumentado, tomando como componente de referência, o eixo dianteiro.

\subsection{PRIMEIRAS CONSTATAÇÕES}

A seguir, apresentam-se as primeiras avaliações realizadas após a importação dos dados para o ambiente computacional, sendo que neste momento, discorrer-se-á sobre uma verificação preliminar desenvolvida para se determinar as possíveis diferenças entre os perfís de condução observados. Esta análise foi desenvolvida com base nas seguintes variáveis:

a) Tempo gasto pelos pilotos para conclusão do percurso;

b) Velocidade instantânea e velocidade média da motocicleta durante a execução do percurso padrão;

c) Porcentagem de abertura do acelerador adotada pelos pilotos durante a execução do percurso. 
$\mathrm{O}$ interesse em avaliar essas grandezas e o motivo pelo qual elas foram escolhidas para serão devidamente apresentados a seguir.

\subsubsection{Tempo Gasto Para Conclusão do Percurso}

De acordo com Reiser et al. (2008), pesquisas executadas entre condutores com o intuito de se avaliar as diferenças entre os perfis de condução, indicaram que o tempo gasto para percorrer um determinado percurso especifico é uma das variáveis mais significativas para que a distinção entre os perfis de condução de um determinado grupo de condutores possa ser executada.

Desta maneira, sabendo que as condições de tráfego foram praticamente as mesmas para os pilotos participantes da pesquisa, o tempo gasto por eles durante a execução do percurso padronizado foi o primeiro ponto avaliado, sendo que com os valores disponíveis adquiridos para cada condutor, construiu-se o gráfico ilustrado na Figura 53.

A figura reflete o comportamento esperado pelo pesquisador, uma vez que o gráfico demonstrou que a classe dos motofretistas apresentou os menores valores registrados, enquanto a classe dos condutores que utilizam a motocicleta durante o lazer, foi a que apresentou os maiores. Tal presunção pôde ser elaborada uma vez que conforme descrito por Forcetto (2016), a classe de trabalhadores que utiliza a motocicleta como meio de locomoção em centros urbanos, popularmente denominado como "motoboys", apresenta um tipo de pilotagem agressiva.

Um ponto importante que deve ser avaliado para determinar este tipo de perfil, é a forma de contrato de trabalho que rege a remuneração deste tipo de profissional, em que além da remuneração fixa, um valor adicional é pago por entrega realizada. Isso incentiva o motofretistas a realizar o maior número de entregas possível durante sua jornada de trabalho, fomentando seu rápido deslocamento.

Apesar de tal modalidade de remuneração não ser aplicada a todos os profissionais desta classe, os dados apontam que dos 10 pilotos mais rápidos, 7 eram motofretistas. Levando em consideração que as condições de tráfego eram as mesmas para todos os condutores participantes da pesquisa, reforça-se a percepção de que a população de motofretistas tende a se deslocar de forma mais rápida que as demais. Tal fato motiva ainda mais a avaliação das influências deste determinado perfil de condução frente aos parâmetros de durabilidade do veículo. 
Figura 53 - Tempo gasto pelos pilotos de cada classe durante a execução do percurso

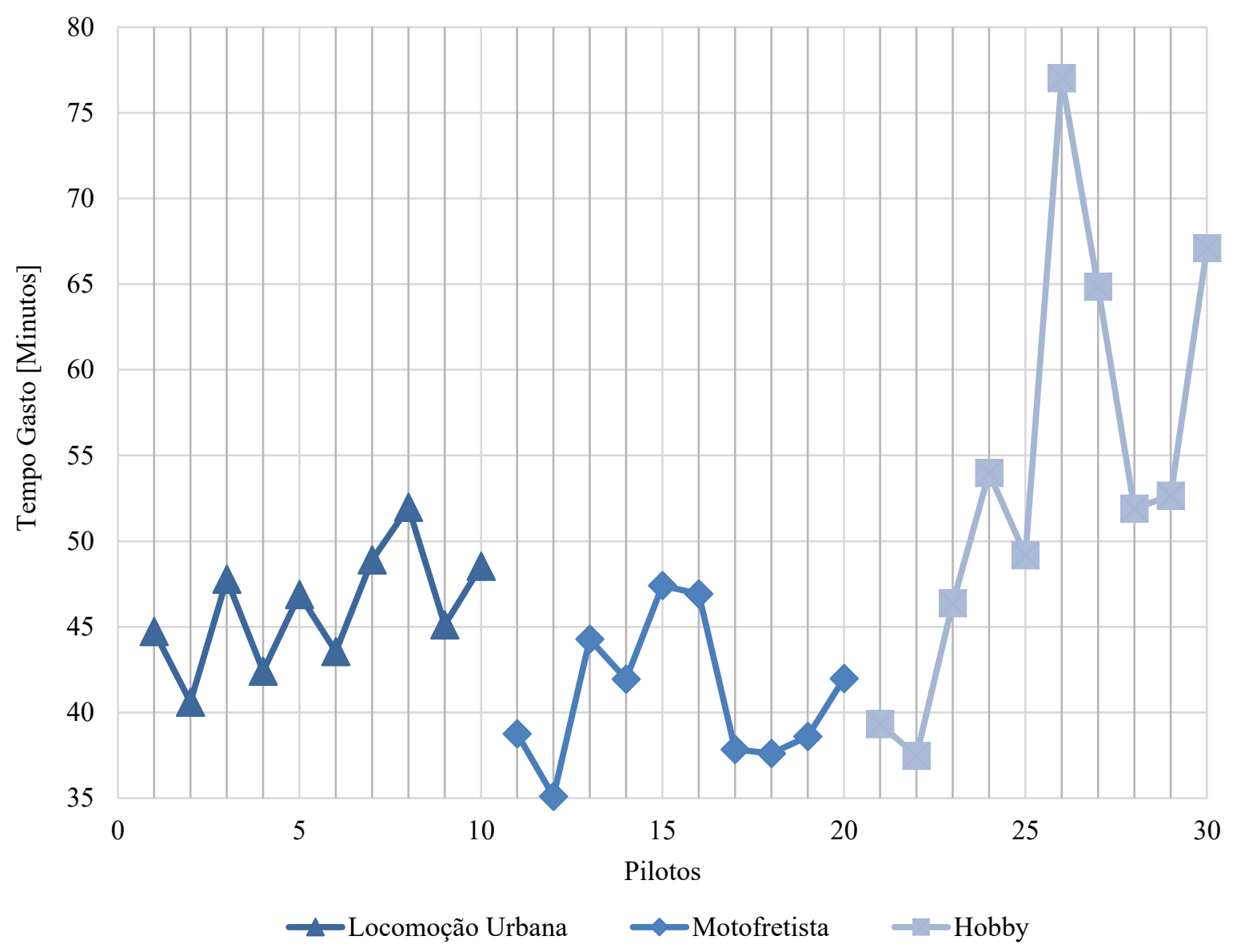

Fonte: Autor

Agrupando-se os dados referentes ao tempo gasto por cada condutor de acordo com sua respectiva amostra, verifica-se uma certa aproximação dos valores entre as classes dos condutores que fazem uso da motocicleta como meio de locomoção urbana e a dos motofretistas. Tal aproximação pode ser verificada através dos valores obtidos para a média e desvio padrão destes grupos, conforme apresentado na Figura 54. 
Figura 54 - Valores das médias e desvios padrão para o tempo gasto pelos pilotos de cada classe

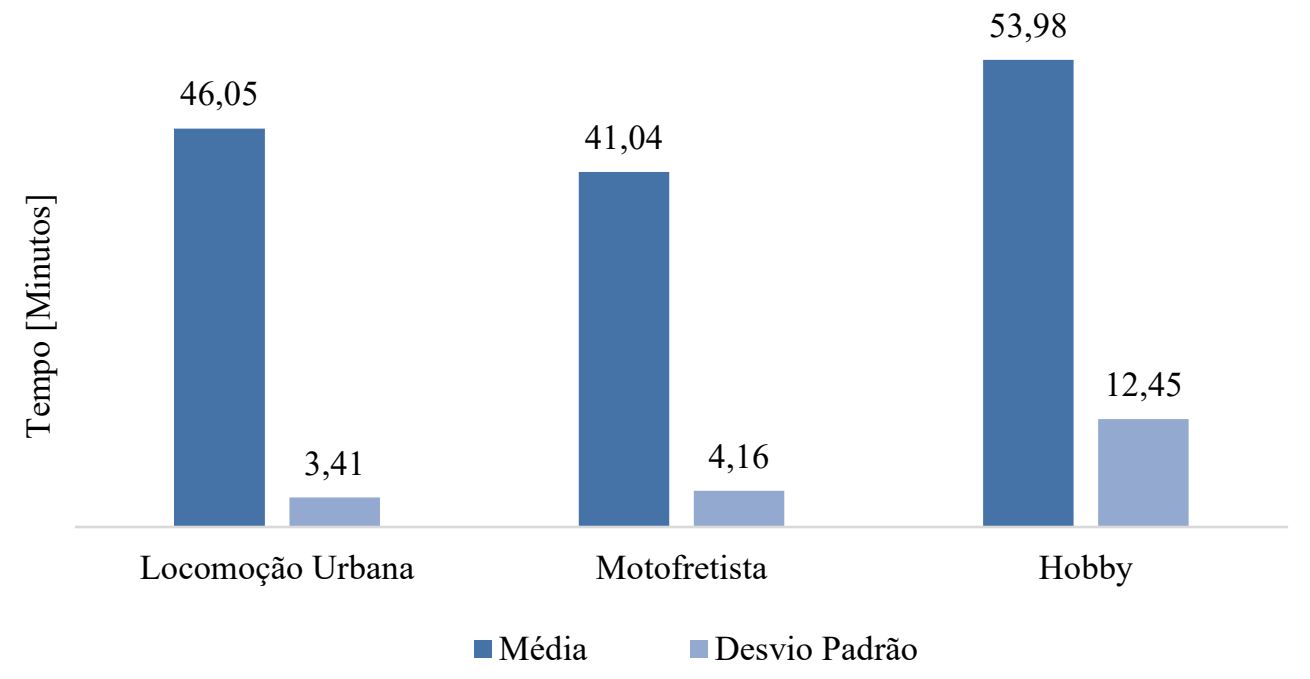

Fonte: Autor

Além dos valores das médias, chama-se a atenção para a diferença observada entre o valor do desvio padrão do grupo de motociclistas que utilizam o veículo de duas rodas como objeto de lazer e os demais. Isso pode ser explicado uma vez que conforme ilustrado na Figura 53, observou-se uma grande dispersão dos valores aferidos para os pilotos desta classe. Como exemplo, mencionam-se os tempos gastos pelos pilotos 22 e 26 conforme exposto na Tabela 4, sendo que neste momento, observa-se também o tempo de experiência (em anos) de cada um deles.

Tabela 4 - Valores para o tempo gasto pelos pilotos 22 e 26 e sua relação com o tempo de experiência dos condutores

\begin{tabular}{c|c|c}
\hline Piloto & Tempo Gasto & Anos de Experiência \\
\hline 22 & 37 Minutos & 28 \\
\hline 26 & 77 Minutos & 1 \\
\hline
\end{tabular}

Fonte: Autor

Durante uma análise preliminar, a associação entre o tempo gasto por condutor e seu respectivo tempo de experiência de condução parece ser bastante sensata, entretanto, percebese que na verdade este não deve ser o único ponto a ser observado, uma vez que conforme dados da Figura 53, o piloto 11 foi capaz de concluir o trajeto em cerca de 40 minutos mesmo tendo metade do tempo de experiência do que o piloto 22 . 


\subsubsection{Velocidade do Veículo e Porcentagem de Abertura do Acelerador}

Conforme apontado por ISO (2009), desde meados dos anos 1990, a Associação Internacional de Fabricantes de Motocicletas (IMMA) vem colhendo dados associados aos padrões de pilotagem de motocicletas ao redor do mundo, com o intuito de se verificar a dinâmica de condução dos veículos de duas rodas e o comportamento de pilotagem adotado por diferentes pilotos de diversas regiões. Estudos como estes deram origem a uma série de análises cientificas, sendo que uma delas, instituiu o World Motorcycle Exhaust Emission Test Cycle (WMTC), padrão de ciclos de condução normalmente aplicado em dinamômetros para aferição do consumo de combustível e emissão de gases poluentes por uma determinada motocicleta. Vale ressaltar que hoje em dia, este tipo de padrão é utilizado durante o processo de análise de emissões de gases de escapamento, utilizado durante o processo de homologação ambiental de motocicletas para o mercado nacional segundo norma NBR 16369 (ABNT, 2017).

Posteriormente, entre 2002 e 2005, ISO (2009) menciona que novos estudos foram desenvolvidos com o intuito de se ampliar a base de dados vinculados aos diferentes padrões de pilotagem. Estas novas pesquisas, envolvendo um total de 22.210 quilômetros percorridos por 43 veículos (11 na Europa, 5 nos Estados Unidos e 27 na Ásia), comprovaram junto a indústria automotiva do segmento de motocicletas em conjunto com as autoridades competentes, a necessidade de revisar o procedimento que até então normalizava os testes para aferição do ruído de passagem emitido por motocicletas. Até então, este tipo de teste era feito em $2^{a}$ e $3^{a}$ marchas ou somente $3^{a}$, enquanto o veículo era conduzido com aceleração total. De acordo com o documento, a principal deficiência deste tipo de teste se relacionava com a incapacidade de simular o perfil real de utilização de motocicletas, uma vez que de acordo com os dados colhidos aos longos dos anos, durante a grande maioria do tempo, motos são conduzidas em regime de aceleração parcial e não aceleração total.

Desta forma, a revisão proposta por ISO (2009) foi desenvolvida com o intuito de aprimorar a metodologia de ensaio de ruído de passagem, aperfeiçoando a metodologia dos testes, de forma que os mesmos pudessem melhor representar a forma com que a maioria dos condutores de motocicletas a nível mundial costumam operar este tipo de veículo durante a maior parte do tempo. Assim, a nova metodologia que passou a alicerçar a execução de testes de ruído de passagem, se baseou nas seguintes principais premissas elementares:

a) Além da aferição do ruído em aceleração total, o ruído em velocidade constante deve ser aferido. Após se obter ambos os resultados, uma média ponderada deve 
ser calculada para determinação do valor referente ao ruído combinado emitido pela motocicleta ensaiada;

b) A velocidade de aferição para o teste em velocidade constante deve variar entre $40 \mathrm{~km} / \mathrm{h}$ para motocicletas cujo $\mathrm{PMR}^{2}$ é menor ou igual 50 e $50 \mathrm{~km} / \mathrm{h}$ para motocicletas cujo PMR é maior que 50, velocidades estas, que segundo a fonte aqui citada, melhor representam a realidade de utilização em centros urbanos.

No Brasil, até a presente data, este procedimento que leva em consideração a ponderação entre o ruído de passagem em regime de aceleração total e velocidade constante não é adotado. Hoje em dia, os testes para aferição do ruído de passagem para fins de homologação ambiental de motocicletas, são baseados na norma NBR 15145, que segundo ABNT (2004), prevê a aferição do ruído de passagem somente quando o veículo está sendo conduzido em regime de aceleração total em $2^{\mathrm{a}}$ e $3^{\mathrm{a}}$ marchas ou somente em $3^{\mathrm{a}}$.

Uma vez que o Brasil não foi incluído nos estudos executados por ISO (2009), conforme apresentado anteriormente, não se é possível documentar tecnicamente que a realidade em territórios urbanos nacionais se assemelha com o que foi determinado nos estudos previamente mencionados, sendo portanto, de interesse da indústria e das autoridades competentes, compreender melhor como de fato o condutor brasileiro conduz motocicletas em centros urbanos, e se realmente nossa realidade se aproxima ou se afasta dos dados referentes as pesquisas até aqui mencionadas.

Assim sendo, uma avaliação dos diferentes perfis de condutores, baseada na velocidade de deslocamento urbano e perfil de utilização do acelerador se faz necessária.

\subsubsection{Velocidade Instantânea Durante a Execução do Percurso}

De forma análoga ao tempo gasto para execução do percurso, a velocidade instantânea adotada pelos pilotos das três classes durante a condução também foi analisada. $O$ intuito foi o de se documentar as percepções observadas durante a coleta de dados, sendo que para isso, foram desenvolvidos diagramas de caixa, ou boxplots, para que os valores dos sinais colhidos pudessem ser facilmente interpretados.

Assim como aqueles já ilustrados pela Figura 25, os diagramas de caixa, conforme sugere Montgomery (2017), são muito uteis para ilustrar dados. Com este tipo de ferramenta

\footnotetext{
${ }^{2}$ Do inglês, Power-to-Mass Ratio, em que, $P M R=\frac{\text { potência do motor }[\mathrm{kW}]}{\text { massa de teste }[\mathrm{kg}]} .1000$
} 
pode-se demonstrar em uma só figura os seguintes valores referentes a um determinado conjunto de dados:

a) $1^{\mathrm{o}}$ quartil: Identifica que, $25 \%$ das observações estão abaixo deste valor;

b) $2^{\circ}$ quartil: ou mediana: Identifica que, $50 \%$ das observações estão abaixo e acima deste valor;

c) $3^{\circ}$ quartil: Identifica que, $75 \%$ das observações estão abaixo deste valor;

d) Pontos discrepantes: Mensurações que de acordo com a maioria do conjunto de dados não segue o mesmo padrão dos demais dados plotados;

e) Haste inferior: Valor mínimo da amostra removendo-se os pontos discrepantes;

f) Haste superior: Valor máximo da amostra removendo-se os pontos discrepantes.

Desta maneira, a partir da compilação dos dados colhidos em campo para a velocidade instantânea adotada durante a realização do percurso pelos 30 pilotos envolvidos na pesquisa, desenvolve-se um diagrama de caixa conforme exposto na Figura 55. Para construção do diagrama, todos os dados de velocidade inferiores a $1 \mathrm{~km} / \mathrm{h}$ foram eliminados.

Figura 55 - Diagrama de caixa para os dados de velocidade instantânea adotada pelo conjunto dos 30 pilotos

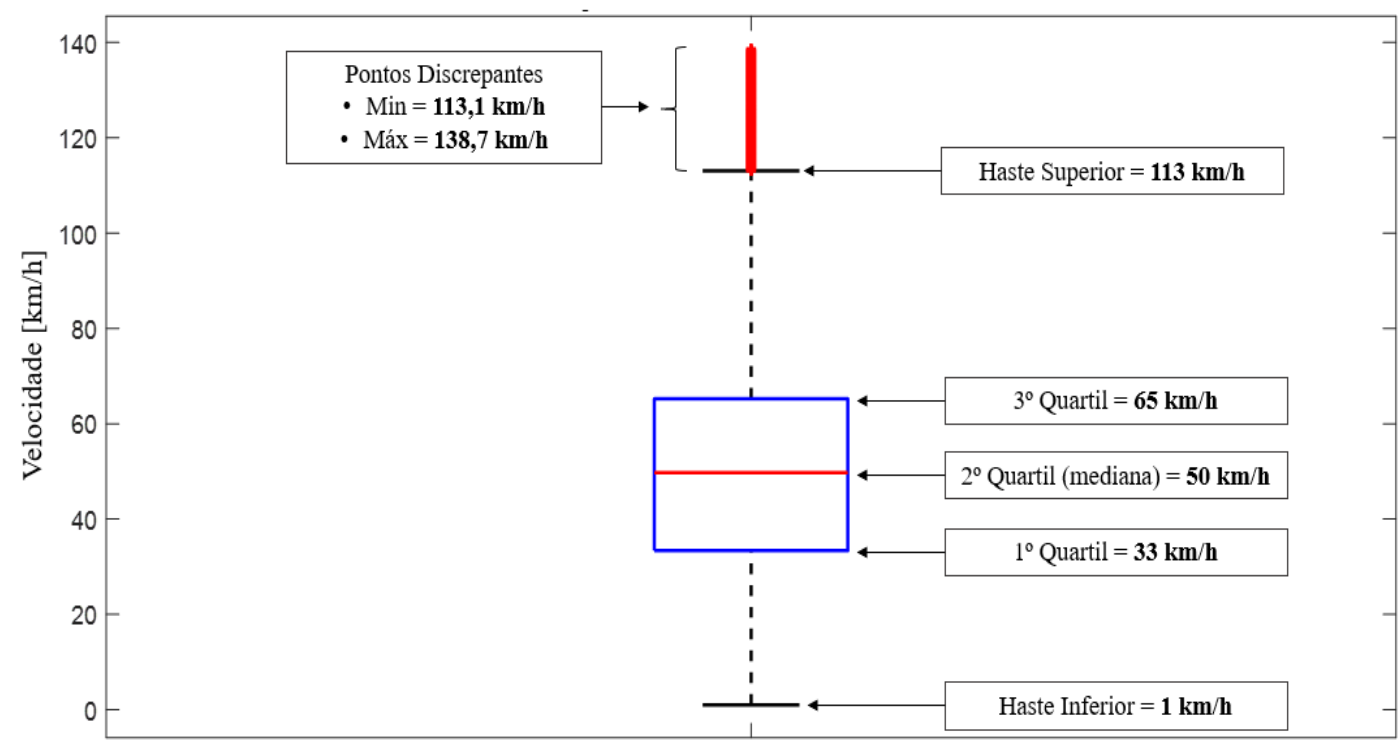

Fonte: Autor

A partir da interpretação da figura anterior, verifica-se em um primeiro momento que a mediana (ou ponto médio) dos dados associados as velocidades instantâneas adotadas pelos 
pilotos durante a execução do percurso foi de $50 \mathrm{~km} / \mathrm{h}$. Tal fato, demonstra uma possível afinidade com os estudos apresentados em ISO (2009), que propõem que em centros urbanos, locais estes que ocorre uma maior proximidade entre veículos e pessoas, a velocidade percorrida por motocicletas do mesmo porte da utilizada no presente estudo, na maior parte do tempo, deve ser próxima a faixa dos $50 \mathrm{~km} / \mathrm{h}$. Neste momento, destaca-se ainda que conforme apresentado na seção 5.1.3, o trajeto escolhido para aquisição de dados apresentou vias coletoras e arteriais com diferentes limites de velocidade, sendo que em 64\% de sua extensão, tais limites permitiam o deslocamento em velocidades superiores a $50 \mathrm{~km} / \mathrm{h}$.

Entende-se, portanto, que mesmo percorrendo um trajeto que em sua maior extensão permitia a prática da pilotagem em velocidades superiores, a maior parte dos dados obtidos sugeriu uma maior adoção de velocidades próximas a faixa dos $50 \mathrm{~km} / \mathrm{h}$, sugerindo a ocorrência de uma harmonização com outras regiões urbanas conforme apontado por ISO (2009). Entretanto, deseja-se executar um estudo individualizado para cada classe de pilotos, sendo que para tal, extrapola-se a utilização dos diagramas de caixa para os sinais da velocidade instantânea para cada piloto conforme ilustrado na Figura 56. 
Figura 56 - Velocidade instantânea adotada pelos pilotos de cada classe
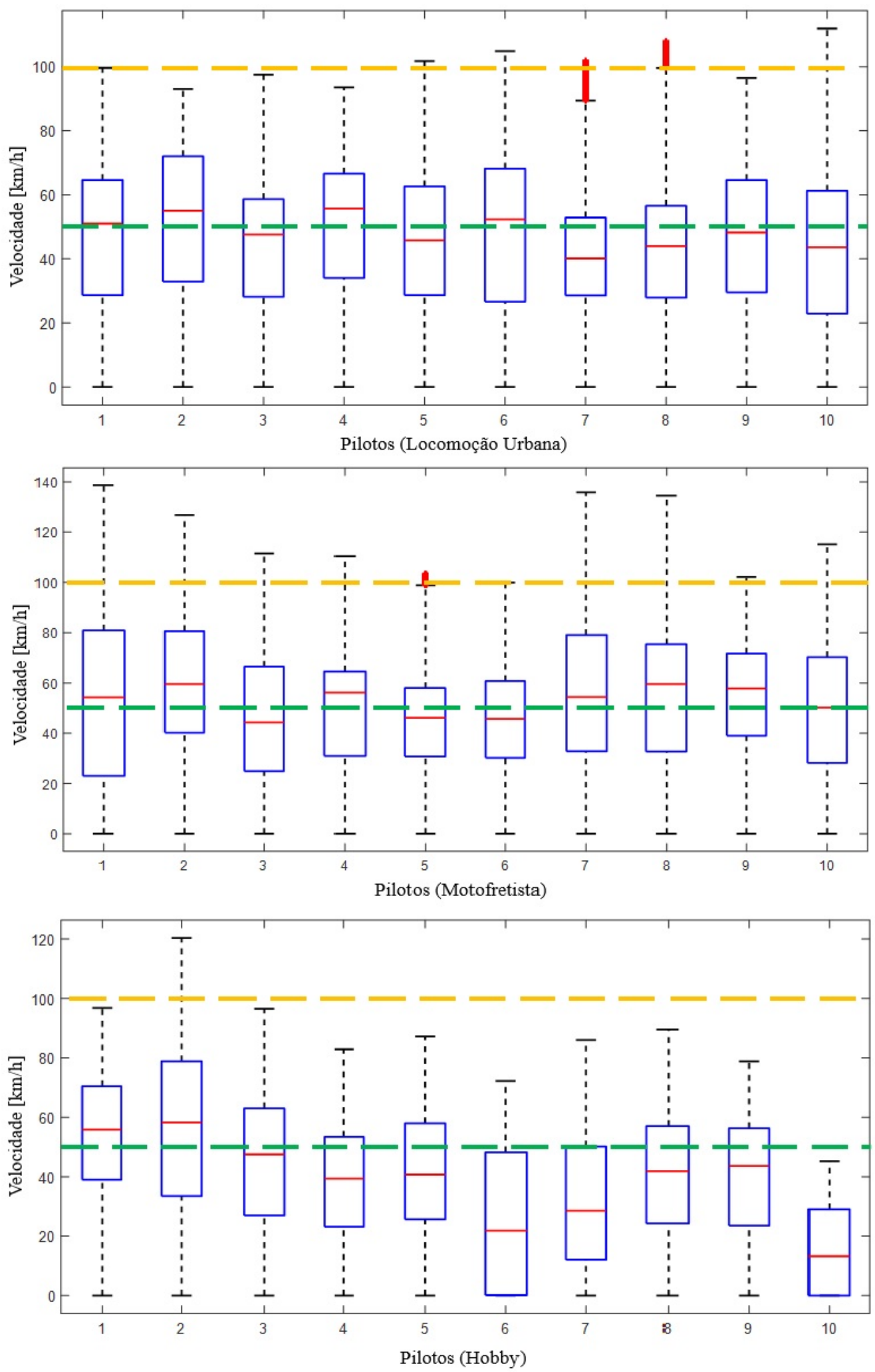

Fonte: Autor 
A partir da análise dos gráficos, verifica-se que pode ocorrer uma diferença no perfil de velocidade adotado pelos três grupos de condutores, sendo que tal suposição, será tratada com maiores detalhes na seção 6.2, em que serão apresentados os testes de hipótese que determinarão se de fato ocorrem diferenças do ponto de vista estatístico junto aos perfis de condução.

Ainda sobre a Figura 56, pontua-se que as linhas tracejadas amarelas e verdes foram posicionadas nos limites de $50 \mathrm{~km} / \mathrm{h}$ e $100 \mathrm{~km} / \mathrm{h}$ respectivamente. Isso foi feito para que fosse possível de se realizar a contagem do número de condutores de cada classe que tiveram a mediana dos valores obtidos acima de $50 \mathrm{~km} / \mathrm{h}$ e velocidade máxima superior a $100 \mathrm{~km} / \mathrm{h}$.

Tabela 5 - Comparação entre os perfis de velocidade de cada classe de condutores

\begin{tabular}{c|c|c|c}
\cline { 2 - 4 } & Locomoção Urbana & Motofretista & Hobby \\
\hline Mediana $>\mathbf{5 0} \mathbf{~ k m} / \mathbf{h}$ & $40 \%$ & $60 \%$ & $20 \%$ \\
\hline Velocidade Máxima $>\mathbf{1 0 0} \mathbf{~ k m / h}$ & $30 \%$ & $80 \%$ & $10 \%$ \\
\hline
\end{tabular}

Fonte: Autor

Supõem-se então que os motofretistas tendem a se deslocar mais rapidamente do que os demais. Os motociclistas que utilizam este tipo de veículo como meio de locomoção, apresentaram grande coesão em relação aos valores verificados para a mediana (próxima de 50 $\mathrm{km} / \mathrm{h}$ ), além disso, uma vez que a maioria das caixas apresentou o mesmo tamanho aproximado, nota-se uma similaridade nos valores de primeiro e último quartis para a velocidade adotada por estes pilotos. Já a classe dos condutores que utilizam a motocicleta como meio de lazer, apresentou a maior variabilidade de perfis, já que blocos de tamanhos diferentes e posicionados de maneira afastada entre si puderam ser encontrados. Tal fato aponta que para este tipo de perfil, podem ocorrer diferentes comportamentos de condução, sugerindo uma maior dificuldade para a determinação da padronização do perfil de velocidade adotada para esta classe.

\subsubsection{Velocidade Média Durante a Execução do Percurso}

De forma a buscar uma segunda forma de avaliação dos dados colhidos para as velocidades, elabora-se uma verificação através da média aritmética das velocidades médias aferidas ao longo do tempo para cada um dos pilotos. De acordo com Jasinski e Baldo (2017), a avaliação dos valores das velocidades médias adotadas por condutores e aferidas através de 
sistemas GPS, se mostram como informações fundamentais durante a construção da avaliação do perfil de condução de veículos. A Figura 57 ilustra os valores das médias das velocidades médias aferidas para cada grupo de condutores com seus respectivos valores de desvio padrão.

Figura 57 - Valores das médias e desvios padrão para a velocidade média dos pilotos de cada classe

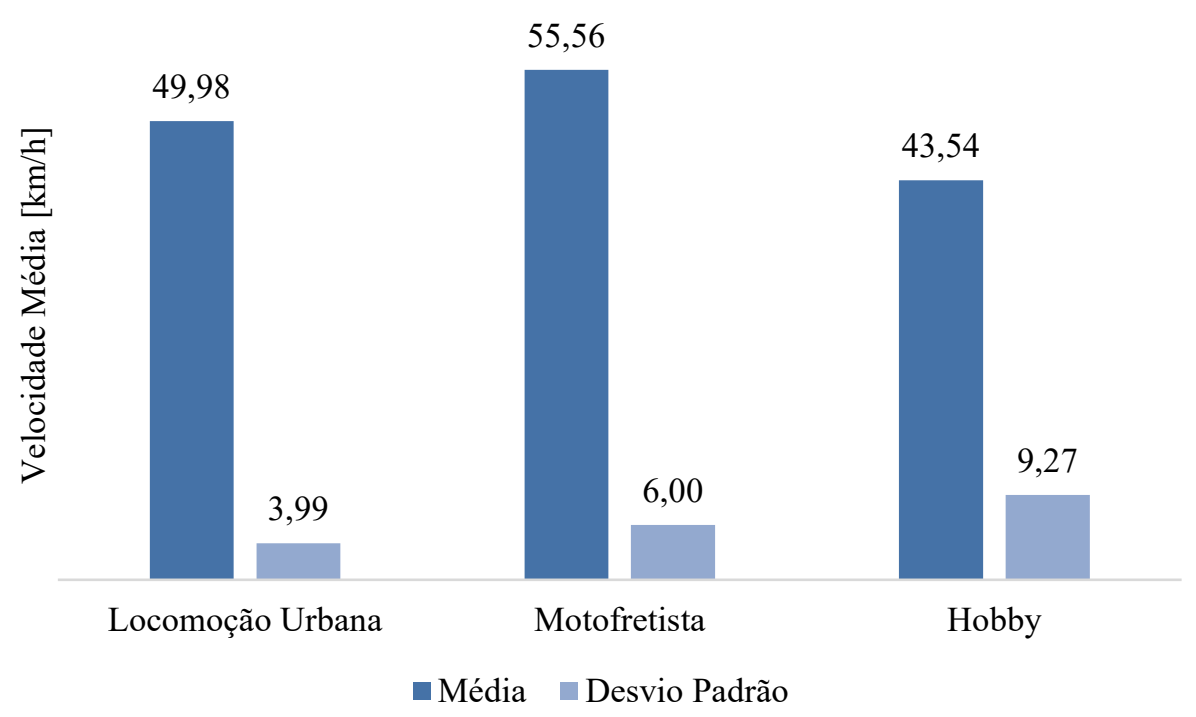

Fonte: Autor

Quando se analisa o valor médio e respectivo desvio padrão das velocidades médias adotadas pelos pilotos das 3 classes envolvidas, percebe-se que tais dados tendem a ratificar o que foi discutido durante as análises dos valores instantâneos e individuais apresentados a partir dos diagramas de caixa.

A partir desta nova análise, pode-se dizer que:

a) As médias ficaram próximas da faixa dos $50 \mathrm{~km} / \mathrm{h}$;

b) A classe dos motofretistas foi aquela que apresentou maior valor absoluto;

c) A classe dos motociclistas que utilizam a motocicleta para locomoção urbana, foi a classe que apresentou menor dispersão na distribuição dos dados (menor desvio padrão);

d) A classe dos motociclistas que utilizam a motocicleta com fins de lazer foi aquela que apresentou menor valor absoluto e maior dispersão de valores em relação a média das velocidades médias (maior desvio padrão). 


\subsubsection{Porcentagem de Abertura do Acelerador}

Segundo Rocha Neto e Menezes Jr. (2016), a forma como o condutor opera o acelerador do veículo deve ser analisada durante o mapeamento do perfil de condução. Isso deve ser feito uma vez que a maneira como o condutor opera o acelerador, pode ter relação com o comportamento daquele determinado indivíduo. Yuen, Karim e Saifizul (2014), também utilizaram os dados obtidos através da leitura do sensor do corpo de borboletas de uma motocicleta, para que o perfil de condução durante a pilotagem em um trajeto curvilíneo fosse determinado.

Através dos dados colhidos em tempo real para o sensor da posição da borboleta do acelerador junto ao veículo em estudo, pode-se, de maneira análoga ao que já foi apresentado para a velocidade do veículo, elaborar um diagrama de caixa para o conjunto de dados referentes aos 30 pilotos. A Figura 58 ilustra este diagrama e aponta que na maior parte do tempo, a porcentagem de abertura da borboleta não superou os $20 \%$. Para desenvolver este diagrama, todos os dados de abertura do acelerador com valores inferiores a $1 \%$ foram eliminados.

Figura 58 - Porcentagem de abertura do acelerador adotada pelo conjunto dos 30 pilotos

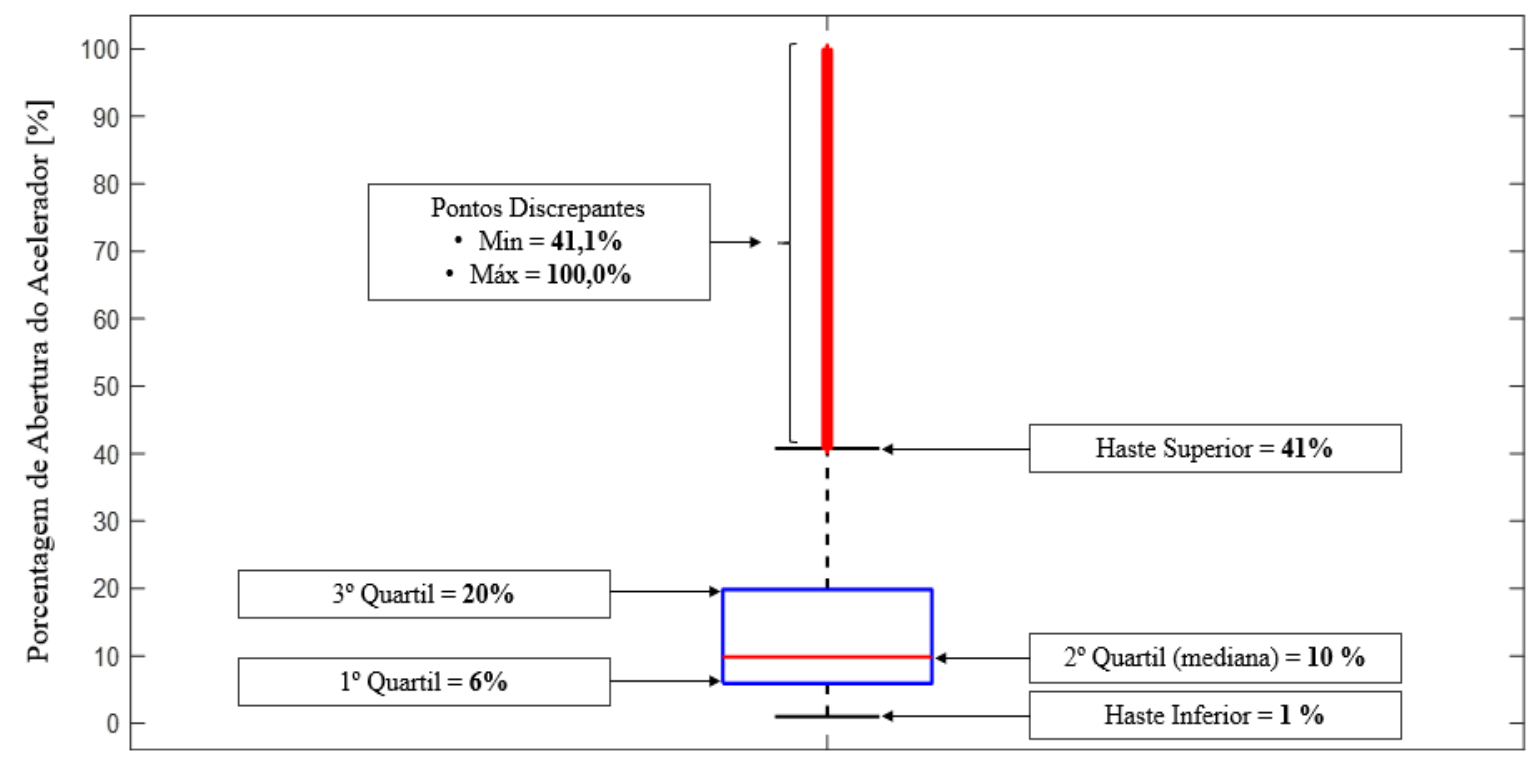

Fonte: Autor

Por conta da quantidade elevada de pontos discrepantes observados durante a análise dos dados associados a leitura do sensor de abertura do acelerador para os 30 pilotos envolvidos, sugere-se que para que uma análise individual, outra ferramenta de visualização dos dados seja utilizada. Aplica-se então o uso de histogramas desenvolvidos por piloto e sua respectiva classe, conforme exposto na Figura 59. 
Figura 59 - Distribuição da porcentagem de abertura do acelerador adotada por cada um dos 30 pilotos durante a execução do percurso
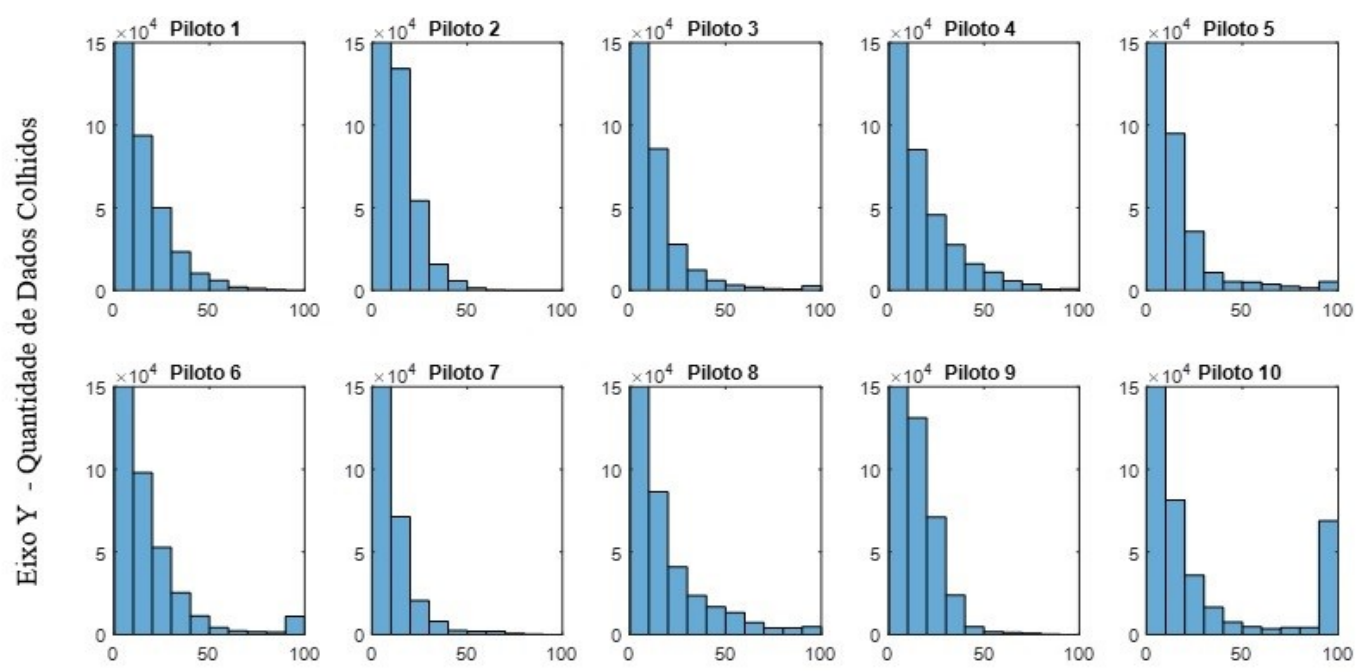

Eixo X - Porcentagem de Abertura do Acelerador [\%] - Pilotos Classe "Locomoção Urbana"
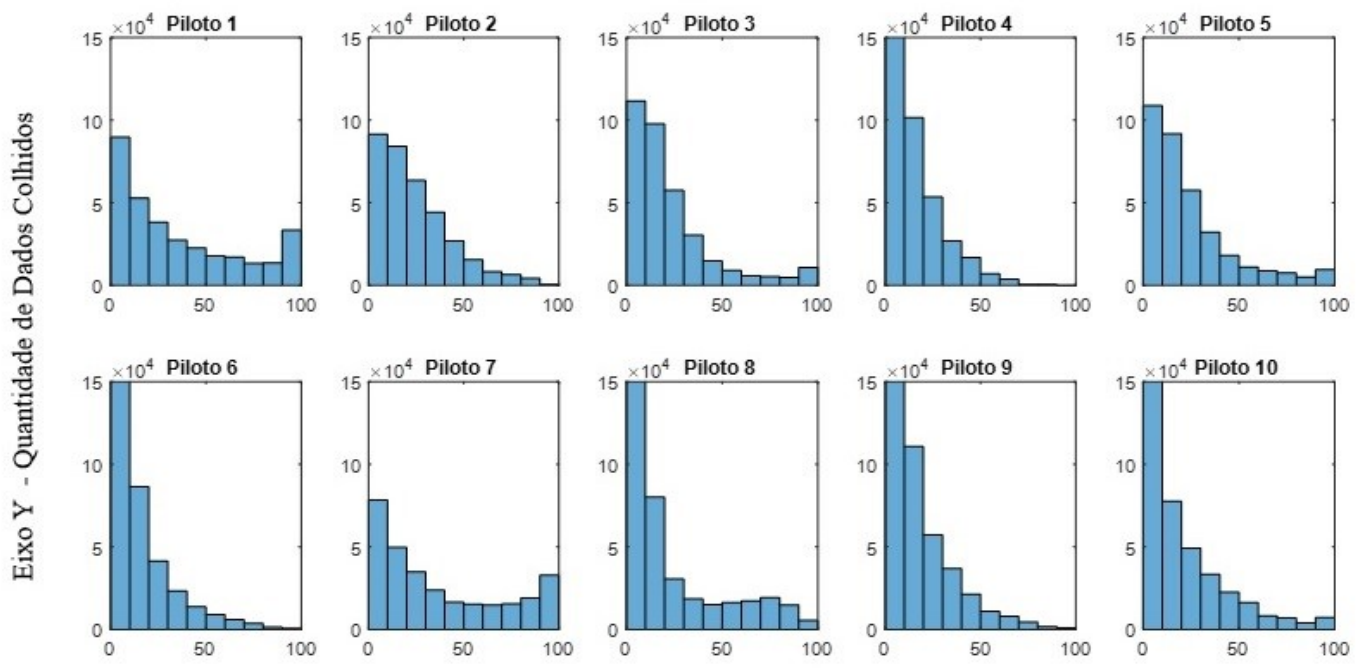

Eixo X - Porcentagem de Abertura do Acelerador [\%] - Pilotos Classe "Motofretista"
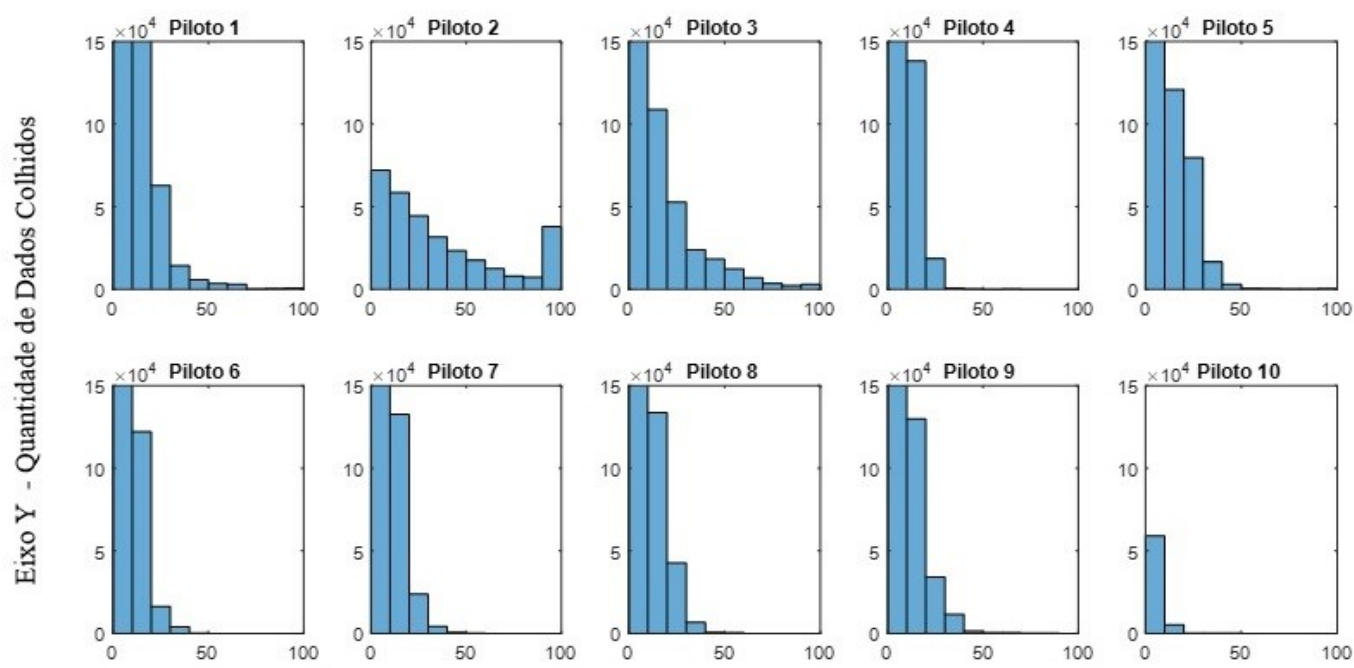

Eixo X - Porcentagem de Abertura do Acelerador [\%] - Pilotos Classe "Hobby"

Fonte: Autor 
Verifica-se, que parece haver uma diferença na quantidade de dados para valores superiores a $50 \%$ de abertura da borboleta do acelerador. Durante uma análise geral dos 30 histogramas, aqueles que estão associados aos condutores da classe "Motofretista" parecem ser aqueles que mais possuem dados para aberturas superiores a $50 \%$, e os condutores da classe "Hobby" os que possuem menos dados para este intervalo.

Figura 60 - Quantidade de dados associados ao intervalo de abertura de borboleta de $50 \%$ a $100 \%$ de acordo com cada classe de condutores
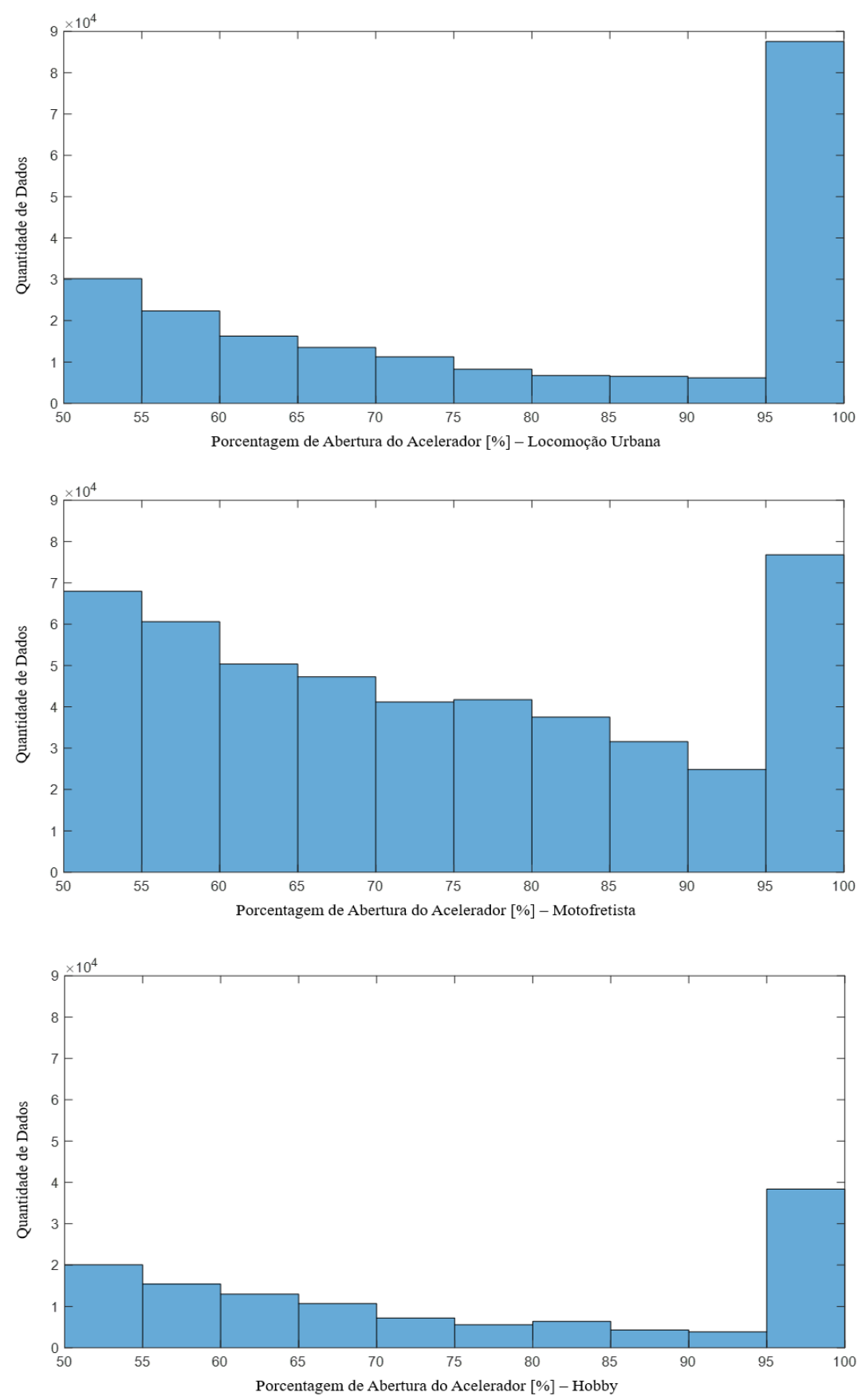

Fonte: Autor 
Para reavaliar esta observação preliminar, executa-se uma nova verificação, agora associada a todos os pilotos dentro de suas respectivas classes, considerando somente o intervalo entre $50 \%$ a $100 \%$ de abertura da borboleta. A Figura 60 ilustra essa verificação e sugere que de fato deve existir diferença significativa na quantidade de dados referentes a abertura da borboleta entre $50 \%$ a $100 \%$ para cada classe avaliada. Para quantificar essa diferença, elabora-se o gráfico ilustrado na Figura 61.

Figura 61 - Quantidade de dados referentes a abertura da borboleta do acelerador de acordo com cada classe em estudo

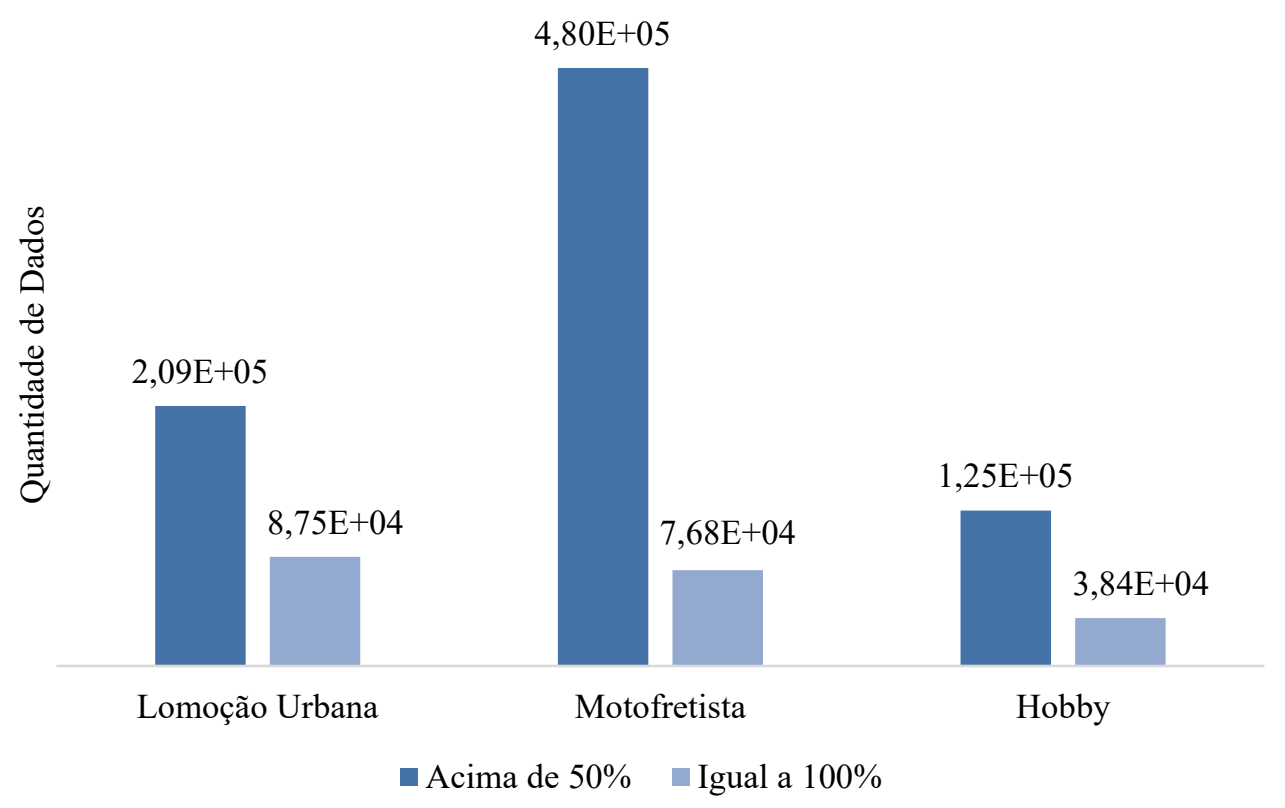

Fonte: Autor

Verifica-se portanto, que os motofretistas fazem o uso do acelerador em regimes de abertura acima de $50 \%$ de forma mais frequente do que os demais condutores. A quantidade de dados chega a ser maior do que o dobro quando se compara os motofretistas com os condutores da classe de "Locomoção Urbana" e quase 4 vezes quando se executa a mesma comparação com os condutores da classe "Hobby".

Não obstante, ressalta-se que os motofretistas não são aqueles que possuem a maioria dos dados para valores de abertura iguais a $100 \%$. Neste quesito, os condutores da classe da "Locomoção Urbana" apresentaram uma superioridade na quantidade dos dados.

Desta maneira, para que uma análise estatística mais abrangente e assertiva sobre as diferenças sobre os perfis de condução seja possível, uma avaliação através de testes de hipóteses se faz necessária. 


\subsection{TESTES DE HIPÓTESES}

De acordo com Montgomery (2017), uma hipótese estatística é uma afirmação feita a partir de parâmetros de uma distribuição de probabilidade ou através de um conjunto de dados de um determinado modelo. De forma prática, os testes de hipóteses são muito úteis para a tomada de decisão durante a avaliação de dados estatísticos colhidos a partir de experimentos.

Para que este tipo de ferramenta possa ser aplicada, determinam-se duas hipóteses, a nula e a alternativa. Para as análises associadas ao presente estudo, determina-se como hipótese nula, a possibilidade das médias aferidas para cada grupo de variáveis apresentadas na seção 6.1 serem iguais, ou seja, parte-se do princípio que todas as classes de condutores possuem os mesmos valores médios para:

a) O tempo gasto para conclusão do percurso;

b) Velocidade média do veículo durante a execução do trajeto;

c) Porcentagem média de abertura do acelerador durante a execução do percurso.

Isso significa que a hipótese nula sugere que o padrão de condução adotado pelos pilotos é igual, sendo que, caso a hipótese nula seja aceita, conclui-se que podem não ocorrer diferenças significativas quanto ao padrão de condução adotado pelos pilotos das diferentes classes avaliadas.

Não obstante, caso a hipótese alternativa seja aceita, verificar-se-á, que haverá diferença entre as médias das grandezas em estudo, o que sinalizará para a ocorrência de diferenças relevantes quanto as médias e consequentemente dos padrões de condução para as classes dos pilotos.

A Tabela 6, resume o método que será aplicado para a execução dos testes de hipóteses para as variáveis mencionadas acima, sendo que para uma maior confiabilidade, um nível de significância de $95 \%(\alpha=0,05)$ será considerado.

Tabela 6 - Método adotado para os testes de hipótese para as variáveis de interesse

\begin{tabular}{l|c}
\hline Hipótese nula & Todas as médias são iguais \\
\hline Hipótese alternativa & Nem todas as médias são iguais \\
\hline Nível de significância & $\alpha=0,05$ \\
\hline
\end{tabular}

Fonte: Autor 
A seguir, ilustrar-se-ão os resultados para os testes de hipótese executados para cada uma das variáveis significativas mencionadas na seção 6.1, sendo que o intuito final, será o de comprovar estatisticamente com $95 \%$ de certeza se de fato os condutores das classes em estudo apresentam ou não padrões de pilotagem diferentes.

\subsubsection{TEMPO DE PERCURSO}

Para o tempo gasto pelos pilotos durante a execução do percurso, elabora-se o gráfico dos intervalos de confiança conforme exposto na Figura 62 e analisam-se as médias e variâncias conforme dados apresentados nas Tabelas 7 e 8, respectivamente, em que n, representa o tamanho da amostra, G.L. os graus de liberdade e S.Q. a soma de quadrados.

Montgomery (2017), sugere que durante a análise de variâncias, o fator mais importante a ser verificado é o valor do parâmetro "P”, que, ao se apresentar como sendo menor do que o índice de significância (neste caso $\alpha=0,05$ ), entende-se que a hipótese nula deve ser rejeitada. Portanto, durante os próximos testes a serem apresentados, dedicar-se-á maior foco para a determinação deste fator, para que a decisão sobre a possibilidade de rejeição da hipótese nula possa ser tomada.

Figura 62 - Valores dos intervalos de confiança (95\%) para o tempo gasto pelos pilotos de cada classe durante a execução do percurso

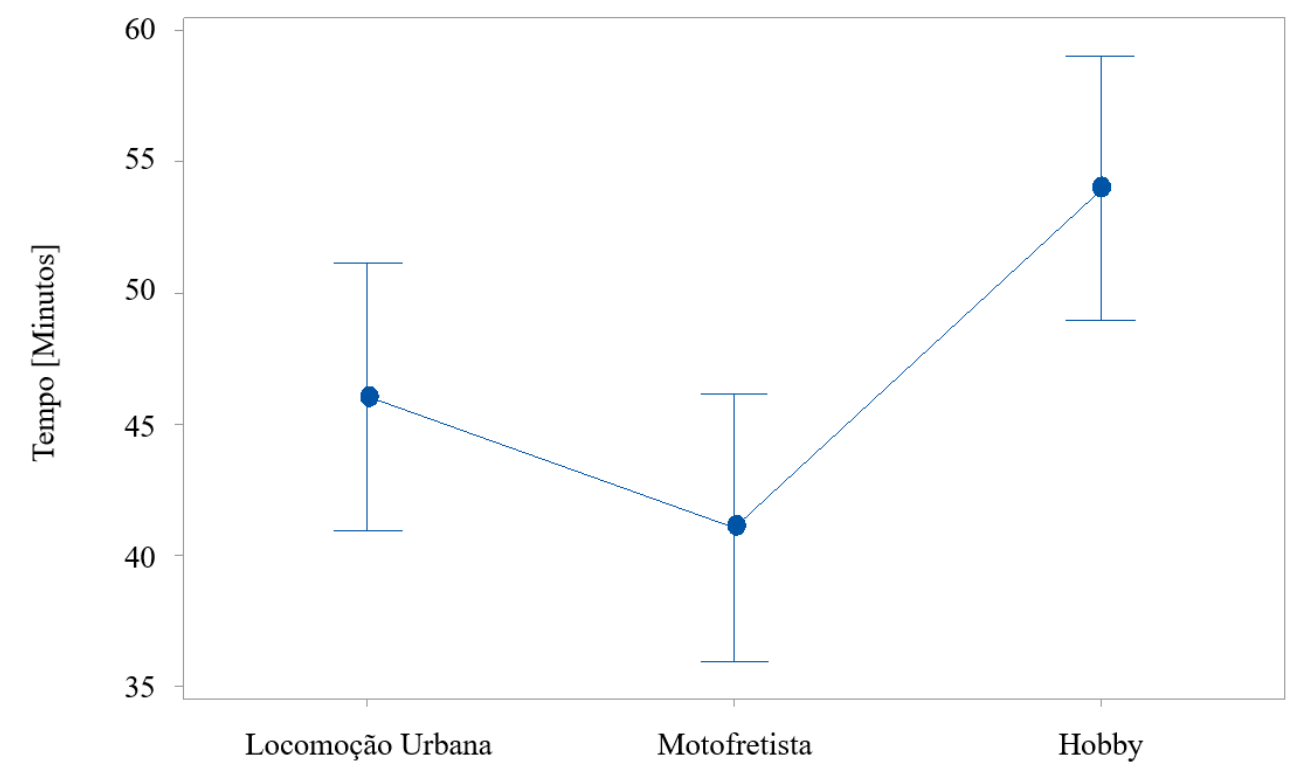

Fonte: Autor 
Tabela 7 - Avaliação das médias para o tempo gasto durante a execução do percurso por cada classe de pilotos

\begin{tabular}{l|c|c|c|c}
\hline Fator & $\mathbf{n}$ & Média & Desvio Padrão & I.C. de 95\% \\
\hline Locomoção Urbana & 10 & 46,05 & 3,41 & $(40,97 ; 51,13)$ \\
\hline Motofretista & 10 & 41,04 & 4,16 & $(35,96 ; 46,13)$ \\
\hline Hobby & 10 & 53,98 & 12,45 & $(48,90 ; 59,07)$ \\
\hline
\end{tabular}

Fonte: Autor

Tabela 8 - Análise de variância para o tempo gasto por cada classe de pilotos

\begin{tabular}{l|c|c|c|c}
\cline { 2 - 4 } & G.L. & S.Q. & Valor F & Valor $\mathbf{P}$ \\
\hline Fator & 2 & 851,5 & 6,94 & 0,004 \\
\hline Erro & 27 & 1656,6 & \multicolumn{2}{|c}{} \\
\hline Total & 29 & 2508,1 & \multicolumn{1}{|c}{} \\
\cline { 1 - 2 } & &
\end{tabular}

Fonte: Autor

Conforme apontado anteriormente, a hipótese nula afirma que os valores médios do tempo gasto pelos condutores são iguais. Como o valor de "P" é menor que o nível de significância de 0,05 , é possível rejeitá-la e concluir com $95 \%$ de certeza, que pelo menos uma das classes é diferente das demais. Pelo gráfico ilustrado pela Figura 62, entende-se que esta diferença se atribui a classe "Hobby", uma vez que os valores registrados para o intervalo de confiança vinculado aos pilotos desta classe, se afastaram dos demais.

\subsubsection{VELOCIDADE MÉDIA DO VEÍCULO}

Da mesma forma como foi desenvolvido para o teste de hipóteses com o intuito de identificar se ocorria diferença entre as médias do tempo gasto pelos pilotos durante a execução do percurso, elabora-se o gráfico para os valores dos intervalos de confiança associados as médias dos valores médios de velocidade adotados por cada piloto dentro de suas respectivas classes. Para que uma maior exatidão fosse obtida, chama-se a atenção para o fato de os dados inferiores a $1 \mathrm{~km} / \mathrm{h}$ terem sido excluídos. A Figura 63, apresenta a análise das médias e respectivos valores dos intervalos de confiança, sendo que a Tabela 9 descreve estas grandezas e a Tabela 10 ilustra as análises para as variâncias. 
Figura 63 - Valores dos intervalos de confiança (95\%) para a velocidade média do veículo de acordo com cada classe em estudo

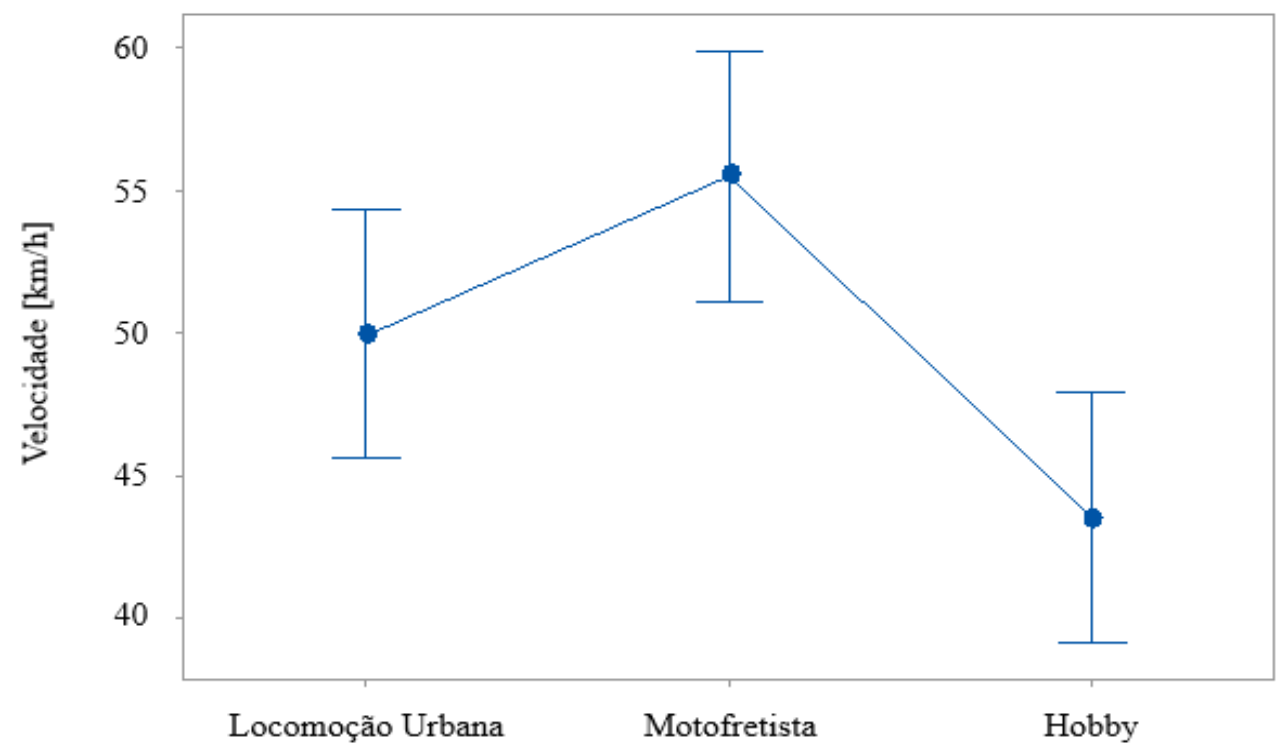

Fonte: Autor

Tabela 9 - Avaliação das médias para a velocidade média do veículo para cada classe de pilotos

\begin{tabular}{l|c|c|c|c}
\hline Fator & $\mathbf{n}$ & Média & Desvio Padrão & I.C. de 95\% \\
\hline Locomoção Urbana & 10 & 49,98 & 3,99 & $(45,58 ; 54,38)$ \\
\hline Motofretista & 10 & 55,56 & 6,00 & $(51,16 ; 59,96)$ \\
\hline Hobby & 10 & 43,54 & 9,27 & $(39,14 ; 47,94)$ \\
\hline
\end{tabular}

Fonte: Autor

Tabela 10 - Análise de variância para a velocidade média do veículo para cada classe de pilotos

\begin{tabular}{c|c|c|c|c}
\hline Fonte & G.L. & S.Q. & Valor F & Valor-P \\
\hline Fator & 2 & 723,40 & 7,87 & 0,002 \\
\hline Erro & 27 & 1240,70 & & \\
\cline { 1 - 2 } Total & 29 & 1964,20 & & \\
\cline { 1 - 2 } & &
\end{tabular}

Fonte: Autor

Da mesma forma como apresentado no item anterior, o valor de "P" é menor que o nível de significância de 0,05 , fazendo com que a hipótese nula seja então rejeitada, permitindo que a 
conclusão (com 95\% de chance de acerto) de que ao menos uma das classes estudadas é diferente das demais, seja tomada. Assim, conforme ilustrado pela Figura 63, verifica-se que novamente a classe "Hobby" é aquela que destoa das demais, apresentando novamente valores inferiores em relação as demais classes.

\subsubsection{PORCENTAGEM DE ABERTURA DO ACELERADOR}

Para que um teste de hipótese para os dados adquiridos junto ao sensor de posição da borboleta do acelerador pudesse ser realizado, utilizaram-se os valores associados as médias aplicadas aos dados colhidos para cada piloto estudado. Isso significa que para a composição dos valores das classes, cada piloto colaborou com o valor da média observada no período em que ele conduziu a motocicleta durante a execução do percurso padrão. Isso foi feito, para que uma melhor representatividade da realidade pudesse ser executada. Reforça-se ainda que todos os valores de abertura inferiores a 1\% foram excluídos da análise, assim como esclarecido na seção 6.1.2.3. A Figura 64, apresenta a análise das médias e valores dos respectivos intervalos de confiança para os dados de interesse, sendo que a Tabela 11 descreve estas informações e a Tabela 12 ilustra as análises para as variâncias

Figura 64 - Valores dos intervalos de confiança (95\%) para a média dos dados associados a abertura da borboleta do acelerador de acordo com cada classe em estudo

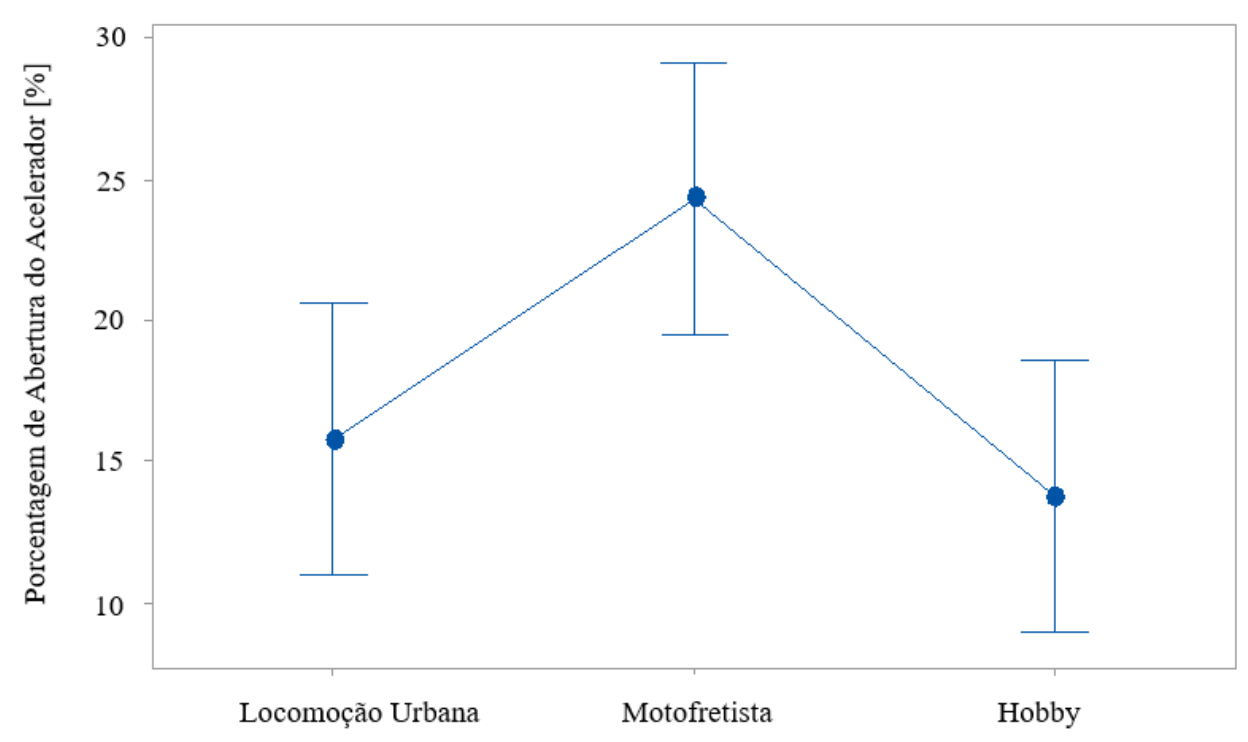

Fonte: Autor 
Tabela 11 - Avaliação das médias para os valores de abertura média do acelerador para cada classe de pilotos

\begin{tabular}{l|c|c|c|c}
\hline Fator & n & Média & Desvio Padrão & I.C. de 95\% \\
\hline Locomoção Urbana & 10 & 15,73 & 5,90 & $(10,92 ; 20,53)$ \\
\hline Motofretista & 10 & 24,32 & 7,45 & $(19,51 ; 29,12)$ \\
\hline Hobby & 10 & 13,71 & 8,62 & $(8,91 ; 18,52)$ \\
\hline
\end{tabular}

Fonte: Autor

Tabela 12 - Análise de variância para os valores de abertura média do acelerador para cada classe de pilotos

\begin{tabular}{l|c|c|c|c}
\hline Fonte & G.L. & S.Q. & Valor F & Valor-P \\
\hline Fator & 2 & 634,10 & 5,78 & 0,008 \\
\hline Erro & 27 & 1480,40 & & \\
\cline { 1 - 2 } Total & 29 & 2114,10 & & \\
\multicolumn{2}{l}{ Fonte: Autor }
\end{tabular}

Assim como foi verificado para as grandezas avaliadas anteriormente através de testes de hipótese, no caso do perfil de utilização do acelerador, o valor de "P" também é menor que o nível de significância de 0,05 . Assim, mais uma vez a hipótese nula pode ser rejeitada com 95\% de chance de certeza e conclui-se, que de fato uma das classes apresenta diferença em relação as demais. Diferentemente das análises anteriores, confirma-se desta vez, que são os integrantes da classe "Motoboy" que se afastam dos demais, possuindo nesta ocasião, valores mais elevados para a porcentagem média de abertura da borboleta do acelerador em comparação com os pilotos das outras classes.

Portanto, uma vez que os testes de hipóteses para as três variáveis em avaliação (tempo, velocidade e abertura do acelerador) confirmaram que as hipóteses alternativas devem ser aceitas, conclui-se estatisticamente que em todos os testes, ao menos uma das classes se destacou em relação as demais. Resta agora saber se este mesmo tipo de diferença será aplicada junto aos critérios de durabilidade do veículo em estudo. 


\subsection{ANÁLISE DOS PARÂMETROS ASSOCIADOS A DURABILIDADE}

A seguir, utilizam-se as informações coletadas durante a fase de aquisição de dados e apresentam-se os cálculos executados seguindo a teoria apresentada no Capítulo 4 , de forma a buscar uma maneira analítica de vincular a forma de condução da motocicleta com os parâmetros de durabilidade do veículo de duas rodas.

\subsubsection{Força Vertical no Eixo da Roda Dianteira}

Partindo-se do repouso e com um carregamento inicial padrão de $75 \mathrm{~kg}$, (massa do condutor padrão), pôde-se então calcular o valor da força vertical no eixo da roda dianteira da motocicleta. A metodologia de cálculo foi empregada conforme descrito na seção 4.8.3. A Figura 65 ilustra o resultado para o valor da força vertical no eixo dianteiro ao longo do tempo, para um piloto da classe "Locomoção Urbana". Para este caso, foram encontrados os seguintes valores conforme abaixo;

$$
\begin{array}{cc}
F_{Z, f M A X}=2.215,10 \mathrm{~N} & F_{Z, f M I N}=-1.226,70 \mathrm{~N} \\
F_{Z, f M E ́ D}=719,04 \mathrm{~N} & F_{Z, f S T D}=149,14 \mathrm{~N}
\end{array}
$$

Figura 65 - Força vertical no eixo da roda dianteira

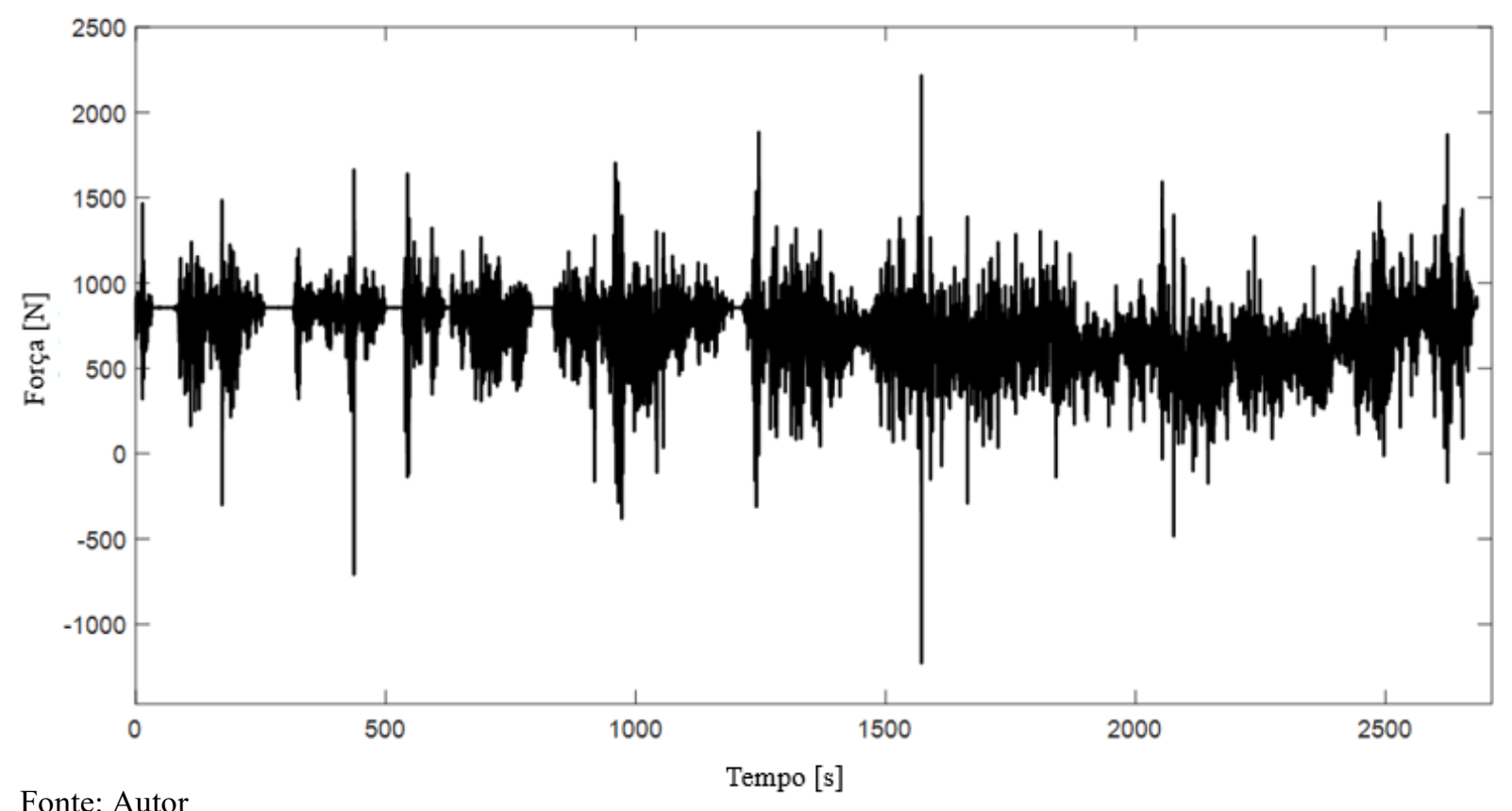

Fonte: Autor 
Para que uma análise holística fosse conduzida, os valores médios para os demais condutores foram calculados. Assumindo que os dados são distribuídos a partir da distribuição log-normal, com intervalo de confiança de 95\%, verifica-se que apesar da classe dos motofretistas ser aquela que aparentemente apresenta uma maior severidade na forma de condução, conforme sugerido pelas informações colhidas nos itens anteriores, ela demonstra valores médios da força vertical no eixo da roda dianteira ligeiramente menores que aqueles encontrados para as demais classes. Atenta-se também ao fato de que os maiores valores médios se relacionam a população que utiliza a motocicleta como meio de lazer, conforme evidenciado na Figura 66. Para efeitos de análise da dispersão dos dados, destaca-se que o valor médio para o desvio padrão vinculado aos valores de $F_{Z f \text { MÉ } D}$ foi igual a 151,75 N.

Figura 66 - Valores verificados para $F z f_{M E ́ D}$ para cada piloto e sua respectiva classe

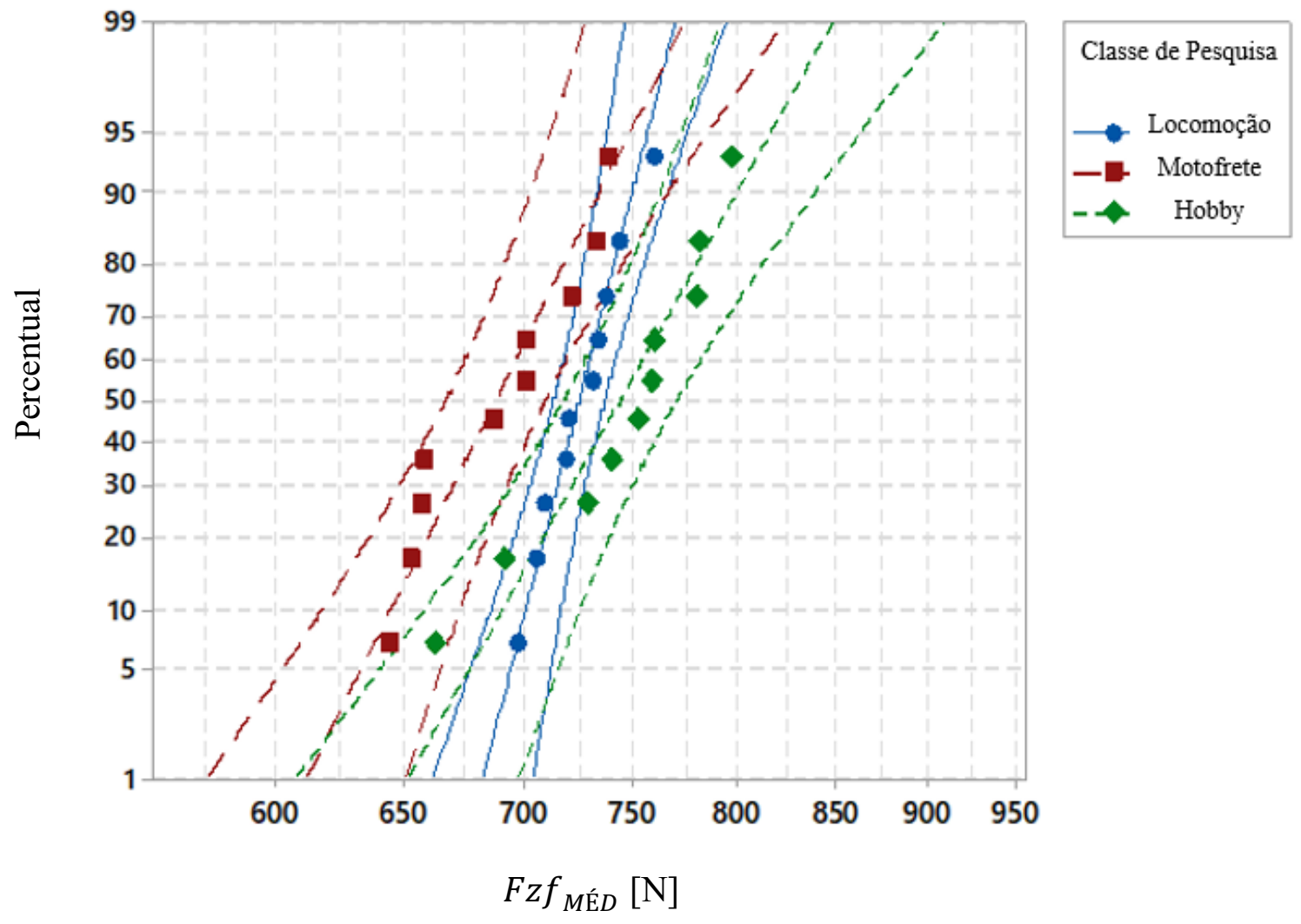

Fonte: Autor

\subsubsection{Contagem de Ciclos Rainflow}

Através do algoritmo (vide Apêndice D), e a partir do espectro da força vertical no eixo da roda dianteira, foram calculados os espectros Rainflow para cada um dos pilotos. A Figura 
67 ilustra os resultados para uma janela de aproximadamente 14 segundos destes dados, obtidos a partir do espectro de força vertical ilustrado na Figura 65.

Além de ilustrar os ciclos Rainflow, a imagem também mostra a aplicação do filtro desenvolvido para eliminar os ciclos com amplitude inferior a 100 N. A intenção da aplicação do filtro foi a de verificar o impacto da remoção dos ciclos com amplitude inferior a este valor, e consequentemente, verificar as possíveis variações nos valores do pseudo dano após a filtragem dos dados. Os pontos pretos na imagem a seguir ilustram os ciclos remanescentes após a filtragem, sendo que as circunferências vermelhas, apontam os dados que foram eliminados pelo filtro.

Figura 67 - Spectro Rainflow com filtragem de ciclos com amplitude inferior a $100 \mathrm{~N}$

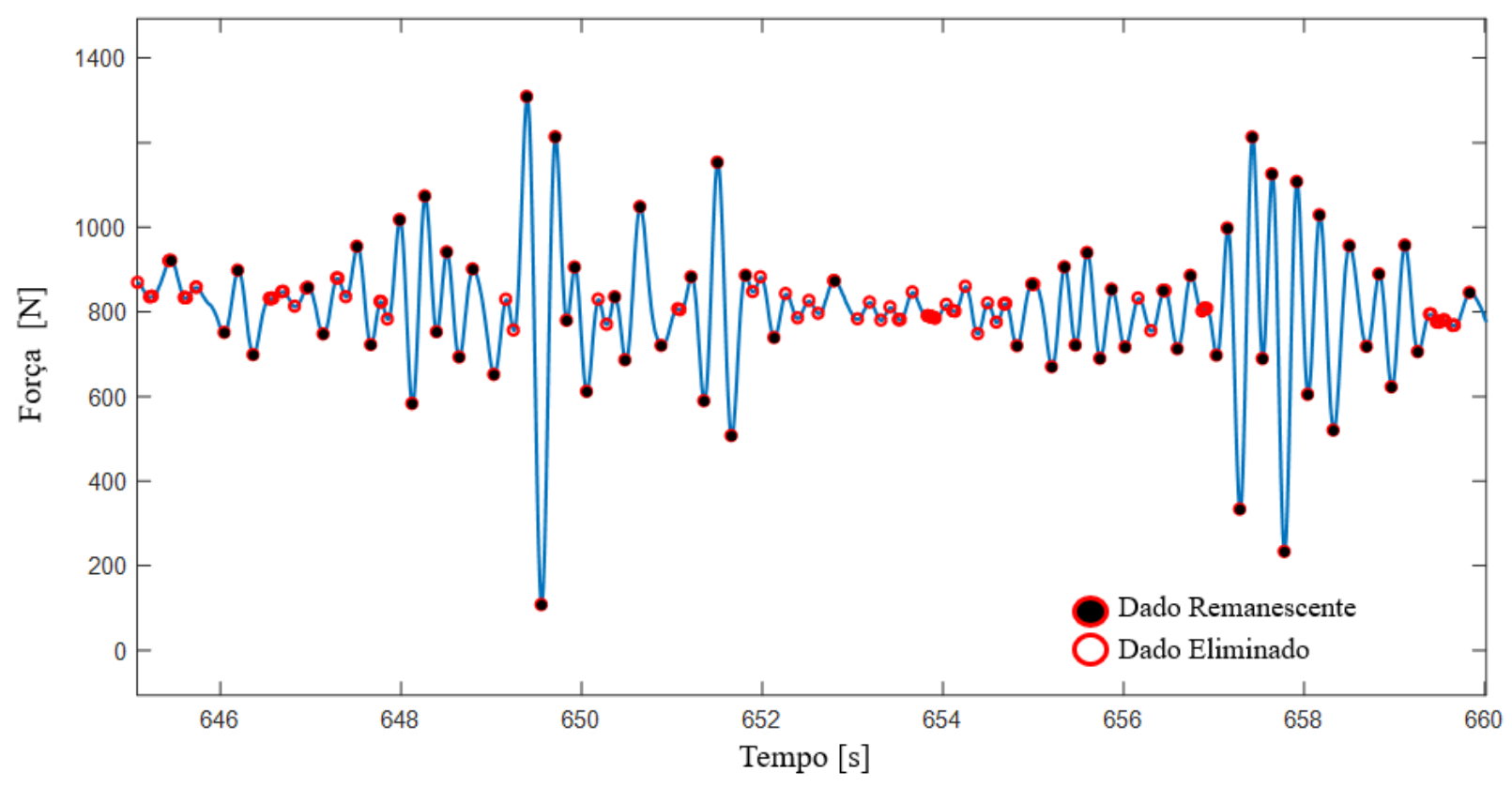

Fonte: Autor

O impacto da aplicação deste filtro pode ser verificado a partir da Figura 68, que ilustra a diferença na quantidade de pontos antes e depois da filtragem. Visualmente, nota-se que a figura do lado direito, aponta uma quantidade de pontos sensivelmente menor que a imagem do lado esquerdo. 
Figura 68 - Representação do número de ciclos Rainflow, sem filtragem $(\mathrm{h}=0)$ e com filtragem $(\mathrm{h}=100)$
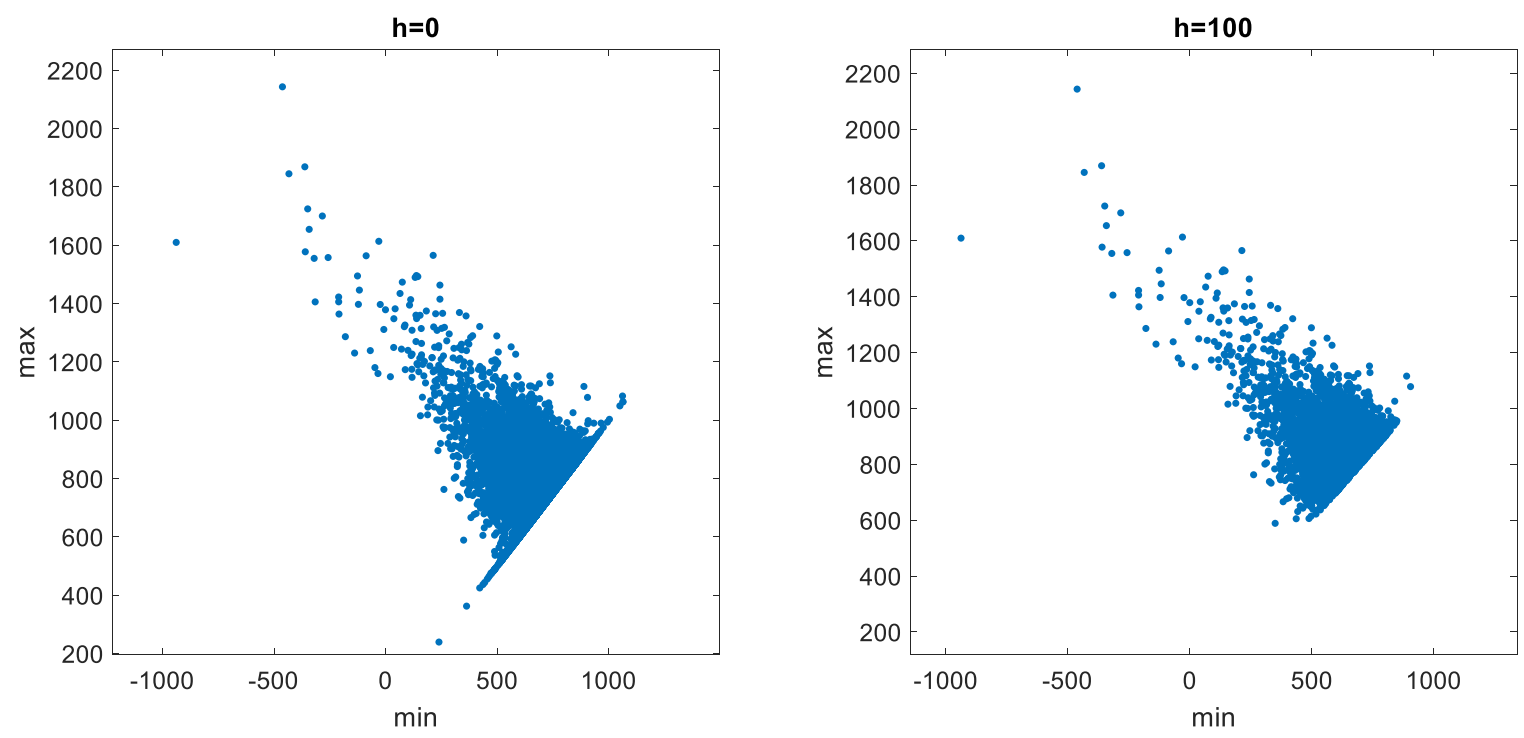

Fonte: Autor

De forma a quantizar a diferença na quantidade de pontos antes e depois da filtragem, elabora-se os histogramas ilustrados a partir da Figura 69, que aponta redução significativa na quantidade de dados após a remoção dos ciclos com amplitude inferior a $100 \mathrm{~N}$ (imagem da direita).

Figura 69 - Histograma de distribuição dos ciclos Rainflow, sem filtragem $(\mathrm{h}=0)$ e com filtragem $(\mathrm{h}=100)$
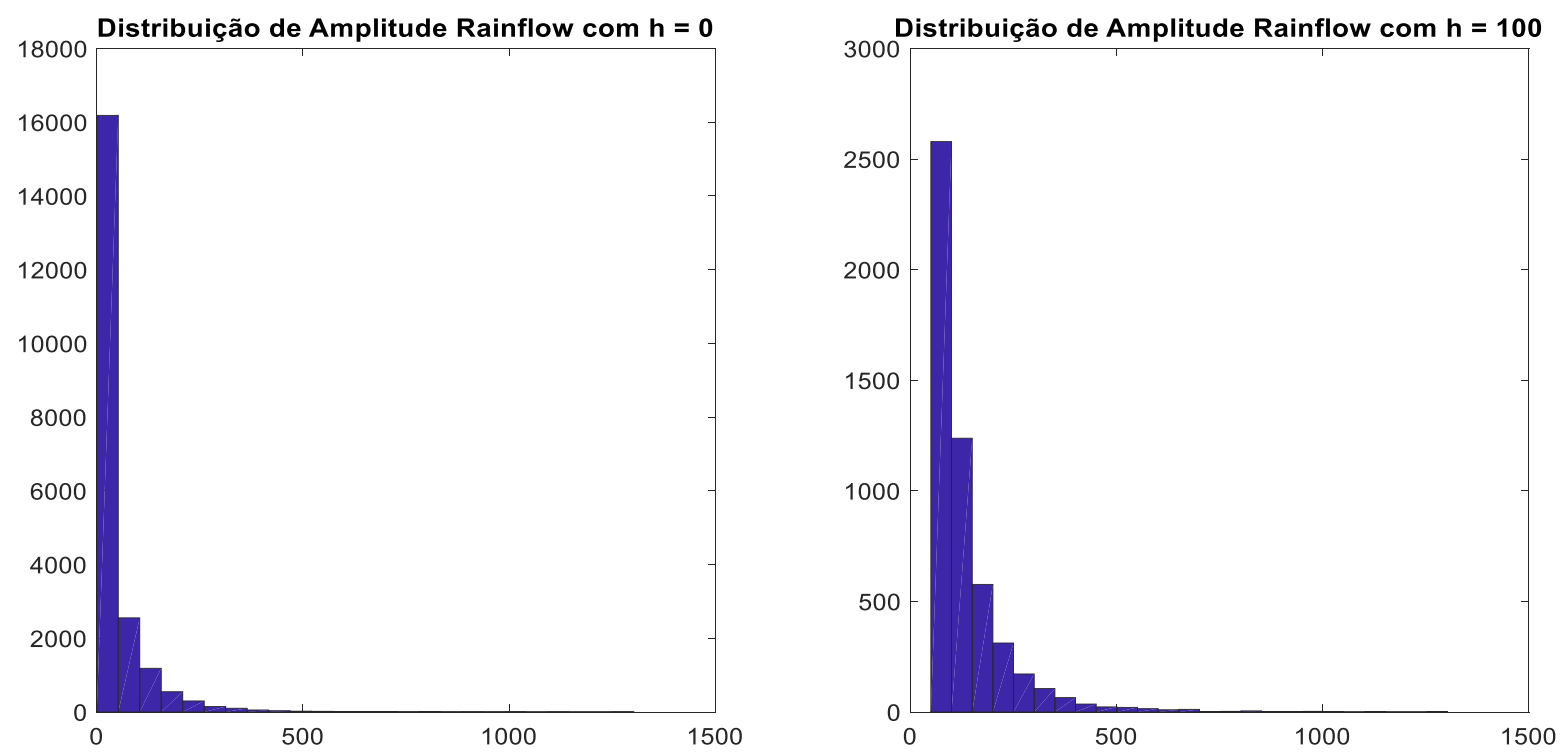

Fonte: Autor 
Verifica-se, portanto, que após a aplicação do filtro, a quantidade de ciclos de baixa amplitude, neste caso aqueles menores que $100 \mathrm{~N}$, foram removidos, sendo que de acordo com a figura anterior, confirma-se que pelo menos 16.000 pontos foram eliminados após a filtragem.

Desta maneira, resta agora verificar os valores calculados para o pseudo dano e consequentemente amplitude equivalente, grandeza fundamental para a sequência das avaliações aqui propostas.

\subsubsection{Pseudo Dano}

A partir dos dados obtidos para os ciclos Rainflow e considerando-se o que foi discutido na seção 4.7.5, aplica-se a Equação $5 \operatorname{com} \beta=5$, assumindo-se componentes automotivos com acabamento grosseiro e calcula-se os valores do pseudo dano para os 30 condutores. $O$ cálculo foi executado a partir do algoritmo conforme apresentado no Apêndice D. A seguir, ilustra-se o cálculo executado utilizando-se os dados do piloto 1 , detentor do spectro de força vertical da roda dianteira conforme descrito na Figura 65.

$$
d=\sum_{i} S_{i}^{\beta} \leftrightarrow d=\sum_{15345} S_{15345}^{5} \leftrightarrow d=3,326 \cdot 10^{16} N^{5}
$$

Desta maneira, entende-se que para o piloto em estudo, foram verificados 15.345 ciclos Rainflow durante a verificação do spectro da força vertical no eixo dianteiro, sendo que o pseudo dano acumulado segundo a teoria de Palmgren-Miner, vide Risitano, Corallo e Risitano (2012) foi dada na casa de $3.10^{16} \mathrm{~N}^{5}$. 
A Figura 70 ilustra estes valores, sendo que assim como foi verificado junto aos dados das velocidades médias, verifica-se uma aproximação entre os valores das classes dos condutores que utilizam a moto para locomoção urbana e os motofretistas.

Figura 70 - Valores calculados para o pseudo dano para cada piloto e sua respectiva classe

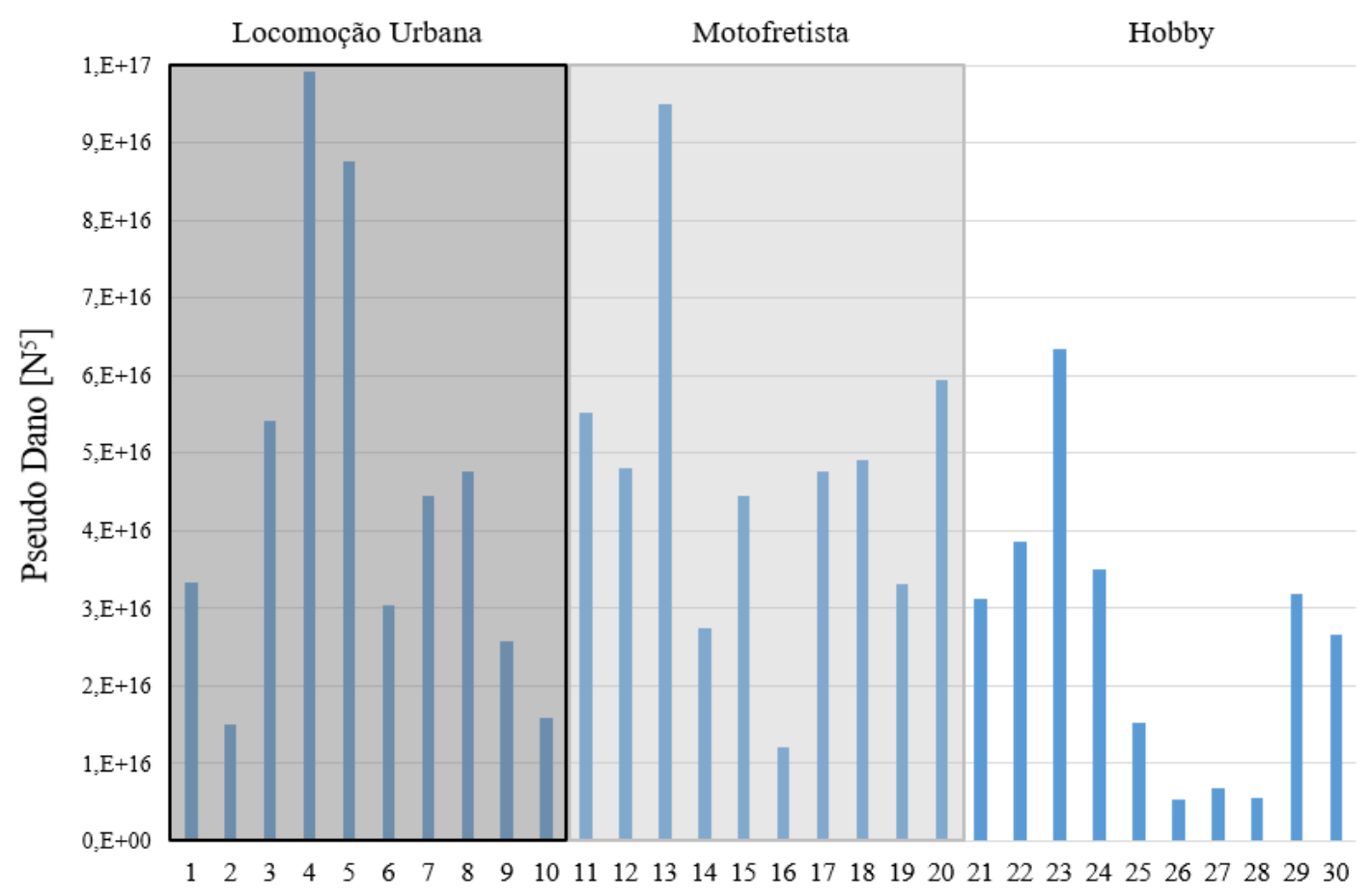

Fonte: Autor

Chama-se atenção para a ocorrência de uma possível separação dos dados referentes aos condutores da classe "Hobby", que apresentaram os 3 menores valores registrados (pilotos 26, 27 e 28). Outro ponto que chama a atenção, é que o registro do maior valor obtido, foi associado com a classe dos condutores da classe "Locomoção Urbana" (piloto 4).

\subsubsection{Amplitude Equivalente}

Tendo calculado os valores para o pseudo dano, aplica-se a teoria apresentada na seção 4.7.6, de forma a se obter o valor da amplitude equivalente para todos os pilotos, sendo que para o cálculo do fator $K$, utilizou-se uma quilometragem total referente a vida útil do veículo igual a $150.000 \mathrm{~km}$. Além disso, conforme destacado na seção 5.1.3, a quilometragem do percurso utilizado para execução da medição foi igual a 35,2 km. 
Considerando um número de ciclos igual a $1.10^{6}$ para determinação da vida útil em fadiga, elabora-se o cálculo da amplitude equivalente a partir da Equação 6 para o piloto 1 .

$$
\begin{gathered}
A_{e q}=\left(\frac{K \cdot d}{N_{0}}\right)^{\frac{1}{\beta}} \leftrightarrow A_{e q}=\left(\frac{\frac{150 \cdot 000}{35,2} \cdot 3,3261 \cdot 10^{16}}{10^{6}}\right)^{\frac{1}{5}} \leftrightarrow \\
\leftrightarrow A_{e q}=676,54 \mathrm{~N}
\end{gathered}
$$

Conforme proposto por Johannesson e Speckert, (2014), este valor pode ser comparado com o valor da amplitude máxima verificada durante o cálculo da Força Vertical no Eixo Dianteiro, que para esse caso, foi calculado conforme exposto a seguir.

$$
F_{Z, f A M P}=\frac{\left(F_{Z, f M A x}-F_{Z, f M I N}\right)}{2}=1720,90 \mathrm{~N}
$$

Sendo que o valor médio da Força Vertical no Eixo Dianteiro calculado a partir do spectro da força vertical igual a:

$$
F_{Z, f M E ́ D}=719,04 N
$$

Uma das possíveis razões para o afastamento do valor calculado da amplitude equivalente em relação a amplitude do espectro da força vertical, é o valor do fator $K$, que depende significativamente da vida útil esperada (em quilómetros) para o veículo em teste e a quilometragem total do percurso utilizado para o teste e aquisição de dados.

A Figura 71 ilustra os valores obtidos para a amplitude equivalente dos demais pilotos, sendo que seguindo a lógica verificada para os dados do pseudo dano, verifica-se que os valores menores foram associados a classe dos condutores que fazem o uso da motocicleta para fins de lazer. Já os maiores dados, ficaram vinculados as outras duas classes, sendo que o maior valor verificado, foi associado ao piloto 4 , da classe dos usuários que dedicam o uso da moto para locomoção urbana. 
Figura 71 - Valores calculados para a amplitude equivalente para cada piloto e sua respectiva classe

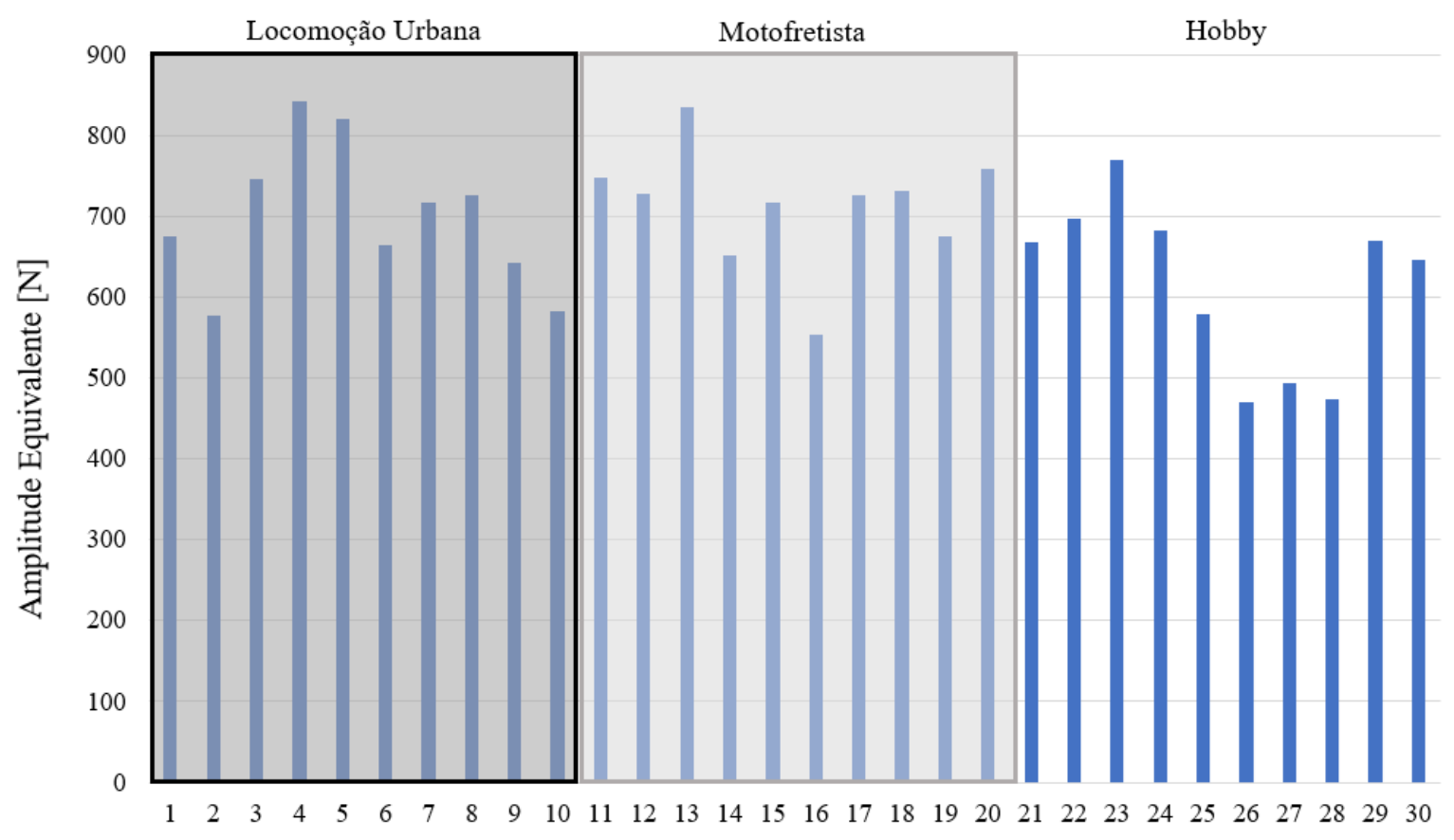

Fonte: Autor

\subsubsection{Caracterização da População}

Conforme apresentado na seção 4.7.1, antes de seguir adiante com a comparação entre as populações, deve-se verificar qual é o tipo de distribuição estatística que rege o comportamento dos dados verificados para a amplitude equivalente. Normalmente, quando se avalia carregamentos randômicos voltados ao segmento automotivo, entende-se que os dados frequentemente podem ser analisados através das distribuições Normal, Weibull ou Lognormal.

Para tanto, através do auxílio do software estatístico Minitab ${ }^{\circledR}$, executa-se um teste de correlação entre as três distribuições mencionadas. De acordo com os dados apresentados na Figura 72, o coeficiente de correlação para a distribuição Weibull considerando os dados referentes a amplitude equivalente calculada para os 30 pilotos foi igual a 0,985. Já para as outras distribuições (Log-normal e Normal), os valores verificados foram 0,963 e 0,979 respectivamente. Sabe-se que quanto mais próximo de 1, maior será a correlação entre os dados verificados e aquele determinado tipo de distribuição, portanto, entende-se que a distribuição de Weibull é aquela que melhor se aplica ao conjunto dos dados em discussão. 
Figura 72 - Gráfico de probabilidade desenvolvido junto ao software estatístico Minitab ${ }^{\circledR}$ para correlação dos dados de amplitude equivalente junto a distribuição de Weibull

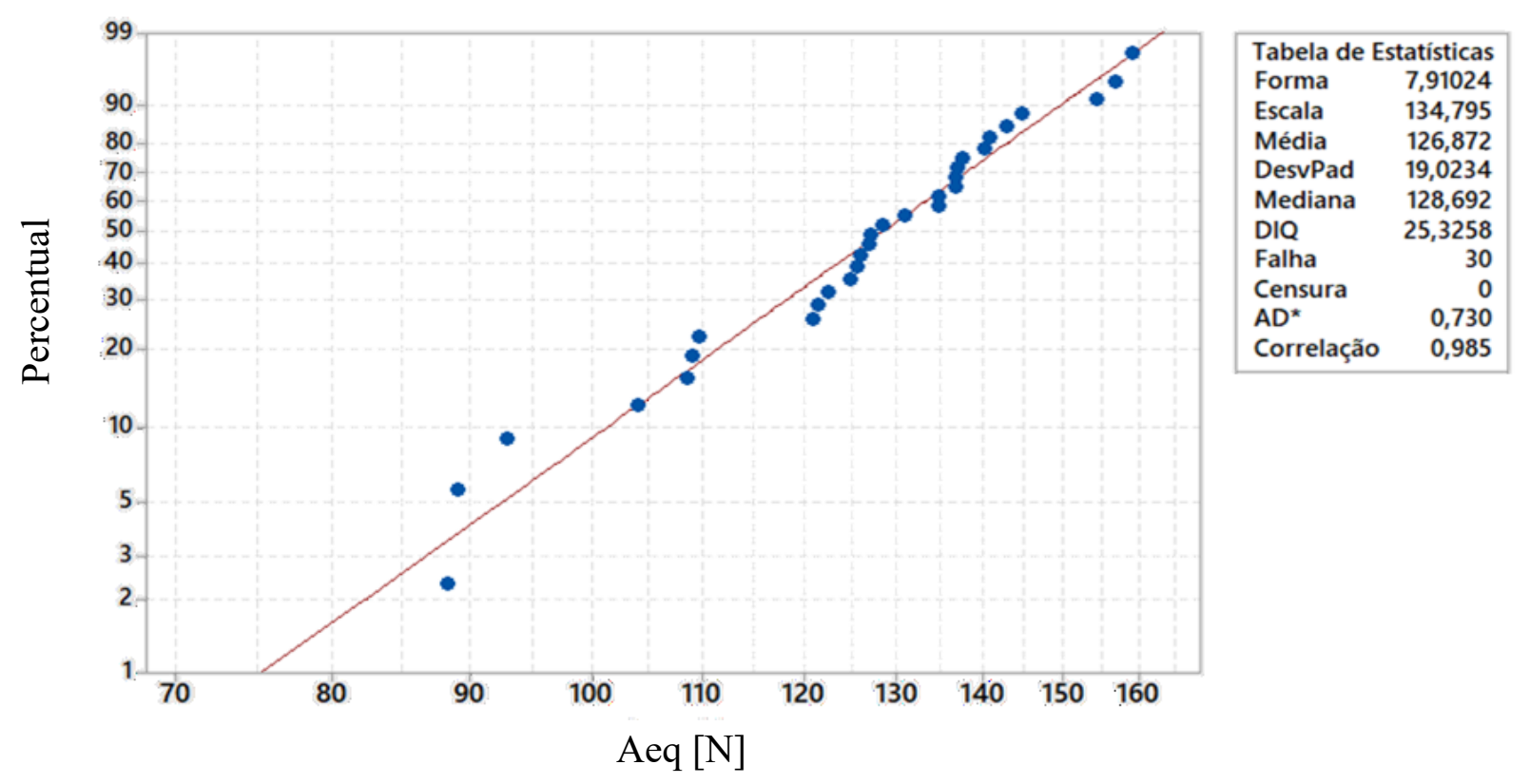

Fonte: Autor

\subsubsection{Comparação Entre as Populações}

Conforme apresentado na seção 4.7.2, deseja-se como objetivo principal identificar se ocorre diferença significativa entre as populações no tocante a durabilidade do produto, quando este é imposto aos carregamentos oriundos dos diferentes perfis de condução. Desta maneira, faz-se necessário a execução do cálculo do intervalo de confiança associado quociente de severidade média, conforme apontou a Equação 17. Para isso, ilustrar-se-á a partir de agora, os passos para o cálculo deste intervalo de confiança para as três populações em estudo.

Sabendo que a população geral dos 30 condutores pode ser distribuída por uma distribuição de Weibull, considerando coeficiente de correção igual a 0,985, assim como foi proposto na seção anterior, deseja-se agora verificar se este tipo de distribuição também deve ser aplicado as populações de forma individual. Para isso, elabora-se o teste de correlação para cada conjunto de amplitudes equivalentes coletados para os pilotos de cada população. A Tabela 13 ilustra o teste de correção para cada tipo de distribuição. 
Tabela 13 - Teste de correlação para os dados de amplitude equivalente observados de acordo com a classe dos pilotos

\begin{tabular}{c|c|c|c}
\hline Distribuição & Locomoção Urbana & Motofretista & Hobby \\
\hline Normal & 0,985 & 0,947 & $\underline{0,955}$ \\
\hline Lognormal & $\underline{0,987}$ & 0,932 & 0,946 \\
\hline Weibull & 0,970 & $\underline{0,962}$ & 0,951 \\
\hline
\end{tabular}

Fonte: Autor

Nota-se, portanto, que cada classe de condutores se assemelhou com um tipo de distribuição, o que tecnicamente dificulta a condução do cálculo do intervalo de confiança associado ao quociente de severidade média. De forma a viabilizar o cálculo deste parâmetro, e consequentemente desempenhar o cálculo comparativo entre a severidade imposta por cada classe de condutores, assume-se como referência a distribuição Log-Normal, uma vez que conforme apontado na seção 4.7.2, as equações de desenvolvimento dos cálculos associados a este intervalo de confiança, foram baseadas neste tipo de distribuição.

De forma a garantir uma assertividade significativa diante desta escolha, calcula-se o erro oriundo da adoção deste tipo de distribuição frente aquelas populações que se mostram representadas pelas distribuições de Weibull e Normal, sendo que na Tabela 14, são ilustrados estes valores.

Tabela 14 - Erro associado a adoção da distribuição lognormal de acordo com cada população

\begin{tabular}{c|c|c}
\hline Locomoção Urbana & Motofretista & Hobby \\
\hline $0,0 \%$ & $3,1 \%$ & $0,9 \%$ \\
\hline
\end{tabular}

Fonte: Autor

Assim, sabendo-se que os valores dos erros associados com a imposição da distribuição normal para as classes dos motofretistas e dos condutores que usam a motocicleta como meio de lazer foi relativamente baixo, calcula-se então a partir de agora os valores da média, desvio padrão e intervalo de confiança $(95 \%)$ da média e desvio padrão para os condutores das três classes em estudo. 


\subsubsection{Determinação das Medianas ${\theta_{1}}^{*},{\theta_{2}}^{*} e{\theta_{3}}^{*}$}

Considerando os dados obtidos para a amplitude equivalente associados aos pilotos da classe dos condutores que utilizam a motocicleta como meio de locomoção urbana conforme descrito na Tabela 15, executam-se os cálculos sugeridos pelas equações 13, 14,15 e 16.

Tabela 15 - Valores de amplitude equivalente associados aos pilotos da classe "Locomoção Urbana"

\begin{tabular}{c|c}
\hline Piloto & Aeq $[\mathrm{N}]$ \\
\hline 1 & 675,545 \\
\hline 2 & 577,433 \\
\hline 3 & 745,784 \\
\hline 4 & 841,971 \\
\hline 5 & 821,198 \\
\hline 6 & 664,517 \\
\hline 7 & 716,970 \\
\hline 8 & 726,928 \\
\hline 9 & 642,917 \\
\hline 10 & 583,352 \\
\hline
\end{tabular}

Fonte: Autor

$$
\begin{gathered}
\mu^{*}=\frac{1}{10} \sum_{\mathrm{i}=1}^{10} \ln \mathrm{A}_{\mathrm{eq}, 10}, \mathrm{~s}^{2}=\frac{1}{10-1} \sum_{\mathrm{i}=1}^{\mathrm{n}}\left(\ln \mathrm{A}_{\mathrm{eq}, \mathrm{i}}-\mu^{*}\right)^{2} \\
\mu^{*}=6,54, \mathrm{~s}^{2}=0,016 \\
\mathrm{I}_{\mu}=\left[6,54-2.0,127 / \sqrt{10} ; 6,54^{*}+2.0,127 / \sqrt{10}\right] \\
\mathrm{I}_{\mu}=[6,518 ; 6,569]
\end{gathered}
$$


Sabendo que $a=\chi_{0,025}^{2}(n-1)$ e $b=\chi_{0,095}^{2}(n-1)$ são quantis da distribuição chi-quadrado com $n-1$ graus de liberdade, calcula-se então o intervalo de confiança para o desvio padrão.

$$
\begin{gathered}
I_{\sigma}=\left[0,127 \cdot \sqrt{\frac{10-1}{19,02}} ; 0,127 \cdot \sqrt{\frac{10-1}{2,7}}\right] \\
I_{\sigma}=[0,087 ; 0,233]
\end{gathered}
$$

Para o cálculo do intervalo de confiança (95\%) da mediana da amplitude equivalente, denominada $\theta$, utiliza-se a Equação 16 e em seguida, calcula-se o valor do ponto médio deste intervalo para obtenção de $\theta_{1}{ }^{*}$.

$$
I_{\theta}=\left[e^{6,54-2.0,127 / \sqrt{10}} ; e^{6,54+2.0,127 / \sqrt{10}}\right]
$$

$$
I_{\theta}=[677,061 ; 712,510]
$$

$$
\theta_{1}^{*}=694,786 \mathrm{~N}
$$

De maneira análoga, utilizam-se os valores das amplitudes equivalentes calculadas para os demais pilotos das outras classes e executam-se os cálculos das medianas $\theta_{2}{ }^{*}$ e $\theta_{3}{ }^{*}$ para estas populações. As Tabelas 16 e 17 ilustram esses valores. 
Tabela 16 - Valores de amplitude equivalente associados aos pilotos da classe "Motofretistas"

\begin{tabular}{c|c}
\hline Piloto & Aeq $[\mathrm{N}]$ \\
\hline 11 & 748,453 \\
\hline 12 & 728,184 \\
\hline 13 & 834,422 \\
\hline 14 & 651,368 \\
\hline 15 & 716,820 \\
\hline 16 & 552,963 \\
\hline 17 & 727,181 \\
\hline 18 & 731,569 \\
\hline 19 & 675,560 \\
\hline 20 & 759,819 \\
\hline$\theta 2 *$ & 709,094 \\
\hline
\end{tabular}

Fonte: Autor

Tabela 17 - Valores de amplitude equivalente associados aos pilotos da classe "Hobby"

\begin{tabular}{c|c}
\hline Piloto & Aeq [N] \\
\hline 21 & 668,401 \\
\hline 22 & 696,586 \\
\hline 23 & 769,737 \\
\hline 24 & 683,257 \\
\hline 25 & 579,484 \\
\hline 26 & 469,570 \\
\hline 27 & 494,078 \\
\hline 28 & 473,872 \\
\hline 29 & 670,380 \\
\hline 30 & 646,505 \\
\hline$\theta 3 *$ & 607,123 \\
\hline
\end{tabular}

Fonte: Autor 


\subsubsection{Determinação dos Intervalos de Confiança Associados aos Quocientes de Severidade Média}

A partir dos valores calculados para as medianas vinculadas aos valores das amplitudes equivalentes para cada população, executam-se os cálculos dos intervalos de confiança associados aos quocientes de severidade média, que segundo apontado por Johannesson e Speckert (2014), podem sinalizar de forma estatística se de fato ocorrem diferenças significativas entre as populações do ponto de vista de durabilidade.

6.3.6.2.1 Comparação entre o Perfil "Motofretista” e "Locomoção Urbana"

$$
\begin{gathered}
I_{\theta_{2} / \theta_{1}}=\left[\frac{709,094}{694,786} e^{-2.0,127 \sqrt{1 / 10+1 / 10}} ; \frac{694,786}{709,094} e^{+20.127 \sqrt{1 / 10+1 / 10}}\right] \\
I_{\theta_{2} / \theta_{1}}=[0,910 ; 1,144]
\end{gathered}
$$

Uma vez que a unidade, se encontra presente no intervalo, pode-se assumir com $95 \%$ de certeza que não ocorre diferença significativa entre estas duas populações com relação aos parâmetros de durabilidade.

6.3.6.2.2 Comparação entre o Perfil "Hobby" e "Motofretista"

$$
\begin{gathered}
I_{\theta_{3} / \theta_{2}}=\left[\frac{607,123}{709,094} e^{-2.0,120 \sqrt{1 / 10+1 / 10}} ; \frac{709,094}{607,123} e^{+2.0,120 \sqrt{1 / 10+1 / 10}}\right] \\
I_{\theta_{3} / \theta_{2}}=[0,847 ; 0,865]
\end{gathered}
$$


Diferentemente do resultado anterior, uma vez que a unidade [1] não se encontra presente no intervalo, pode-se assumir com $95 \%$ de certeza que ocorre diferença significativa entre estas duas populações com relação aos parâmetros de durabilidade.

\subsection{Comparação entre o Perfil "Hobby" e "Locomoção Urbana"}

$$
\begin{gathered}
I_{\theta_{3} / \theta_{1}}=\left[\frac{607,123}{694,786} e^{-2.0,128 \sqrt{1 / 10+1 / 10}} ; \frac{694,786}{607,123} e^{+2.0,128 \sqrt{1 / 10+1 / 10}}\right] \\
I_{\theta_{3} / \theta_{1}}=[0,780 ; 0,979]
\end{gathered}
$$

Da mesma forma como calculado no item anterior, a unidade [1] não se encontra presente no intervalo, e por isso, assume-se com 95\% de certeza que ocorre diferença significativa entre estas duas populações quando se analisa os quesitos de durabilidade.

\subsection{Consolidação dos Resultados}

De forma a sumarizar o que foi contabilizado a partir dos cálculos dos intervalos de confiança mencionados acima, calculados para cada classe de condutores, elabora-se a Tabela 18 a seguir.

Tabela 18 - Comparação entre os valores calculados para as medianas dos valores de amplitude equivalente

\begin{tabular}{c|c|c|c|c}
\cline { 2 - 5 } & Mediana $-\theta^{*}[\mathrm{~N}]$ & Locomoção Urbana & Motofretista & Hobby \\
\hline Locomoção Urbana & 694,79 & & $2 \%$ & $13 \%$ \\
\hline Motofretista & 709,09 & $2 \%$ & & $14 \%$ \\
\hline Hobby & 607,12 & $13 \%$ & $14 \%$ & \\
\hline
\end{tabular}

Fonte: Autor

Conforme exposto, conclui-se que apesar de não haver diferença significativa do ponto estatístico entre os condutores da classe "Locomoção Urbana" e "Motofretista" (conforme comprovado pelos cálculos dos I.C. para os quocientes de severidade média), entende-se que a classe dos motofretistas é de fato aquela que possui uma forma de utilização mais severa. Em 
seguida, com uma diferença de $2 \%$ em relação a mediana dos valores associados a amplitude equivalente, a classe "Locomoção Urbana" ocupou o segundo lugar de acordo com a avaliação executada. Já a classe dos usuários que utilizam a motocicleta como objeto de lazer, assim como era esperado, apresentou uma diferença significativa entre a classe dos motofretistas (14\% menos severa) e a dos usuários da classe "Locomoção Urbana" (13\% menos severa). 


\section{CONCLUSÕES E RECOMENDAÇÕES}

Através do presente trabalho foi possível executar a coleta e análise de dados de trinta motociclistas brasileiros que conduziram uma motocicleta instrumentada pelas ruas da cidade de São Paulo.

Após o tratamento dos sinais colhidos, a análise dos dados demonstrou que existem diferenças entre os perfis de condução estudados, sendo estes relacionados aos motociclistas que utilizam a motocicleta como um meio de locomoção diário pelas ruas da cidade, aos motociclistas profissionais, denominados motofretistas, e aos indivíduos que fazem o uso da motocicleta como um objeto de lazer.

As principais diferenças observadas se associaram com o tempo gasto pelos condutores das diferentes classes para a execução do percurso padrão, distribuição da velocidade de deslocamento do veículo e porcentagem de abertura da borboleta do acelerador. Foi comprovado através do auxílio de testes de hipóteses, que em cada um dos testes, pelo menos uma das classes se mostrou diferente das demais. Durante a análise das variáveis tempo e velocidade, a classe "Hobby" se mostrou estatisticamente diferente, já durante a análise da variável porcentagem de abertura do acelerador, a classe "Motoboy" foi a destoante.

Após a análise preliminar dos dados, uma correlação entre o perfil de condução e parâmetros de durabilidade do veículo foi executada. A partir da implementação de um algoritmo com base na teoria de contagem de ciclos Rainflow, verificou-se que do ponto de vista estatístico, os danos causados pelas classes dos motofretistas e daqueles usuários que utilizam a motocicleta como meio de locomoção urbana, são bastante próximos. Já a classe dos usuários que fazem o uso da motocicleta como objeto de lazer, se mostrou diferente, apresentando valores cerca de 15\% menores em comparação com as demais classes.

Sendo assim, para que futuros projetos de veículos do segmento das duas rodas possam ser desenvolvidos para o mercado brasileiro, recomenda-se que uma análise detalhada sobre o perfil do público alvo do possível comprador do veículo seja executada. Esta análise deve considerar a premissa de que realmente podem ocorrer diferenças significativas entre a magnitude dos carregamentos impostos pelas diferentes classes de condutores locais.

Para que futuros estudos a respeito da associação do perfil de condução do veículo de duas rodas e os parâmetros de durabilidade da motocicleta sejam executados, recomenda-se que um banco de dados mais amplo, contendo dados de mais condutores seja construído. Isso é recomendado, para que uma análise mais robusta contando com a aplicação de algoritmos classificadores seja tecnicamente possível de ser conduzida. 


\section{REFERÊNCIAS}

ABRACICLO - ASSOCIAÇÃO BRASILEIRA DOS FABRICANTES DE MOTOCICLETAS CICLOMOTORES MOTONETAS BICICLETAS E SIMILARES. Anuário da indústria brasileira de duas rodas 2019. São Paulo: Ponto \& Letra Comunicação, 2019. 139 p.

ABRACICLO - ASSOCIAÇÃO BRASILEIRA DOS FABRICANTES DE MOTOCICLETAS CICLOMOTORES MOTONETAS BICICLETAS E SIMILARES (São Paulo). Motocheck-up na Marginal Pinheiros supera a meta de participantes. 2017. Disponível em: <http://www.abraciclo.com.br/2017/1104-motocheck-up-na-marginalpinheiros-supera-a-meta-de-participan>. Acesso em: 29 out. 2019.

ADAC - ALLGEMEINER DEUTSCHER AUTOMOBIL-CLUB (Alemanha). Vorbereitung zur Motorrad-HU: Fristen für die Haupt- und Nachuntersuchung beachten. München: ADAC, 2019. 2 p. Disponível em: <https://www.adac.de/rund-ums-fahrzeug/motorradroller/technik-zubehoer-rueckrufe/vorbereitung-hauptuntersuchung/>. Acesso em: 29 out. 2019.

ALEMANHA. KRAFTFAHRT BUNDESAMT (KBA). Krafträder: Untersuchungen von Krafträdern in den Jahren 2009 bis 2018 nach Untersuchungsergebnissen. Flensburg: Kraftfahrt Bundesamt, 2019.2 p. Disponível em:

$<$ https://www.kba.de/DE/Statistik/Fahrzeuge/Fahrzeuguntersuchungen/Hauptuntersuchungen/ z_fu_haupt_unte>. Acesso em: 29 out. 2019.

ANGELO, Clayton Mamedes. Fadiga de amplitude variável como parâmetro de projeto para eixos traseiros automotivos: uma análise do efeito das sobrecargas e da filtragem matemática na predição de vida em fadiga. 2007. 75 f. Dissertação (Mestrado em Engenharia Metalúrgica) - Escola Politécnica, Universidade de São Paulo, São Paulo, 2007.

ASSOCIAÇÃO BRASILEIRA DE NORMAS TÉCNICAS. NBR 16369: Motociclos e veículos similares - Determinação de hidrocarbonetos, monóxido de carbono, óxidos de nitrogênio e dióxido de carbono no gás de escapamento. 2 ed. Rio de Janeiro: ABNT, 2017. $51 \mathrm{p}$.

ASSOCIAÇÃO BRASILEIRA DE NORMAS TÉCNICAS. NBR 15145: Acústica - Medição de ruído emitido por veículos rodoviários automotores em aceleração - Método de engenharia. 1 ed. Rio de Janeiro: ABNT, 2004. 19 p.

BEER, Ferndinand P. et al. Mecânica dos materiais. 5. ed. Porto Alegre: Amgh, 2011. 799 p. Tradução Técnica de José Benaque Rubert e Walter Libardi.

BMW (Alemanha). Das BMW Group Testgelände Miramas, Frankreich (07/2008). 2008. Disponível em: <https:/www.press.bmwgroup.com/deutschland/photo/detail/P0044470/dasbmw-group-testgel-c3-a4nde-miramas-frankreich-07-2008>. Acesso em: 29 out. 2019.

BMW MOTORRAD (Alemanha). Manual de operação e manutenção G 310 R. 82. ed. Munique: Bmw Motorrad, 2016. 158 p. Disponível em: $<$ https://manuals.bmwmotorrad.com/manuals/BA-Extern/IN/BA-INTERNET-

COM/PDF/G_0G01_RM_1016_82.pdf>. Acesso em: 29 out. 2019. 
BRASIL. Constituição. Código de Trânsito Brasileiro no 9503, de 23 de setembro de 1997. Art. 104 do Código de Trânsito Brasileiro. Brasília, DF, 1997. Disponível em: $<$ https://www.jusbrasil.com.br/topicos/10614847/artigo-104-da-lei-n-9503-de-23-desetembro-de-1997>. Acesso em: 29 out. 2019.

BRASIL. Maiesse Gramacho. Ministério do Meio Ambiente (MMA). Resolução do Conama que obriga inspeção veicular é publicada no DOU. 2009. Disponível em:

$<$ https://www.mma.gov.br/informma/item/5944-resolucao-do-conama-que-obriga-inspecaoveicular-e-publica>. Acesso em: 29 out. 2019.

\section{BUNDESMINISTERIUM DER JUSTIZ UND FÜR VERBRAUCHERSCHUTZ.}

Straßenverkehrs-Zulassungs-Ordnung (StVZO): Anlage VIII ( $\$ 29$ Absatz 1 bis 4, 7, 9, 11 und 13) Untersuchung der Fahrzeuge. Alemanha, 2012. p. 734-740. Disponível em:

$<$ https://www.gesetze-im-internet.de/stvzo_2012/anlage_viii.html>. Acesso em: 29 out. 2019.

CALLISTER JUNIOR, William D. Ciência e engenharia de materiais: uma introdução. 7. ed. Rio de Janeiro: LTC, 2008. 705 p. Tradução de: Sergio Murilo Stamile Soares.

CARDEN, Frank; JEDLICKA, Russell; HENRY, Robert. Telemetry systems engineering. Norwood: Artech House, 2002. 628 p.

CHINDAMO, Daniel et al. Design of a road simulator for motorcycle applications. Applied Sciences. Basel, p. 1-13. 25 nov. 2017.

CONAMA. Resolução no 418, de 25 de novembro de 2009. Dispõe Sobre Critérios Para A Elaboração de Planos de Controle de Poluição Veicular - PCPV e Para A Implantação de Programas de Inspeção e Manutenção de Veículos em Uso - I/m Pelos órgãos Estaduais e Municipais de Meio Ambiente e Determina Novos Limites de Emissão e Procedimentos Para A Avaliação do Estado de Manutenção de Veículos em Uso. Brasília, DF, Disponível em:

$<$ https://www.mma.gov.br/estruturas/182/_arquivos/resoluo_conama_182.pdf $>$. Acesso em: 29 out. 2019.

CONTRAN. Deliberação no 170, de 05 de abril de 2018. Suspende, Por Tempo Indeterminado, A Resolução Contran $\mathbf{N}^{0}$ 716, de 30 de Novembro de 2017, Que Estabelece A Forma e As Condições de Implantação e Operação do Programa de Inspeção Técnica Veicular em Atendimento Ao Disposto no Art. 104 da Lei No 9.503, de 23 de Setembro de 1997, Que Instituiu O Código de Trânsito Brasileiro (CTB). Brasília, DF, 06 abr. 2018. Disponível em: <https://www.legisweb.com.br/legislacao/?id=358644>. Acesso em: 29 out. 2019.

CONTRAN. Resolução no 716, de 30 de novembro de 2017. Estabelece A Forma e As Condições de Implantação e Operação do Programa de Inspeção Técnica Veicular. Brasília, DF, 08 dez. 2017. Disponível em: $<$ https://www.legisweb.com.br/legislacao/?id=353462>. Acesso em: 28 out. 2019.

COSSALTER, Vittore. Motorcycle dynamics. 2. ed. Padova: Lulu, 2006. 360 p. 
DAIMLERCHRYSLER CORPORATION (Estados Unidos). Nasser M. Barkesseh; Way J. Perzanowski. Vehicle data acquisition and analysis system. US n ${ }^{\circ}$ US 6,208,919 B1, 24 set. 1999, 27 mar. 2001.

DETRAN-SP. Frota de Veículos em SP: Por tipo de veículo. Disponível em:

$<$ https://www.detran.sp.gov.br/wps/wcm/connect/portaldetran/detran/detran/EstatisticasTransi to/sa-frotaVeiculos/d28760f7-8f21-429f-b039-

$0547 \mathrm{c} 8 \mathrm{c} 46 \mathrm{ed} 1$ ? presentationtemplate $=$ portaldetran $\% 2 \mathrm{FAT}$-detranPaginaODetranImpressao $>$. Acesso em: 29 out. 2019.

EM DISCUSSÃO: Revista de Audiências Públicas do Senado Federal. Brasília: Secretaria Especial de Editoração e Publicações — Seep, v. 3, n. 13, 2012.

FERREIRA, Felipe Ferreira de. Fatores de risco em acidentes envolvendo motocicletas em vias urbanas: a percepção dos condutores PR. 2009. 91 f. Dissertação (Mestrado em Engenharia de Produção) - Universidade Federal do Rio Grande do Sul, Porto Alegre, 2009.

FERREIRA, Paulo César Pêgas; SANTOS, Márcio Peixoto de Sequeira; NASSI, Carlos David. Análise comportamental de motociclistas brasileiros no trânsito urbano. Rio de Janeiro: Programa de Engenharia de Transportes - Coppe/UFRJ, 2014. 11 p.

FOLHA DE SÃO PAULO (São Paulo). Segunda tem nova faixa de ônibus na avenida Nove de Julho. 2015. Disponível em:

$<$ http://f.i.uol.com.br/folha/cotidiano/images/1335338.jpeg>. Acesso em: 29 out. 2019.

FORCETTO, André Luiz Silva. Poluição sonora urbana: a influência de modificações em escapamentos de motocicletas na emissão de ruído. 2016. 125 f. Dissertação (Mestrado em Ambiente, Saúde e Sustentabilidade) - Faculdade de Saúde Pública, Universidade de São Paulo, São Paulo, 2016.

GAO - Government Accountability Office. Vehicle data privacy: industry and federal efforts under way, but NHTSA needs to define its role. Estados Unidos: U.S. Government Accountability Office, 2017. 64 p.

GORGES, Christian; ÖZTÜRK, Kemal; LIEBICH, Robert. Customer loads of two-wheeled vehicles. International Journal Of Vehicle Mechanics And Mobility. Viena, v. 35, n.12, p. 1842-1864. 13 jun. 2017.

HAUS, Siedro Augusto. Influência do efeito Bauschinger no retorno elástico em aços avançados de elevada resistência. 2011. 92 f. Dissertação (Mestrado em Engenharia Mecânica) - Universidade Federal do Paraná, Curitiba, 2011.

Instituto Brasileiro de Geografia e Estatística (IBGE). Pesquisa nacional por amostra de domicílios contínua: PNAD contínua. 2019. Disponível em:

$<$ https://www.ibge.gov.br/estatisticas/sociais/trabalho/17270-pnad-continua.html? $=\& \mathrm{t}=$ serieshistoricas $>$. Acesso em: 28 out. 2019.

IMMA - INTERNATIONAL MOTORCYCLE MANUFACTURERS ASSOCIATION. The shared road to safety: a global approach for safer motorcycling. Genebra: IMMA, 2014. 96 p. Contribution to the 2nd Global High-Level Conference on Road Safety. 
ISO - INTERNATIONAL ORGANIZATION FOR STANDARDIZATION. ISO 362:

measurement of noise emitted by accelerating road vehicles - engineering method - Part 2: L category. 2 ed. Genebra: ISO, 2009. 44 p.

JASINSKI, Marcio Geovani; BALDO, Fabiano. A method to identify aggressive driver behaviour based on enriched GPS data analysis. In: INTERNATIONAL CONFERENCE ON ADVANCED GEOGRAPHIC INFORMATION SYSTEMS, APPLICATIONS, AND SERVICES, 10., 2017, Nice. Proceedings... Nice: Geoprocessing, 2017. p. 97-102.

JOÃO Doria veta retorno da inspeção veicular obrigatória em São Paulo. Metro. São Paulo, p. 1-1. 18 jan. 2018. Disponível em: $<$ https://www.metrojornal.com.br/foco/2018/01/18/joaodoria-veta-retorno-da-inspecao-veicular-obrigato>. Acesso em: 29 out. 2019.

JOHANNESSON, Par; SPECKERT, Michael. Guide to load analysis for durability in vehicle engineering. United Kingdom: John Wiley \& Sons Ltd, 2014. 434 p.

KNEUPER, Ralf. Die geschichtliche Entwicklung des V-Modells. Bad Honnef: Iubh Internationale Hochschule, 2018. 11 p.

LIN, K-y; HWANG, J-r; CHANG, J-m. Accelerated durability assessment of motorcycle components in real-time simulation testing. Journal of Automobile Engineering. Chiyoda, p. $245-259.21$ jul. 2009.

MAPS, Google. Trajeto Escolhido para Aferição do Perfil de Pilotagem. 2019. Disponível em: $<$ https://www.google.com.br/maps/dir/Av.+Cidade+Jardim, $+\mathrm{S} \% \mathrm{C} 3 \% \mathrm{~A} 3 \mathrm{o}+\mathrm{Paulo}+-$ $+\mathrm{SP} / \mathrm{Pra} \% \mathrm{C} 3 \% \mathrm{~A} 7 \mathrm{a}+\mathrm{Campo}+\mathrm{de}+$ Bagatelle+-+Santana, $+\mathrm{S} \% \mathrm{C} 3 \% \mathrm{~A} 3 \mathrm{o}+\mathrm{Paulo}+-+\mathrm{SP} /-$ 23.5555532,-46.7191501/-23.5832487,-46.6862956/@-23.5831848,-$46.6882268,17 \mathrm{z} / \mathrm{data}=! 4 \mathrm{~m} 21 ! 4 \mathrm{~m} 20 ! 1 \mathrm{~m} 10 ! 1 \mathrm{~m} 1 ! 1 \mathrm{~s} 0 \mathrm{x} 94 \mathrm{ce} 57155 \mathrm{e} 243 \mathrm{~d} 3 \mathrm{~b}: 0 \mathrm{x} 9 \mathrm{a} 6 \mathrm{e} 7 \mathrm{~d} 0 \mathrm{eda} 80086$ $\mathrm{d} ! 2 \mathrm{~m} 2$ ! $1 \mathrm{~d}-46.6863545 ! 2 \mathrm{~d}-23.5830472 ! 3 \mathrm{~m} 4$ ! $1 \mathrm{~m} 2$ ! $1 \mathrm{~d}-46.6379275 ! 2 \mathrm{~d}-$

23.5473917!3s0x94ce58530d213275:0xc3383117c708ba07!1m5!1m1!1s0x94ce5886e1b5759 5:0xa720d2c6714e1ad2!2m2!1d-46.6292293!2d-23.5135426! $1 \mathrm{~m} 0 ! 1 \mathrm{~m} 0 ! 3 \mathrm{e} 0>$. Acesso em: 29 out. 2019.

MASING, Georg. Grundlagen der metallkunde in anschaulicher darstellung. 2. ed. Heidelberg: Springer-verlag Berlin Heidelberg, 1941. 144 p.

MONTGOMERY, Douglas C.. Design and analysis of experiments. 9. ed. Arizona: John Wiley \& Sons, 2017. 749 p.

MURAKAMI, Y.. The rainflow method in fatigue: The Tatsuo Endo Memorial Volume. Fukuoka: Butterworth-heinemann, 1992. 235 p.

NATALE, Marco di et al. Understanding and using the cotroller aerea network communication protocol: theory and practice. New York: Springer Dordrecht Heidelberg London, 2012. 242 p.

NAVET, Nicolas; SIMONOT-LION, Françoise. Automotive embedded systems handbook. Florida: Taylor \& Francis, 2009. 490 p. 
NEYMAN, Jerzy. Outline of a theory of statistical estimation based on the classical theory of probability. Royal Society. Londres, p. 333-380. 30 ago. 1937.

QQ, Duan et al. Quantitative Relations between S-N Curve Parameters and Tensile Strength for Two Steels: AISI 4340 a. Journal of Material Science. Desconhecido, p. 1-16. 09 jan. 2018.

REISER, Christian et al. Kundenfahrverhalten im Fokus der Fahrzeugentwicklung. ATZ, Wiesbaden, p.684-692, jul. 2008.

RISITANO, A.; CORALLO, D.; RISITANO, G.. Cumulative Damage by Miner's Rule and by Energetic Analisys. SDHM. Henderson, p. 91-109. fev. 2012.

ROBERT BOSCH GMBH. Automotive Handbook. 8. ed. Plochingen: Robert Bosch Gmbh, 2011. 1265 p.

ROCHA NETO, Wilson Borba da; MENEZES JUNIOR, José Maria Pires de. Perfil de conduçâo de motoristas: análise por meio de algoritmos de reconhecimento de padrões. In: CONGRESSO BRASILEIRO DE AUTOMÁTICA, 22., 2018, João Pessoa. Proceedings... João Pessoa: Cba, 2018. p. 1 - 7.

RYCHLIK, I.; LEADBETTER, M. R.. Analysis of Ocean Waves y Crossing-And Oscillation-Intensities. Desconhecido: Desconhecido, 1997. 8 p.

SHI, Xiaohui et al. Motorcycle Dynamics Simulation Based on Real Road Load. Applied Mechanics and Materials. Basel, p. 318-322. 12 out. 2009.

SIEMENS. Road Load Data. 2019. Disponível em:

$<$ https://www.plm.automation.siemens.com/media/global/en/road_load_data_tcm279603.jpg >. Acesso em: 29 out. 2019.

SILVA, Ayrton Senna da. Epígrafe: em entrevista ao jornalista João Dória Júnior. 1994. Disponível em: <https://www.pensador.com/frase/MTE4ODIx/>. Acesso em: 29 out. 2019.

SILVA, Ricardo Barbosa da. Os motoboys no globo da morte: Circulação no Espaço e Trabalho Precário na Cidade de São Paulo. 2009. 245 f. Dissertação (Mestrado em Geografia Humana) - Curso de Programa de Pós-graduação em Geografia Humana, Faculdade de Filosofia, Letras e Ciências Humanas - Departamento de Geografia, Universidade de São Paulo, São Paulo, 2009.

STOFFREGEN, Jürgen. Motorradtechnik: Grundlagen und Konzepte von Motor, Antrieb und Fahrwerk. 7. ed. München: Vieweg + Teubner, 2010. 470 p.

SUBBU, Rama; ANTHONYSAMY, Baskar; SHARMA, Piyush Mani. Durability Analysis of Motorcycle Front Fender through Virtual Simulation, on Road Testing and Laboratory Testing Using NVH Tool. Grand Rapids: Sae International, 2015.

TATUI MOTORS TEST (Brasil). Pistas Especiais Para Testes de Durabilidade. 2019. Disponível em: <https://www.tatuimotorstest.com.br/>. Acesso em: 05 set. 2019. 
VAES, David; SAS, Paul; SWEVERS, Jan. Experimental multivariable tracking control on an automotive vibration test rig. In: INTERNATIONAL CONFERENCE ON NOISE AND VIBRATION ENGINEERING, Leuven, Proceedings... Leuven: Isma, 2004. p. 311-324.

VEIGA, Edison. Quantos Motoboys Existem em São Paulo. O Estadão. São Paulo, p. 1-6. 22 ago. 2016. Disponível em: <https://sao-paulo.estadao.com.br/blogs/edison-veiga/quantosmotoboys-existem-em-sp/>. Acesso em: 28 out. 2019.

VIEIRA, André. São Paulo quer regular aplicativos de entregas para salvar motoboys. Metro Jornal. São Paulo, p. 1-20. 18 mar. 2019. Disponível em:

$<$ https://www.metrojornal.com.br/foco/2019/03/18/sao-paulo-aplicativos-de-entregas-salvarmotoboys.html>. Acesso em: 28 out. 2019.

WAFO (Org.). Wafo: A Matlab toolbox for analysis of random waves and loads. Lund: Lund Univerity, 2011. 185 p.

WEBER, Julian. Automotive Development Processes. Heidelberg: Springer-verlag, 2009. $321 \mathrm{p}$.

WECHSELKENNZEICHEN: Informationen zum Wechselkennzeichen. Informationen zum Wechselkennzeichen. 2019. Disponível em:

$<$ https://www.wechselkennzeichen.net/saisonkennzeichen-motorrad>. Acesso em: 29 out. 2019.

YAN, Jun. Study of Bauschinger Effect in Various Spring Steels. 1998. 95 f. Dissertação (Mestrado em Engenharia Mecânica) - Universidade de Toronto, Toronto, 1998. Disponível em < https://tspace.library.utoronto.ca/bitstream/1807/12732/1/MQ45601.pdf > . Acesso em 29 out. 2019.

YUEN, Choon Wah; KARIM, Mohamed Rehan; SAIFIZUL, Ahmad. Analysis of Motorcyclist Riding Behaviour on Speed Table. The Scientific World Journal. Cairo, v. 2014. p. 1-14. 01 jun. 2014.

ZAMEL, Eduardo. Características sociodemográficas e de personalidade de uma amostra de motociclistas profissionais da cidade de Porto Alegre. 2009. 82 f. Dissertação

(Mestrado em Psicologia Clínica) - Pontifícia Universidade Católica do Rio Grande do Sul, Porto Alegre, 2009. 
APÊNDICE A- QUESTIONÁRIO 


\section{AVALIAÇÃO DO PERFIL DE PILOTAGEM DO MOTOCICLISTA BRASILEIRO NA CIDADE DE SÃO PAULO}

Questionário ao Participante da Pesquisa

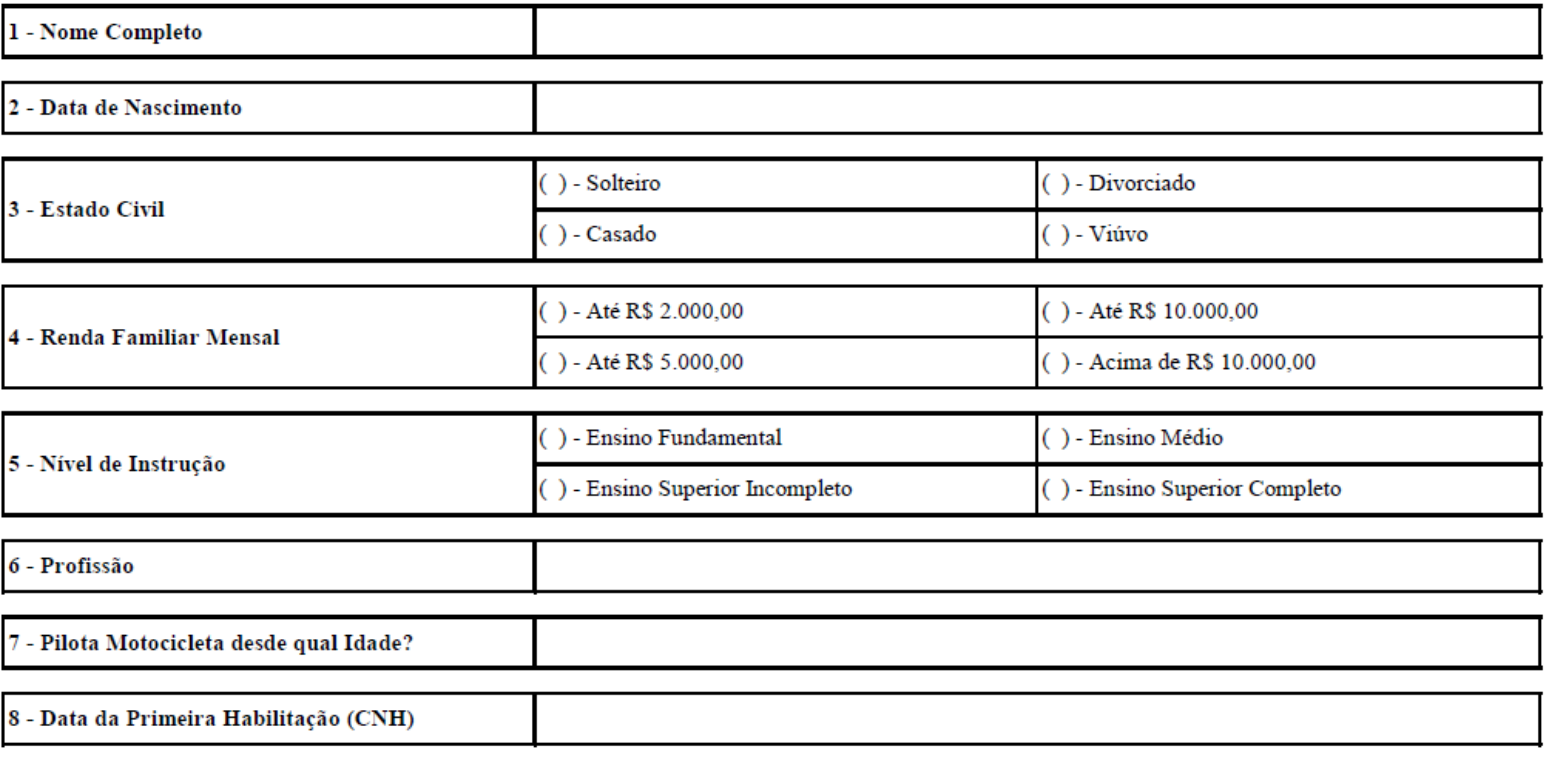

\begin{tabular}{|l|l|l|}
\hline \multirow{2}{*}{ - Utiliza a Motocicleta Para } & ( ) - Trabalho (Motofretista) & ( ) - Locomoção Urbana \\
\cline { 2 - 3 } & ( ) - Lazer & ( ) - Locomoção Urbana + Lazer \\
\hline
\end{tabular}

\begin{tabular}{|l|lll|l|}
\hline 10 - Possui Motocicleta Própria? & $1)$ & $/$ & $3)$ & $/$ \\
\cline { 2 - 5 } Se sim, informar marca/modelo/ano. & $2)$ & $/$ & ( ) - Não Possuo Motocicleta Própria \\
\hline
\end{tabular}

\begin{tabular}{|l|l|l|}
\hline \multirow{2}{*}{11 - Você pratica direção defesiva? } & ( ) - Sempre & ( ) - Somente quando não estou com pressa \\
\cline { 2 - 3 } & ( ) - Nunca & ( ) - Não sei o que é isso \\
\hline
\end{tabular}

\begin{tabular}{|l|l|l|}
\hline \multirow{2}{*}{$\begin{array}{l}12 \text { - Na sua opinião sua forma de } \\
\text { pilotagem é... }\end{array}$} & ( ) - Muito Conservadora & ( ) - Agressiva \\
\cline { 2 - 3 } & ( ) - Conservadora & ( ) - Muito Agressiva \\
\hline
\end{tabular}

\begin{tabular}{|l|l|l|}
\hline \multirow{2}{*}{13 - Você utiliza o corredor? } & ( ) - Nunca & ( ) - Sempre \\
\cline { 2 - 3 } & ( ) - Somente quando o trânsito está parado & \\
\hline
\end{tabular}

\begin{tabular}{|l|l|l|}
\hline \multirow{2}{*}{14 - Você utiliza a faixa exclusiva de ônibus? } & ( ) - Nunca & ( ) - Sempre \\
\cline { 2 - 3 } & ( ) - Somente quando o trânsito está parado & \\
\hline
\end{tabular}

\begin{tabular}{|l|l|}
\hline 15 - Durante o trabalho ou locomoção na cidade, quantos $\mathrm{km}$ você roda por dia (média)? & \\
\cline { 2 - 2 } Responder somente se utilizar motocicleta para trabalho ou locomoção urbana. & $\mathrm{km} / \mathrm{dia}$ \\
\hline
\end{tabular}
Responder somente se utilizar motocicleta para trabalho ou locomoção urbana.

\begin{tabular}{|l|l|}
\hline $\begin{array}{l}16 \text { - Durante viagens de lazer, quantos km você roda por mês (média)? } \\
\text { Responder somente se utilizar motocicleta para lazer. }\end{array}$ & $\mathrm{km} / \mathrm{mês}$ \\
\cline { 2 - 3 } &
\end{tabular}

17 - Você deseja receber os resultados da pesquisa? Se sim, escreva seu e-mail ao lado

São Paulo, __ de de 
APÊNDICE B - ALGORÍTIMO DESENVOLVIDO EM MATLAB ${ }^{\circledR}$ PARA ANÁLISE DO PERFIL DE VELOCIDADE ADOTADO PELOS 30 PILOTOS 
clear all

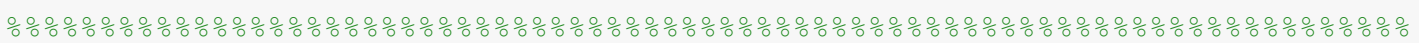
-Início da Leitura dos Dados do Piloto 1

open 'C: \Mestrado\Medições com Datalogger \01.mat';

sinalvelsf = ans.signale.V_WHL_FT_MOTBK_2010.daten';

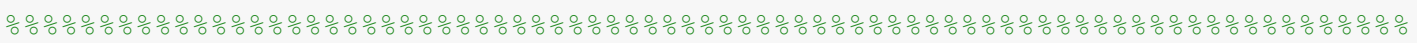
oInício da Leitura dos Dados do Piloto 2

open 'C: \Mestrado\Medições com Datalogger \02.mat' ;

sinalvelrs = ans.signale.V_WHL_FT_MOTBK_2010.daten';

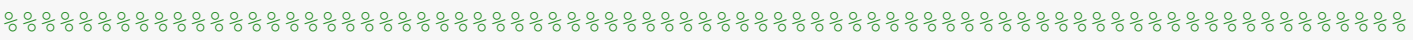
\%Início da Leitura dos Dados do Piloto 3

open 'C: \Mestrado\Medições com Datalogger \03.mat';

sinalveleb = ans.signale.V_WHL_FT_MOTBK_2010.daten';

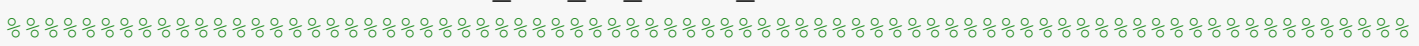
onício da Leitura dos Dados do Piloto 4

open 'C: \Mestrado\Medições com Datalogger \04.mat';

sinalvelfa = ans.signale.V_WHL_FT_MOTBK_2010.daten';

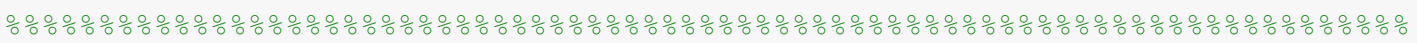
onício da Leitura dos Dados do Piloto 5

open 'C: \Mestrado\Medições com Datalogger\05.mat' ;

sinalveldc = ans.signale.V_WHL_FT_MOTBK_2010.daten';

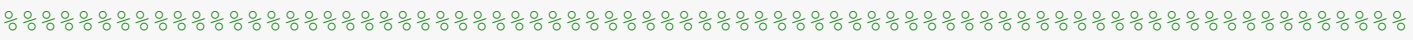
\%Início da Leitura dos Dados do Piloto 6

open 'C: \Mestrado\Medições com Datalogger\06.mat';

sinalvelrn = ans.signale.V_WHL_FT_MOTBK_2010.daten';

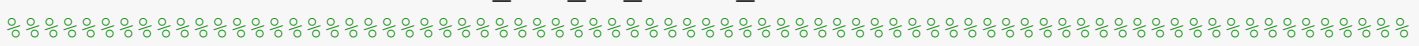
onício da Leitura dos Dados do Piloto 7

open 'C: \Mestrado\Medições com Datalogger \07.mat';

sinalvelrt = ans.signale.V_WHL_FT_MOTBK_2010.daten';

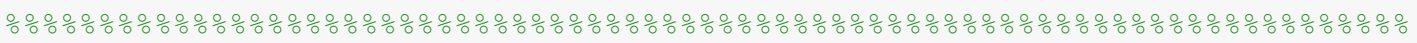
onício da Leitura dos Dados do Piloto 8

open 'C: \Mestrado\Medições com Datalogger\08\01.mat';

vel1 = ans.signale.V_WHL_FT_MOTBK_2010.daten;

open 'C: \Mestrado\Medições com Datalogger \08\02.mat';

vel2 = ans.signale.V_WHL_FT_MOTBK_2010.daten;

o Unificando os Vetores por Conta da Queda do Motor

sinalvelfm = $\operatorname{cat}(2$, vell, vel2)';

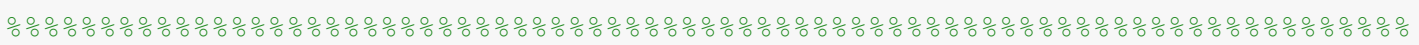
onício da Leitura dos Dados do Piloto 9

open 'C: \Mestrado\Medições com Datalogger \09\01.mat';

vel3 = ans.signale.V_WHL_FT_MOTBK_2010.daten;

open 'C: \Mestrado\Medições com Datalogger\09\02.mat';

vel4 = ans.signale.V_WHL_FT_MOTBK_2010.daten;

o Unificando os Vetores por Conta da Queda do Motor

sinalvelpa $=\operatorname{cat}(2$, vel3, vel4)';

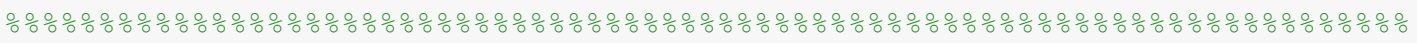
onício da Leitura dos Dados do Piloto 10

open 'C: \Mestrado\Medições com Datalogger \10.mat';

sinalvelmh = ans.signale.V_WHL_FT_MOTBK_2010.daten';

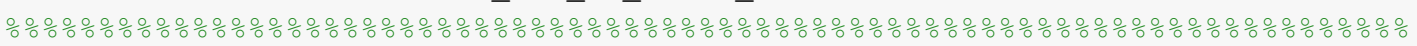

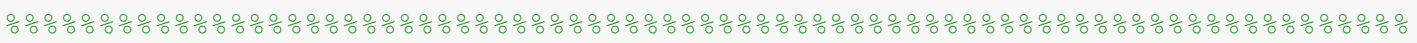
\%Início da Leitura dos Dados do Piloto 11

open 'C: \Mestrado\Medições com Datalogger \11 \01.mat';

sinalvelin1 = ans.signale.V_WHL_FT_MOTBK_2010.daten; 
open 'C: \Mestrado\Medições com Datalogger \11\02.mat'; sinalvelin2 = ans.signale.V_WHL_FT_MOTBK_2010.daten; o Unificando os Vetores por Conta da Queda do Motor sinalvelin = cat (2, sinalvelin1, sinalvelin2)';

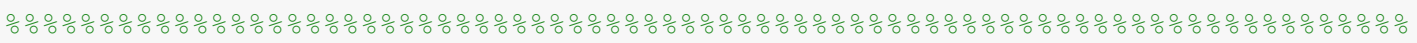
\%Início da Leitura dos Dados do Piloto 12

open 'C: \Mestrado\Medições com Datalogger \12.mat'; sinalveldf = ans.signale.V_WHL_FT_MOTBK_2010.daten';

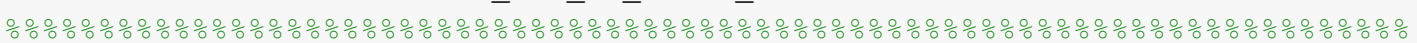
onício da Leitura dos Dados do Piloto 13

open 'C: \Mestrado\Medições com Datalogger \13.mat'; sinalveljs = ans.signale.V_WHL_FT_MOTBK_2010.daten';

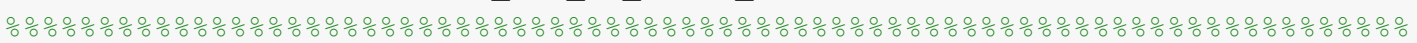
\%Início da Leitura dos Dados do Piloto 14 open 'C: \Mestrado\Medições com Datalogger\14\01.mat'; sinalvelpn1 = ans.signale.V_WHL_FT_MOTBK_2010.daten; open 'C: \Mestrado\Medições com Datalogger\14\02.mat'; sinalvelpn2 = ans.signale.V_WHL_FT_MOTBK_2010.daten; \% Unificando os Vetores por Conta da Queda do Motor sinalvelpn $=\operatorname{cat}(2$, sinalvelpn 1 , sinalvelpn2)';

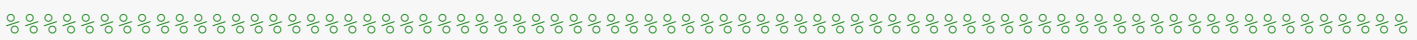
-Início da Leitura dos Dados do Piloto 15

open 'C: \Mestrado\Medições com Datalogger \15.mat'; sinalvelse = ans.signale.V_WHL_FT_MOTBK_2010.daten';

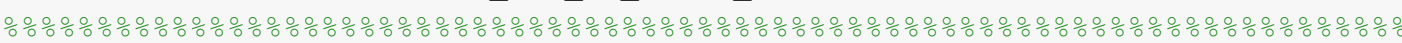
oInício da Leitura dos Dados do Piloto 16 open 'C: \Mestrado\Medições com Datalogger\16\01.mat'; sinalvelrd1 = ans.signale.V_WHL_FT_MOTBK_2010.daten; open 'C: \Mestrado\Medições com Datalogger\16\02.mat'; sinalvelrd2 = ans.signale.V_WHL_FT_MOTBK_2010.daten; open 'C: \Mestrado\Medições com Datalogger\16\03.mat'; sinalvelrd3 = ans.signale.V_WHL_FT_MOTBK_2010.daten; \% Unificando os Vetores por Conta da Queda do Motor sinalvelrd $=\operatorname{cat}(2$, sinalvelrd1, sinalvelrd2, sinalvelrd3)';

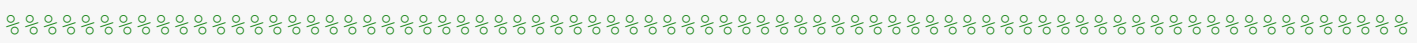
-Início da Leitura dos Dados do Piloto 17 open 'C: \Mestrado\Medições com Datalogger \17\01.mat'; sinalvelws1 = ans.signale.V_WHL_FT_MOTBK_2010.daten; open 'C: \Mestrado\Medições com Datalogger \17\02.mat'; sinalvelws2 = ans.signale.V_WHL_FT_MOTBK_2010.daten; \% Unificando os Vetores por Conta da Queda do Motor sinalvelws $=\operatorname{cat}(2$, sinalvelws1, sinalvelws 2$)$ ';

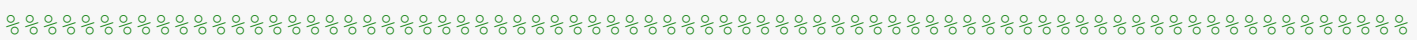
onício da Leitura dos Dados do Piloto 18

open 'C: \Mestrado\Medições com Datalogger \18.mat'; sinalvelva = ans.signale.V_WHL_FT_MOTBK_2010.daten';

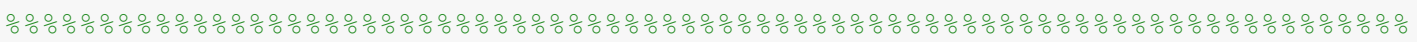
oInício da Leitura dos Dados do Piloto 19 open 'C: \Mestrado\Medições com Datalogger \19\01.mat'; sinalvelvd1 = ans.signale.V_WHL_FT_MOTBK_2010.daten; open 'C: \Mestrado\Medições com Datalogger\19\02.mat'; sinalvelvd2 = ans.signale.V_WHL_FT_MOTBK_2010.daten; open 'C: \Mestrado\Medições com Datalogger\19\03.mat'; sinalvelvd3 = ans.signale.V_WHL_FT_MOTBK_2010.daten; \% Unificando os Vetores por Conta da Queda do Motor 
sinalvelvd = cat (2, sinalvelvd1, sinalvelvd2, sinalvelvd3) ' ;

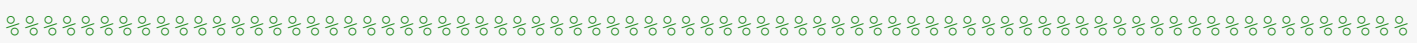
oInício da Leitura dos Dados do Piloto 20

open 'C: \Mestrado\Medições com Datalogger\20.mat' ;

sinalvelri = ans.signale.V_WHL_FT_MOTBK_2010.daten';

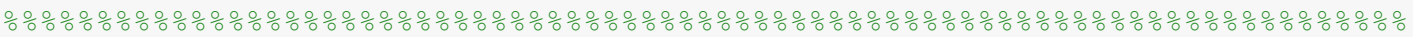

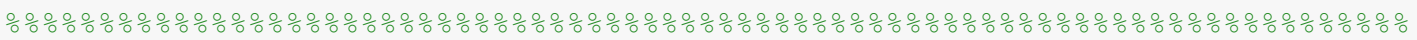

OInício da Leitura dos Dados do Piloto 21

open 'C: \Mestrado\Medições com Datalogger\21\01.mat';

sinalvelan1 = ans.signale.V_WHL_FT_MOTBK_2010.daten;

open 'C: \Mestrado\Medições com Datalogger $\backslash 21 \backslash 02 . m a t '$;

sinalvelan2 = ans.signale.V_WHL_FT_MOTBK_2010.daten;

\% Unificando os Vetores por Conta da Queda do Motor

sinalvelan = cat $(2$, sinalvelan 1, sinalvelan2)';

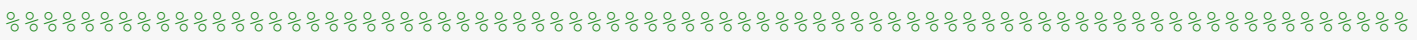

oInício da Leitura dos Dados do Piloto 22

open 'C: \Mestrado\Medições com Datalogger\22.mat';

sinalvells = ans.signale.V_WHL_FT_MOTBK_2010.daten';

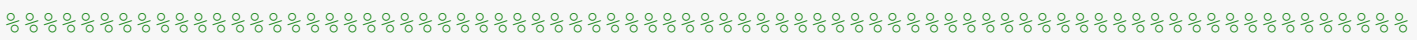

onício da Leitura dos Dados do Piloto 23

open 'C: \Mestrado\Medições com Datalogger \23.mat';

sinalvelmt = ans.signale.V_WHL_FT_MOTBK_2010.daten';

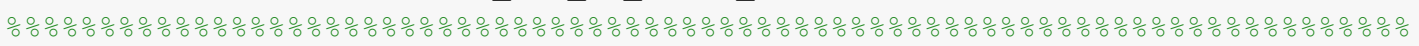

oInício da Leitura dos Dados do Piloto 24

open 'C: \Mestrado\Medições com Datalogger \24.mat' ;

sinalvella = ans.signale.V_WHL_FT_MOTBK_2010.daten';

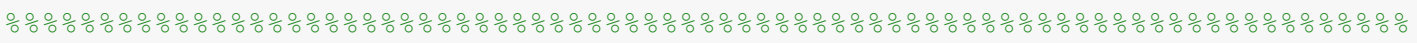

\%Início da Leitura dos Dados do Piloto 25

open 'C: \Mestrado\Medições com Datalogger \25.mat' ;

sinalvelep = ans.signale.V_WHL_FT_MOTBK_2010.daten';

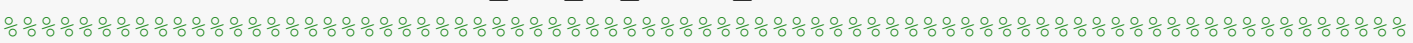

onício da Leitura dos Dados do Piloto 26

open 'C: \Mestrado\Medições com Datalogger \26\01.mat';

signvveh1 = ans.signale.V_WHL_FT_MOTBK_2010.daten; \%.Sinal da velocidade [ $\mathrm{km} / \mathrm{h}]$ open 'C: \Mestrado\Medições com Datalogger $26 \backslash 02 . m a t '$;

signvveh2 = ans.signale.V_WHL_FT_MOTBK_2010.daten; \%.Sinal da velocidade [km/h] open 'C: \Mestrado\Medições com Datalogger\26\03.mat';

signvveh3 = ans.signale.V_WHL_FT_MOTBK_2010.daten; \%Sinal da velocidade [km/h] open 'C: \Mestrado\Medições com Datalogger\26\04.mat';

signvveh4 = ans.signale.V_WHL_FT_MOTBK_2010.daten; \%Sinal da velocidade [km/h] open 'C: \Mestrado\Medições com Datalogger\26\05.mat';

signvveh5 = ans.signale.V_WHL_FT_MOTBK_2010.daten; \%Sinal da velocidade [km/h] open 'C: \Mestrado\Medições com Datalogger\26\06.mat';

signvveh6 = ans.signale.V_WHL_FT_MOTBK_2010.daten; \%Sinal da velocidade [km/h] open 'C: \Mestrado\Medições com Datalogger\26\07.mat';

signvveh7 = ans.signale.V_WHL_FT_MOTBK_2010.daten; \%Sinal da velocidade [km/h] open 'C: \Mestrado\Medições com Datalogger \26\08.mat';

signvveh8 = ans.signale.V_WHL_FT_MOTBK_2010.daten; \%Sinal da velocidade [km/h] open 'C: \Mestrado\Medições com Datalogger\26\09.mat';

signvveh9 = ans.signale.V_WHL_FT_MOTBK_2010.daten; \%Sinal da velocidade [km/h] open 'C: \Mestrado\Medições com Datalogger\26\10.mat';

signvveh10 = ans.signale.V_WHL_FT_MOTBK_2010.daten; \%Sinal da velocidade [km/h] open 'C: \Mestrado\Medições com Datalogger \26\11.mat';

signvveh11 = ans.signale.V_WHL_FT_MOTBK_2010.daten; \%Sinal da velocidade [km/h] 
\% Unificando os Vetores por Conta da Queda do Motor sinalvelpc $=$

cat (2, signvveh1, signvveh2, signvveh3, signvveh4, signvveh5, signvveh6, signvveh7, signvve h8, signvveh9, signvveh10, signvveh11) ' ;

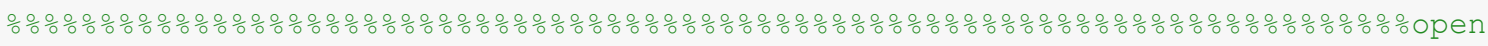
\%Início da Leitura dos Dados do Piloto 27

open 'C: \Mestrado\Medições com Datalogger $27 \backslash 01 . m a t '$;

signvvehd1 = ans.signale.V_WHL_FT_MOTBK_2010.daten; \%Sinal da velocidade [km/h] open 'C: \Mestrado\Medições com Datalogger $27 \backslash 02 . m a t '$;

signvvehd2 = ans.signale.V_WHL_FT_MOTBK_2010.daten; \%Sinal da velocidade [km/h] open 'C: \Mestrado\Medições com Datalogger $27 \backslash 03$. mat' $^{2}$;

signvvehd3 = ans.signale.V_WHL_FT_MOTBK_2010.daten; \%Sinal da velocidade [km/h] open 'C: \Mestrado\Medições com Datalogger $27 \backslash 04 . m a t '$;

signvvehd4 = ans.signale.V_WHL_FT_MOTBK_2010.daten; \%Sinal da velocidade [km/h]

\% Unificando os Vetores por Conta da Queda do Motor

sinalveldl = cat (2, signvvehd1, signvvehd2, signvvehd3, signvvehd4) ' ;

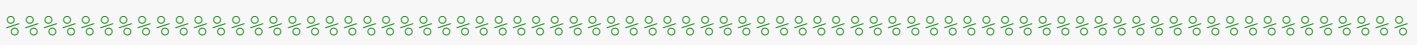

Início da Leitura dos Dados do Piloto 28

open 'C: \Mestrado\Medições com Datalogger \28.mat' ;

sinalvelgl = ans.signale.V_WHL_FT_MOTBK_2010.daten' ;

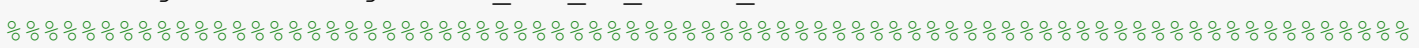

\%Início da Leitura dos Dados do Piloto 29

open 'C: \Mestrado\Medições com Datalogger \29.mat' ;

sinalvelsd = ans.signale.V_WHL_FT_MOTBK_2010.daten' ;

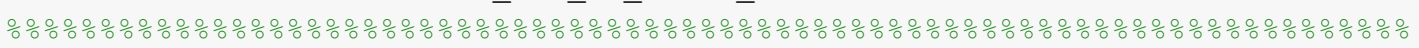

\%Início da Leitura dos Dados do Piloto 30

open 'C: \Mestrado\Medições com Datalogger \30.mat' ;

sinalveljg = ans.signale.V_WHL_FT_MOTBK_2010.daten' ;

-Concatena os Dados Em um Unico Vetor

$\mathrm{s} 1=$

cat (1, sinalvelsf, sinalvelrs, sinalveleb, sinalvelfa, sinalveldc, sinalvelrn, sinalvelrt, sinalvelfm, sinalvelpa, sinalvelmh, sinalvelin, sinalveldf, sinalveljs, sinalvelpn, sinalv else, sinalvelrd, sinalvelws, sinalvelva, sinalvelvd, sinalvelri, sinalvelan, sinalvells, s inalvelmt, sinalvella, sinalvelep, sinalvelpc, sinalveldl, sinalvelgl, sinalvelsd, sinalve ljg) ;

ofiltro - Remoção dos dados abaixo de $1 \mathrm{~km} / \mathrm{h}$

$\mathrm{A}=\mathrm{s} 1$;

rowstoDelete $=\mathrm{A}<1$;

$\mathrm{A}($ rowstoDelete) $=$ [];

\%Plota Histograma

figure

edges $=[0: 5: 150]$;

hist $=$ histogram $(\mathrm{A}$, edges $)$;

oplota Boxplot

figure

hold on

boxplot $(\mathrm{A})$;

title('Distribuição da Velocidade Para os 30 Pilotos')

xlabel ('Pilotos')

ylabel ('Velocidade ( $\mathrm{km} / \mathrm{h})$ ') 
APÊNDICE C - ALGORÍTIMO DESENVOLVIDO EM MATLAB ${ }^{\circledR}$ PARA ANÁLISE DO PERFIL DE UTILIZAÇÃO DO ACELERADOR PELOS 30 PILOTOS 
clear all

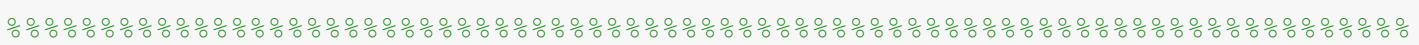
oInício da Leitura dos Dados do Piloto 1

open 'C: \Mestrado\Medições com Datalogger \01.mat';

sinalacelsf = ans.signale.ANG_THVA_MOTBK_2010.daten';

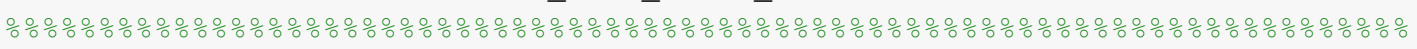
oInício da Leitura dos Dados do Piloto 2

open 'C: \Mestrado\Medições com Datalogger \02.mat';

sinalacelrs = ans.signale.ANG_THVA_MOTBK_2010.daten';

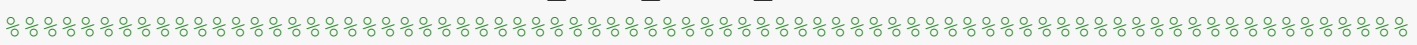
onício da Leitura dos Dados do Piloto 3

open 'C: \Mestrado\Medições com Datalogger \03.mat';

sinalaceleb = ans.signale.ANG_THVA_MOTBK_2010.daten' ;

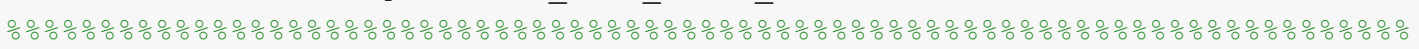
onício da Leitura dos Dados do Piloto 4

open 'C: \Mestrado\Medições com Datalogger\04.mat';

sinalacelfa = ans.signale.ANG_THVA_MOTBK_2010.daten' ;

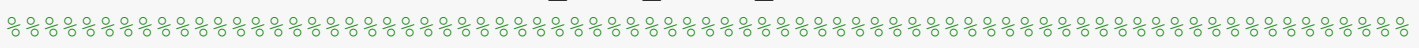
onício da Leitura dos Dados do Piloto 5

open 'C: \Mestrado\Medições com Datalogger\05.mat';

sinalaceldc = ans.signale.ANG_THVA_MOTBK_2010.daten';

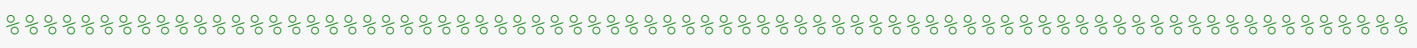
\% Início da Leitura dos Dados do Piloto 6

open 'C: \Mestrado\Medições com Datalogger \06.mat';

sinalacelrn = ans.signale.ANG_THVA_MOTBK_2010.daten';

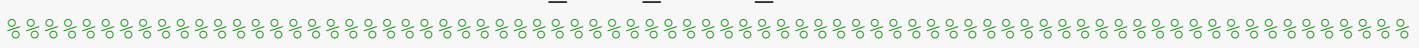
-Início da Leitura dos Dados do Piloto 7

open 'C: \Mestrado\Medições com Datalogger \07.mat';

sinalacelrt = ans.signale.ANG_THVA_MOTBK_2010.daten';

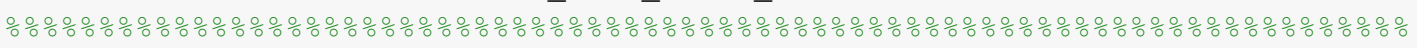

\%Início da Leitura dos Dados do Piloto 8

open 'C: \Mestrado\Medições com Datalogger \08\01.mat';

acel1 = ans.signale.ANG_THVA_MOTBK_2010.daten;

open 'C: \Mestrado\Medições com Datalogger \08\02.mat' ;

acel2 = ans.signale.ANG_THVA_MOTBK_2010.daten;

o Unificando os Vetores por Conta da Queda do Motor

sinalacelfm = $\operatorname{cat}(2, \operatorname{acel} 1, \operatorname{acel} 2)^{\prime}$;

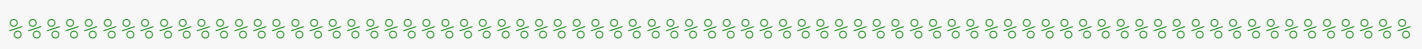
oInício da Leitura dos Dados do Piloto 9

open 'C: \Mestrado\Medições com Datalogger \09\01.mat';

acel3 = ans.signale.ANG_THVA_MOTBK_2010.daten;

open 'C: \Mestrado\Medições com Datalogger \09\02.mat' ;

acel4 = ans.signale.ANG_THVA_MOTBK_2010.daten;

\% Unificando os Vetores por Conta da Queda do Motor

sinalacelpa $=\operatorname{cat}(2, \operatorname{acel} 3, \operatorname{acel} 4)$ ';

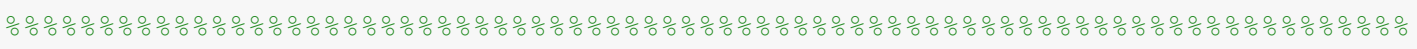
oInício da Leitura dos Dados do Piloto 10

open 'C: \Mestrado\Medições com Datalogger\10.mat';

sinalacelmh = ans.signale.ANG_THVA_MOTBK_2010.daten';

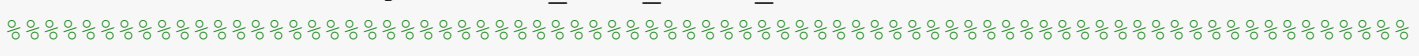

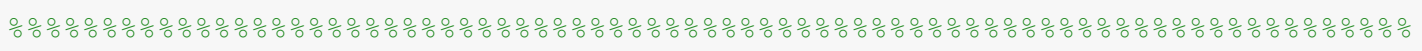
oInício da Leitura dos Dados do Piloto 11

open 'C: \Mestrado\Medições com Datalogger \11\01.mat';

sinalacelin1 = ans.signale.ANG_THVA_MOTBK_2010.daten; 
open 'C: \Mestrado\Medições com Datalogger \11 \02.mat'; sinalacelin2 = ans.signale.ANG_THVA_MOTBK_2010.daten; o Unificando os Vetores por Conta da Queda do Motor sinalacelin = cat $(2$, sinalacelin1, sinalacelin2)';

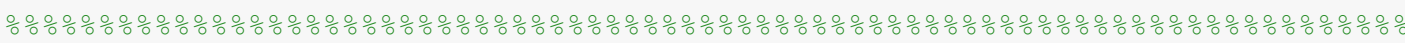
\%Início da Leitura dos Dados do Piloto 12

open 'C: \Mestrado\Medições com Datalogger\12.mat'; sinalaceldf = ans.signale.ANG_THVA_MOTBK_2010.daten';

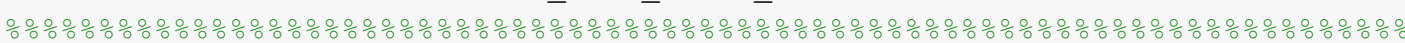
onício da Leitura dos Dados do Piloto 13

open 'C: \Mestrado\Medições com Datalogger \13.mat'; sinalaceljs = ans.signale.ANG_THVA_MOTBK_2010.daten';

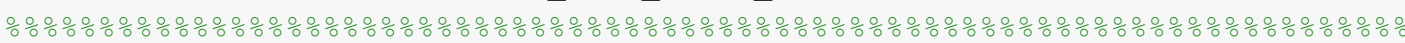
oInício da Leitura dos Dados do Piloto 14 open 'C: \Mestrado\Medições com Datalogger\14\01.mat'; sinalacelpn1 = ans.signale.ANG_THVA_MOTBK_2010.daten; open 'C: \Mestrado\Medições com Datalogger\14\02.mat'; sinalacelpn2 = ans.signale.ANG_THVA_MOTBK_2010.daten; \% Unificando os Vetores por Conta da Queda do Motor sinalacelpn $=\operatorname{cat}(2$, sinalacelpn1, sinalacelpn2)';

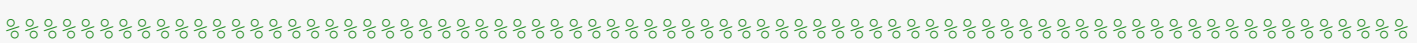
oInício da Leitura dos Dados do Piloto 15

open 'C: \Mestrado\Medições com Datalogger \15.mat'; sinalacelse = ans.signale.ANG_THVA_MOTBK_2010.daten';

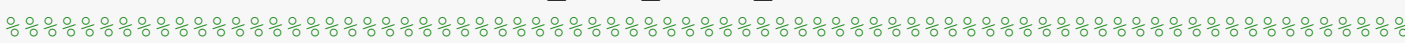
oInício da Leitura dos Dados do Piloto 16 open 'C: \Mestrado\Medições com Datalogger\16\01.mat'; sinalacelrd1 = ans.signale.ANG_THVA_MOTBK_2010.daten; open 'C: \Mestrado\Medições com Datalogger\16\02.mat'; sinalacelrd2 = ans.signale.ANG_THVA_MOTBK_2010.daten; open 'C: \Mestrado\Medições com Datalogger\16\03.mat'; sinalacelrd3 = ans.signale.ANG_THVA_MOTBK_2010.daten; \% Unificando os Vetores por Conta da Queda do Motor sinalacelrd $=\operatorname{cat}(2$, sinalacelrd1, sinalacelrd2, sinalacelrd3) ';

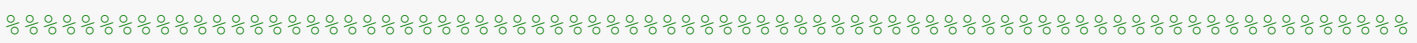
-Início da Leitura dos Dados do Piloto 17 open 'C: \Mestrado\Medições com Datalogger \17\01.mat'; sinalacelws1 = ans.signale.ANG_THVA_MOTBK_2010.daten; open 'C: \Mestrado\Medições com Datalogger\17\02.mat'; sinalacelws2 = ans.signale.ANG_THVA_MOTBK_2010.daten; \% Unificando os Vetores por Conta da Queda do Motor sinalacelws $=\operatorname{cat}(2, \text { sinalacelws } 1 \text {, sinalacelws } 2)^{\prime}$ ';

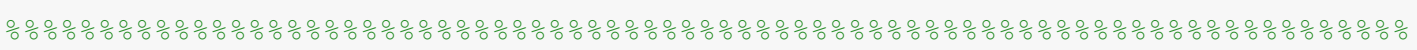
onício da Leitura dos Dados do Piloto 18 open 'C: \Mestrado\Medições com Datalogger \18.mat' ; sinalacelva = ans.signale.ANG_THVA_MOTBK_2010.daten' ;

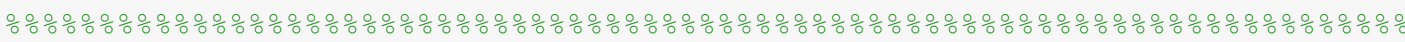
oInício da Leitura dos Dados do Piloto 19 open 'C: \Mestrado\Medições com Datalogger \19\01.mat' ; sinalacelvd1 = ans.signale.ANG_THVA_MOTBK_2010.daten; open 'C: \Mestrado\Medições com Datalogger\19\02.mat'; sinalacelvd2 = ans.signale.ANG_THVA_MOTBK_2010.daten; open 'C: \Mestrado\Medições com Datalogger\19\03.mat'; sinalacelvd3 = ans.signale.ANG_THVA_MOTBK_2010.daten; \% Unificando os Vetores por Conta da Queda do Motor 
sinalacelvd = cat $(2$, sinalacelvd1, sinalacelvd2, sinalacelvd3)' ;

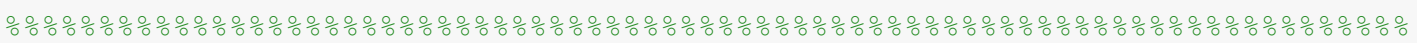
oInício da Leitura dos Dados do Piloto 20

open 'C: \Mestrado\Medições com Datalogger $\backslash 20$. mat';

sinalacelri = ans.signale.ANG_THVA_MOTBK_2010.daten' ;

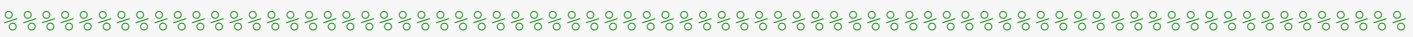

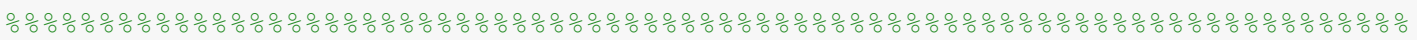

OInício da Leitura dos Dados do Piloto 21

open 'C: \Mestrado\Medições com Datalogger\21\01.mat';

sinalacelan1 = ans.signale.ANG_THVA_MOTBK_2010.daten;

open 'C: \Mestrado\Medições com Datalogger \21\02.mat';

sinalacelan2 = ans.signale.ANG_THVA_MOTBK_2010.daten;

o Unificando os Vetores por Conta da Queda do Motor

sinalacelan = $\operatorname{cat}(2, \text { sinalacelan1, sinalacelan } 2)^{\prime}$ ';

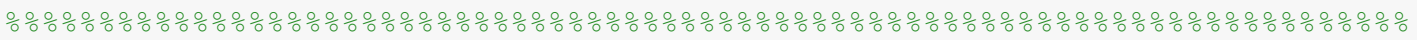

onício da Leitura dos Dados do Piloto 22

open 'C: \Mestrado\Medições com Datalogger\22.mat';

sinalacells = ans.signale.ANG_THVA_MOTBK_2010.daten';

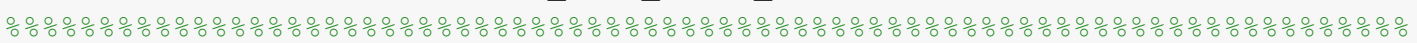

oInício da Leitura dos Dados do Piloto 23

open 'C: \Mestrado\Medições com Datalogger\23.mat';

sinalacelmt = ans.signale.ANG THVA MOTBK 2010.daten';

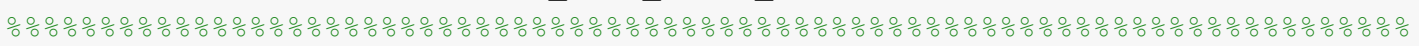

oInício da Leitura dos Dados do Piloto 24

open 'C: \Mestrado\Medições com Datalogger \24.mat' ;

sinalacella = ans.signale.ANG_THVA_MOTBK_2010.daten';

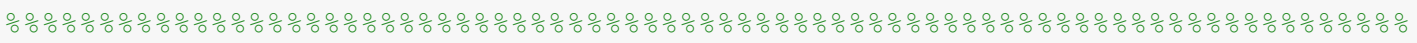

\%Início da Leitura dos Dados do Piloto 25

open 'C: \Mestrado\Medições com Datalogger \25.mat';

sinalacelep = ans.signale.ANG_THVA_MOTBK_2010.daten';

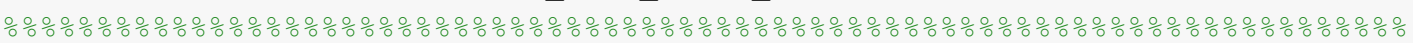

onício da Leitura dos Dados do Piloto 26

open 'C: \Mestrado\Medições com Datalogger \26\01.mat';

signalacelpc1 = ans.signale.ANG_THVA_MOTBK_2010.daten;

open 'C: \Mestrado\Medições com Datalogger\26\02.mat';

signalacelpc2 = ans.signale.ANG_THVA_MOTBK_2010.daten;

open 'C: \Mestrado\Medições com Datalogger\26\03.mat';

signalacelpc3 = ans.signale.ANG_THVA_MOTBK_2010.daten;

open 'C: \Mestrado\Medições com Datalogger\26\04.mat';

signalacelpc4 = ans.signale.ANG_THVA_MOTBK_2010.daten;

open 'C: \Mestrado\Medições com Datalogger\26\05.mat';

signalacelpc5 = ans.signale.ANG_THVA_MOTBK_2010.daten;

open 'C: \Mestrado\Medições com Datalogger\26\06.mat';

signalacelpc 6 = ans.signale.ANG_THVA_MOTBK_2010.daten;

open 'C: \Mestrado\Medições com Datalogger \26\07.mat';

signalacelpc7 = ans.signale.ANG_THVA_MOTBK_2010.daten;

open 'C: \Mestrado\Medições com Datalogger \26\08.mat';

signalacelpc8 = ans.signale.ANG_THVA_MOTBK_2010.daten;

open 'C: \Mestrado\Medições com Datalogger \26\09.mat';

signalacelpc9 = ans.signale.ANG_THVA_MOTBK_2010.daten;

open 'C: \Mestrado\Medições com Datalogger\26\10.mat';

signalacelpc10 = ans.signale.ANG_THVA_MOTBK_2010.daten;

open 'C: \Mestrado\Medições com Datalogger\26\11.mat';

signalacelpc11 = ans.signale.ANG_THVA_MOTBK_2010.daten;

\% Unificando os Vetores por Conta da Queda do Motor 
sinalacelpc $=$

cat (2, signalacelpc1, signalacelpc2, signalacelpc3, signalacelpc4, signalacelpc5, signala celpc6, signalacelpc7, signalacelpc8, signalacelpc9, signalacelpc10, signalacelpc11) ' ;

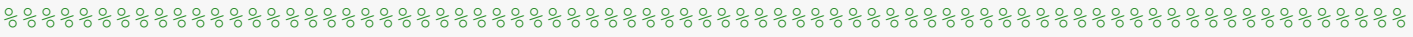
Início da Leitura dos Dados do Piloto 27

open 'C: \Mestrado\Medições com Datalogger\27\01.mat';

signalaceldl1 = ans.signale.ANG_THVA_MOTBK_2010.daten;

open 'C: \Mestrado\Medições com Datalogger\27\02.mat';

signalaceldl2 = ans.signale.ANG_THVA_MOTBK_2010.daten;

open 'C: \Mestrado\Medições com Datalogger \27\03.mat';

signalaceldl3 = ans.signale.ANG_THVA_MOTBK_2010.daten;

open 'C: \Mestrado\Medições com Datalogger\27\04.mat';

signalaceldl4 = ans.signale.ANG_THVA_MOTBK_2010.daten;

- Unificando os Vetores por Conta da Queda do Motor

signalaceldl = cat (2, signalaceldl1, signalaceldl2, signalaceldl3, signalaceldl4) ';

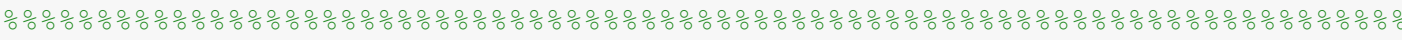

\%Início da Leitura dos Dados do Piloto 28

open 'C: \Mestrado\Medições com Datalogger \28.mat';

sinalacelgl = ans.signale.ANG_THVA_MOTBK_2010.daten';

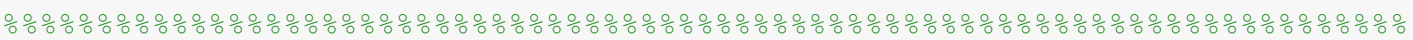

oInício da Leitura dos Dados do Piloto 29

open 'C: \Mestrado\Medições com Datalogger \29.mat';

sinalacelsd = ans.signale.ANG_THVA_MOTBK_2010.daten';

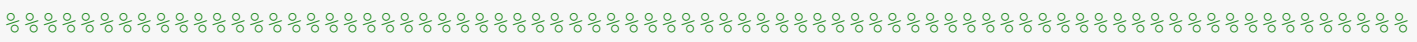

\%Início da Leitura dos Dados do Piloto 30

open 'C: \Mestrado\Medições com Datalogger\30.mat';

sinalaceljg = ans.signale.ANG_THVA_MOTBK_2010.daten';

oConcatena os Dados Em um Unico Vetor

$\mathrm{s} 1=$

cat (1, sinalacelsf, sinalacelrs, sinalaceleb, sinalacelfa, sinalaceldc, sinalacelrn, sinal acelrt, sinalacelfm, sinalacelpa, sinalacelmh, sinalacelin, sinalaceldf, sinalaceljs, sina lacelpn, sinalacelse, sinalacelrd, sinalacelws, sinalacelva, sinalacelvd, sinalacelri, sin alacelan, sinalacells, sinalacelmt, sinalacella, sinalacelep, sinalacelpc, signalaceldl,s inalacelgl, sinalacelsd, sinalaceljg);

oFiltro - Remoção dos dados abaixo de 1\% de abertura e elimina dados

o"Fantasma" acima de 100\% de abertura

$\mathrm{A}=\mathrm{s} 1$;

rowsToDelete $=\mathrm{A}<1 \mid \mathrm{A}>100$;

$A($ rowstoDelete $)=[]$;

oPlota Histograma

figure

$\mathrm{x}=[\mathrm{A}]$;

edges $=[0: 5: 150]$;

hist $=$ histogram $(x$, edges $)$;

oPlota Boxplot

figure

boxplot $(\mathrm{x})$;

title('Perfil de Utilização do Acelerador para os 30 Pilotos')

xlabel ('Pilotos')

ylabel ('Porcentagem De Abertura do Acelerador (\%) ') 
APÊNDICE D - ALGORÍTIMO DESENVOLVIDO EM MATLAB ${ }^{\circledR}$ PARA CÁLCULO DA FORÇA VERTICAL NO EIXO DIANTEIRO, CONTAGEM DE CICLOS RAINFLOW, CÁLCULO DO PSEUdO DANO E AMPLITUDE EQUIVALENTE PARA CADA PILOTO 


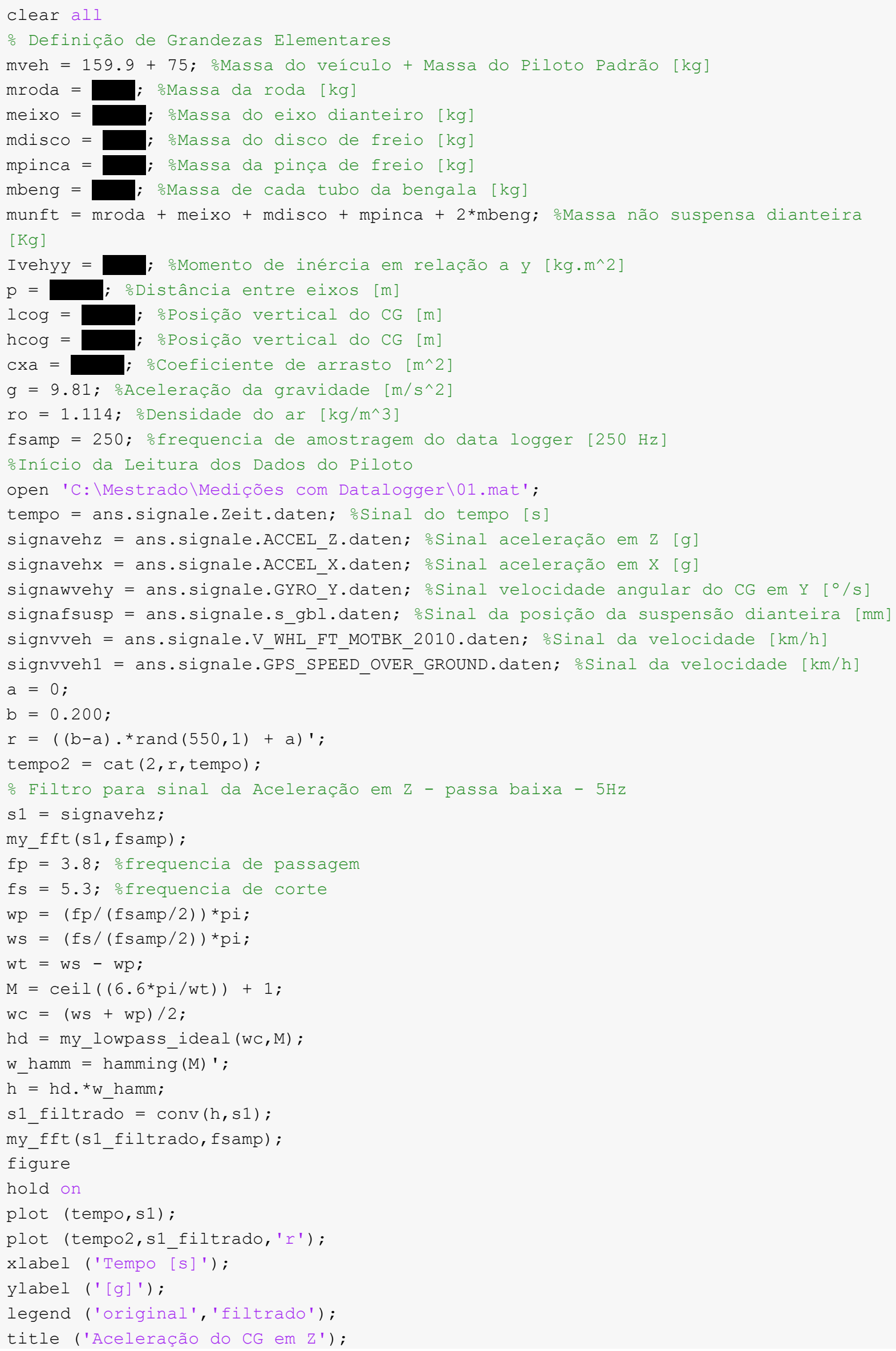




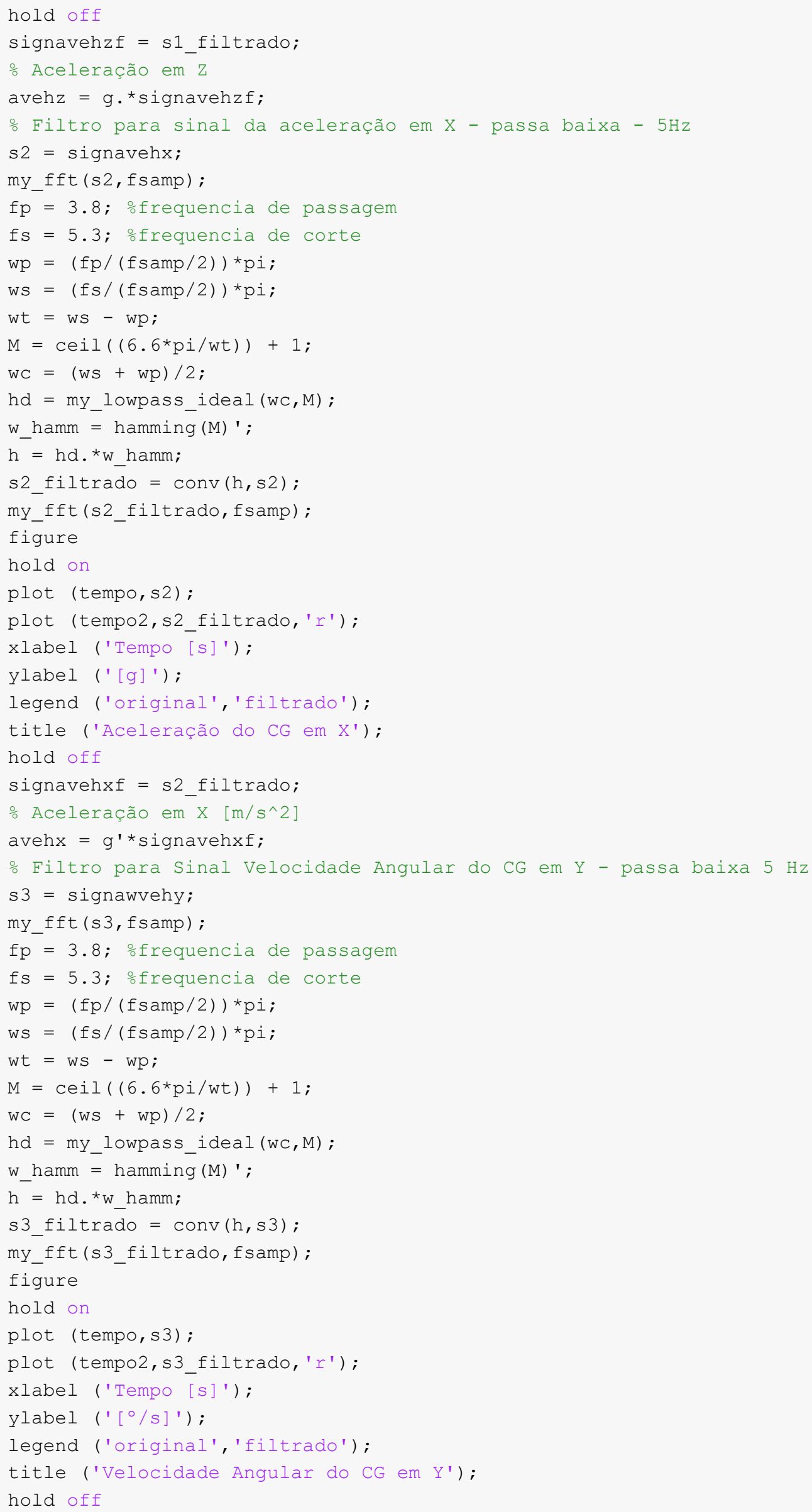




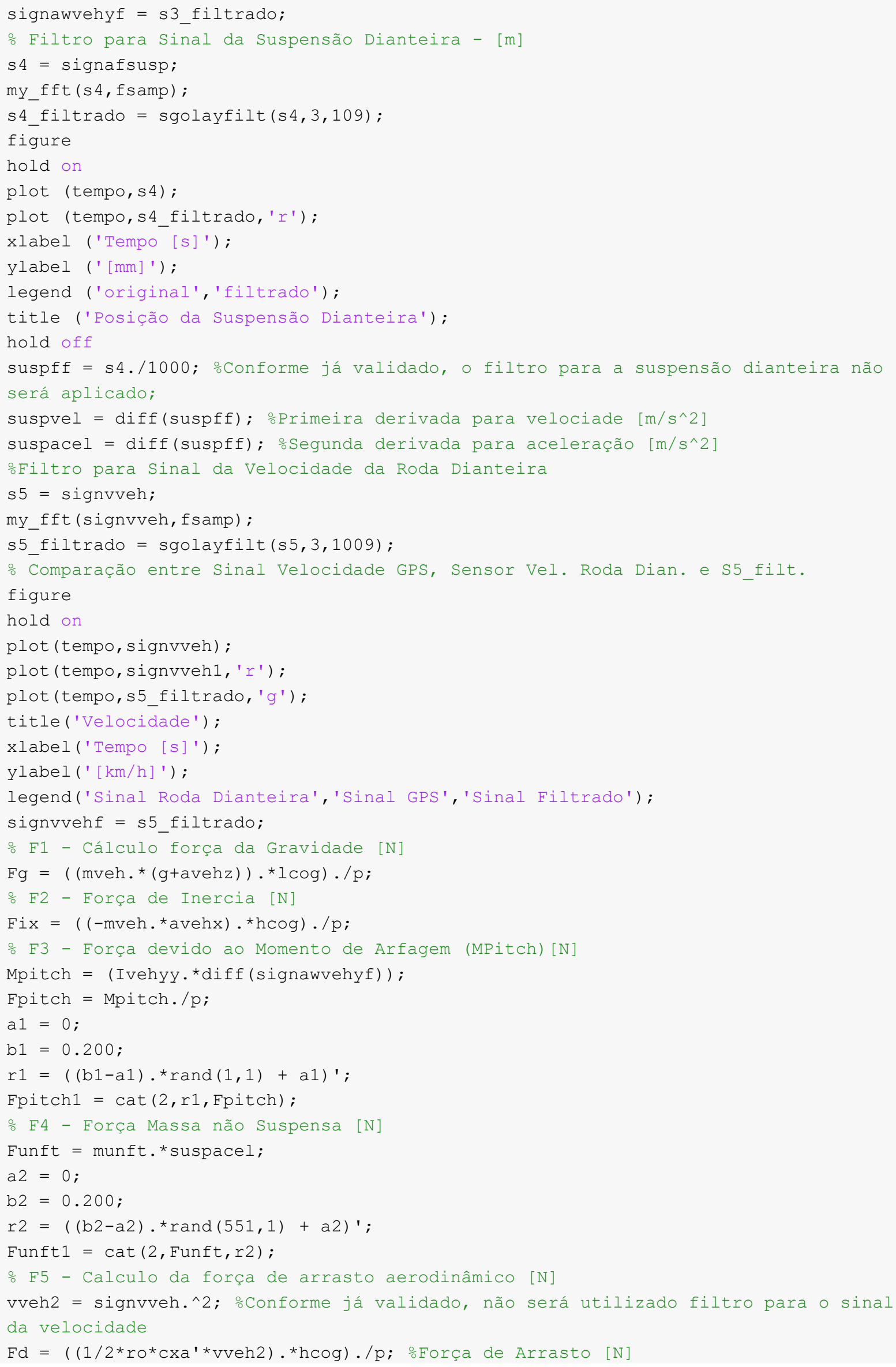




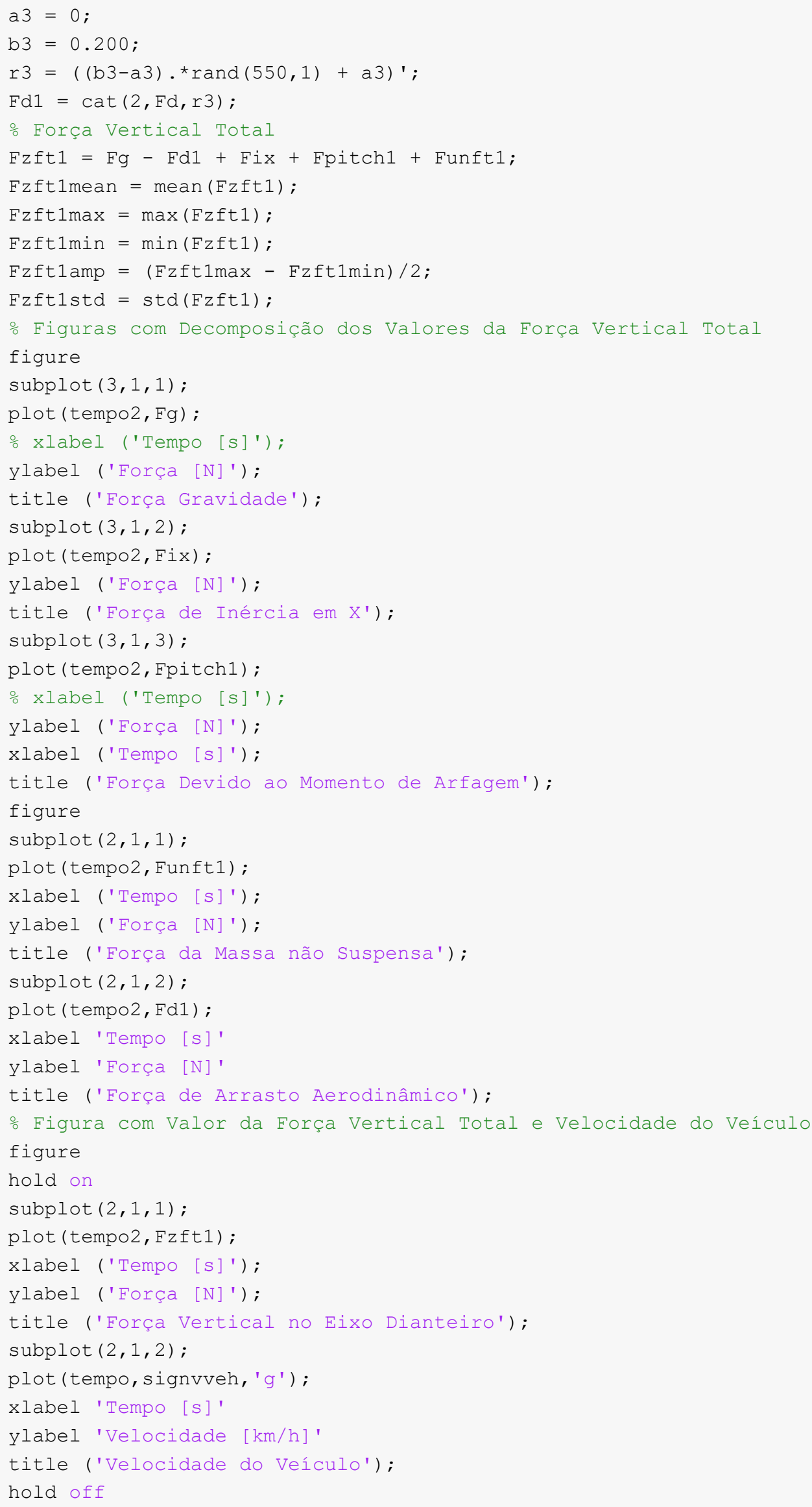




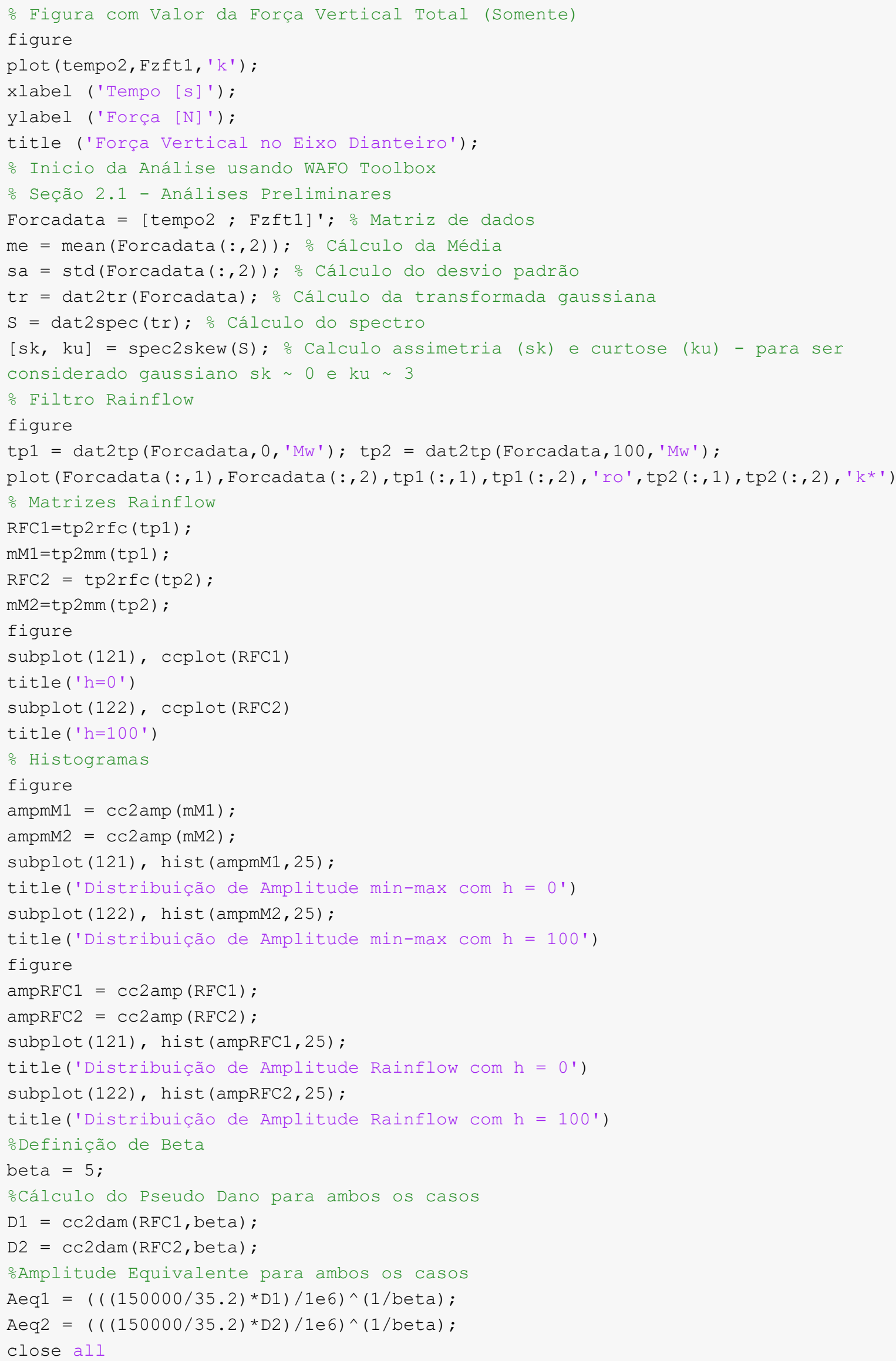

